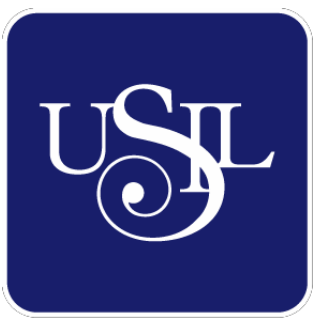

UNIVERSIDAD

SAN IGNACIO

DE LOYOLA

ESCUELA DE POSTGRADO

\title{
PLAN DE NEGOCIOS PARA UNA CADENA DE FAST FOOD DE PIZZAS PERSONALIZADAS EN LIMA METROPOLITANA
}

Trabajo de Investigación para optar el grado de:

MARYCRUZ ALVAREZ MELÉNDEZ

Maestro en Ciencias Empresariales con Mención en Gestión del Capital Humano

ALEJANDRO VLADIMIR HURTADO LUCERO Maestro en Ciencias Empresariales con Mención en Gestión del Capital Humano

ANDREA FABIOLA VIZCARRA HERNÁNDEZ

Maestro en Ciencias Empresariales con Mención en Gestión del Capital Humano

Asesor:

Julio Enrique De La Puente De La Borda

Lima - Perú

2019 


\section{Resumen Ejecutivo}

En los últimos años el crecimiento constante del rubro de restaurantes, y sus altos niveles de ventas, hace posible la aparición de nuevos conceptos, donde cada vez hay más alternativas de fast food. Como señaló el Instituto Nacional de Estadística e Informática (2017) en su Encuesta Mensual de Sector Servicio en el mes de octubre el rubro comidas y bebidas, donde la categoría fast food creció en un 1.6\%, presentando una tendencia positiva junto con el crecimiento económico.

En este contexto, se desarrolla el presente Plan de Negocios referido a la implementación de una Cadena Fast Food de Pizzas Personalizadas en Lima Metropolitana para los años 2018 - 2022, mediante la empresa Pizza Lab, que ofrece una propuesta diferente a las ya existentes en el mercado, a través la experiencia de personalización fundamentada en el valor del producto final, ya que el negocio propone que el cliente tenga una experiencia única en un local fast food, con la opción de elegir su propia pizza dentro una variedad de ingredientes.

El negocio ofrece su propuesta, a través de locales fast food ubicados en tres centros comerciales de Lima Metropolitana, tales como: Mall del Sur, Jockey Plaza y Plaza Norte, que concentran al público objetivo del proyecto. Ya que en el estudio de mercado se determinó que dicho público se encuentra en los niveles socioeconómicos $\mathrm{A}, \mathrm{B}$ y $\mathrm{C}$ de las edades de 13 a 59 años además se evaluó los factores que influyen directamente en la oferta y demanda del producto ofrecido descubriendo diversas características del servicio que se presenta en el plan de marketing respectivo.

En el análisis estructural del sector se muestra, el crecimiento constante en los últimos años en la demanda de alimentos y bebidas, así como el crecimiento del sector fast food, 
aumento de gasto per cápita en alimentación fuera del hogar, así como el crecimiento del PBI del sector, a fin de obtener una visión integral de la industria para evaluar la viabilidad del proyecto.

Para el presente proyecto la inversión inicial requerida es de S/ 758,950, por lo cual se evaluó contar con un préstamo bancario para el financiamiento del $60 \%$ del monto de inversión. Se calculó el presupuesto de costos, mano de obra directa e indirecta, depreciación e impuestos. Al determinar el flujo de caja económico bajo las condiciones expuestas, se obtuvo un VANF positivo de S/. 138,219.84 con un TIRF de 35\%. Finalmente se realizó un análisis de sensibilidad considerando diversas variables y escenarios siendo en todos los casos los resultados favorables determinando la rentabilidad del proyecto. 


\section{INDICE}

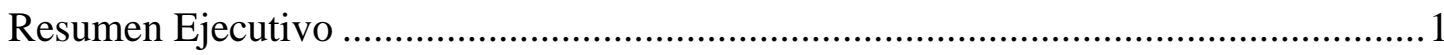

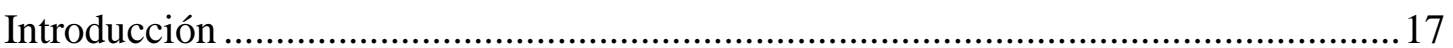

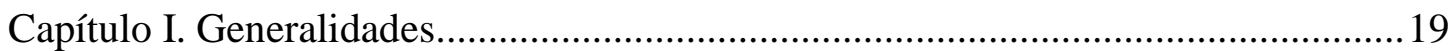

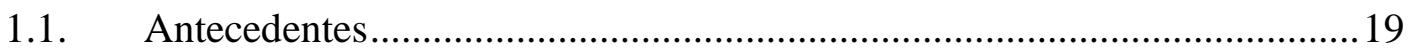

1.2. Determinación del problema u oportunidad ............................................2 21

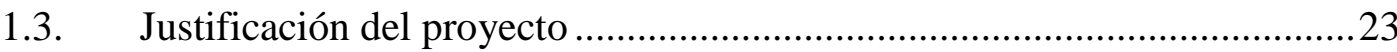

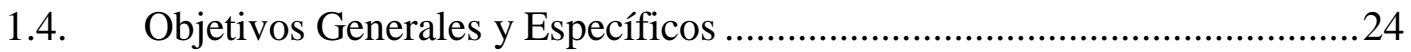

A continuación se detalla los objetivos del presente plan de negocio: ....................24

1.4.1. Objetivo General del Proyecto...........................................................24

1.4.2. Objetivos específicos del Proyecto. ...................................................25

1.5. Alcances y Limitaciones de la Investigación ............................................25

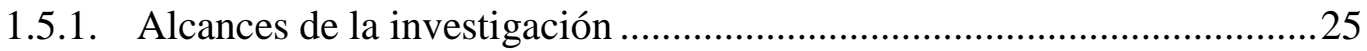

1.5.2. Limitaciones de la Investigación ...........................................................26

Capítulo II. Estructura Económica del Sector..........................................................2

2.1. Descripción del estado actual de la industria.........................................27

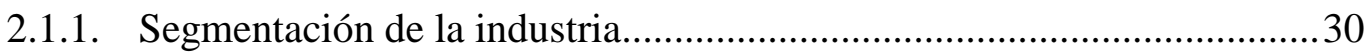

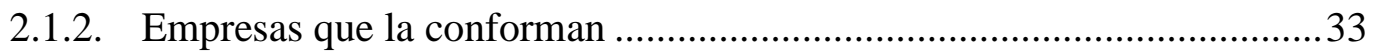

2.2. Tendencias de la industria (crecimiento, inversiones)............................. 37

2.3. Análisis Estructural del Sector Industrial .................................................. 37

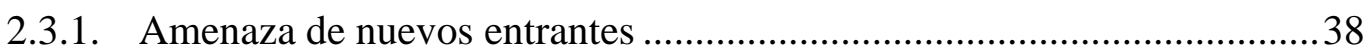


2.3.2. Poder de negociación de los proveedores .39

2.3.3. Poder de negociación de los compradores 41

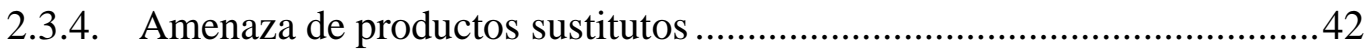

2.3.5. Rivalidad entre competidores existentes ..............................................4 43

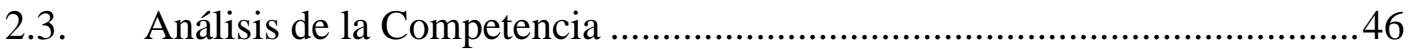

2.4.1. Empresas que ofrecen el mismo producto o servicio .............................46

2.4.2. Participación de mercado de competidores .............................................48

2.4.3. Matriz de Perfil Competitivo ............................................................. 49

2.5. Análisis de Contexto Actual y Esperado ..................................................53

2.5.1. Análisis Político-Gubernamental ........................................................54

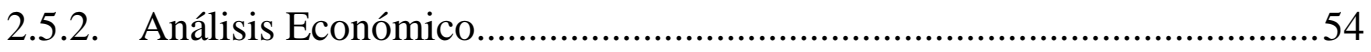

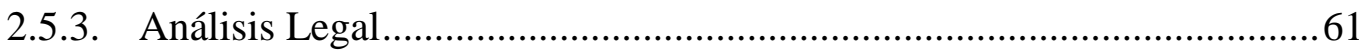

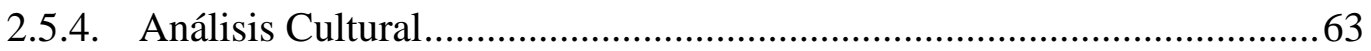

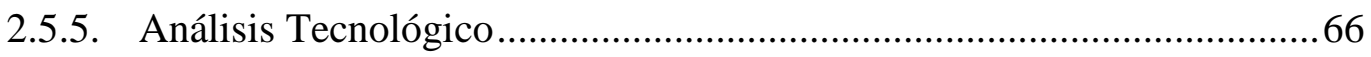

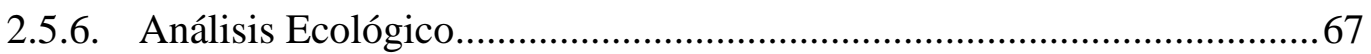

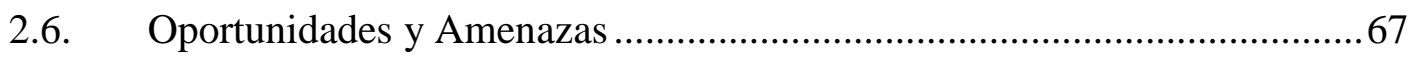

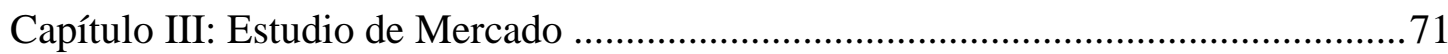

3.1. Descripción del producto y servicio ..................................................... 71

3.2. Selección del segmento de mercado ........................................................ 72

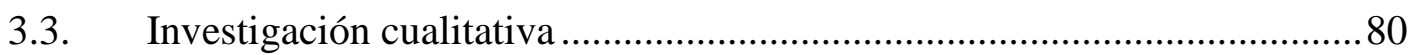

3.3.1. Proceso de muestreo de la investigación cualitativa ...............................80 
3.3.2. Diseño de instrumento de la investigación cualitativa .81

3.3.3. Análisis y procesamiento de datos .83

3.4. Investigación cuantitativa .89

3.4.1. Proceso de muestreo de la investigación cuantitativa 90

3.4.2. Diseño del instrumento de la investigación cuantitativa .92

3.4.3. Análisis y Procesamiento de Datos 93

3.5. Conclusiones y recomendaciones del Estudio Cualitativo y Cuantitativo .98

3.6. Perfil de consumidor tipo y sus variantes 100

Capítulo IV. Proyección del mercado objetivo. 103

4.1. El ámbito de la proyección 103

4.2. Selección del método de proyección. 103

4.2.1. Mercado Potencial. 104

4.2.2. Mercado Disponible 107

4.2.3. Mercado Efectivo 108

4.2.4. Mercado Objetivo 108

4.3. Pronóstico de Ventas 110

4.4. Aspectos críticos que impactan el pronóstico de ventas 112

5.1. Estudio de ingeniería 114

5.1.1. Modelamiento y selección de procesos productivos 114

5.1.2. Selección del equipamiento 123

5.1.3. Lay out. 126 
5.2. Determinación del Tamaño 137

5.2.1. Proyección del crecimiento 137

5.2.2. Recursos 138

5.2.3. Tecnología 139

5.3. Estudio de localización. 140

5.3.1. Definición de factores locacionales. 142

5.3.2. Consideraciones legales 152

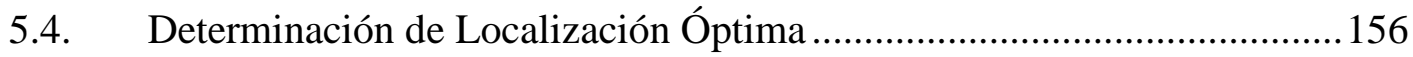

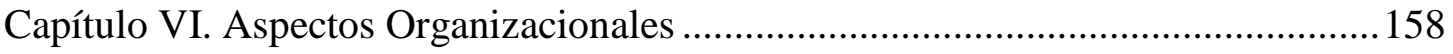

6.1. Caracterización de la cultura organizacional deseada ............................. 158

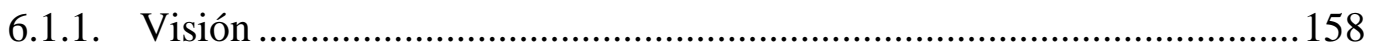

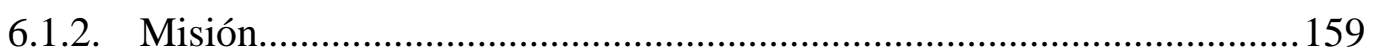

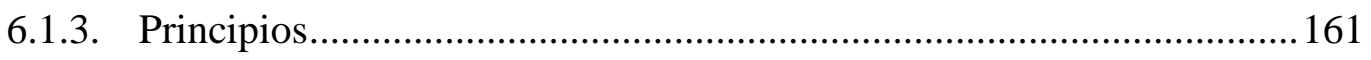

6.2. Formulación de Estrategias del Negocio ............................................... 161

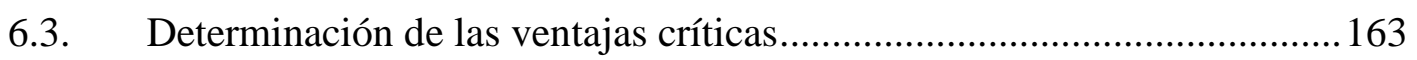

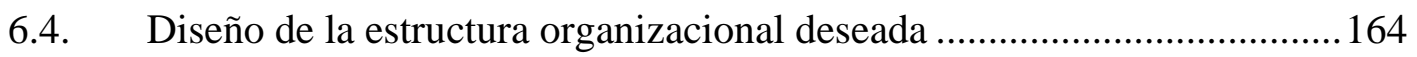

6.5. Diseño de los Perfiles de puestos claves ............................................... 165

6.6. Remuneraciones Compensaciones e Incentivos ..................................... 168

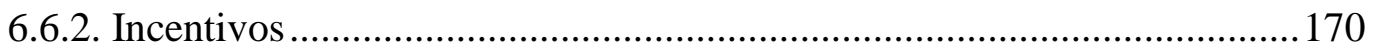

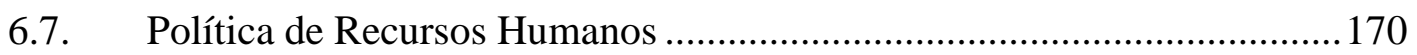

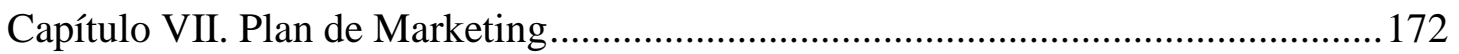




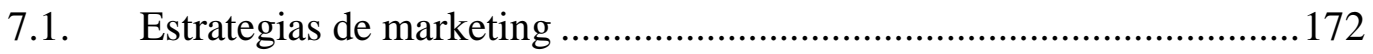

7.1.1. Estrategia de Producto.......................................................................... 172

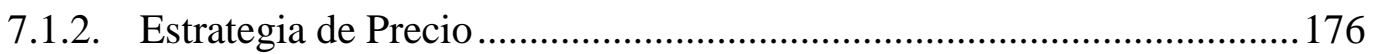

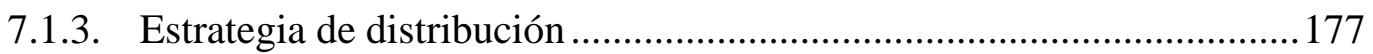

7.1.4. Estrategia de promoción y publicidad................................................. 179

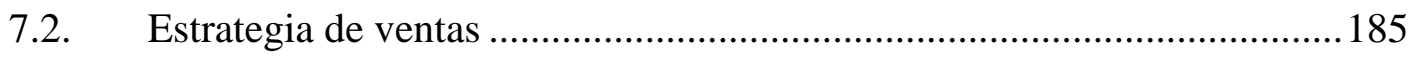

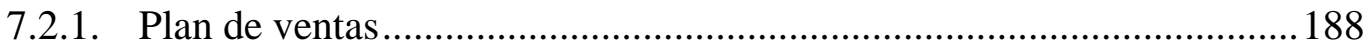

7.2.2. Políticas de servicios y garantías......................................................... 189

Capítulo VIII. Planificación Financiera ..................................................................... 191

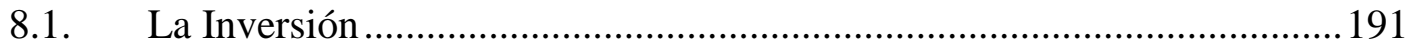

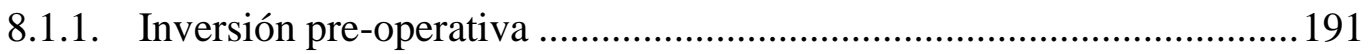

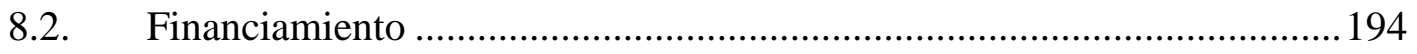

8.2.1. Endeudamiento y Condiciones .......................................................... 194

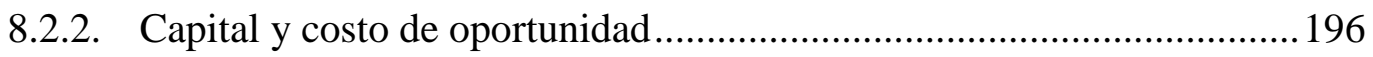

8.2.3. Costo de Capital Promedio Ponderado ................................................ 198

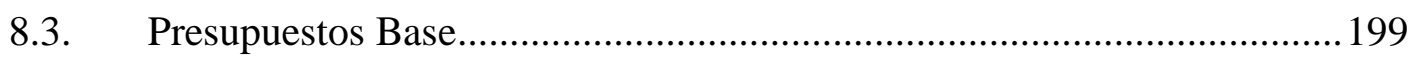

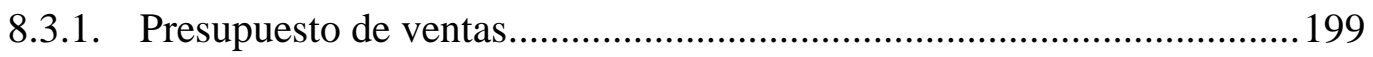

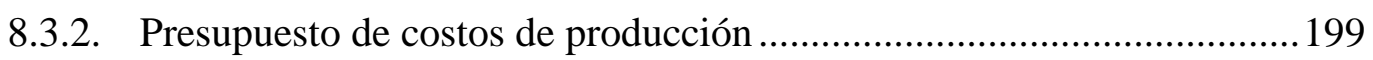

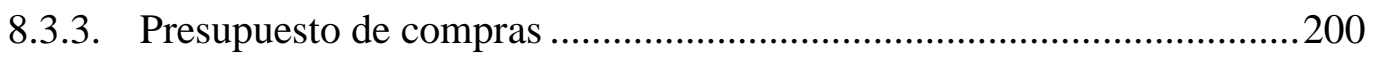

8.3.4. Presupuesto de gastos administrativos ...............................................2200

8.3.5. Presupuesto de marketing y ventas .....................................................201 
8.3.6. Presupuesto de gastos financieros.

201

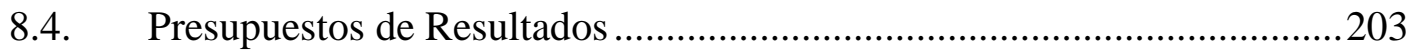

8.4.1. Estado de ganancias y pérdidas proyectado .........................................203

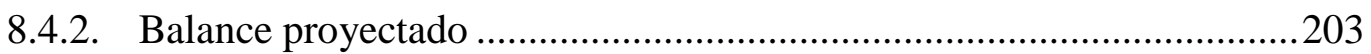

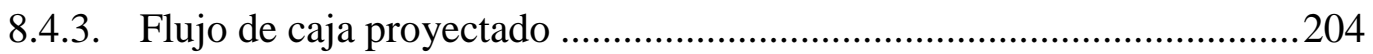

Capítulo IX. Evaluación Económica Financiera.....................................................205

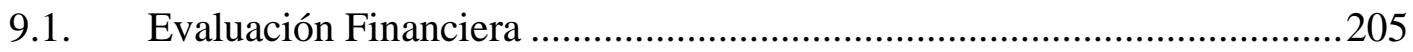

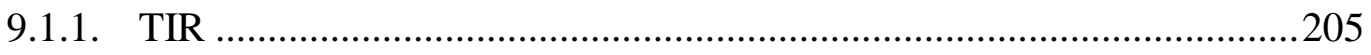

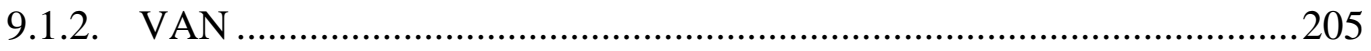

9.1.3. ROE

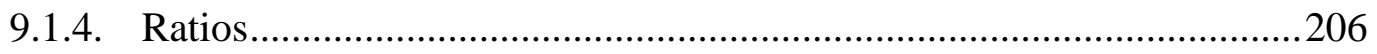

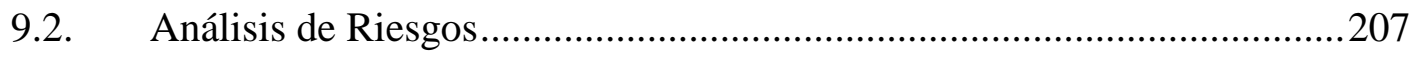

9.2.1. Análisis de Punto de Equilibrio........................................................208

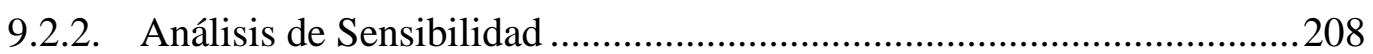

9.2.3. Análisis de escenarios.........................................210

9.2.3.1 Matriz de Riesgos Financieros......................................211

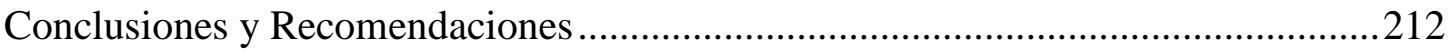

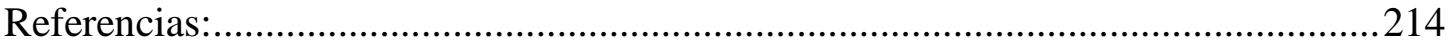




\section{INDICE DE FIGURAS}

Figura 1. Principales cadenas de fast food. 19

Figura 2. Evolución mensual de la actividad de restaurantes....

Figura 3. Sector Restaurantes Ventas Julio: 1,02\%

Figura 4. Participación de mercado de fast food de pizzas. .49

Figura 5. Producto Bruto Interno de Perú......................................55

Figura 6. Producto Bruto Interno per cápita....................................56

Figura 7. Sueldo mínimo vital.............................................57

Figura 8. Inflación....................................................... 58

Figura 9. Intención de cambio de compra tradicional..............................90

Figura 10. Caracteristicas de la Pizza.........................................94

Figura 11. Evaluación de lo atractivo del proyecto.............................95

Figura 13. Intención de compra del nuevo concepto............................95

Figura 13. Principales lugares para encontrar el producto.........................96

Figura 14. Monto dispuesto a pagar.........................................97

Figura 15. Frecuencia de Compra........................................97

Figura 16. Presentación del producto.........................................98

Figura 17. Géneros......................................................... 100

Figura 18. Grupos de Edad...................................................100 
Figura 19. Blueprint........................................................ 118

Figura 20. Flujo de Recepción de Mercadería...................................119

Figura 21. Flujo de Almacenamiento de productos perecibles.....................120

Figura 22. Flujo de Almacenamiento de Secos.................................121

Figura 23. Flujo de Preparación y Reparación..................................121

Figura 24. Flujo de Atención del Cliente......................................122

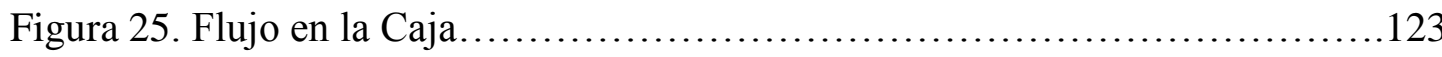

Figura 26. Lay out...................................................... 133

Figura 27. Lay out................................................... 134

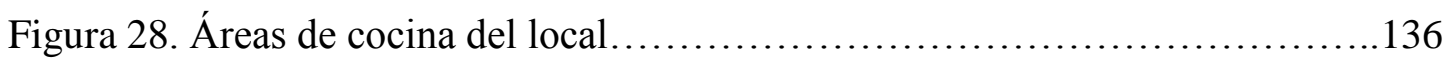

Figura 29. Tres estrategias genéricas de Porter..................................162

Figura 30. Organigrama.................................................. 165

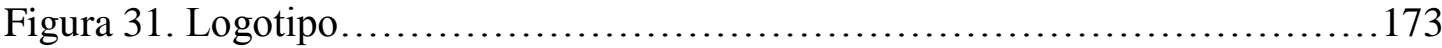

Figura 32. Envase...................................................... 174 


\section{INDICE DE TABLAS}

Tabla 1. Locales en Lima y Callao de Fast Food. .34

Tabla 2. Cantidad de Trabajadores de las Principales Cadenas Fast Food de Lima

Metropolitana

Tabla 3. Las ventas en comida rápida por categoría 36

Tabla 4. Tabulación de Proveedores 41

Tabla 5. Resumen de las Cinco Fuerzas de Porter 45

Tabla 6. Matriz de Perfil Competitivo .52

Tabla 7. Población Económicamente activa (PEA) de Lima

Metropolitana 57

Tabla 8. PBI de Alojamiento y Restaurantes. .59

Tabla 9. Precio Promedio por Kilo de Harina sin preparar .60

Tabla 10. Número de Personas según Edad y Zonas de Lima.... .64

Tabla 11. Matriz de Evaluación de Factores Externos (EFE)

Tabla 12. Habitantes, Hogares y Viviendas de Lima Metropolitana .73

Tabla 13. Número de Personas según Edad y Zonas de Lima... .74

Tabla 14. Información Demográfica Lima Metropolitana...........................75

Tabla 15. Población de Lima Metropolitana en edad de trabajar. .76

Tabla 16. Población Economicamente Activa de Lima Metropolitana................76 
Tabla 17. Variable Demografica .77

Tabla 18. Niveles Socioeconómicos de Lima Metropolitana y Zonas...............78

Tabla 19. Gasto Mensual Familiar por NSE en Lima Metropolitana..................79

Tabla 20. Objetivos de las Entrevistas de Profundidad............................82

Tabla 21. Distribución de Muestra........................................992

Tabla 22. Ventas en Consumo de servicios Fast Food..............................101

Tabla 23. Población Proyectada de Lima Metropolitana............................104

Tabla 24. Proporción de las zonas de Lima.....................................105

Tabla 25. Proporción de edades según zonas de Lima Metropolitana................105

Tabla 26. Proporción de NSE según zonas de Lima Metropolitana.................106

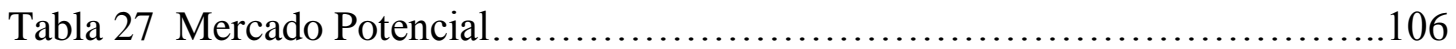

Tabla 28. Mercado Disponible..............................................107

Tabla 29. Mercado Efectivo............................................... 108

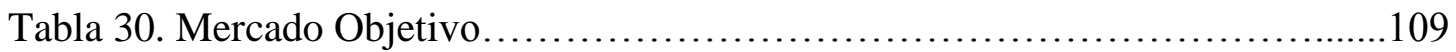

Tabla 31. Frecuencia de compra estimada....................................110

Tabla 32. Ventas expresadas en platos vendidos...............................111

Tabla 33. Ticket Promedio...................................................111

Tabla 34. Ventas proyectadas en Soles........................................112

Tabla 35. Equipamiento.................................................. 124

Tabla 36. Consumo de energía eléctrica...................................... 125 
Tabla 37. Consumo de energía de GLP 126

Tabla 38. Tamaño Óptimo de Pizza Lab.

Tabla 39. Factores Objetivos. 147

Tabla 40. Resumen de factores Objetivos Fo. 147

Tabla 41. Factores Subjetivos Fs 148

Tabla 42. Resumen de Factores Subjetivos. 149

Tabla 43. Puntajes Relativos Factores Subjetivos 150

Tabla 44. Resumen de Factores Subjetivos. 150

Tabla 45. Calculo MLP. .151

Tabla 46. Método de Factores por Puntos....

Tabla 47. Elementos de la Visión. 159

Tabla 48. Componentes de la Misión. 160

Tabla 49. Matriz VRIO. .164

Tabla 50. Sueldos de los Trabajadores 169

Tabla 51. Inversión Anual en sueldos y salarios 169

Tabla 52. Gastos en la etapa de intriga. 181

Tabla 53. Gasto en la etapa de lanzamiento. .183

Tabla 54. Gasto en la etapa de mantenimiento 184

Tabla 55. Proyección de ventas por productos 188

Tabla 56. Inversión en maquinaria, equipos y acondicionamiento .191 
Tabla 57. Gastos pre-operativos

Tabla 58. Capital de trabajo. .193

Tabla 59. Costo del proyecto. 194

Tabla 60. Calendario de Inversiones. .195

Tabla 61. Estructura del Financiamiento 195

Tabla 62. Costo de Capital. 197

Tabla 63. CPCC 198

Tabla 64. Presupuesto de ventas 199

Tabla 65. Presupuesto de costos de producción. .200

Tabla 66. Presupuesto de compras. .200

Tabla 67. Gastos administrativos. .201

Tabla 68. Gastos de marketing y ventas. .201

Tabla 69. Amortización de préstamo .202

Tabla 70. Estado de resultados .203

Tabla 71. Balance Proyectado .203

Tabla 72. Flujo de caja proyectado .204

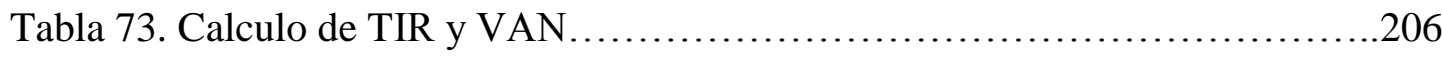

Tabla 74. Calculo del ROE 206

Tabla 75. Ratios Financieros. .207

Tabla 76. Análisis de Punto de Equilibrio. .208 
Tabla 77. Sensibilidad por Precio.

.209

Tabla 78. Sensibilidad por Cantidad Vendida..................................209

Tabla 79. Sensibilidad por Costo Variable......................................209

Tabla 80. Análisis de Escenarios.................................................210

Tabla 8|. Matriz de Riesgos Financieros.......................................211 


\section{Introducción}

El presente Plan de Negocios busca evaluar la implementación de una cadena de fast food de pizzas personalizadas en Lima Metropolitana. La finalidad es plantear, analizar y definir la idea de negocio, así como evaluar su rentabilidad.

El presente Plan de Negocios consta de nueve capítulos, los cuales se detallan a continuación:

- El capítulo I, presenta la importancia del Plan de Negocios, detallando los antecedentes, objetivos, justificación, limitaciones y alcances de la investigación.

- El capítulo II, contiene información sobre el sector de restaurantes de comida rápida orientados a la venta de pizza, así como la tendencia mundial y nacional. A la vez se estudia a la competencia, obteniendo las oportunidades y amenazas del sector.

- El capítulo III, detalla lo relacionado al estudio de mercado, así como el cálculo de la muestra, técnicas e instrumentos de recolección y análisis de datos, que se usaron para la investigación cualitativa y cuantitativa, con la finalidad de conocer el grado de aceptación del presente proyecto.

- El capítulo IV, determina el tamaño del mercado potencial, disponible, efectivo y objetivo, así como la proyección de ventas en unidades y en soles.

- El capítulo V, demuestra la factibilidad técnica de la producción y servicio para la venta de pizzas personalizadas y complementos adicionales. A la vez se muestra el diseño de los locales. 
- El capítulo VI, corresponde a los aspectos organizacionales, en el cual se formula la misión, la visión, la cultura organizacional, los principios y diversas políticas organizacionales; que ayudaron a determinan las estrategias del negocio.

- El capítulo VII, define el plan de marketing, en el cual se detalla las estrategias de desarrollo de producto, precio, distribución y promoción, con ayuda del análisis del marketing mix. A la vez se detallan las estrategias y políticas de ventas.

- El capítulo VIII, presenta la planificación financiera, en el cual se muestran los estados financieros proyectados del presente plan de negocios; así como el estado de ganancias y pérdidas, el balance y el flujo de caja.

- El capítulo IX, evalúa la rentabilidad de del Plan de Negocios, a través de indicadores financieros como VAN y TIR, entre otros.

- Por último, se mencionan las conclusiones y recomendaciones del presente proyecto. 


\section{Capítulo I. Generalidades}

En este capítulo se comenta acerca de los antecedentes del presente plan de negocios, con la finalidad de determinar el problema u oportunidad, objetivos generales y específicos. Así como también definir los alcances y limitaciones para la implementación de una cadena de fast food de pizzas personalizadas en Lima Metropolitana.

\subsection{Antecedentes}

Amiel (2014) menciona que los antecedentes proporcionan información histórica de estudios confiables realizados a lo largo del tiempo, con la finalidad de determinar mejores definiciones respecto al tema en estudio, y a la vez investigar profundamente trabajos antes realizados.

Arbaiza, Cánepa, Cortez, y Levano (2014) mencionan en su análisis prospectivo del sector de comida rápida en Lima, que según la EAE Business School un fast food es definido como un establecimiento de servicio rápido con puntos de venta en locales de ocio (cines, teatros, etc.) o en la propia calle, donde se sirve comida tanto para comprar y como para llevar. A la vez se dice que el concepto nació en el año 1955 con la apertura del primer local de la cadena de McDonald’s en Illinois, USA.

Luego de ello, este concepto se fue expandiendo al resto de mundo hasta a la actualidad. Como indica Rodríguez y Lamas (2011), América Latina es el mayor consumista de comida rápida con un 47\%. A diferencia de Asia - Pacifico con un 36\% y Europa con $17 \%$ del consumo de esta comida.

Siendo las principales cadenas de fast food en el mundo: McDonald's, Burger King, Subway, Wendy's, Pizza Hut, Taco Bell, Domino's Pizza y KFC (Ver figura 1). (Conoce las diez cadenas de fast food, 2010) 


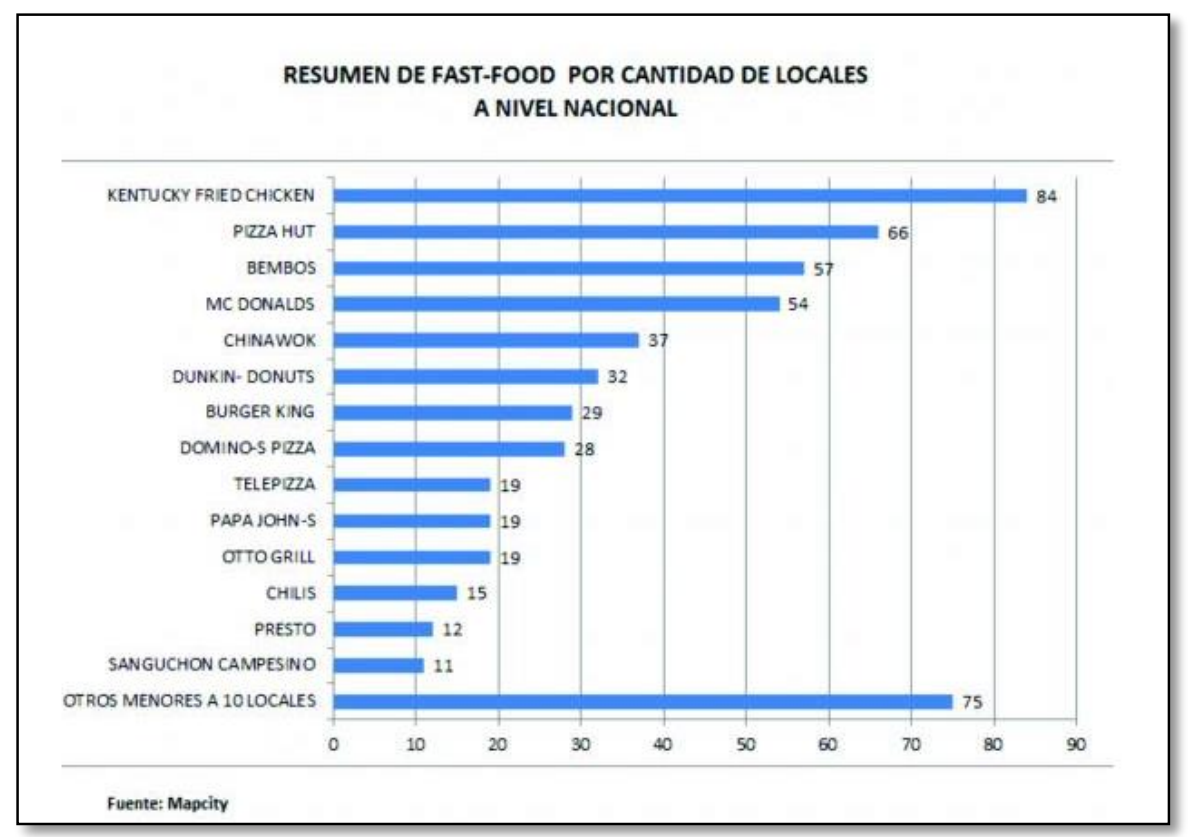

Figura 1. Principales cadenas de fast food. Tomado de: "Como se está moviendo el mercado de los fast food en el Perú", por Mott.pe, 2015. Recuperado de https://mott.pe/noticias/conoce-como-se-esta-moviendo-el-mercado-de-los-fast-food-en-elperu/

Arbaiza et al. Indicaron que el sector fast food se introdujo en el Perú en 1980 con el ingreso de diversas franquicias como Pizza Hut y KFC, que forman parte del grupo Delosi. Luego de ello el sector despegó en el año 1990, obteniendo un gran dinamismo en el Perú como nuevo modelo económico nacional.

El sector "fast food" siguió creciendo en el Perú con dos grandes competidores: Delosi e Intercorp. El grupo Delosi opera hace más de 30 años manteniéndose en el tiempo con su marca KFC que cuenta con varios locales a nivel nacional. De las marcas fast food en Perú, seis son las que tienen mayor demanda en centros comerciales y en lugares con puerta a la calle, tales como: Pizza Hut, Bembos, KFC, McDonald’s, Burger King y Domino's Pizza. (Panorama del Mercado Fast Food, PerúRetail.com, 2015) 
En ese sentido, Juárez y Palomino (2016) señalaron que en el Perú actualmente existe la presencia de grandes cadenas de franquicias de fast food, en el rubro de pizzas, entre ellas se puede mencionar.

- Franquicia internacional Pizza Hut que ofrece pizzas y pastas, así como guarniciones y postres. Cuenta con locales en Lima y en diversas ciudades del país.

- Franquicia internacional Papa John’s que ofrece variedad de sabores de pizzas. Cuenta con locales en Lima y en diversas ciudades del país.

- Franquicia internacional Telepizza, líder en el sector de reparto a domicilio de comida preparada, cuenta con diversos locales en la ciudad de Lima como en el resto del país.

Por otro lado cabe mencionar que dichas franquicias operan en los centros comerciales, donde se han logrado posicionar, tanto en patios de comida como en locales propios.

Según indica Euromonitor la expectativa es que las cadenas fast food logren un crecimiento en valor de 4\% este año. (Top10: Conoce las marcas que dominan, El Comercio, 2017). Lo que genera nuevas oportunidades en el mercado peruano, ya que el crecimiento de restaurantes de comida rápida, siendo la mayoría franquicias internacionales, hacen atractivo al sector.

\subsection{Determinación del problema u oportunidad}

Actualmente, la creatividad y la innovación se han vuelto un punto crítico para la población en general, al momento de escoger un lugar para su recreación entretenimiento y diversión. Además, existe una tendencia por comer un plato de comida hecho a la medida del cliente, que hace que la mayoría de personas no solo se fijen en los precios, sino que busquen mayores beneficios al momento de comprar un producto o servicio. 
"La innovación abarca diferentes puntos, actualmente el mundo cambia constantemente. La innovación es una actitud, por ello, todos deberían vivir evolucionando, analizando y transformando" (Contreras, 2015, p. 148)

La palabra innovación conlleva muchas realidades. Finalmente, innovar es llevar a la realidad, al mercado, al público, una propuesta no antes vista que genera algo nuevo. En muchos casos, la innovación tiene alcance en la ejecución, ya que hay métodos y trabajos donde la tecnología, el diseño y también el marketing aportan al proceso de innovación. (Aizega, 2016, p. 58)

Según las últimas tendencias del mercado gastronómico nacional, se observa que existe una mayor cantidad de población que sale a comer en sus tiempo libres y que tienen como destino principal las pollerías, restaurantes de comida criolla y fast foods. Consumir en un fast food es una práctica que cada vez se está volviendo más habitual entre los limeños.

“El 73\% de los limeños asiste a un fast food una vez cada 15 días por lo menos; y el 40\% de los jóvenes asisten a este tipo de establecimientos una vez por semana" (Ochoa, 2015, p. 5)

“El 56\% de los peruanos indica que en los próximos doce meses realizará más gastos realizando compras en centros comerciales; además, este indicador ha tenido un aumento en 13\% en comparación a Junio del 2017” (Prialé, 2017, p. 15).

“Entre las marcas que prefieren los limeños, destaca KFC con el 41\% de menciones, seguida de Bembos con el 35\%. En el tercer lugar está Norky’s con un 33\%, arriba de Pizza Hut (28\%)" (Ochoa, 2015, p. 7)

El concepto de un restaurante con atención rápida, ingredientes frescos, y cierta estética en la preparación; además de brindar la opción a que el cliente personalice su plato, ha probado tener éxito en otros países. 
“Chipotle que cuenta con más de 1,000 locales en Estados Unidos, Canadá, Francia y Reino Unido llevando la comida Tex-Mex a un concepto rápido de servicio, pero respetando los sabores y tradición culinaria de la misma.” (Comida con Integridad, chipotle.com, n.d.)

“Subway, que cuenta con 44,556 locales en 113 países, tiene un concepto en el cual el cliente crea su sándwich con los ingredientes a su elección." (La Historia de los Restaurantes Subway, subway.pe, 2016)

Teniendo como diferenciación la libertad de crear un plato a la medida del cliente, la línea de interacción y la estética de los fast food ya conocidos, el presente proyecto busca ser una alternativa de consumo de pizza en un esquema rápido de atención, pero respetando los patrones de preparación.

De acuerdo a lo expuesto anteriormente, se planteó la siguiente pregunta de investigación ¿Qué rentabilidad tendría un Plan de Negocios para la creación de un fast food de pizzas personalizadas ubicadas en patios de comida de Centros Comerciales de Lima Metropolitana?

\subsection{Justificación del proyecto}

Hernández, Fernández, y Baptista (2014) señalaron que la justificación de la investigación indica el porqué de la investigación exponiendo sus razones. Por medio de la justificación se debe demostrar que el estudio es necesario e importante.

En la creación del presente Plan de Negocios se han aplicado conceptos adquiridos a través de la maestría, así como la experiencia observable en el rubro de alimentos y bebidas, que ayudan a tomar las decisiones de manera sustentada y correcta para plantear la implementación de una cadena de fast food de pizzas personalizadas ubicadas en diferentes centros comerciales en Lima Metropolitana. 
Debido a que no existe en el mercado de Lima Metropolitana una pizzería fast food que se dedique solo a la venta de pizzas hechas a la medida del cliente, los miembros del grupo decidieron proponer este concepto con una imagen joven y dinámica, con la finalidad de obtener un alto nivel de aceptación.

Como se puede apreciar en la figura 1, uno de los establecimientos fast foods más consumidos es Pizza Hut, lo cual da señal que los limeños consumen pizza a precio bajo y con un rápido servicio. Por otro lado, cada vez se apertura más centros comerciales en diferentes sectores de Lima Metropolitana, lo cual indica que el consumo en estos aumentará.

Este tipo de propuesta busca inducir la venta sugestiva mediante la visualización de los productos durante el periodo de atención. La interacción directa del cliente en la elaboración de la pizza juega un rol fundamental en la posibilidad de elección de alimentos que el concepto ofrece. Ayudando a reforzar la imagen de frescura y creatividad en la comida, mediante la exposición directa de la zona de atención, proyectando una imagen clara de las formas de preparación, manipulación que reforzará el mensaje de frescura hacia los clientes. El presente proyecto busca diferenciarse de los fast food tradicionales al tratar que los consumidores interactúen con el concepto, coman saludable y gocen de un ambiente acogedor y atractivo.

\subsection{Objetivos Generales y Específicos}

A continuación se detalla los objetivos del presente plan de negocio:

\subsubsection{Objetivo General del Proyecto.}

Desarrollar un Plan de Negocios que permita plantear, analizar y establecer la factibilidad y viabilidad de desarrollar una cadena de fast food de pizzas personalizadas en Lima Metropolitana. 


\subsubsection{Objetivos específicos del Proyecto.}

- Realizar un estudio de mercado con el fin de obtener y analizar información de los gustos y preferencias de los consumidores de fast food en Lima Metropolitana.

- Definir la estructura del negocio, planteando estrategias que permitan alcanzar las metas de la organización.

- Implementar un plan operativo para determinar los procesos productivos y operacionales, hacia la optimización de los diferentes recursos.

- Desarrollar un análisis económico-financiero para determinar la rentabilidad del plan de negocios.

\subsection{Alcances y Limitaciones de la Investigación}

Según Pino (2010) “la limitación se encuadra más al propósito que tiene cualquier profesional para limitar su ámbito de estudio. Es decir, no solo se refiere al ámbito moral o material se refiere a cualquier tipo de ámbito” (p. 465). A la vez menciona que estas limitaciones hacen referencia a las tareas que realiza el investigador y a los inconvenientes que se le presenta para ejecutar su trabajo.

Hernández et al. señalaron que "los alcances resultan de la revisión de la literatura y de la perspectiva del estudio. Dependen de los objetivos del investigador para combinar los elemento en el estudio". (p. 89)

\subsubsection{Alcances de la investigación}

- El Plan de Negocios busca evaluar la viabilidad de implementar un fast food de pizzas personalizadas en Lima Metropolitana.

- El plan de negocios busca tener sostenibilidad, considerando que los activos cumplan con su vida útil y adquieran sustentabilidad en el mercado. 


\subsubsection{Limitaciones de la Investigación}

- Antigüedad de bibliografía especializada del sector de fast food.

- Acceso limitado a información relacionada con los procesos y funcionamiento del rubro de fast food de pizzas.

- Acceso limitado a información relacionada con la competencia.

- Acceso limitado en base de datos de poblaciones de Lima Metropolitana para definir método de investigación. 


\section{Capítulo II. Estructura Económica del Sector}

En este capítulo se analiza el estado actual del sector de restaurantes, así como las nuevas tendencias mundiales y nacionales. A la vez se estudia el ambiente competitivo, obteniendo diversas oportunidades y amenazas del sector, con el fin de adquirir información clave para el desarrollo del presente negocio.

\subsection{Descripción del estado actual de la industria}

Según Arbaiza (2015) “analizar el sector comprende conocer todos aquellos factores que influyen e intervienen en el ingreso y a la supervivencia de una empresa en el mercado" (p. 57).

"Una industria consiste en un conjunto de empresas que ofrecen productos o servicios similares en el mercado. Para la clasificación formal de las industrias se sigue el código Industrial Internacional Uniforme (CIIU) de las Naciones Unidas” (Francés, 2006, p. 127).

Es por ello que describir la industria va a permitir analizar las empresas existentes y activas en el rubro de fast food que ofrecen productos o servicios semejantes, tanto cadenas nacionales como internacionales. Dentro de las cadenas internacionales más destacadas se encuentran Pizza Hut, KFC, Burger King, McDonald’s, entre otros.

La CIUU agrupa y clasifica a diversas actividades económicas, es decir, actividades que representan la producción de bienes y servicios, las mismas que se registran en el Sistema de Cuentas Nacionales y en la Clasificación Central de Productos. (Clasificación Industrial Internacional, inei.pe, 2010) 
Según la Clasificación Industrial (2010) el servicio de comidas rápidas está dentro de las actividades de servicios de comidas y bebidas, que se encuentran en la División 56, Clase CIIU 5610: Actividades de restaurantes y de servicio móvil de comidas.

El informe "El Boom Gastronómico Peruano 2013” de Apega sostiene que el sector de restaurantes y hoteles presenta algunas características tales como: es uno de los motores de incremento de la economía, es un generador de empleo y tiene una proyección internacional en los últimos años debido al reconocimiento de restaurantes peruanos en el extranjero, siendo un ejemplo el Grupo Acurio que cuenta con 32 restaurantes en 12 países (Díaz, Merino, \& Salas, 2015).

En este sentido según el informe de Euromonitor, Juárez y Palomino (2016) señalaron que actualmente el rubro de comida rápida ha tenido un crecimiento de ventas de $17 \%$ en el 2013, alcanzando 7,765 millones de soles. A la vez se menciona que en el año 2016 la industria estaba liderada por el grupo Delosi con sus marcas Starbucks, Pinkberry, Chili’s, KFC, Pizza Hut, Burger King, entre otros con una participación de mercado de $10 \%$ y en segundo lugar se encontraba NGR del grupo Intercorp con marcas como Bembos, ChinaWok, Dunkin Donuts, Papa Johns, entre otros.

El sector restaurantes creció en $0,81 \%$ en el 2017 con la venta de comidas rápidas, restaurantes, carnes y parrillas, restaurantes turísticos entre otros. (Encuesta mensual del sector servicios, inei.pe, 2017). (Ver Figura 2) 


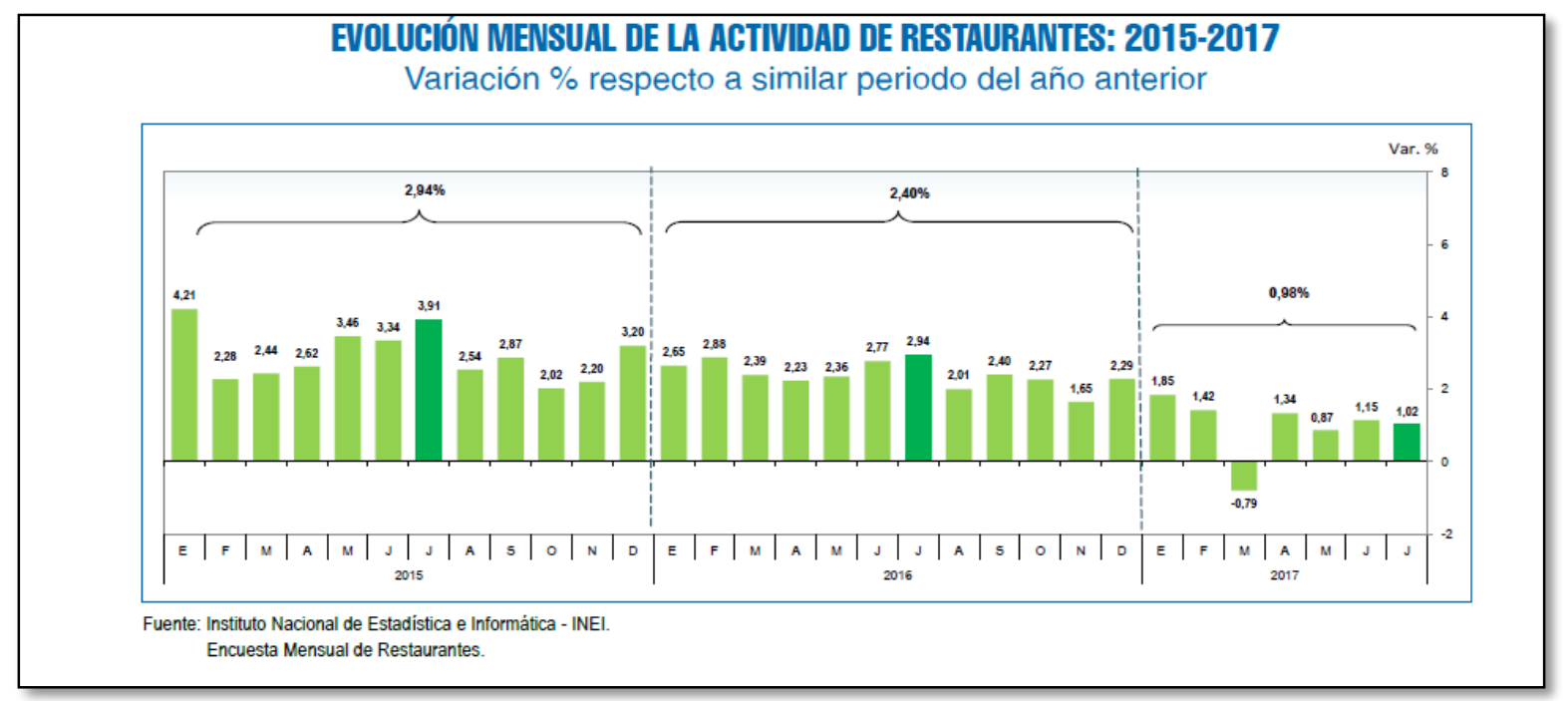

Figura 2. Evolución mensual de la actividad de restaurantes: 2015-2017. Tomado de: "Boletín Estadístico Encuesta Mensual del Sector Servicios Julio 2017”, por inei.gob.pe, 2017. Recuperado de http://m.inei.gob.pe/biblioteca-virtual/boletines/

A la vez se menciona que el sector restaurantes obtuvo un aumento debido a la afluencia de consumidores nacionales y extranjeros, así como otras celebraciones, feriados o ferias gastronómicas, donde la categoría de fast food tuvo un incremento de 1,6 \% (Ver Figura 3).

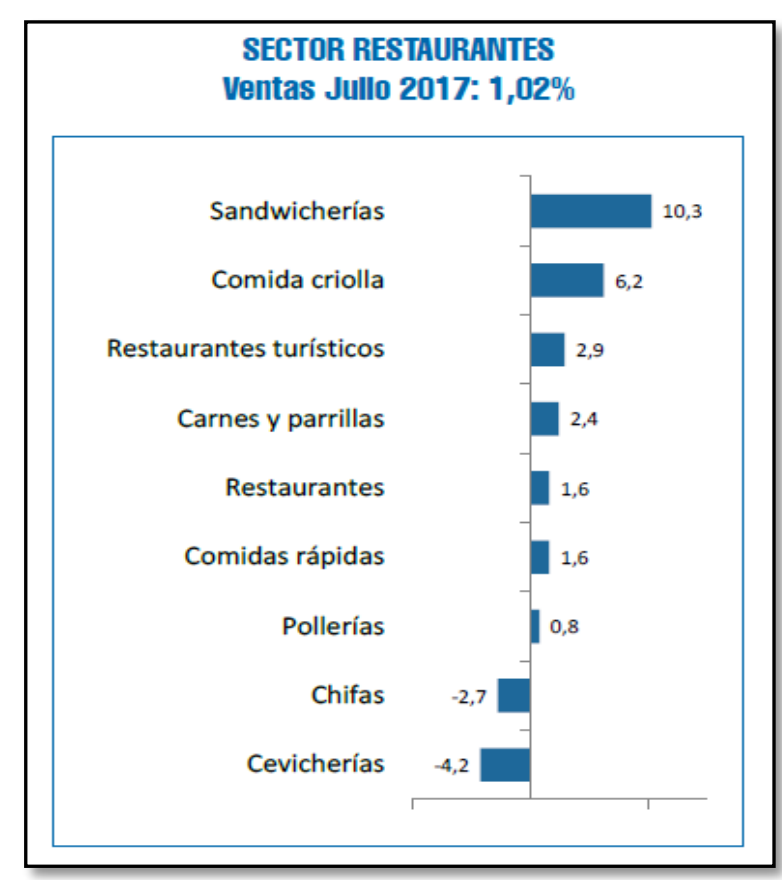

Figura 3. Sector Restaurantes Ventas Julio: 1,02\%. Tomado de: "Boletín Estadístico Encuesta Mensual del Sector Servicios Julio 2017”, por inei.gob.pe, 2017. Recuperado de http://m.inei.gob.pe/biblioteca-virtual/boletines/ 
El crecimiento constante del rubro de restaurantes, y sus altos niveles de ventas, hace posible la aparición de nuevos conceptos, donde cada vez hay más alternativas de fast food.

En conclusión se aprecia que la industria de fast food está siendo atractiva ya que no solo existen tiendas en la capital sino también en distintas provincias del Perú, donde actualmente se encuentran presentes las grandes marcas de fast food internacionales, que ubican sus tiendas en centros comerciales, lo que permite la rápida evolución del sector. Así mismo, los consumidores, cada día se encuentran en búsqueda de variadas opciones exigiendo productos de alta calidad. Se puede apreciar también, que las grandes cadenas de fast food extranjeras tienen mayor confiabilidad respecto a cadenas nacionales de comida rápida, ya que están mejor posicionadas por el gran poder económico y reconocimiento de marcas.

\subsubsection{Segmentación de la industria}

Según Porter (2010) "la segmentación de la industria es necesaria para abordar la cuestión central del alcance competitivo dentro de una industria o los segmentos que una empresa debería atender y cómo debería hacerlo" (p. 265).

Porter menciona que para segmentar la industria se utilizan cuatro clases de variables perceptibles individualmente o en combinación para mezclar diferencias entre productores y compradores. Las variables son:

\section{- Tipo de Producto}

La industria de los fast food según Euromonitor (2016) sostiene que los peruanos cada vez están más familiarizados con marcas internacionales de comida rápida, generalmente las franquicias que ofrecen productos diversificados que no solo se limitan al pollo y a las hamburguesas, sino que también ofrecen muchas más opciones orientadas a determinados clientes. La comida rápida se divide en las siguientes categorías de productos: 
- Comida rápida asiática

- Comida rápida de Panadería

- Comida rápida de Hamburguesas

- Comida rápida de Pollo

- Comida rápida de Pescado

- Comida rápida - Helados

- Comida rápida de América Latina

- Comida rápida de Medio Oriente

- Comida rápida del Este

- Comida rápida Pizza

- Otros

Las empresas de fast food que ofrecen los tipos de comida rápida antes mencionados generalmente se encuentran dentro de patios de comida de centros comerciales, siendo caracterizadas por ser autoservicio.

- Tipo de Cliente

En el estudio de segmentación de la industria de fast food realizado por Andrade, Morales, y Andrade (2008) se menciona que el tipo de cliente que asiste a establecimientos franquiciados de comida rápida, son personas entre 19 a 25 años, es decir, que los consumidores son adultos que estudian, trabajan o que acuden a dichos establecimientos como opción para satisfacer sus necesidades. En cuanto a la clase social la mayoría de 
empresas tienen como mercado objetivo al nivel socioeconómico "C", así como las demás empresas se dirigen a los niveles A/B.

En conclusión se puede afirmar que los usuarios finales de las cadenas fast food son adultos que estudian y trabajan, generalmente buscando en un fast food una opción para satisfacer sus necesidades de acuerdo a su ritmo de vida.

- Canal (Cliente Inmediato)

Según Euromonitor (2016) menciona que muchos establecimientos de comida rápida ofrecen sus productos mediante la venta por teléfono, donde se toma la orden y se entrega el pedido directamente en la casa. A la vez menciona que algunos establecimientos ofrecen servicio al carro, aunque actualmente no es tan popular pese al gran crecimiento del número de vehículos en la ciudad de Lima. Siendo la opción más popular la entrega de comida a domicilio donde se registró una tasa baja en el 2015, ya que los peruanos prefieren vivir la experiencia de comer fuera de casa.

En este sentido Peña (2017) “de acuerdo a la extensión del mundo online se presentan opciones interesantes como aplicaciones móviles de delivery, entre las aplicaciones de delivery en el Perú se encuentran: Lima Delivery, Bembos, Diloo, Telepizza, Chifa Express, Mr. Sushi, entre otros" (p. 27).

Los canales de venta para comida rápida son: los restaurantes de servicio rápido, donde se vende comida y bebida pero no se sirve en la mesa, es decir, son establecimientos de "comprar y llevar" donde los clientes se llevan la comida para consumo fuera del local. Venta en la calle, donde se vende comida preparada en stands y locales de ocio como: casinos, teatros, cines, entre otros (Rodríguez \& Lamas, 2011).

Según el tipo de canal la venta de comida rápida generalmente depende de cada empresa, ya que algunas se encuentran en patios de comida, en locales puerta a la calle y a la 
vez ofrecen servicio delivery, y otras solamente ofrecen servicio para comprar y llevar, o también consumir dentro de un patio de comida en un centro comercial.

- Ubicación Geográfica del Consumidor

Como anteriormente se mencionó la mayoría de consumidores de fast food son adultos de19 años en adelante, y se encuentran en los niveles socioeconómicos predominando el nivel C, seguidos de los niveles A y B.

Según el estudio realizado por Ávila, Orellana, y Vera (2016) observaron que la mayoría de visitantes de cadenas de fast food se encuentran en centros comerciales como por ejemplo el C.C. Real Plaza, donde consumen en el patio de comidas o para llevar a casa. Sin embargo se menciona que los grupos mayoritarios de visitantes y consumidores de fast-food residen en los alrededores como Cercado de Lima y distritos colindantes como Breña y La Victoria, siguiéndoles los residentes de San Juan de Lurigancho que cuentan con un grado de educación técnico o universitario.

\subsubsection{Empresas que la conforman}

Arbaiza et al. Señalaron que en el Perú existen grandes cadenas de fast food, dentro de ellas franquicias internacionales como KFC y Pizza Hut, que forman parte del grupo Delosi, que cuentan con un crecimiento sostenido a nivel de la industria.

Según el Boletín estadístico el INEI (2017) en julio del 2017 el sector de restaurantes y bebidas registró un crecimiento en ventas de $1.02 \%$ debido al dinamismo, avance de los negocios y la mayor afluencia de consumidores nacionales y extranjeros. Es por ello que el servicio de fast food reportó un aumento de $1.6 \%$.

MapCity menciona que Lima Metropolitana cuenta con 816 locales de fast food, siendo Miraflores y Surco los distritos con mayor concentración de locales que oscilan entre 
los 68 y 56 tiendas respectivamente. Seguido de Independencia, Cercado de Lima y San Borja. Y en provincias Arequipa y la Libertad con 33 a 55 locales. (Fast Food en el Perú, Codigo.pe, 2017) (Ver tabla 1).

Tabla 1

Locales en Lima y Callao de Fast Food

\begin{tabular}{llc}
\hline & & Locales en Lima y Callao \\
\hline Fast food & Total* & $\%$ \\
\hline 1. Kentucky Fried Chicken & 77 & $12 \%$ \\
2. Pizza Hut & 59 & $10 \%$ \\
3. Bembos & 56 & $9 \%$ \\
4. Dunkin' Donuts & 49 & $8 \%$ \\
5. Mc Donald's & 43 & $7 \%$ \\
6. Pizza Raúl & 42 & $7 \%$ \\
7. Chinawok & 26 & $4 \%$ \\
8. Papa John's & 26 & $4 \%$ \\
9. Burger King & 25 & $4 \%$ \\
10. Telepizza & 23 & $4 \%$ \\
11. Subway & 22 & $4 \%$ \\
12. Sanguchón Campesino & 17 & $3 \%$ \\
13. Chili's & 15 & $2 \%$ \\
14. Otto Grill & 15 & $2 \%$ \\
15. Popeyes & 13 & $2 \%$ \\
16. Nitos & 11 & $2 \%$ \\
17. Doggis & 10 & $2 \%$ \\
18. Empanadas Paulistas & 7 & $1 \%$ \\
19. Frutix & 7 & $1 \%$ \\
20. La Lucha & 7 & $1 \%$ \\
21. Otros & 67 & $11 \%$ \\
Total & 617 & $100 \%$ \\
\hline
\end{tabular}

Nota. Adaptado de "Fast food en el Perú: con rentabilidad del $20 \%$ y con ventas de us $\$ 700$ millones este año", por Codigo.pe, 2017. Recuperado de

https://www.codigo.pe/marketing/fast-food-peru-rentabilidad-del-20-ventas-us700-milloneseste-ano/

Las marcas antes mencionadas forman parte de franquicias nacionales como internacionales, a continuación se detallará la cantidad de trabajadores por cada marca.

Según muestra SUNAT (2017), las franquicias como KFC o Pizza Hut cuentan con un aproximado 4, 569 trabajadores a nivel del Perú en todos sus locales, en el caso de 
cadenas nacionales como Pizza Raúl cuentan con 250 trabajadores aproximadamente (Ver Tabla 2).

Tabla 2

Cantidad de Trabajadores de las Principales Cadenas Fast Food de Lima Metropolitana

\begin{tabular}{llc} 
Razón Social & \multicolumn{1}{c}{ Nombre Comercial } & Cantidad de \\
Trabajadores & & \\
\hline Delosi S.A & Kentucky Fried chic & 4569 \\
Sigdelo S.A. & Burger king - Pizza Hut & 3636 \\
Bembos S.A.C & Bembos & 1929 \\
Nutra S.A & Dunkin Donuts & 479 \\
Operaciones arcos & McDonald's & 1531 \\
dorados de Perú S.A & & \\
Pizza Raúl EIRL & Pizza Raúl & 250 \\
Alert del Perú S.A & Chinawok & 822 \\
Corporación Peruana & & \\
De Restaurantes S.A & Papa John's & 1302 \\
Telepizza Andina S.A.C & Telepizza & 487 \\
Inversiones Perú Panamá S.A.C & Subway & 50 \\
Campesino Fast Food S.A.C & Sanguchón Campesino & Sin datos \\
Familia Popeyes S.A.C & Popeyes & Sin datos \\
Corporación GloriMar & Nitos & 42 \\
Lucha Partners S.A.C & La Lucha & 832 \\
\hline
\end{tabular}

Nota: Adaptado de "Consulta Ruc" por la Superintendencia Nacional de Aduanas y Administración Tributaria (SUNAT), 2017. Recuperado de http://econsultaruc.sunat.gob.pe/cl-ti-itmrconsruc/jcrS00Alias

Según el estudio de Euromonitor el sector fast food registró un crecimiento de valor en ventas en el 2015 de 6.2 mil millones de soles. La comida rápida de pizza fue una de las categorías de fast food más dinámicas en 2015, ya que tuvo un crecimiento del valor de servicio de alimentos del $12 \%$ y el crecimiento en puntos de venta del $7 \%$.

La segmentación de la industria se clasifica por tipos de productos ofrecidos en distintas cadenas de fast food, dichos establecimientos que por lo general se encuentran en centros comerciales muy transitados y son caracterizados por brindar servicios generalmente rápidos, lo que genera que los consumidores estén dispuestos a pagar para obtenerlos. En la 
Tabla 3 se detalla los niveles de ventas alcanzados de la clasificación de fast food por categorías.

Tabla 3

Las ventas en comida rápida por categoría: Valor Foodservice 2013- 2015

Las ventas de comida rápida por Categorías 2013 - 2015

\begin{tabular}{lccc} 
Millones de Soles & 2013 & 2014 & 2015 \\
\hline - Comida rápida de Pollo & 3,643 & 4,107 & 4,062 \\
- Comida rápida / Comida rápida & 5,512 & 6,151 & 6,233 \\
- Comida rápida Asiática & 139,2 & 148,3 & 163,8 \\
- Comida rápida de Panadería & 175,1 & 197,7 & 214,1 \\
- Comida rápida Hamburguesas & 683,6 & 712,2 & 737,5 \\
- Comida rápida de Pescado & 189,8 & 208,8 & 227,8 \\
- Comida rápida - Helado & 165,0 & 175,4 & 165,6 \\
- Comida rápida de América Latina & 308,2 & 335,7 & 370,9 \\
- Comida rápida Pizza & 126,9 & 132,8 & 148.2 \\
- Comida rápida - Otros & 116,3 & 122,2 & 131,5 \\
- Productos de preparación rápida & 94,0 & 101,7 & 108,4 \\
- Comida rápida de Medio Oriente & 10,7 & 11,0 & 11,7 \\
\hline
\end{tabular}

Nota: Adaptado de Euromonitor Internacional de las estadísticas oficiales, asociaciones comerciales, prensa especializada, la investigación de la empresa, entrevistas comerciales, fuentes comerciales, 2016. Recuperado de: http://www.euromonitor.com/peru

Por otro lado las marcas que han aumentado su rentabilidad actualmente son las cadenas de hamburguesas y pollo broaster, que oscilan entre un 10\% y 20\%. En el año 2017 los fast food en el Perú aumentaron su rentabilidad en un 20\%. (Cadenas de Fast Food, peruretail.com, 2017)

Los fast food segmento que tiene dinamismo en los centros comerciales, según cifras de la consultora Inversiones y Asesorías Araval, ya pueden alcanzar ventas anuales que ascienden los US\$570 millones. Así como también para Euromonitor, la expectativa es que los fast food logren un aumento en valor de $4 \%$ este año. (El pollo se impone, Gestión.pe, 2017) 


\subsection{Tendencias de la industria (crecimiento, inversiones)}

Como ya se ha mencionado la industria de restaurantes y bebidas tuvo un crecimiento de $1.02 \%$ respecto a años pasados (INEI, 2017 c.). Es por ello que se puede apreciar que el sector de fast food en el Perú tiene una tendencia creciente, ya que los consumidores acuden con frecuencia a centros comerciales para satisfacer sus necesidades de alimentación.

Como indica el presidente de la consultora Front Consulting, Luis Kiser, el ticket promedio de consumo en los locales de fast food es alrededor de S/ 25, y la frecuencia de visitas es de por lo menos una vez cada 15 días. (El negocio de los fast food, peru-retail.com, 2017)

Euromonitor indica un crecimiento en comida rápida en el 2015 de marcas internacionales como KFC, Dunkin` Donuts, Burger King, al igual que marcas nacionales como Otto Grill, Norky’s, entre otros.

Los consumidores peruanos a medida que pasa el tiempo se vuelven más exigentes y sofisticados, es por ello que los restaurantes de servicio están diversificando su oferta cada vez más, mientras que otros restaurantes de servicio completo se orientan a clientes exigentes que no les interesa un precio elevado con tal de obtener un producto de mayor calidad. Todo ello conlleva a la creciente demanda de consumidores de productos distintos, ya que desean obtener productos de mayor calidad a precios competitivos, de marcas establecidas.

\subsection{Análisis Estructural del Sector Industrial}

En éste análisis se utiliza el modelo de las Cinco Fuerzas desarrolladas por Michael Porter con el fin de determinar la capacitad competitiva de la empresa y conocer sus ventajas para enfrentar el mercado. 
Según Porter (2010) "la combinación de las cinco fuerzas ayuda a determinar si éstas pueden condicionar los precios y costos restando la rentabilidad de la industria" (p. 125).

\subsubsection{Amenaza de nuevos entrantes}

Se identificó diferentes barreras que pueden impedir el ingreso al mercado:

\section{Economías de escala.}

Los fast food como Pizza Hut, Pizzas Raúl, Telepizza tienen mayor ventaja por diferentes factores como confiabilidad, rentabilidad y posicionamiento tanto en el mercado nacional como internacional, además de estar estructurados por ser franquicias. Por lo tanto, se considera que es una barrera de entrada alta y exige a que se desarrollen buenas estrategias de crecimiento para cubrir las necesidades del mercado.

Según Porter (2013) "las economías de escala se dan cuando las empresas más competitivas del sector realizan fuertes inversiones logrando que las nuevas empresas no puedan competir y acepten una desventaja en costos u opciones menos atractivas" (p. 127).

\section{Diferenciación de productos}

En el mercado existen diferentes pizzerías, los precios son competitivos, el servicio se diferencia dependiendo de un fast food o un restaurante, en algunos casos según el entrenamiento del personal, las opciones del producto también son similares, es por ello se busca brindar un valor agregado logrando satisfacer a un público más exigente y que se adecue específicamente a lo que buscan, por tal motivo, se considera que la barrera es baja.

Las empresas que ya tienen tiempo en el mercado han ganado posicionamiento por la publicidad, atención al cliente, productos, etc., por lo tanto, los nuevos ingresos podrían invertir más si desean llegar a ese nivel, sin embargo es muy arriesgado y los resultados pueden verse a largo plazo (Porter, 2013, p. 129). 


\section{Necesidades de capital}

En éste sector, la inversión de capital es alta, los socios o inversionistas deben primero investigar las necesidades de mercado y realizar un análisis para evitar los fracasos.

\section{Costos por el cambio.}

En el caso de proveedores, existe un mercado amplio y competitivo, los insumos que se utilizan en ésta industria no son de difícil acceso, es por ello que la barrera de entrada es baja ya que se puede negociar en cualquier momento con otros proveedores que generen un valor agregado al negocio como en precios, tiempo de entrega, vencimientos, etc.

\section{Acceso a los canales de distribución}

Las barreras de entrada dependerán de la ubicación del negocio frente a la de los competidores. En ésta industria, se encuentran locales en cada distrito y centros comerciales, es por ello que se considera una barrera de entrada baja, se debe colocar puntos de venta similares para llegar más rápido a los clientes y captando la atención con publicidad y promociones.

\subsubsection{Poder de negociación de los proveedores}

Los proveedores juegan un papel importante, en éste sector, los insumos son de fácil acceso así como negociar con diferentes proveedores con el fin de encontrar al que se acomode a las necesidades del negocio que puede ir desde precio, entrega, calidad, etc.

\section{Concentración de proveedores}

La concentración de proveedores es de una barrera baja, puesto que la accesibilidad a éstos insumos es rápida y pueden ser encontrados en diferentes mercados mayoristas o en supermercados que venden productos al por mayor. Así mismo, si se decide cambiar de 
proveedor, el costo del mismo es cero puesto que es de libre elección tanto de precio o abastecimiento.

En la industria, se puede trabajar con los siguientes proveedores porque ofrecen garantías de un producto de calidad, entrega a tiempo y precios justos.

- Embutidos Santa Cruz: se dedican a la elaboración de diferentes embutidos y tienen una planta de producción con tecnología de vanguardia y cumplen con todos los estándares de calidad que el mercado requiere.

- Alicorp: cuenta con diferentes distribuidores en todo Lima y ofrecen productos de alta calidad y confianza para la elaboración de masas y otros alimentos. Se escogerán a aquellos distribuidores que estén aledaños a los distritos del Cercado de Lima (C.C. Plaza Norte), Santiago de Surco (C.C. Jockey Plaza) y San Juan de Miraflores (C.C. Mall del Sur).

- Kimberly Clark: ofrece productos de higiene y limpieza.

- Dimerc: proveedor de útiles de oficina con precios accesibles.

- Facusa: proveedor de utensilios de cocina.

\section{Costos por cambio de proveedor}

En éste punto, la industria no asume los costos por cambio de proveedor, es una barrera baja porque existe la negociación de precios así como la opción de tener diferentes proveedores para asegurar el abastecimiento de productos e inclusive adquirirlos por medio de mayoristas.

El $90 \%$ de los proveedores representan el 80\% de los insumos, sin embargo existe un poder de negociación puesto que se ha considerado trabajar con Embutidos Santa Cruz, pero se puede negociar también con Embutidos San Fernando, Breadt, etc., en el caso de harinas 
(abarrotes) se puede negociar con diferentes distribuidores que ofrecen productos de la empresa Alicorp y en el caso de carnes se tiene proveedores como Carnes Naveda, Inpelsa, Zedina con precios muy competitivos en el mercado. Ver tabla 4.

Tabla 4

Tabulación de proveedores

\begin{tabular}{lr}
\hline Embutidos y quesos & $35 \%$ \\
Carnes & $15 \%$ \\
Harina (abarrotes) & $40 \%$ \\
Utensilios & $5 \%$ \\
Limpieza & $5 \%$ \\
\hline TOTAL & $100 \%$ \\
\hline
\end{tabular}

3. Disponibilidad de insumos sustitutos

Son pocos los insumos estacionales y en caso se necesiten, se puede optar por frutas o verduras envasadas al vacío, los demás insumos se encuentran en toda época del año, es por ello que se consideran barreras de entrada baja.

\subsubsection{Poder de negociación de los compradores}

Para realizar un análisis del poder de negociación de los compradores, se consideró lo siguiente:

\section{Concentración de clientes}

Los clientes de éste sector, buscan alimentos de fácil y rápida preparación y a la vez encontrar diferentes insumos en el mismo producto, más adelante se estudiará el perfil del consumidor. 
"Jóvenes son los que acuden una vez a la semana a estos locales y la tendencia es asistir más a la hora del almuerzo que de la cena”. (Más del 70\% de limeños acude cada quince días a los fast food, gestión, 2015).

Por lo tanto, se puede concluir que el nivel de concentración de clientes es alto.

\section{Diferenciación}

La ventaja competitiva que existe en esta industria es que algunos fast food ofrecen productos a precios accesibles con diferentes promociones, rápida atención al cliente y delivery. Por otro lado, los restaurantes se diferencian por ofrecer diversos ingredientes y de calidad, mejor preparación, servicio al cliente y hasta infraestructura, logrando que el cliente se lleve una buena experiencia. Por tal motivo, se considera que el poder de diferenciación tiene una barrera media.

\section{Costos de cambio para el consumidor}

En los establecimientos de ésta industria, no se cobra el ingreso sino el consumo, es por ello que si el consumidor desea optar por otra opción sin antes haber consumido, no genera ningún costo por cambiar de fast food y por lo tanto la barrera es baja.

\subsubsection{Amenaza de productos sustitutos}

\section{Disponibilidad de sustitutos}

Hay disponibilidad de sustitutos con las nuevas tendencias que se están generando como las opciones de comida saludable, que pueden darse desde casa y buscar restaurantes que brinden éstas opciones las cuales las encuentras con más frecuencia en centros comerciales e inclusive en patios de comida de las universidades en el Perú. 


\section{Precio relativo entre el producto ofrecido y el sustituto}

Existe la amenaza de productos sustitutos porque los restaurantes que ofrecen comida saludable se encuentran también en centros comerciales e inclusive en universidades como Esan, UPC, entre otras, donde los precios son muy competitivos. La comida saludable no tiene bajos precios.

Sin embargo, la calidad y el servicio, no siempre son los mismos, lo cual hace equilibrar las diferentes alternativas antes de tomar una decisión de compra de un sustituto.

\subsubsection{Rivalidad entre competidores existentes}

Para realizar un análisis del poder de negociación de los compradores, se consideró lo siguiente:

\section{Concentración}

Pizza Lab está dirigido al grupo estratégico de los fast food y son quienes tienen características parecidas como: el tipo de ingreso, los cuales son de un nivel socioeconómico A, B y C; gustos y preferencias, que se dan con la diferenciación al personalizar la pizza con los ingredientes que el cliente necesite, lugar cómodo y tranquilo; calidad en servicio; producto; y así como los que están dentro de la zona geográfica.

Por otro lado, Pizza Lab se concentrará en los centros comerciales iniciando sólo con tres locales, pero no en patios de comida, sino en un espacio cerrado para comodidad del cliente como los restaurantes de comida italiana los cuales podrían ser la Bodega de la Tratoria, Punto Italiano, entre otras. 


\section{Costos fijos}

Los costos fijos de Pizza Lab son aquellos como el alquiler del espacio dentro del centro comercial, la luz, el agua, teléfono, Internet, los sueldos de los trabajadores y los pagos para el outsourcing.

\section{Crecimiento de la demanda}

"En 2017 los consumidores demandan más de los productos, servicios y marcas y usan herramientas digitales para articular y satisfacer sus necesidades. Desean autenticidad y esperan elementos de personalización tanto en bienes producidos en masa como en artículos de lujo", afirma la autora y Consultora de tendencias de consumo en Euromonitor International, Daphne Kasriel-Alexander" (Euromonitor: Diez principales tendencias de consumo para 2017, elcomercio.pe, 2017)

Por lo tanto, los consumidores buscan servicios diferenciados, por tal motivo se desea apostar por la personalización y rapidez de producto, servicio y tecnología que se implementará en Pizza Lab.

Así mismo se tiene el caso del restaurante Mamma Tomato, quienes ofrecen pizzas saludables, siendo una competencia directa "El gerente general de Mamma Tomato busca abrirse paso en un mercado donde reina la imagen de personas abalanzándose a grandes cajas marcadas de grasa y cambiarlo por el de comensales que se reúnen a comer un producto saludable, balanceado y rico, en un ambiente distendido donde encuentran también tapas y bebidas" (Mamma Tomato busca abrir hasta tres locales por año, gestion.pe, 2017)

El crecimiento también ha ido aumentando "El ir a comer a un fast food es una práctica que se vuelve cada vez más habitual entre los consumidores. Así, en promedio, el 73\% de limeños acude por lo menos una vez cada 15 días a estos recintos, según un estudio 
elaborado por la consultora Quality Research". (Más del 70\% de limeños acude cada quince días a los fast food, gestión.pe, 2015)

Tabla 5

Resumen de las Cinco Fuerzas de Porter

Cinco Fuerzas de Porter

Alta Media Baja

1. Amenaza de nuevos entrantes

Economías de escala

Diferenciación de productos

Necesidades de capital

Costos por el cambio

Acceso a canales de distribución

\begin{tabular}{lll}
5 & 3 & 1 \\
1 & 3 & 5 \\
5 & 1 & 3 \\
1 & 3 & 5 \\
1 & 3 & 5 \\
\hline
\end{tabular}

2. Poder de negociación de los proveedores

Concentración de proveedores

Costos por cambio de proveedor

$\begin{array}{lll}1 & 3 & 5\end{array}$

Disponibilidad de productos sustitutos

3. Poder de negociación de compradores

Concentración de clientes

$\begin{array}{lll}1 & 3 & 5\end{array}$

Diferenciación

Costos por el cambio para el consumidor

4. Amenaza de productos sustitutos

Disponibilidad de sustitutos

Precio relativo entre el producto ofrecido y el sustituto

13

$3 \quad 5$

5. Rivalidad entre competidores

Concentración

Costos fijos

Crecimiento de la demanda

Totales

\begin{tabular}{lll}
5 & 3 & 1 \\
1 & 5 & 3 \\
1 & 3 & 5 \\
\hline
\end{tabular}

El resumen de las cinco fuerzas de Porter, brinda un detalle de todo lo descrito

anteriormente, generando un resultado con barreras bajas de entrada en ésta Industria, por

consiguiente, existe la posibilidad de ingresar Pizza Lab a éste sector con menor riesgo,

además que el mercado de restaurantes es amplio, atractivo y competitivo, ya que cuenta con

variables muy interesantes y diversificadas para aprovechar y lograr que el negocio sea

exitoso. 


\subsection{Análisis de la Competencia}

\subsubsection{Empresas que ofrecen el mismo producto o servicio}

El concepto de restaurantes de comida rápida, en especial pizzerías, es muy común en el mercado nacional e internacional, sin embargo, se evalúa la opción de analizar un mercado más exigente, con necesidades aún no satisfechas y donde éste plan de negocios busca ofrecer diferentes atributos que se diferencien de los típicos conceptos de fast food de pizza.

Por tal motivo, se presenta el siguiente análisis en cuanto a competencias:

\section{Competencia directa}

Se considera a aquellas marcas que ofrecen productos, servicios y precios similares como éste plan de negocios y que estén ubicados en los patios de comida de los centros comerciales de Lima Metropolitana.

Las cuatro empresas de fast food que se van a mencionar son semejantes al presente plan de negocio porque el producto principal es la pizza, sin embargo, el valor agregado será la personalización de pizzas a gusto del cliente y captando la atención de aquel consumidor que busca productos bajos en grasa.

- Pizza Hut

Inició sus actividades en 1983 en el Perú, actualmente tiene 80 locales en el Perú, de los cuales 30 aproximadamente se encuentran en Lima. Sus locales están estratégicamente ubicados como en patios de comida y en salones de los centros comerciales, poseen locales en diferentes distritos y los precios varían según el tamaño, masa, ingredientes, etc. La atención dependerá del local a donde acuden los consumidores, puede ser en mesa o en counter en donde se recoge el pedido. (Pizzahut.com.pe, 2017) 
- Papa John's

Esta cadena de restaurantes tiene 12 años en el Perú y cuenta con aproximadamente 30 locales. Tiene presencia en pocos patios de comida de centros comerciales, el local que tiene mayor venta es el ubicado en el Aeropuerto Jorge Chávez. (papajohns.com.pe, 2017)

- Telepizza

Esta cadena española ingresó al mercado peruano en el año 2011 y cuenta con 5 locales, 2 de ellos se encuentran en Centros Comerciales y aunque tiene poca participación en el mercado por las ubicaciones, prevén encontrar inversionistas para continuar con la expansión de su franquicia. (Telepizza.com, 2017)

- Pizza Raúl

Es una cadena nacional que dio ingresó al mercado en el año 1994 y cuenta con 40 locales en Lima. Siendo empresa peruana, es líder en el rubro de pizzerías peruanas y buscan expandir sus sucursales en provincia. (pizzaraul.com, 2017)

\section{Competencia indirecta}

Se considera como competencia indirecta a aquellos restaurantes que ofrecen productos y precios similares, sin embargo, éstos se encuentran fuera de centros comerciales y la carta es de mayor variedad:

- La Romana

Cuenta con 4 locales, en San Borja, Miraflores, Pueblo Libre y San Isidro.

Cuenta con una variedad de ingredientes para las elaboraciones de pizzas, además de tener una carta variada de comida italiana. 
- Mamma Tomato

Pizzería que ha crecido rápidamente en el año 2017, cuenta con 4 locales los cuales están ubicados en La Molina, Surco, Barranco y San Miguel.

La semejanza con el plan de negocios analizado es que también ofrece pizzas con diferentes combinaciones y no solo se enfoca en los tradicionales fast food, sino en ofrecer alternativas sanas y bebidas auténticas.

- La Bodega de la Trattoria

Cuenta con 7 locales, de los cuales 4 están en centros comerciales como el Jockey Plaza, Plaza San Miguel y Mega Plaza, lo cual lo hace semejante al negocio.

Ofrece buenas alternativas de pizza y comida italiana y los precios son similares.

- Ántica Pizzería

Cuenta con 4 locales en Lima y uno está ubicado en el Boulevard de Asia.

Ofrecen alternativas de pizzas elaboradas a la leña y una variedad de platos de comida italiana en un ambiente cálido y acogedor.

\subsubsection{Participación de mercado de competidores}

Pizza Hut, Pizza Raúl, Telepizza y Papa John’s tienen una participación de mercado de $11.9 \%, 7.2 \%, 4.5 \%$ y $3.7 \%$ respectivamente (Ver figura 4). En cuanto a ventas, las cifras son de 60 millones de dólares, 36.3 millones de dólares, 22.6 millones de dólares y 18.6 millones de dólares respectivamente. (¿Cómo se desarrolla el mercado de la pizza en Perú?, PeruRetail.com, 2016)

Pizza Hut, Papa John’s y Telepizza están ubicados en patios de comida y locales en los centros comerciales, además de contar con locales en puntos estratégicos de diferentes 
distritos de Lima Metropolitana. En el caso de Pizza Raúl que cuenta con aproximadamente 43 locales, se ubica en diferentes distritos de Lima Metropolitana estratégicamente ubicados.

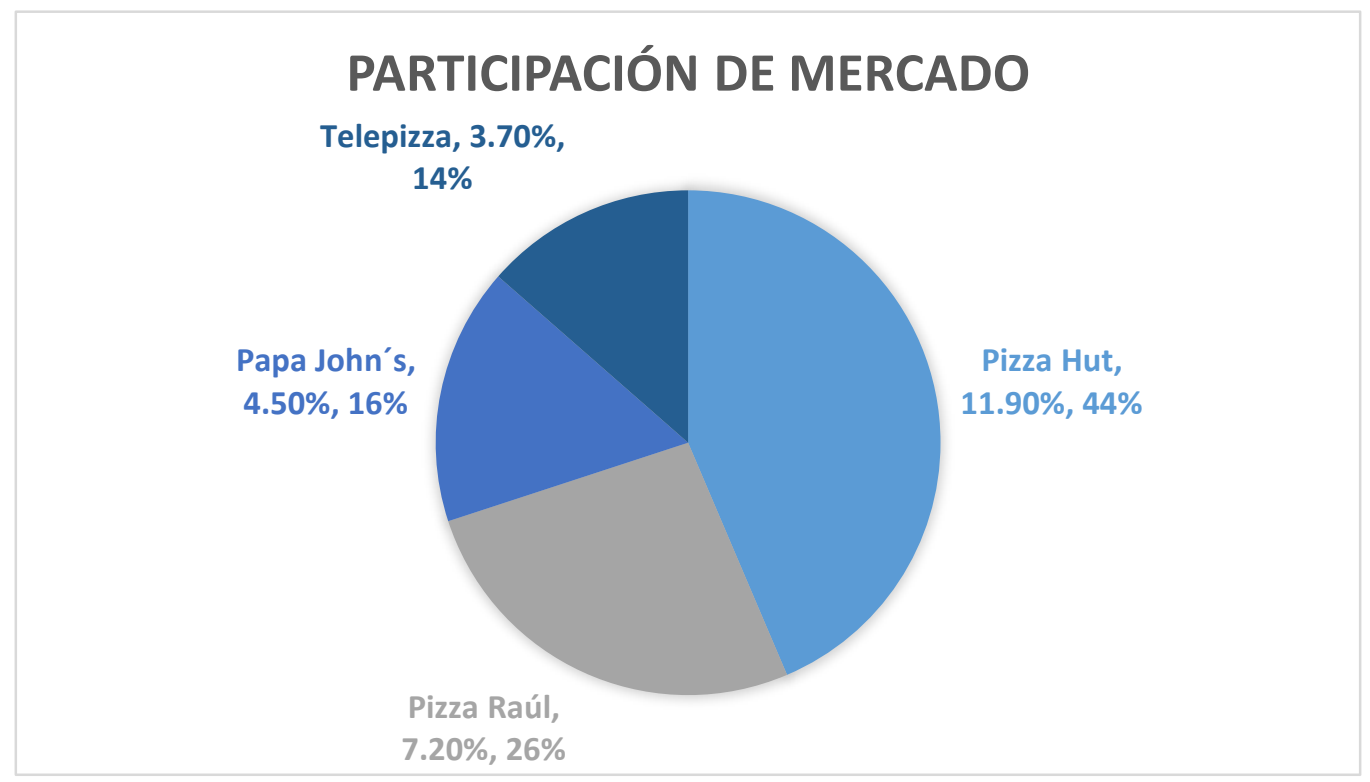

Figura 4. Participación de mercado de fast food de pizzas. Tomado de ¿Cómo se desarrolla el mercado de la pizza en Perú?, por PeruRetail.com, 2016. Recuperado de http://www.peruretail.com/estudio-investigacion/como-se-desarrolla-el-mercado-de-la-pizza-en-peru/

\subsubsection{Matriz de Perfil Competitivo}

"La matriz de perfil competitivo (MPC) identifica los principales competidores de la compañía, así como sus fortalezas y debilidades particulares en relación con la posición estratégica de una firma muestra.” (David, 2013, p. 83)

Según David (2013) a diferencia de una matriz EFE, en una matriz MPC incluyen cuestiones internas como externas; además, las calificaciones y puntuaciones ponderadas para las compañías rivales pueden ser comparadas con las del proyecto.

Esta matriz de perfil competitivo cuenta con siete factores claves de éxito, los cuales fueron extraídos de los factores más importantes que generan el valor agregado del proyecto, según los expertos de las entrevistas a profundidad. 
El primer factor de éxito del fast food de pizzas personalizadas fue precisamente la libertad de personalizar la pizza, ya que en el caso de la competencia, no tienen esta opción tan definida como la del proyecto. Algunas de las marcas analizadas ofrecen mezclar los ingredientes de dos pizzas en una sola, de manera que se pueda probar más de un tipo; sin embargo, ninguna ofrece la opción de crear una pizza personalizada con los ingredientes a elección del cliente.

El segundo factor es la rapidez en el servicio, es una de las innovaciones que presenta este proyecto en el rubro de las pizzerías, debido a que tiene una línea de interacción dividida en dos partes: la primera es la barra donde se ubican los alimentos separados por tipos (salsas, quesos, proteínas e ingredientes adicionales) y la segunda, es la zona de pago. El producto se va creando mientras el cliente elige sus ingredientes; de esta manera, desde que se atiende el pedido del cliente hasta recibir su comprobante de pago, no debería pasar más de tres minutos, y adicionalmente unos cuatro minutos más para recibir su pedido, gracias al horno que se usará, que tiene la capacidad de llegar hasta los $500^{\circ} \mathrm{C}$.

El tercer factor del proyecto es la interacción con el cliente, ya que este proyecto permite que el cliente decida qué ingredientes y qué cantidad de cada ingrediente elegir, razón por la cual se ofrecen diferentes opciones de cada tipo de alimento, para que el cliente tenga la opción de elegir, y también, para que vuelva pronto a probar otra combinación. Estos diferenciales permitirán competir correctamente con pizzerías como Pizza Hut, Telepizza, y otros restaurantes que compiten dentro de patio de comidas.

El cuarto factor a estudiar es la ubicación, ya que el presente proyecto se ubicará en patios de comidas de restaurantes, junto con Pizza Hut, Papa John's y Telepizza. Los competidores, incluyendo a Pizza Raúl, tienen establecimientos independientes e incluso abarcan distintos distritos de Lima. 
El quinto factor es la variedad de opciones que se ofrece. En éste caso, las opciones del resultado final de la pizza, serán casi ilimitadas a diferencia de las opciones de la competencia que pueden ser más por lo que manejan una carta, e incluso un servicio diferente; pero no brindan el servicio de realizar una pizza personalizada.

El sexto factor está basado en la infraestructura y ambiente, ya que el proyecto tendrá un espacio pequeño de servicio, la decoración debe tener temática del producto a ofrecer. Por el contrario, la competencia mantiene locales más grandes e infraestructura más vistosa, debido al servicio que ofrecen.

Finalmente el sétimo factor, es el reconocimiento de marca, en la cual el proyecto obtiene una baja calificación, ya que es un nuevo negocio que ingresará al rubro de pizzerías. La competencia definitivamente tiene la ventana en este punto.

Estos factores fueron previamente consultados en las entrevistas a profundidad, así como las ponderaciones y pesos que tendrían cada uno de estos; estas entrevistas se pueden encontrar en el Anexo 5. Se tomaron en cuenta la opinión de los entrevistados en la investigación cualitativa; así mismo, se contaron con experiencias reales en cada uno de los establecimientos estudiados. (Ver tabla 6) 
Tabla 6

Matriz de Perfil Competitivo

\begin{tabular}{lccccccccc}
\multirow{2}{*}{ Factor clave } & Ponderación & \multicolumn{2}{c}{ Pizza Hut } & \multicolumn{2}{c}{ Papa John's } & \multicolumn{2}{c}{ Pelepizza Raúl } \\
\cline { 2 - 8 } & & Calificación & Puntaje & Calificación & Puntaje & Calificación & Puntaje & Calificación & Puntaje \\
\hline $\begin{array}{l}\text { Libertad para } \\
\text { personalizar }\end{array}$ & 0,2 & 2 & 0,4 & 2 & 0,4 & 3 & 0,6 & 2 & 0,4 \\
$\begin{array}{l}\text { Rapidez en el } \\
\text { servicio }\end{array}$ & 0,2 & 3 & 0,6 & 3 & 0,6 & 3 & 0,6 & 3 & 0,6 \\
$\begin{array}{l}\text { Interacción con el } \\
\text { cliente }\end{array}$ & 0,1 & 3 & 0,3 & 3 & 0,3 & 2 & 0,2 & 3 & 0,3 \\
$\begin{array}{l}\text { Ubicación } \\
\text { Variedad de }\end{array}$ & 0,15 & 4 & 0,6 & 3 & 0,45 & 2 & 0,3 & 2 & 0,3 \\
$\begin{array}{l}\text { opciones } \\
\text { Infraestructura y }\end{array}$ & 0,1 & 4 & 0,4 & 3 & 0,3 & 2 & 0,2 & 3 & 0,3 \\
ambiente & 0,1 & 3 & 0,3 & 4 & 0,4 & 2 & 0,2 & 3 & 0,3 \\
Reconomiento & 0,15 & 4 & 0,6 & 4 & 0,6 & 3 & 0,45 & 3 & 0,45 \\
\hline Resultado & 1 & & 3,2 & & 3,05 & & 2,55 & 2,65
\end{tabular}

Nota. El número 1 indica debilidad principal, el número 2 indica debilidad menor, el número 3 indica fortaleza es menor y el número 4 es fortaleza principal 
Tomando en cuenta el resultado de factores de éxito de 3.20, el concepto Pizza Hut tiene ventaja frente a los demás competidores. Sin embargo, el punto más bajo dentro de los factores de éxito es la interacción con el cliente; factor que el presente proyecto tiene como diferencial.

\subsection{Análisis de Contexto Actual y Esperado}

De acuerdo con corporaciones más influyentes clasifican el entorno social en cuatro áreas y centran el monitoreo de cada área en las tendencias que tienen importancia corporativa. Este monitoreo se denomina análisis PEEST, también conocido como PESTEL acrónimo del análisis político, económico, sociocultural, tecnológico, ecológico y legal. Las tendencias existentes en cualquier área pueden ser muy importantes para las empresas de la industria, pero menos importantes para las de otras (Wheelen \& Hunger, 2013, p.109).

El análisis del entorno donde se sitúa la empresa y del proyecto que se evalúa implementar es fundamental para determinar el impacto de las variables controlables y no controlables, así como para definir las distintas opciones mediante las cuales es posible emprender la inversión. Tan importante como identificar y dimensionar las fuerzas del entorno que influyen o afectan el comportamiento del proyecto, la empresa o, incluso, el sector industrial al que pertenece es definir las opciones estratégicas de la decisión en un contexto dinámico. (Sapag, 2011, p. 25)

A continuación, se presentan las tendencias que influyen de alguna manera positiva o negativamente al sector en el cual se planea ubicar el proyecto, aplicando el análisis PESTEL. 


\subsubsection{Análisis Político-Gubernamental}

Actualmente existen diferentes países que regulan la oferta de restaurantes, en cuanto a la salubridad de lo que ofrecen. En el Perú aun no existen regulaciones dirigidas exclusivamente al rubro de restaurantes.

La Sociedad Nacional de Industrias propuso en el año 2017, la Ley de Alimentación Saludable; sin embargo, se comunicó que esta ley no aplica para fast foods ni otro tipo de restaurantes. En el 2018, la ley fue aprobada, y está enfocado en los alimentos procesados. No obstante, Alejandro Daly, presidente de la Sociedad Nacional de Industrias, no ha descartado que más adelante se apliquen medidas para restaurantes, con la finalidad de brindarle información al consumidor y pueda tomar una decisión responsable al momento de consumir en un restaurante (SNI advierte: Ley de Alimentación Saludable no contempla a 'fast food' ni restaurantes, gestión.pe, 2017)

En conclusión, actualmente no existen leyes directas que regulen el rubro de restaurantes en cuanto a la alimentación saludable, pero se proyecta que se desarrollarán en los próximos años; lo cual representa una amenaza para el presente proyecto, ya que la comida que se ofrece es considerada alta en grasas.

\subsubsection{Análisis Económico}

El Producto Bruto Interno total del Perú registró un crecimiento en el periodo comprendido entre los años 2007 y 2016 impulsado principalmente por el sector minero, manufacturero y del comercio. Tal como se puede observar en la figura 5 la tendencia ascendente del PBI se ha mantenido en los últimos nueve años y se mantendrá su crecimiento en los próximos años. 


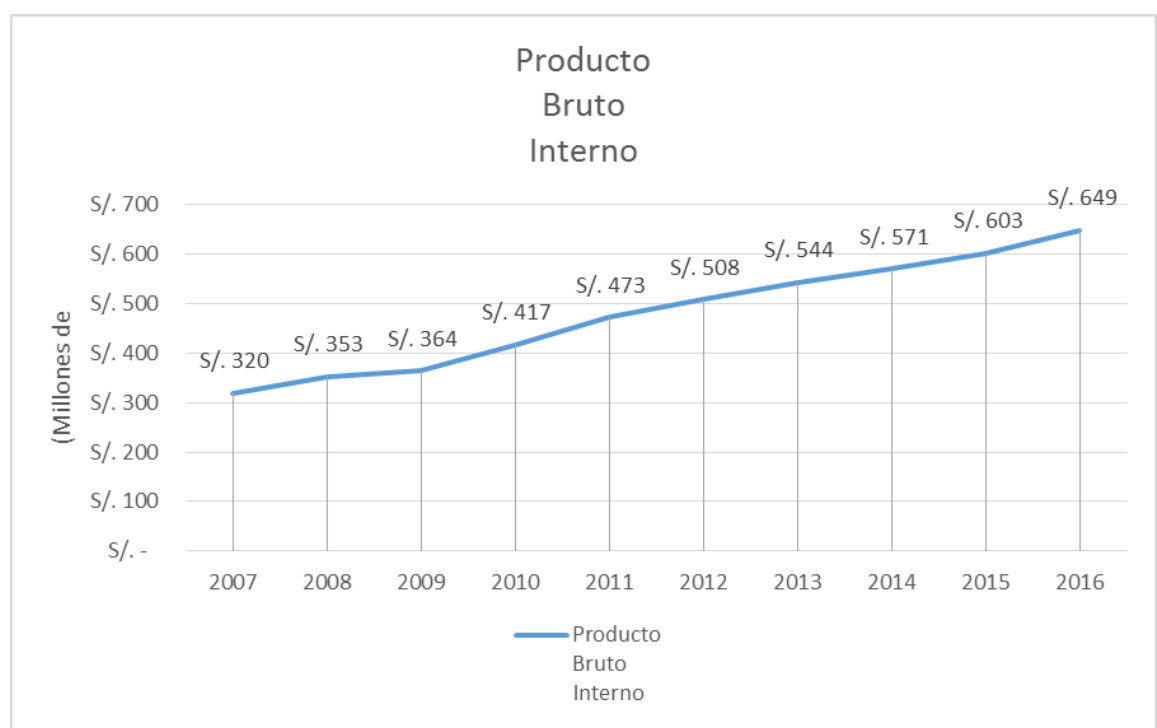

Figura 5. Producto Bruto Interno de Perú. Tomado de "Producto Bruto Interno Total y por Habitante 1994-2016 (Valores a precios corrientes)", por el INEI (2017). Recuperado de https://www.inei.gob.pe/estadisticas/indice-tematico/economia/

“El Ministerio de Economía y Finanzas (MEF) indicó que la previsión de crecimiento de PBI para el 2019 es de 4.2\%. Además, indicó el Marco Macroeconómico Multianual (MMM) que se proyecta un aumento PBI de 3.5\% en el 2017 a 4.5\% en el 2022” (MEF elevó su proyección de crecimiento del PBI, gestión.pe, 2018)

“El Instituto de Economía y Desarrollo Empresarial (IEDEP) de la Cámara de Comercio de Lima (CCL) estimó que la economía peruana alcanzaría un crecimiento económico de $2.6 \%$ en el 2017 y 3.5\% en el 2018.” (CCL proyecta crecimiento económico para Perú, gestion.pe, 2017)

El PBI per cápita nacional ha logrado desarrollarse de manera creciente a lo largo de la última década mostrando un crecimiento sostenido desde el año 2007; presenta entre los años 2007 y 2016 un aumento de 83.54\% (Ver figura 6). En términos del análisis del PBI per cápita nacional, esto demostraría que los usuarios han aumentado su capacidad adquisitiva mediante el incremento de la renta individual, demostrando que 
existe la posibilidad de que adquieran mayor cantidad de bienes de consumo no tradicionales, como los servicios de un restaurante, una vez cubierta todas las necesidades básicas de los individuos.

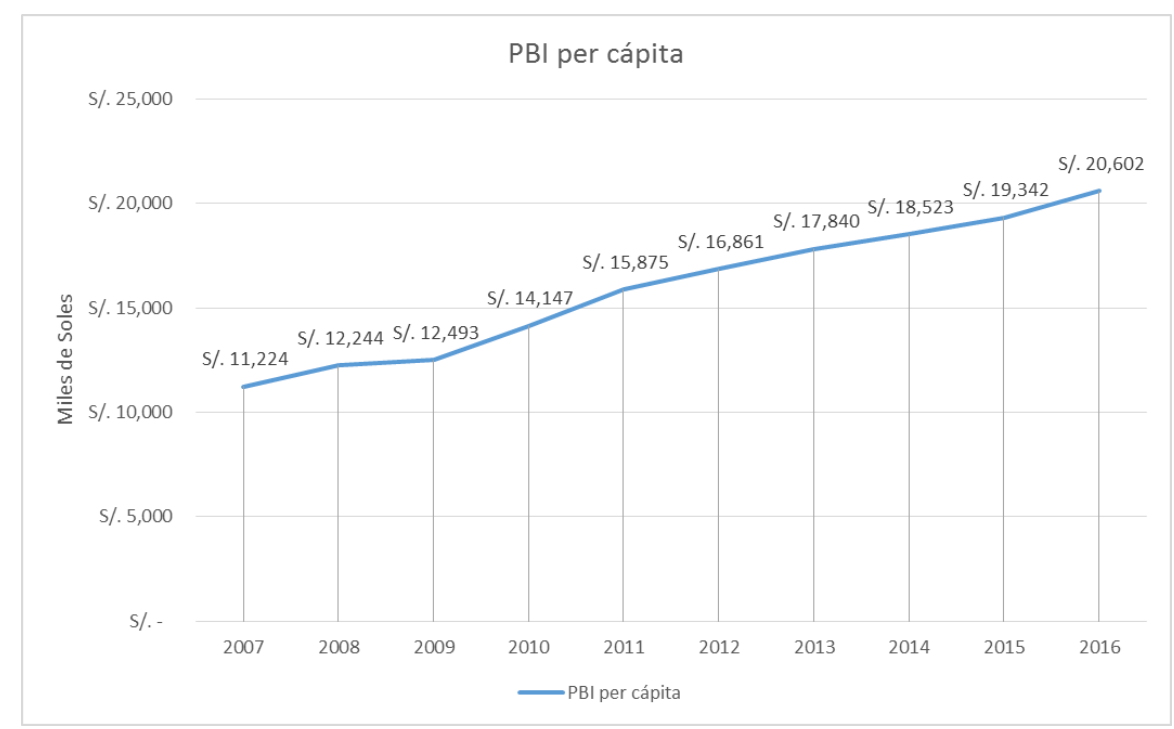

Figura 6. Producto Bruto Interno per cápita. Tomado de "Producto Bruto Interno Total y por Habitante 1994-2016 (Valores a precios corrientes)", por el INEI (2017). Recuperado de https://www.inei.gob.pe/estadisticas/indice-tematico/economia/

La población económicamente activa (PEA) de Lima Metropolitana presentó una tendencia positiva desde el año 2009 hasta el 2015 con una tasa de crecimiento promedio anual de $2.25 \%$, a pesar que se presentó un decrecimiento en los años 2013 y 2015. En comparación con la PEA a nivel nacional que ha registrado una tasa de crecimiento promedio de $1.64 \%$, la capital ha logrado obtener mejores resultados en el análisis de la PEA y muestra la mayor concentración geográfica en comparación del resto del país; inclusive a pesar que a nivel nacional no se ha tenido decrecimiento en ninguno de los años del periodo mencionado. Lo cual enmarca a Lima Metropolitana como una de las ciudades del territorio nacional que engloba a la población con mayor posibilidad de gasto. (Ver tabla 7) 
Tabla 7

Población Económicamente activa (PEA) de Lima Metropolitana

\begin{tabular}{|c|c|c|c|c|c|c|c|}
\hline Ámbito geográfico & 2009 & 2010 & 2011 & 2012 & 2013 & 2014 & 2015 \\
\hline Total & 15448.2 & 15735.7 & 15949.1 & 16142.1 & 16328.8 & 16396.4 & 16498.1 \\
\hline $\begin{array}{l}\text { Lima } \\
\text { Metropolitana 1/ }\end{array}$ & 4785.1 & 4942.4 & 5030.1 & 5144.1 & 5133.3 & 5121.4 & 5231.1 \\
\hline $\begin{array}{l}\text { Resto País } \\
\text { Área de residencia }\end{array}$ & 10663.1 & 10793.3 & 10919.0 & 10998.0 & 11195.5 & 11275.0 & 11267.1 \\
\hline Urbana & 11243.6 & 11592.3 & 11856.2 & 12116.9 & 12353.4 & 12436.4 & 12583.8 \\
\hline $\begin{array}{l}\text { Rural } \\
\text { Región natural }\end{array}$ & 4204.6 & 4143.5 & 4092.8 & 4025.3 & 3975.4 & 3960.0 & 3914.3 \\
\hline Costa & 8337.3 & 8548.4 & 8639.1 & 8852.6 & 8892.7 & 8889.0 & 8983.8 \\
\hline Sierra & 5147.1 & 5178.4 & 5256.2 & 5215.3 & 5344.6 & 5387.4 & 5423.0 \\
\hline Selva & 1963.8 & 2009.0 & 2053.8 & 2074.3 & 2091.6 & 2120.0 & 2091.4 \\
\hline
\end{tabular}

Nota. Expresado en miles de personas. Tomado de "Población económicamente activa, según ámbitos geográficos", por INEI (2015). Recuperado de https://www.inei.gob.pe/estadisticas/indice-tematico/ocupacion-y-vivienda/

La remuneración mínima ha registrado incrementos en la última década yendo desde S/. 425 nuevos soles en el 2003 a S/. 850 nuevos soles en el año 2017, es decir ha tenido un aumento del 100\%. (Ver figura 7)

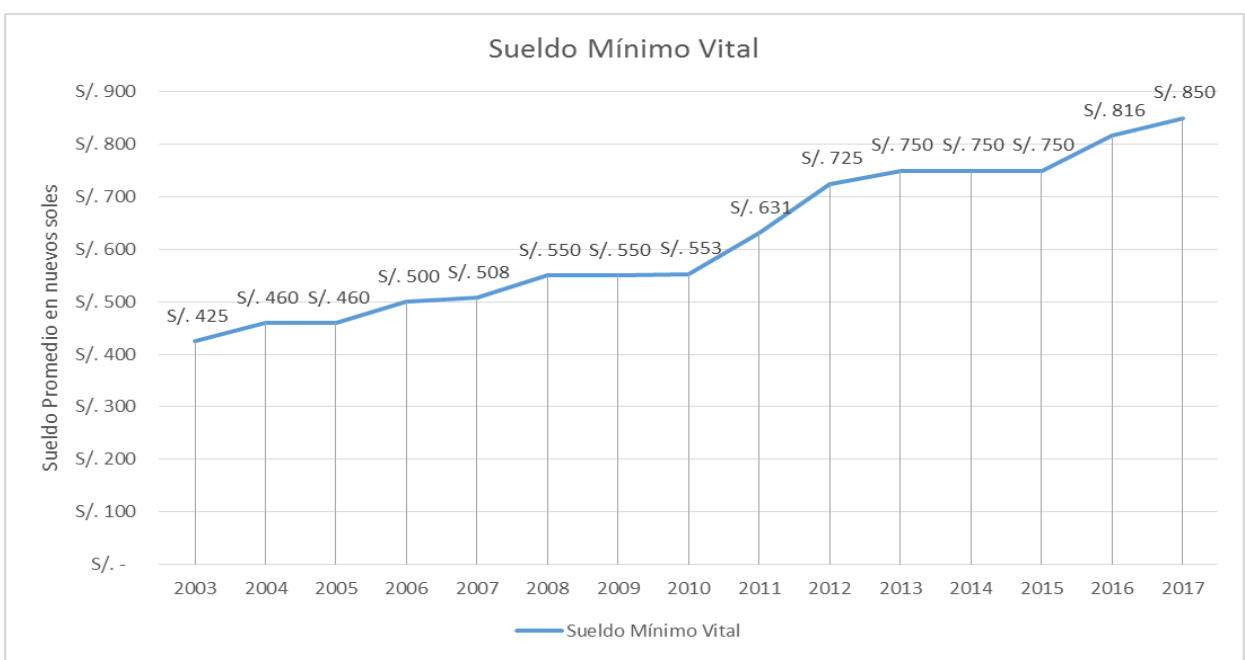

Figura 7. Sueldo mínimo vital. Tomado de "Lima Metropolitana: Remuneración mínima vital mensual", por INEI (2017d). Recuperado de https://www.inei.gob.pe/estadisticas/indicetematico/salaries/ 
Esto, junto a los datos anteriormente mencionados, demuestra una relación vinculante al crecimiento del PBI per cápita y el gasto promedio. Es decir, se demuestra que los consumidores han logrado aumentar su capacidad adquisitiva y por ende, mejorar su calidad de vida; mediante la adquisición de servicios y productos que antes no se podían consumir como se demuestra en la teoría de la posibilidad de consumo.

La tasa de inflación en el Perú se ha visto afectada principalmente por alzas en los precios de alimentos, combustibles y tarifas eléctricas, según el Reporte de Inflación de Junio 2017 emitido por el BCRP. La inflación para Junio 2017 se encuentra por encima del rango máximo aceptado, impulsada principalmente por la volatilidad de los alimentos y la energía.

(Ver figura 8)

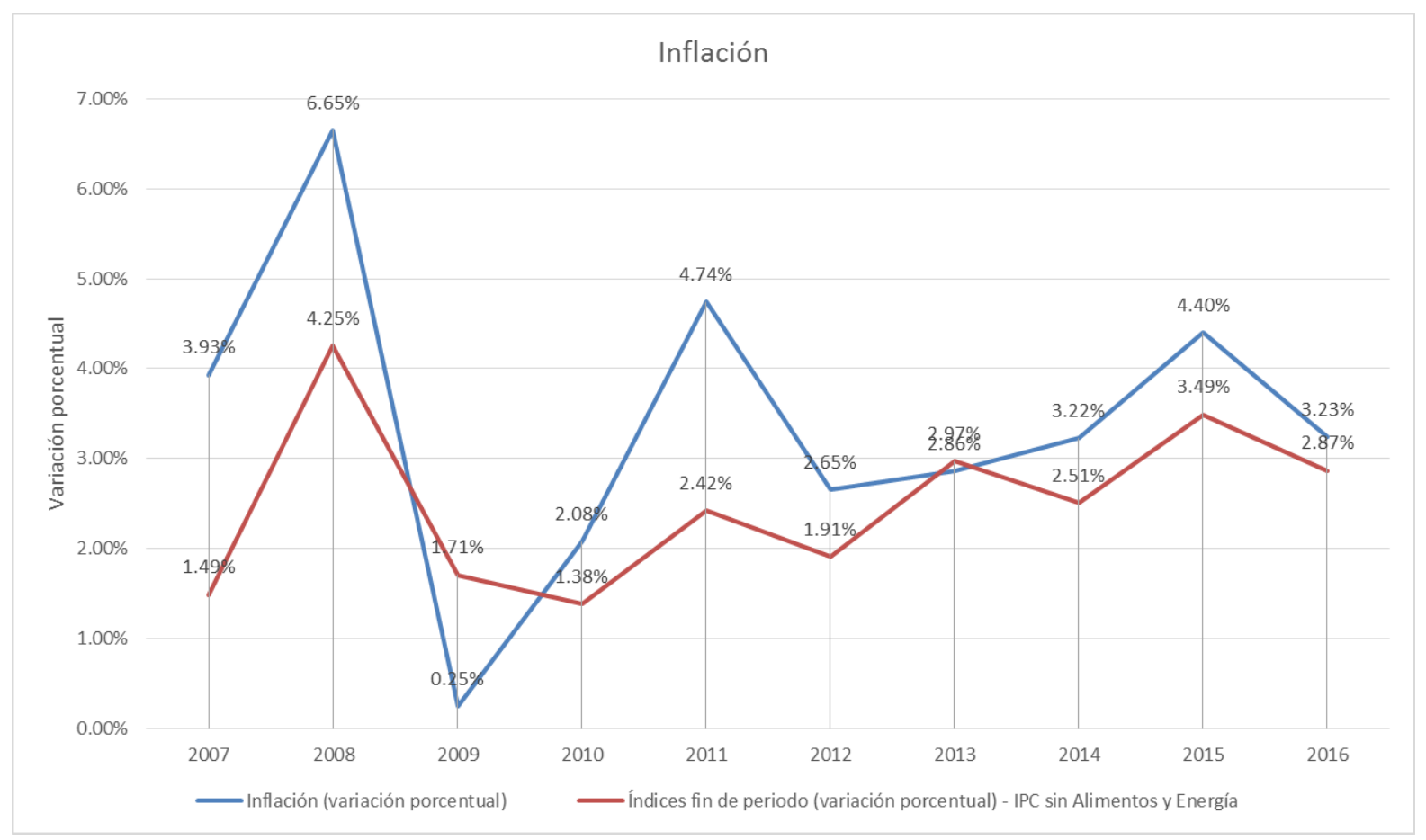

Figura 8. Inflación. Tomado de "Inflación”, por BCRP (2017) Recuperado de https://estadisticas.bcrp.gob.pe/estadisticas/series/mensuales/inflacion

“El Banco Central de Reserva (BCR) indicó que la meta de inflación anual hasta el 2022 es de $2 \%$. Todos los esfuerzos del BCR se dirigen hacia lograr esa meta. Sin embargo el 
MEF proyecta un 2.5\%" (MEF proyecta una mayor inflación en el BCR al 2022, elcomercio.pe, 2018)

El Producto Bruto Interno del Sector Restaurantes ha registrado un crecimiento variable entre los primeros trimestres del año 2017. (Ver tabla 8). En el presente de año se percibió una variación constante en el crecimiento de PBI en dichos meses que se mantiene casi constante entre trimestre y trimestre. Como se puede observar el movimiento del PBI en el sector es muy variable y depende muchas veces de diversos factores como la estación, eventos, clima y contextos en los que se encuentre el público objetivo, sean vacaciones, tiempos de trabajo, etc. (Producto Bruto Interno, INEI, 2017i)

Tabla 8

PBI de Alojamiento y Restaurantes

\begin{tabular}{|c|c|c|c|c|c|c|c|c|}
\hline \multirow{4}{*}{ Actividad } & \multicolumn{4}{|c|}{$2016 / 2015$} & \multicolumn{4}{|c|}{$2017 / 2016$} \\
\hline & $\mathrm{I}$ & II & I & 4 & I & II & I & 4 \\
\hline & Trim. & Trim. & Sem. & Últimos & Trim. & Trim. & Sem. & Últimos \\
\hline & & & & Trim. & & & & Trim. \\
\hline Alojamiento y & 2.9 & 2.6 & 2.7 & 2.9 & 0.8 & 1.3 & 1.1 & 1.7 \\
\hline \multicolumn{9}{|l|}{ restaurantes } \\
\hline Alojamiento & 4.1 & 1.5 & 2.8 & 3.1 & 0.3 & 2.4 & 1.3 & 3 \\
\hline Restaurantes & 2.7 & 2.8 & 2.7 & 2.8 & 0.9 & 1.1 & 1 & 1.5 \\
\hline
\end{tabular}

El precio del harina sin preparar por kilo al por mayor ha aumentado desde el año 2006 al 2017 en un 46.23\%, debido al crecimiento económico constante del país , el cual se ve reflejado en el crecimiento del PBI per cápita y del dinero destinado a la alimentación dentro del hogar. Sin embargo, en los últimos tres años, el precio no ha sufrido cambios 
considerables, por lo cual se puede suponer que el precio se mantendrá constante o con un cambio mínimo. (Ver tabla 9)

Tabla 9

Precio Promedio por Kilo de Harina sin preparar

\begin{tabular}{lll}
\hline Año & \multicolumn{2}{l}{ Precio Promedio por Kilo } \\
& $(\mathrm{S} /)$. & \\
\hline 2006 & S/. & 2.96 \\
2007 & S $/$. & 3.09 \\
2008 & S $/$. & 3.60 \\
2009 & S/. & 3.60 \\
2010 & S/. & 3.59 \\
2011 & S $/$. & 3.70 \\
2012 & S/. & 3.78 \\
2013 & S/. & 3.85 \\
2014 & S/. & 3.92 \\
2015 & S/. & 3.89 \\
2016 & S/. & 4.18 \\
2017 & S/. & 4.32 \\
\hline
\end{tabular}

Nota. Precios por kilogramos. Tomado de "Precios Promedio al Consumidor de Cereales y Derivados”, por INEI (2017). Recuperado de http://iinei.inei.gob.pe/iinei/siemweb/publico/

De acuerdo al giro de la empresa, esta está obligada a pagar el impuesto la renta según los parámetros de la renta de tercera categoría la cual estipula que este tipo de impuesto, grava la renta obtenida por la realización de actividades empresariales que desarrollan las personas naturales y jurídicas. Generalmente estas rentas se producen por la participación 
conjunta de la inversión del capital y el trabajo. Este impuesto grava un 30\% sobre la utilidad obtenida en el año fiscal. (Decreto Supremo N 179-2004-EF, sunat.gob.pe, 2004)

"Las personas que trabajen formalmente sea de manera independiente (cuarta categoría) o dependiente (quinta categoría) tienen oportunidad de deducir sus consumos en hoteles, bares y restaurantes de su pago anual de Impuesto a la Renta. Desde el pasado 1 de Enero de 2019, entró en vigencia la disposición de Sunat para que las personas puedan deducir el $15 \%$ de sus gastos en consumo por servicios de hoteles, restaurantes y bares con un tope máximo de S/ 12.600” (¿Cómo deducir gastos en hoteles, restaurantes y bares, y pagar menos Impuesto a la Renta, larepublica.pe, 2019). Este último punto genera que los restaurantes estén alineados operativamente para estos nuevos procesos que impone la SUNAT.

La economía nacional muestra crecimiento y estabilidad, posicionándose como oportunidad para el fomento de la inversión nacional y extranjera en diversos sectores. Siendo uno de los más atractivos el sector de restauración, por los crecimientos sostenidos que representa, el boom gastronómico, el incremento de la capacidad adquisitiva no básica de los consumidores y la oportunidad para la diversificación de la oferta mediante nuevos conceptos.

\subsubsection{Análisis Legal}

"Para abrir un restaurante es indispensable informarse si la municipalidad correspondiente hace una distinción sobre los tipos de restaurantes que se pueden abrir por calle.” (E1 paso a paso para abrir un restaurante, elcomercio.pe, 2010)

Se debe tener en cuenta ciertas normas de actividad en el sector de restaurantes. Se tiene que cumplir con el Reglamento de Restaurantes D.S. N 025-2004-MINCETUR, la cual establece los parámetros para la categorización, calificación y supervisión del funcionamiento 
de los restaurantes; asimismo establece los órganos competente en dicha materia. En función a esta reglamentación el establecimiento será catalogado, y para esto es necesario cumplir con las condiciones generales y particulares que cada categoría tiene normado.

Otra disposición que tienen que seguir todos los restaurantes es el Reglamento sobre la vigilancia y control sanitario de Alimentos y Bebidas - D.S. 007-98-SA. Este reglamento establece un marco para todo el control sanitario en la producción de alimentos y bebidas. Comienza por el origen de los insumos a utilizar, su origen y el estado en el que deben estar para permanecer inocuos.

La Norma Sanitaria para la Aplicación del Sistema HACCP en la fabricación de Alimentos y Bebidas (Aprobada Mediante Resolución Ministerial º 449-2006/Minsa) no es obligatoria en el país, sin embargo, tener esta certificación brinda mayor seguridad y prestigio al establecimiento. Esta norma ve la implementación de sistema HACCP (Hazard Analysis and Critical Control Points) en la producción de alimentos, el cual involucra el diseño de un plan para asegurar la calidad e inocuidad de los alimentos y bebidas para consumo humano. Este plan involucra un análisis de todos los posibles riesgos que hay en los procesos de preparación de alimentos y bebidas, y a su vez establece contingencias. (Proyecto Norma Sanitaria sobre el Procedimiento, digesa.minsa.gob.pe, 2005)

Se debe cumplir también algunas leyes dispuestas por el gobierno, como la Ley $\mathrm{N}^{\circ}$ 29783: Ley de Seguridad y Salud en el Trabajo. El objetivo principal es promover una cultura de prevención de riesgos laborales en todo el país. Para lograr ese objetivo, esta ley cuenta con el deber de prevención de los empleadores, así como el rol de fiscalización y control del Estado y la participación de los trabajadores y sus organizaciones sindicales, quienes a través del diálogo social continuo, velan por la promoción, difusión y cumplimiento de la normativa sobre la materia. (Ley de Seguridad y Salud en el Trabajo, munlima.gob.pe, 2016) 
La Norma Sanitaria para el funcionamiento de Restaurantes y Servicios Afines. RESOLUCIÓN MINISTERIAL Nº 363-2005/MINSA_se basa en tres principios: Asegurar la inocuidad de los alimentos y bebidas, establecer los requisitos sanitarios operativos y las Buenas Prácticas de Manipulación (BPM), y establecer las condiciones higiénico-sanitarias y de infraestructura. La norma abarca las condiciones que tienen que tener las estructuras físicas, los mínimos estándares cas para realizar los procesos de alimentos y bebidas, y su adecuado control a fin de evitar contaminación de los alimentos y mantener la higiene tanto en los procesos como en el personal.

En conclusión, las normas y legislaciones en el Perú estructuran todo lo necesario para un correcto funcionamiento de un establecimiento de alimentos y bebidas, indicando los controles y cuidados que se deben tener tanto para el comensal como para los trabajadores. En el ambiente actual muchos restaurantes no cumplen las normas anteriormente mencionadas y los propietarios no comprenden que no solo son normas y legislaciones, sino que también son guías para trabajar. Estas herramientas suben la calidad de la experiencia brindada por tanto produce un mayor porcentaje de éxito en el negocio.

\subsubsection{Análisis Cultural}

El proyecto estará enfocado en su etapa inicial de desarrollo en la ciudad de Lima Metropolitana. Para realizar esta selección se han tomado factores tales como: la escasa descentralización del país y población en la ciudad de Lima.

El INEI (2017) estima que la población del Perú para este 2017 es de 31'826,018 habitantes. Lima Metropolitana para ese año tendría, según la misma estimación, 10’132,914 habitantes lo cual representaría un $31.83 \%$ de la población total del país. Bajo este panorama se puede determinar que en términos poblacionales Lima Metropolitana constituye una ciudad atractiva por ser la capital, centro financiero y principal eje de la economía nacional. 
La tendencia poblacional por grupo quinquenal a nivel de la ciudad de Lima (Ver tabla 10), muestra comportamientos similares con respecto a la pirámide poblacional nacional. Teniendo mayor predominancia en la base que en los grupos superiores a los 45 años. Lo cual demostraría que la estructura poblacional de la ciudad de Lima, está contenida por personas jóvenes, en edad productiva y que han desarrollado un poder adquisitivo mayor para otros tipos de bienes no básicos.

Tabla 10

Número de Personas según Edad y Zonas de Lima

Número de Personas según Edad y Zonas de Lima

\begin{tabular}{llllllll} 
Edad & Lima & \multicolumn{7}{c}{ Zonas de Lima } \\
\cline { 3 - 8 } & Metropol & Norte & Este & Centro & Moderna & Sur & Callao \\
& itana & & & & & & \\
& & & & & & & \\
\hline Menos de 7 & 1182405 & 307899 & 313080 & 80706 & 109001 & 241805 & 129915 \\
De 7 a 12 & 1028562 & 271787 & 265426 & 71163 & 98276 & 211787 & 110121 \\
De 13 a 20 & 1529333 & 395693 & 401082 & 113030 & 162519 & 302351 & 154659 \\
De 21 a 35 & 2780063 & 699335 & 722460 & 211356 & 332715 & 538872 & 275325 \\
De 36 a 59 & 2652834 & 665281 & 597761 & 225684 & 410430 & 480977 & 272701 \\
De 60 a & 9 9'59718 & 218131 & 173126 & 107703 & 217835 & 147096 & 95826 \\
más & & & & & & & \\
\end{tabular}

Nota. Tomado de "Población total al 30 de junio de cada año, según sexo y grupos de edad", por INEI (2017). Recuperado de https://www.inei.gob.pe/estadisticas/indicetematico/poblacion-y-vivienda/ 
Los niveles socioeconómicos que predominan en la población limeña son el NSE D y C, con porcentajes de $33.91 \%$ y $34.35 \%$ respectivamente. El mercado al que está dirigido el proyecto, el sector, B y C, que en conjunto tiene un porcentaje de $66.02 \%$, lo cual lo haría un mercado bastante amplio que si se aprovecha correctamente.

Según el reporte de IPSOS Apoyo, el 70\% de los adultos jóvenes trabajan actualmente. Lo cual genera mayor poder adquisitivo, independencia y decisión de compra en ellos. En promedio asisten a fast food 2.1 veces por mes. KFC es al que asisten con mayor frecuencia. Además, el $43 \%$ del adulto joven que trabaja, compra su almuerzo. (Perfil del Adulto Joven, ipsos.com, 2016).

De acuerdo con José Luis Camino (como se cita en Salas, 2016), "los peruanos nacieron comiendo pollo a la brasa y chifa, en cambio, la pizza es un concepto importado que pese a no estar en el ADN viene escalando posiciones en el país y en el mundo.”

Según un estudio de Euromonitor, en el 2015 los peruanos gastaron US\$ 504 millones en comprar pizza. Esto los coloca casi a la zaga de la región, pero por encima de Chile y Venezuela y claro muy lejos de los US\$ 41,056 millones que mueve esta categoría en Estados Unidos o Italia (US\$22,124 millones), pero no por ello deja de ser un mercado atractivo y con gran potencial. (Salas, 2016, p. 76)

De acuerdo a la encuesta realizada (Ver Anexo 5: Resultados de encuestas), EL 70\% de los consumidores de pizza suelen gastar entre S/ 15.00 y S/ 25.00. Además, el $81.9 \%$ de los encuestados indicó que consumen pizza en promedio 1.5 veces al mes. El 86.4\% expresó que suelen consumir pizza de noche.

En conclusión, el entorno cultural deja puntos favorables en cuanto al tamaño del público al que va dirigido el proyecto, en relación a las variables de segmentación como el NSE (B y C) y la edad (de 20 a 45). Además, el rango de edades del presente proyecto tiene 
un perfil favorable, como: su tipo de establecimiento más concurrido son los de comida rápida, acuden a C.C. 2 veces al mes en promedio y el 12\% de esta población acude exclusivamente para comer y/o tomar algo.

\subsubsection{Análisis Tecnológico}

Según el último estudio de IMS (Information Management System) y Comscore, el 88\% de peruanos accede a internet a través de un Smartphone o una tablet” (Amaro, 2015, p. 4).

Las cadenas de comida rápida como por ejemplo Domino`s Pizza tienen un sistema de pedidos vía Web. Nace lo que se ha denominado como fast software; es decir, ecosistemas y software pensados para hacer las cosas más rápido, de forma sencilla y remota. De la misma manera, se pueden adaptar estos softwares a aplicaciones de celulares, y así el cliente pueda pre visualizar su pedido, y saber su precio.

Existen actualmente equipos de cocina que facilitan la operación e incluso generan ahorros considerables en cuanto a operatividad se refiere. El horno de cúpula a gas, leña y/o carbón, puede llegar a temperaturas de hasta $500^{\circ} \mathrm{C}$, logrando poder cocinar pizzas hasta los cinco minutos. También el Abatidor Irinox Multifresh, máquina de congelamiento y conservación rápida que permite, congelar, fermentar, descongelar, regenerar, pasteurizar, e incluso cocer a baja temperatura. Es el correcto aliado para los restaurantes que buscan alargar la vida útil de sus alimentos y mantener cadena fría de preparación.

En conclusión, estos equipos avanzados generan un ahorro considerable en recursos materiales y humanos, que se puede traducir en un ahorro de dinero. Por otro lado, el proyecto puede aprovechar las aplicaciones para celulares y la página web para crear una aplicación en la cual el cliente pueda ver lo que se ofrece, y hacer su combinación, para así poder pre-visualizarlo y saber su precio. 


\subsubsection{Análisis Ecológico}

En el Perú, como lo establece el Compendio de la Legislación Ambiental Peruana elaborado por Ministerio del Ambiente (2005), la Dirección General de Salud Ambiental DIGESA, se encarga de fiscalizar el cumplimiento inmediato o gradual de las disposiciones de ley y sus normas reglamentarias, a todas las empresas que generan residuos sólidos, como es el caso de restaurantes o establecimientos a fines como los restaurantes de comida rápida.

Según Núñez (2016) el uso eficiente de los recursos (73\%) y la correcta gestión de los residuos $(70 \%)$, son los aspectos más destacados por los usuarios para desarrollar un modelo de restauración más sostenible. Les siguen la compra de productos kilómetro cero o de proximidad, que se basa en contar con proveedores que no tengan que realizar grandes recorridos para dejar mercadería con la finalidad de disminuir la contaminación por el transporte, con un 69\%; la promoción de un entorno laboral responsable (56\%); y la oferta de una dieta saludable (45\%). Según Nuñez (2016), resulta significativa la diferencia de opinión a la hora de fijar medidas para fomentar la sostenibilidad: ocho de cada diez usuarios considera que los establecimientos deberían estar obligados por ley a aplicar medidas sostenibles.

El proyecto propone que el consumidor perciba que es un fast food eco amigable en el que puedan confiar y sentirse que ayudan al medioambiente consumiendo los productos.

\subsection{Oportunidades y Amenazas}

Para poder realizar una correcta valoración de los factores externos evaluados anteriormente en el análisis PESTEL, se realizó una matriz EFE.

"La matriz de evaluación de factores externos (EFE) permite que los estrategas resuman y evalúen información económica, social, cultural, demográfica, ambiental, política, gubernamental, legal, tecnológica y competitiva" (David, 2013, p. 80) 
Para aplicar la matriz se asignó una ponderación de acuerdo a la industria para cada uno de los factores analizados. El rango es entre 0.0 (no es importante) a 1.0 (muy importante). La suma de todos los pesos asignados a los factores es de 100\%. También se calificó en una escala del 1 al 4 a cada uno de los factores determinantes para el éxito del proyecto, todo esto con la finalidad de plasmar si las estrategias actuales tienen relación con la eficacia de los factores. (Ver Tabla 11). 
Tabla 11

Matriz de Evaluación de Factores Externos (EFE)

Factores externos clave

Ponderación Calificación Puntuación

ponderada

Oportunidades

\begin{tabular}{llll}
\hline La economía nacional muestra crecimiento & 0.08 & 3 & 0.24
\end{tabular}

y estabilidad.

Mayor presencia en NSE B y C entre 20 y $0.08 \quad 4 \quad 0.32$

45 años en Lima Metropolitana

$\begin{array}{llll}\text { Alto consumo de pizza en Lima } & 0.13 & 4 & 0.52 \\ \text { Mayor ingreso promedio del consumidor } & 0.11 & 3.5 & 0.39\end{array}$

peruano

$\begin{array}{llll}\text { Mayor gasto del peruano por comer fuera } & 0.12 & 3.5 & 0.42\end{array}$

de casa

$\begin{array}{llll}\text { Uso de tecnología para reducir carga } & 0.08 & 3 & 0.24\end{array}$

operativa

Amenazas

\begin{tabular}{llll}
\hline Alza de la inflación en los precios de los & 0.08 & 2.5 & 0.20
\end{tabular}

alimentos

Gran cantidad de normas sanitarias y

0.07

2.5

0.18

reglamentos que cumplir.

Fenómenos naturales que afectan el

0.07

2.5

0.18

abastecimiento de insumos.

Incertidumbre política y económica.

$0.08 \quad 3$

0.24

Desaceleración económica.

0.10

2.5

0.25

Total

1.00

3.17

Nota. El número 1 significa una respuesta mala, el 2 una respuesta con calificación media, el 3 una respuesta superior a la media y el 4 una respuesta superior.

El peso ponderado total de las oportunidades es de 2.13 y de las amenazas es 1.04 , lo cual dio un resultado general de 3.17 , lo cual indica que el entorno en general es favorable para el negocio. Los pesos y las ponderaciones se obtuvieron de la información que brindó 
Carlos Camino, actual propietario de los restaurantes Papachos, junto con Gastón Acurio. (Ver Anexo 5)

Las principales oportunidades para este tipo de restaurantes son el alto consumo de pizzas en Lima Metropolitana y el aumento en el gasto del peruano por comer fuera de casa, por ello obtuvieron un peso de 0.13 y 0.12 , respectivamente y una calificación de 4 en ambos casos.

Por otro lado, se identificó como principal amenaza la desaceleración económica con un peso de 0.1 y un puntaje de 2.5 , ya que esto afecta el consumo de productos no básicos. Otra amenaza que tendría impacto directo con el negocio propuesto, es la inflación en los precios de los alimentos, ya que afectaría en los costos de producción. 


\section{Capítulo III: Estudio de Mercado}

En el presente capítulo se detalla lo relacionado al estudio de mercado a través de la investigación cualitativa y cuantitativa. Así como el cálculo de la muestra, técnicas e instrumentos de recolección y análisis de datos que se usaron, con la finalidad de conocer el grado de aceptación del presente proyecto con el fin de determinar la aceptación y el tamaño del mercado.

\subsection{Descripción del producto y servicio}

El presente proyecto está basado en un restaurante de comida rápida que busca integrar todos los ingredientes de una pizza con una línea de servicio interactiva en la que el cliente podrá personalizar su pedido, mediante la selección de ingredientes que se ofrecen, entre los que se encuentran el tipo de masa, el tipo de queso, verduras, proteínas, salsas, hortalizas, embutidos, frutas, y condimentos. Las pizzas personales tendrían una medida de $18 \mathrm{~cm}$. y se servirían en platos descartables.

El nombre del negocio será Pizza Lab, debido a su relación con un laboratorio en el cual se realizan inventos o creaciones. Se propone ubicar los locales dentro de centros comerciales. El ambiente debe tener los colores: rojo, anaranjado y amarillo.

El valor agregado del siguiente proyecto se encuentra en los siguientes factores: (a) el concepto de servicio original, que cuenta con un local ambientado acorde a un fast food de pizza, (b) la libertad de personalizar la pizza, es decir que el cliente tenga la opción de elegir el tipo de masa, el tipo de queso, el tipo de salsa base, la proteína y los ingredientes adicionales, que puede poner en su pizza; (c) la rapidez en el servicio, es una de las innovaciones que presenta este proyecto en el rubro de las pizzerías, debido a que tiene una línea de interacción dividida en dos partes: la primera es la barra donde se ubican los 
alimentos separados por tipos (salsas, quesos, proteínas e ingredientes adicionales) y la segunda, es la zona de pago. El producto se va creando mientras el cliente elige sus ingredientes; de esta manera, desde que se atiende el pedido del cliente hasta recibir su voucher de pago, no deben pasar más de tres minutos, y adicionalmente unos cinco minutos más para recibir su pedido. (d) La interacción con el cliente, ya que este proyecto permite que el cliente decida qué ingredientes y qué cantidad de cada ingrediente comer, razón por la cual se ofrecen diferentes opciones de cada tipo de alimento, para que el comensal tenga el poder de elegir, y también, para que vuelva pronto a probar otra combinación. Estos diferenciales permitirán competir con pizzerías como Pizza Hut, Telepizza, Domino’s, y otros restaurantes que se encuentran dentro de centros comerciales.

\subsection{Selección del segmento de mercado}

Kotler y Keller (2012) definieron al segmento de mercado como un grupo de clientes que comparten similares deseos y necesidades. A la vez indican que la segmentación, consiste en dividir al mercado en partes homogéneas según gustos, necesidades, características o comportamientos de clientes, utilizando diversas variables descriptivas.

Según Kotler y Armstrong (2012) con la segmentación las empresas dividieron los mercados en segmentos pequeños y heterogéneos para así poder llegar de manera efectiva a los clientes, ofreciéndoles bienes y servicios que se adecuen a sus gustos y necesidades.

De los conceptos anteriores se aprecia una relación entre división de mercados con gustos y necesidades específicas de los clientes. Para este proyecto se consideraron los siguientes criterios de segmentación: la segmentación geográfica y demográfica.

\section{- Segmentación Geográfica}

“Definen a la segmentación geográfica como la división de mercado en bloques geográficos como regiones, ciudades, etc.” (Kotler, 2012, p. 35). 
El presente proyecto está dirigido a Lima Metropolitana, el INEI ha estimado que la población de Lima para el año 2018 será aproximadamente de 10, 184,576 habitantes. Este dato será importante para la estimación de demanda futura del proyecto. Los locales del proyecto estarán situados dentro de centros comerciales de alto transito ubicados en distritos que albergan gran cantidad de personas de niveles socioeconómicos A, B y C. Es por ello que se consideró la población de las zonas de: Lima Norte, Moderna y Lima Sur (Ver tabla 12).

Tabla 12

Habitantes, Hogares y Viviendas de Lima Metropolitana

\begin{tabular}{lllllll}
\hline Habitantes, & Lima & Lima & Lima & Lima & Lima & Lima \\
hogares, viviendas & Metropolitana & Norte & Este & Centro & Moderna & Sur \\
y manzanas & & & & & & \\
\hline Total de habitantes & $9^{\prime} 588,985$ & $2^{\prime} 420,807$ & $2^{\prime} 340,189$ & 766,181 & $1^{\prime} 259,339$ & $11^{\prime} 819,669$ \\
\hline \% respecto al total & $100 \%$ & $25.20 \%$ & $24.50 \%$ & $8.00 \%$ & $13.10 \%$ & $19.00 \%$ \\
de habitantes & & & & & & \\
\end{tabular}

\begin{tabular}{lcccccc}
\hline Total de hogares & $2 ׳ 347,679$ & 555,886 & 528,886 & 236,479 & 366,375 & 417,892 \\
\hline Total de viviendas & $2 ׳ 339,778$ & 534,166 & 523,282 & 247,914 & 391,519 & 404,329 \\
& & & & & & \\
ocupadas & & & & & &
\end{tabular}

\begin{tabular}{lllllll}
\hline Total de manzanas & 92,897 & 23,088 & 24,041 & 5,233 & 9,800 & 19,701
\end{tabular}

\begin{tabular}{lllllll}
\hline$\%$ respecto al total & $100 \%$ & 0 & $26.20 \%$ & $5.70 \%$ & $10.70 \%$ & $21.40 \%$
\end{tabular}

de manzanas

\begin{tabular}{lllllll}
\hline Superficie $(\mathrm{km} 2)$ & $2,799.80$ & 856.7 & 24.4 & 49.3 & 164.4 & 851.7
\end{tabular}

Nota: Adaptado de Estadística Poblacional NSE APEIM 2013. Tomado de: Perfiles Zonales de Lima Metropolitana, 2013 (p.10), por Ipsos Marketing (2012b), Lima, Perú: Depósito Legal N²012-08467. 


\section{- Segmentación Demográfica:}

Kotler et.al definen a la segmentación demográfica como la división de mercados de acuerdo a variables como edad, genero, ciclo de vida, raza, religión entre otros.

Para la segmentación demográfica se consideró a hombres y mujeres de 13 a 59 años, según Estadística Poblacional Ipsos, mostrada en la tabla 12. Dicho grupo de edad ha sido definido en base a la población económicamente activa y que el proyecto busca captar. (Ver tabla 13 y 14$)$

Tabla 13

Número de Personas según Edad y Zonas de Lima

\begin{tabular}{lccccccc}
\hline Número de Personas según Edad y Zonas de Lima & & & & \\
\hline Edad & $\begin{array}{c}\text { Lima } \\
\text { Metropolitana }\end{array}$ & & & & & \\
& & & & & & \\
\cline { 3 - 8 } & & Norte & Este & Centro & Moderna & Sur & Callao \\
\hline $\begin{array}{l}\text { Menos de } \\
7\end{array}$ & $1,182,405$ & 307,899 & 313,080 & 80,706 & 109,001 & 241,805 & 129,915 \\
\hline De 7 a 12 & $1,028,562$ & 271,787 & 265,426 & 71,163 & 98,276 & 211,787 & 110,121 \\
\hline $\begin{array}{l}\text { De 13 a } \\
20\end{array}$ & $1,529,333$ & 395,693 & 401,082 & 113,030 & 162,519 & 302,351 & 154,659 \\
\hline $\begin{array}{l}\text { De 21 a } \\
35\end{array}$ & $2,780,063$ & 699,335 & 722,460 & 211,356 & 332,715 & 538,872 & 275,325 \\
\hline $\begin{array}{l}\text { De 36 a } \\
59\end{array}$ & $2,652,834$ & 665,281 & 597,761 & 225,684 & 410,430 & 480,977 & 272,701 \\
\hline
\end{tabular}

Nota. Tomado de "Población total al 30 de junio de cada año, según sexo y grupos de edad", por Instituto Nacional de Estadística e Informática (INEI), 2017. Recuperado de https://www.inei.gob.pe/estadisticas/indice-tematico/poblacion-y-vivienda/ 
Tabla 14

Información Demográfica Lima Metropolitana - Género

\begin{tabular}{lllllll}
\hline Genero & Lima & Lima & Lima & Lima & Lima & Lima Sur \\
& Metropolitana & Norte & Este & Centro & Moderna & \\
& & & & & & \\
\hline Masculino & 4'688,115 $^{\prime}$ & $1^{\prime} 189,544$ & $1^{\prime} 166,097$ & 372,848 & 577,580 & 899,452 \\
\hline Femenino & $4^{\prime} 900,870$ & $1^{\prime} 231,263$ & $1^{\prime} 174,092$ & 393,333 & 681,759 & 920,217 \\
\hline Total & $9^{\prime} 588,985$ & $2^{\prime} 420,807$ & $2^{\prime} 340,189$ & 766,181 & $1^{\prime} 259,339$ & $1^{\prime} 819,669$
\end{tabular}

Nota: Adaptado de Estadística Poblacional NSE APEIM 2013. Tomado de: Perfiles Zonales de Lima Metropolitana, 2013 (p.10), por Ipsos Marketing (2013 b), Lima, Perú: Depósito Legal N²012-08467.

Dicho grupo de edad ha sido definido en base a la población económicamente activa (PEA) y la Población económicamente no activa (NO PEA) ya que el proyecto busca captar la población de 14 y más años de edad, durante el año 2018 la PEA representó el 67,9\% (5 millones 233 mil 200 personas) de la población en edad de trabajar. A la vez la población económicamente no activa (NO PEA) que es aquella población de 14 y más años de edad que no participa en el mercado laboral que está conformada por los estudiantes, jubilados, pensionistas, rentistas, personas dedicadas exclusivamente a los quehaceres del hogar, entre otros representó el 32,1\% (2 millones 468 mil 600 personas) de la población inactiva. (Situación del mercado laboral en Lima Metropolitana, Inei.com, 2018) (Ver tabla 15 y 16). 
Tabla 15

Población de Lima Metropolitana en edad de trabajar según condición de actividad Enero - Diciembre 2017 y 2018 (Miles de personas)

\begin{tabular}{|c|c|c|c|c|}
\hline \multirow[b]{3}{*}{ Condición de actividad } & \multicolumn{4}{|c|}{ Anual } \\
\hline & \multicolumn{4}{|c|}{ Enero - Diciembre } \\
\hline & 2017 & 2018 & $\begin{array}{c}\text { Variación } \\
\text { Absoluta } \\
\text { (Miles) }\end{array}$ & Variación (\%) \\
\hline $\begin{array}{l}\text { Total de población en edad de trabajar } \\
\text { (PET) }\end{array}$ & $\begin{array}{c}7 \\
596,1\end{array}$ & $\begin{array}{c}7 \\
701,8 \\
\end{array}$ & 105,7 & 1.4 \\
\hline Población económicamente activa (PEA) & $\begin{array}{c}5 \\
204,3\end{array}$ & $\begin{array}{c}5 \\
233,2\end{array}$ & 28,9 & 0,6 \\
\hline Ocupada & $\begin{array}{c}4 \\
846,0\end{array}$ & $\begin{array}{c}4 \\
885,1\end{array}$ & 39,1 & 0,8 \\
\hline Desocupada & 358,4 & 348,1 & -10.3 & -2.9 \\
\hline $\begin{array}{l}\text { Población económicamente no activa (NO } \\
\text { PEA) }\end{array}$ & $\begin{array}{c}2 \\
391,7\end{array}$ & $\begin{array}{c}2 \\
468,6\end{array}$ & 76,9 & 3,2 \\
\hline
\end{tabular}

Nota: Adaptado de Encuesta Permanente de Empleo. Tomado de: Situación del Mercado Laboral en Lima Metropolitana, por Instituto Nacional de Estadística e Informática (INEI), 2018. Recuperado de https://www.inei.gob.pe/media/MenuRecursivo/boletines/03-informetecnico-n03_mercado-laboral-dic2017-ene-feb2018.pdf

Tabla 16

Población Económicamente Activa de Lima Metropolitana, según sexo, edad - Anual: Enero - Diciembre 2017 y 2018 (Miles de personas)

\begin{tabular}{lcccc}
\hline & \multicolumn{4}{c}{ Enero - Diciembre } \\
\cline { 2 - 5 } Características & 2017 & 2018 & $\begin{array}{c}\text { Variación } \\
\text { Absoluta } \\
\text { (Miles) }\end{array}$ & Variación (\%) \\
\hline Total & 5204,3 & 5233,2 & 28,9 & 0,6 \\
\hline Sexo & 2819,4 & 2825,8 & 6,4 & 0,2 \\
\hline Hombre & 2385,0 & 2407,5 & 22,5 & 0,9 \\
\hline Mujer & & & & \\
\hline Grupos de edad & 1145,1 & 1080,5 & -64.6 & -5.6 \\
\hline De 14 a 24 años & 2739,5 & 2719,0 & -20.5 & -0.8 \\
\hline De 25 a 44 años & 1319,7 & 1433,7 & 114,0 & 8,6 \\
\hline De 45 y más años & 130,0 &
\end{tabular}

Nota: Adaptado de Encuesta Permanente de Empleo. Tomado de: Situación del Mercado Laboral en Lima Metropolitana, por Instituto Nacional de Estadística e Informática (INEI), 2018. Recuperado de https://www.inei.gob.pe/media/MenuRecursivo/boletines/03-informetecnico-n03_mercado-laboral-dic2017-ene-feb2018.pdf 
A continuación, en la tabla 17, se detalla el cuadro resumen de la variable demográfica de segmentación:

Tabla 17

Variable Demográfica

\begin{tabular}{ll}
\hline Edad & 13 a 59 años \\
\hline Sexo & Femenino y Masculino
\end{tabular}

Nota: Variable demográfica. Tomado de Marketing (p.192), por Kotler y Armstrong, 2012, México, D.F., México: Copyrigth 2012 por Pearson Education

- Nivel socioeconómico:

El presente proyecto está orientado a los niveles socioeconómicos A, B y C de la población de Lima Metropolitana, ya que dichos segmentos representan el $49.65 \%$ de la población de Lima (Ver tabla 18). 
Tabla 18

Niveles Socioeconómicos de Lima Metropolitana y Zonas

\begin{tabular}{lcccc}
\multirow{2}{*}{ Zonas } & \multicolumn{5}{c}{ Estructura económica } \\
\cline { 2 - 5 } & $\mathrm{AB}$ & $\mathrm{C}$ & $\mathrm{D}$ & $\mathrm{E}$ \\
\hline Lima Norte & $22.9 \%$ & $44.1 \%$ & $27.6 \%$ & $5.4 \%$ \\
Lima Centro & $33.1 \%$ & $43.3 \%$ & $20.2 \%$ & $3.5 \%$ \\
Lima Moderna & $76.8 \%$ & $17.4 \%$ & $4.5 \%$ & $1.3 \%$ \\
Lima Este & $17.7 \%$ & $45.7 \%$ & $29.6 \%$ & $7.0 \%$ \\
Lima Sur & $13.3 \%$ & $53.4 \%$ & $27.4 \%$ & $5.9 \%$ \\
Callao & $21.7 \%$ & $45.9 \%$ & $23.6 \%$ & $8.8 \%$
\end{tabular}

Nota. Adaptado de estructura económica por zonas de Lima Metropolitana. Tomado de: Marketreport Población 2018 (p.10), por Compañía peruana de estudios de mercados y opinión pública, Lima, Perú. Recuperado de:

http://cpi.pe/images/upload/paginaweb/archivo/26/mr_poblacional_peru_201905.pdf 
Los segmentos antes mencionados representan un porcentaje alto de la población, ya que su ingreso promedio per cápita mensual para el nivel NSE A es de S/ 1,650, para NSE B es de S/ 1,365 en promedio y para el NSE C es de S/. 804 en promedio (Ipsos, 2013b). De las cantidades mencionadas gastan S/ 600, S/ 300 y S/ 160 respectivamente en promedio en comer fuera de casa, esto representa el $30 \%, 26 \%$ y $20 \%$ respectivamente de su ingreso y al ser estos dos segmentos bastante grandes este gasto se convierte en un oportunidad para el proyecto (Ver tabla 19).

Tabla 19

Gasto Mensual Familiar por NSE en Lima Metropolitana

Gasto Mensual Familiar destinado a Alimentación por NSE en Lima Metropolitana (s/.)

\begin{tabular}{lcccc}
\hline Nivel & Alimentación & Dentro & Fuera del & \% Fuera del \\
Socioeconómico & & del Hogar & Hogar & Hogar \\
\hline A & 1950 & 1350 & 600 & $30.77 \%$ \\
\hline B & 1150 & 850 & 300 & $26.09 \%$ \\
\hline C & 800 & 640 & 160 & $20.00 \%$
\end{tabular}

Nota: Adaptado de Gasto Mensual Familiar destinado a Alimentación por NSE en Lima Metropolitana, por Ipsos Public Affairs (2013d). Recuperado de https://www.ipsos.com/es$\mathrm{pe} / \mathrm{search}$ ?search=gasto+mensual

Analizando los datos anteriores se puede apreciar que los niveles socioeconómicos A, B y C tienen un alto gasto porcentual en función a sus ingresos y en comparación a los otros niveles es un porcentaje considerable que combinándolo con los rangos de edad es un amplio mercado. (Ver tabla 18 y 19) 


\subsection{Investigación cualitativa}

Según Malhotra (2008) la investigación cualitativa es "la metodología de investigación exploratoria sin estructura, basada en muestras pequeñas, que proporciona conocimientos y comprensión del entorno del problema” (p. 143).

Se utilizó la técnica de las entrevistas en profundidad "entrevista no estructurada, directa y personal, en la cual un entrevistador altamente capacitado interroga a un solo encuestado, para descubrir motivaciones, creencias, actitudes y sentimientos subyacentes sobre este tema" (Malhotra, 2008, p. 158).

A la vez se utilizó los focus group o sesiones de grupo que son según Malhotra (2008) “entrevista realizada por un moderador capacitado con un grupo pequeño de individuos, de una forma no estructurada y natural" (p. 145).

\subsubsection{Proceso de muestreo de la investigación cualitativa}

Se tomó una muestra de casos no representativos, es decir datos no estadísticos.

Las entrevistas de profundidad se realizaron a cuatro personas quienes se encuentran trabajando en el sector fast food y que con su experiencia lograron brindar diferentes aportes y/o críticas para el presente plan de negocios (ver anexo 5), los participantes se agruparon en base a las siguientes características:

- Participante con experiencia en Proyectos.

- Participante con experiencia administrando fast food.

- Participante con experiencia en Marketing.

- Participante con experiencia en cocina.

Las sesiones de grupo se realizaron con uno de los miembros del grupo, que contaba con experiencia como moderador. Estas sesiones se dividieron de la siguiente manera: 
- Sesión de grupo de consumidores que van a los restaurantes ubicados en centros comerciales

- Sesión de grupo $\mathrm{N}^{\circ}$ 1: 6 personas del NSE A.

- Sesión de grupo $\mathrm{N}^{\mathrm{o}}$ 2: 6 personas del NSE B y C.

- Sesión de grupo de consumidores que van a los fast food en establecimientos fuera de centros comerciales.

- Sesión de grupo $\mathrm{N}^{\circ}$ 1: 6 personas del NSE A

- Sesión de grupo $\mathrm{N}^{\circ}$ 2: 6 personas del NSE B y C

El NSE se determinó según el cuestionario socioeconómico que se encuentra en el Anexo 3: Filtro de Nivel Socioeconómico.

Finalmente, se utilizarán ambas técnicas, es decir, entrevistas de profundidad y sesiones de grupo de mínimo seis personas cada uno, con el fin de obtener información de gustos y preferencias, hábitos de consumo, experiencias anteriores y actuales personas que trabajan en el sector así como recibir críticas u aportes sobre el presente plan de negocios.

\subsubsection{Diseño de instrumento de la investigación cualitativa}

El diseño del instrumento de la investigación cualitativa son directos, es decir con focus group y entrevistas en profundidad.

\section{Entrevistas de profundidad}

El objetivo fue obtener más detalles de la realidad de ésta industria e información del crecimiento, procesos, funcionamiento, características y hasta las diferentes barreras a las que pueden presentarse con frecuencia. En la tabla 21 se muestran los diferentes objetivos de las entrevistas. 
Tabla 20.

Objetivos de las Entrevistas de Profundidad

\begin{tabular}{cl}
\hline Objetivos & \multicolumn{1}{c}{ Descripción } \\
\hline \multirow{3}{*}{ Objetivo General } & Conocer el funcionamiento de los principales competidores en los centros comerciales \\
& Conocer la valoración del concepto del plan de negocios. \\
& Obtener información actual del status del sector. \\
& Identificar los actuales procesos que optimicen recursos en la Industria. \\
& Obtener información sobre las barreras de entrada en los centros comerciales \\
& Obtener críticas y/o aportes sobre los posibles nombres de la marca. \\
Objetivos específicos & Obtener críticas y/o aportes sobre el nuevo concepto. \\
& Identificar los posibles problemas operativos. \\
\hline
\end{tabular}

Nota: Los objetivos fueron propuestos por los miembros del equipo.

Para realizar las entrevistas de profundidad, se formuló una guía de pautas con el fin de abarcar diferentes temas y que los aportes de los participantes sean los más adecuados en la búsqueda de información del sector.

Los resultados fueron favorables, ya que todos tienen alta experiencia en éste mercado y les gustó la idea del plan de negocios, por tal motivo, en el Anexo 5 se detallan los resultados de cada entrevista.

2. Sesiones de grupo

Las sesiones de grupo se realizaron según los siguientes objetivos:

- Identificar hábitos y frecuencia de consumo.

- Conocer la afluencia de clientes a los principales competidoras (precio, producto, plaza y promoción).

- Detectar los productos o servicios adicionales que les gustaría encontrar en una pizzería. 
- Obtener críticas y/o aportes sobre el ingreso del nuevo restaurante de pizzas al mercado.

Para desarrollar las sesiones de grupo se consideraron las etapas de presentación, calentamiento y estudio de profundidad, ver la guía de pautas en el Anexo 2 y ver ficha de reclutamiento en el Anexo 4.

\subsubsection{Análisis y procesamiento de datos}

Los resultados del estudio cualitativo se clasificaron de acuerdo a los objetivos planteados para las sesiones de grupo, a continuación se muestran los resultados:

\section{Objetivo 1: Identificar hábitos y frecuencia de consumo}

- Todos los participantes indicaron la preferencia y consumo de pizza (de varias combinaciones).

- Dentro de los motivos de consumo indicaron: por antojo, por rapidez, por la preferencia de los hijos pequeños, conversar con amigos, relajarse. Generalmente van acompañados de su pareja y la familia, por ocasiones especiales como cumpleaños, entre otros.

- La mayoría de los participantes manifestaron que las pizzas más consumidas son: pizza hawaiana, americana, peperoni, suprema.

- Los participantes indicaron que acompañan la pizza con los siguientes complementos: chorizo, tocino, verduras, carnes, aceitunas.

- Los participantes indicaron que suelen consumir la pizza por las tardes, noches y en cualquier época del año.

- La gran mayoría de participantes indicaron que consumen pizza por delivery y también en tiendas de centros comerciales. 
- La mayoría de los participantes indicaron que la frecuencia de consumir pizza es de 1 a 2 veces al mes, llegando a un extremo de hasta 4 veces.

\section{- Objetivo 2: Hábitos de consumo en general}

- La mayoría de los participantes indicaron que al momento de un almuerzo prefieren comidas tradicionales como: comida marina, pastas o también pollo a la brasa.

- Para los participantes el presupuesto promedio destinado para un almuerzo fuera de casa es de $\mathrm{S} / 15.00$ a $\mathrm{S} / 40.00$ soles por persona.

- La mayoría de los participantes en los últimos 12 meses han asistido a restaurantes de pizzas como: Pizza Hut, Papa John’s, Don Pizza (ubicado en Santiago de Surco). Así como también a restaurantes tradicionales como: cevicherías y restaurantes de comida criolla.

- Los participantes consideran que el momento del día más importante para visitar un restaurante es a la hora de almuerzo o también la cena (saliendo del trabajo).

- En cuanto a los principales factores que influyen en su decisión de asistir a un restaurante son: la atención, reconocimiento de marca, calidad de producto, infraestructura, promociones, adicionales en productos.

- Los participantes desearían que los establecimientos de fast food tengan un buen ambiente, personal con buen trato, atención rápida y productos adicionales (alitas, postres, lasagnas).

- La mayoría de los participantes estaría dispuesto a visitar diariamente un solo restaurante si es que ofrecerían más productos adicionales mencionados en el punto anterior así como varias promociones $(2 \times 1)$. 
- Los participantes indicaron que los fast food a los que asisten con mayor frecuencia son: Pizza Hut, Norky’s, Papa John`s, Bembos, KFC. Ya que son céntricos, tienen buen servicio y diversidad de platos.

- En cuanto a la decoración de los fast food mencionaron que les gusta, tanto los colores como infraestructura. Las nuevas ideas que propondrían son locales temáticos o retro con música suave y luces más bajas.

- La gran mayoría de los participantes indicaron que no visitan centros comerciales para comer con gran frecuencia y prefieren locales propios fuera de centros comerciales. Las razones por las que no acuden a centros comerciales son por el bullicio, cantidad de personas, demora en atención, poca privacidad.

- Objetivo 3: Conocer los principales competidores.

- La mayoría de los participantes conocen las siguientes pizzerías: Pizza Hut, Dominós Pizza, Papa John`s, Pizza Raúl, La Romana, Antica, Mamma Tomato.

- La gran mayoría de los participantes valoran los siguientes atributos de las pizzerías: espacio, infraestructura, sabor de producto, promociones, producto artesanal.

- Los participantes desearían un establecimiento fast food (pizzería ideal) que tenga libertad de elección de ingredientes, personal muy amable, música italiana, servicio rápido y temática retro.

- Objetivo 4: Evaluación de concepto de negocio.

- La mayoría de los participantes indicaron que el proyecto les parece innovador, interesante, fuera de lo común y divertido.

- Para los participantes la característica más importante del concepto es la interacción del cliente pudiendo elegir los ingredientes de su gusto para elaborar su pizza. 
- Los participantes indicaron que asistirían a la pizzería con una frecuencia de 2 veces al mes o como máximo 3 veces al mes.

- A la mayoría de los participantes les gustaría encontrar el concepto en distintos distritos y lugares céntricos, así como también cercanos a oficinas, centros de estudios y centros comerciales.

- Para los participantes el momentos más indicado para asistir al local es el almuerzo o la cena.

- Los participantes no tenían nombres para el concepto en el momento, pero algunos opinaron que le darían un nombre relacionado al libre gusto, a la libre elección de ingredientes, donde el concepto emita que se puede crear una pizza al gusto.

- La mayoría índico que les gustaría encontrar no solo pizzas personales, sino también pizzas familiares (en el caso de padres de familia).

- Para los participantes se deberían de vender adicionales como: pastas, bebidas sin gas (ice tea), postres, lasagnas y bocadillos.

- La mayoría indicó que no consumirían la pizza por delivery, ya que el pedido tardaría mucho tiempo en llegar a sus domicilios.

\section{- Objetivo 5: Evaluación de Marca}

- La mayoría de los participantes opinaron que asocian al nombre Pizza Lab, a un laboratorio clínico más no al concepto. Solo algunos lo relacionaron al concepto de creación.

- Para los participantes los dos logos que más les gusto fueron:
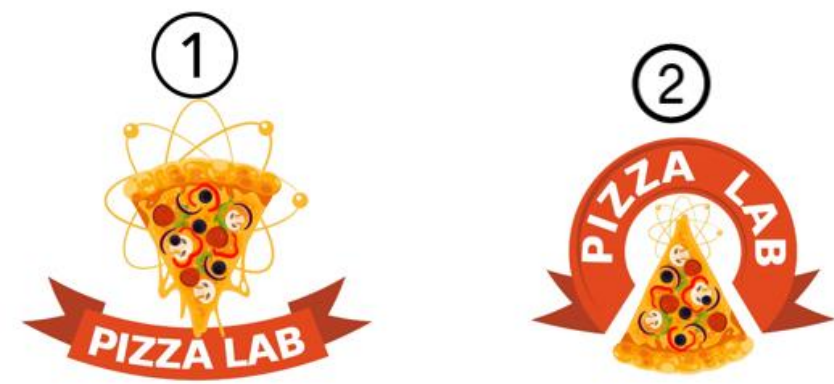
- Para los participantes los colores rojo y naranja indican comida rápida, ya que la mayoría de los fast food, como KFC, Bembos, Pizza Hut, utilizan los mismos colores.

- Los participantes indicaron que el medio de comunicación por el cual desearían enterarse son las redes sociales como: Facebook, Instagram, Twitter. Solo algunos indicaron que les gustaría enterarse por televisión.

- La mayoría de los participantes asistirían al local, ya que les parece una idea innovadora el poder mezclar los ingredientes que ellos prefieran en sus pizzas, ya que muchas veces tienen que retirar algunos de ellos que no son de su gusto.

- Para los participantes lo que no les gusto del proyecto es: el nombre del negocio, la ubicación en patios de comidas. A la vez indicaron que se podría mejorar el logo con más combinación de colores y cambios de figuras.

- Para los participantes una de las desventajas del local es el tiempo, ya que al escoger los ingredientes les tomara más tiempo del debido y algunos por el trabajo tienen menos de una hora para almorzar.

- Se determinaron conclusiones como: al ser un concepto de libre elección de ingredientes les gustaría que haya una persona que les recomiende las mezclas adecuadas, a la vez se podría adicionar opciones saludables, y tener un aplicativo móvil que les permita hacer su pedido por ese medio.

\section{- Análisis de las entrevistas de profundidad}

Las entrevistas fueron realizadas a profesionales especialistas en el rubro gastronómico con experiencia en diferentes puestos operativos y administrativos del sector fast food, como Gerente de Proyectos, Alejandro Villa-García; Gerente de Marca, Eduardo Verano; Gerente de restaurante, Mónica Ortega; y Chef principal, Edwin Cahuana. La información que se obtuvo de las entrevistas a profundidad se procesó, y las respuestas se pueden ver en el Anexo 6. 
Los expertos indicaron que el mercado de comida rápida aún es amplio y queda mucho por abarcar. A la vez se comentó que la innovación en los productos es lo que actualmente hace la diferencia entre los restaurantes fast food. Así como también resulta complejo encontrar el lugar indicado para operar, ya que los locales se deben ubicar lo más accesibles al mercado objetivo. Se concluyó que ingresar a un centro comercial tiene barreras de entrada altas, muchas veces medidas por el prestigio, es por ello que ingresar con una buena idea de negocio hace los trámites más fáciles.

Sobre el concepto, fue fácil entender el significado de "pizza personalizada", se asoció a pizzas en las que el cliente elige los ingredientes. La ubicación de los locales tuvo como recomendación situarse en un restaurante independiente dentro de un centro comercial. Consideraron que el mercado para este proyecto debería abarcar todo Lima, ya que consideran que es un producto para todas las edades. El nombre tuvo aprobación, ya que se encontró una fuerte relación con la creación de una pizza; sin embargo, se recomendó no usar palabras en inglés ya que no todos se encontrarían identificados.

Sobre el producto, el experto en cocina sugirió tener un total entre 20 y 30 opciones de ingredientes, para que el concepto tome más fuerza. Se recomendó que existan algunos acompañamientos, y variedad de bebidas para acompañar la pizza. Se obtuvieron comentarios que indicaban que el mayor problema sería el tiempo en que demoraría en hornearse la pizza; sin embargo, el experto recomendó usar un horno de cúpula, ya que llegan a temperaturas más altas, logrando cocinar las masas en menores tiempos. Por otro lado, la opción de dar opción a vender pizzas en masa delgada, es un punto a favor, ya que estas se cocinan mucho más rápido en el horno. Se debe tomar en cuenta que la masa de pizza necesita un tiempo de reposo y leudado, además del espacio que se necesitará para estirar la masa. 
El experto en elaboración de proyectos comentó que el local necesita por lo menos un área de $70 \mathrm{~m} 2$. El proceso pre-operativo podría demorar entre 45 y 60 días, dependiendo de la intensidad en que se realice. Se recomendó tener asesoría técnica para temas eléctricos, infraestructura, legal, operaciones y municipales.

Finalmente, se obtuvieron apreciaciones sobre la marca. Indicaron que la idea de negocio era muy buena, pero debe ir de la mano con un correcto plan de marketing y publicidad; además se debe considerar crear una imagen y ambiente que esté alineado con el concepto de creación y personalización.

\subsection{Investigación cuantitativa}

Según Malhotra (2008) "la investigación cuantitativa es la "metodología de investigación que busca cuantificar los datos y que, por lo general, aplica algún tipo de análisis estadístico” (p. 143).

Después de la investigación cualitativa, se inició el desarrollo de la investigación cuantitativa a través de encuestas estructuradas para obtener una información más detallada en base a hábitos de consumo y opinión del Pizza Lab.

Se realizó la investigación descriptiva con encuestas con el fin de obtener información exacta de diferentes características.

"La investigación descriptiva tiene como objetivo describir las características de grupos de consumidores en cuanto a conductas, percepción restaurante Pizza Lab, variables de localización y otras opiniones referente al mercado" (Malhotra, 2008, p. 145).

Así mismo, "se utilizó el diseño transversal simple que es realizar encuestas, es decir, se toma una parte de la población meta para obtener información una vez" (Malhotra, 2008, p. 145). 
En éste caso, se realizó encuestas a consumidores de diferentes distritos para obtener información de preferencias en cuanto a ubicación del plan de negocios, frecuencia y gastos en el consumo de un producto así como opinión sobre la disposición de frecuentar y consumir un nuevo producto.

\subsubsection{Proceso de muestreo de la investigación cuantitativa}

Para realizar el muestreo, la técnica utilizada fue No Probabilística en Muestreo por Cuotas, con la inclusión del siguiente criterio:

- Población de Lima Metropolitana del rango de edad y nivel socioeconómico elegido para el público objetivo, pregunta filtro de tipo demográfico, presente en la encuesta.

"El muestro no probabilístico por cuotas en ocasiones llamado "accidental" se basa generalmente sobre la base de los estratos de una población más representativa o adecuada para los fines de la investigación" (Cuesta y Herrero, 2014, p. 87).

De esta forma, se pudo seleccionar la muestra después de dividir a la población en grupos, tales como sexy y edad, luego e ello eligiendo cuotas mediante elecciones proporcionales al tamaño de estratos, obteniendo el número 396, que constituye el tamaño de la muestra.

No se eligió el muestreo probabilístico estratificado ya que no se cuenta con una base de datos exacta acerca de la población estudiada (local y flotante), que es un requerimiento para aplicar este tipo de muestreo y además por sus altos costos.

- Metodología: Cuantitativa

- Técnica: Encuesta

- Tipo de Muestreo: Muestreo por cuotas (Niveles socioeconómicos) 
- Herramienta: Cuestionario online, mediante el uso de la herramienta Google Docs.

- Fecha de Campo: 2 de Octubre al 16 de Octubre del 2017.

- Universo: Hombres y Mujeres de 13 a 59 años de edad, de los NSE A, B, y C que residen en la ciudad de Lima Metropolitana.

Distribución de la Muestra:

Para la estimación del tamaño de muestra, se utilizó la fórmula de criterio de cuotas de elección proporcional al tamaño de estrato, donde la cuota de cada grupo es proporcional a los elementos del mismo. En cada estrato se seleccionaron una cantidad de personas donde la cuota en cada grupo es proporcional a los elementos que se utilizaron en el cálculo de mercado potencial (Ver tabla 25), la fórmula utilizada es para poblaciones infinitas, y se muestra a continuación:

$$
n i=n \cdot \frac{N i}{N}
$$

Donde:

$\mathrm{N}=$ Número de elementos de la población

$\mathrm{n}=$ Numero de la muestra

$\mathrm{Ni}=$ número del estrato $\mathrm{i}$

La distribución de la muestra se determinó a través de la formula anterior, donde se seleccionó la cantidad de personas por estratos que se muestra en la tabla 21 , los detalles se encuentran en el anexo 11. 
Tabla 21

Distribución de Muestra

\begin{tabular}{lccccc}
\hline Grupos & Norte & Centro & Moderna & Sur & Total \\
\hline Edades/Grupos & 47 & 49 & 49 & 54 & 198 \\
\hline 13 a 20 Femenino & 12 & 11 & 10 & 13 & 46 \\
\hline 21 a 35 Femenino & 6 & 11 & 12 & 11 & 41 \\
\hline 36 a 59 Femenino & 3 & 3 & 4 & 5 & 14 \\
\hline 13 a 20 Masculino & 10 & 11 & 11 & 12 & 44 \\
\hline 21 a 35 Masculino & 11 & 9 & 9 & 9 & 37 \\
\hline 36 a 59 Masculino & 4 & 4 & 4 & 4 & 16 \\
\hline NS /Grupos & 47 & 48 & 49 & 54 & 198 \\
\hline NS A Femenino & 12 & 9 & 9 & 12 & 42 \\
\hline NS A Masculino & 7 & 12 & 11 & 10 & 40 \\
\hline NSB Femenino & 8 & 5 & 4 & 6 & 23 \\
\hline NSB Masculino & 8 & 8 & 9 & 11 & 36 \\
\hline NS C Femenino & 6 & 8 & 9 & 7 & 30 \\
\hline NSC Masculino & 6 & 6 & 7 & 8 & 27 \\
\hline
\end{tabular}

De las 396 encuestas, se logró obtener información del distrito al que pertenecen, así como el grupo de personas que prefieren las pizzas, consumo y localización que servirá para la determinación final del proyecto.

\subsubsection{Diseño del instrumento de la investigación cuantitativa}

Para ésta investigación se usó la técnica de encuesta, donde se utilizó un cuestionario, que es un instrumento estructurado en donde se obtuvo información sobre comportamientos, conocimientos, demografía, estilos de vida, frecuencias de consumo y gastos, etc., de una muestra de la población y se realizó mediante cuestionarios de encuesta asistidas por computadora mediante el uso de la herramienta Google Docs (Ver Anexo 7).

A continuación se muestran las principales características que se tomaron en cuenta para realizar las encuestas estructuradas:

- Las encuestas se aplicaron al público principal que consume pizzas en fast food tanto dentro y fuera de centros comerciales y para el público que consume pizzas en restaurantes independientes de comida italiana. 
- Se filtró a aquellos consumidores que estaban dentro del rango de edad que es de 13 a 59 años. Los demás quedaron excluidos.

- El instrumento tuvo 19 preguntas, se excluía al público que no se encontraba dentro del NSE y una pregunta sobre si consume el producto o no.

- La duración de la encuesta fue de 5 minutos aproximadamente y se realizó por encuestas personales asistidas por computadora.

\subsubsection{Análisis y Procesamiento de Datos}

Las encuestas fueron realizadas vía online con un sistema que permite descartar las encuestas que no pasaron los filtros; es decir, los resultados mostrados representan el resultado de 396 encuestados que pasaron los filtros satisfactoriamente.

En relación al estudio de mercado, donde fueron encuestadas 396 personas, se obtuvieron distintos resultados, que se detallan a continuación:

Con respecto al concepto del nuevo negocio y la interacción del mismo, los encuestados se mostraron atraídos a la idea por tanto, la data recolectada muestra que el $98 \%$ tendría la intención de comprar una pizza personalizada en vez de una tradicional. La idea les pareció más atractiva (Ver Figura 9).

\section{¿Optaría usted por comprar una pizza personalizada por la que actualmente consume?}
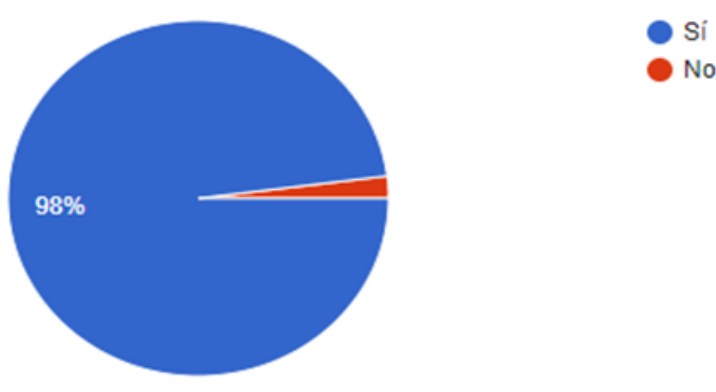

Figura 9. Intención de cambio de compra tradicional. 
Los entrevistados indicaron que lo más importante que percibían en una pizza es el sabor, seguido por la calidad del producto. Lo que menos les pareció importante, según los resultados, fue el valor nutricional que esta tenía.

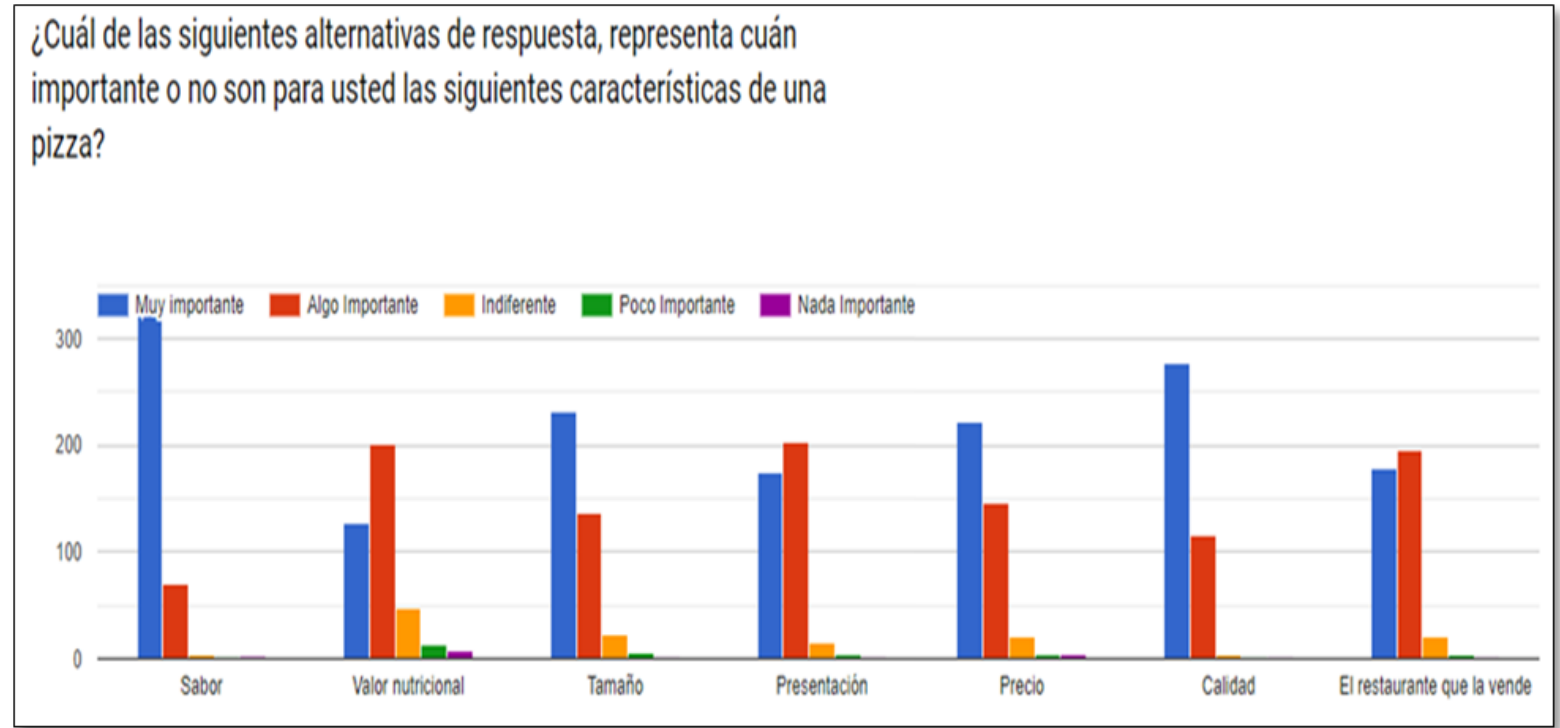

Figura 10. Caracteristicas de la Pizza

Una vez explicado el concepto del proyecto, el 77.5.6\% que es la mayoría de los encuestados contestó que el proyecto les atraía mucho, seguido por el $22.0 \%$ que son aquellos que expresaron que les atraía algo. También hubo encuestados que respondieron que el proyecto les atraía poco, con un porcentaje de $2 \%$. Esta pregunta demuestra el interés que tiene la muestra por el proyecto, la cual se usará para determinar el mercado disponible (Ver Figura 11). 


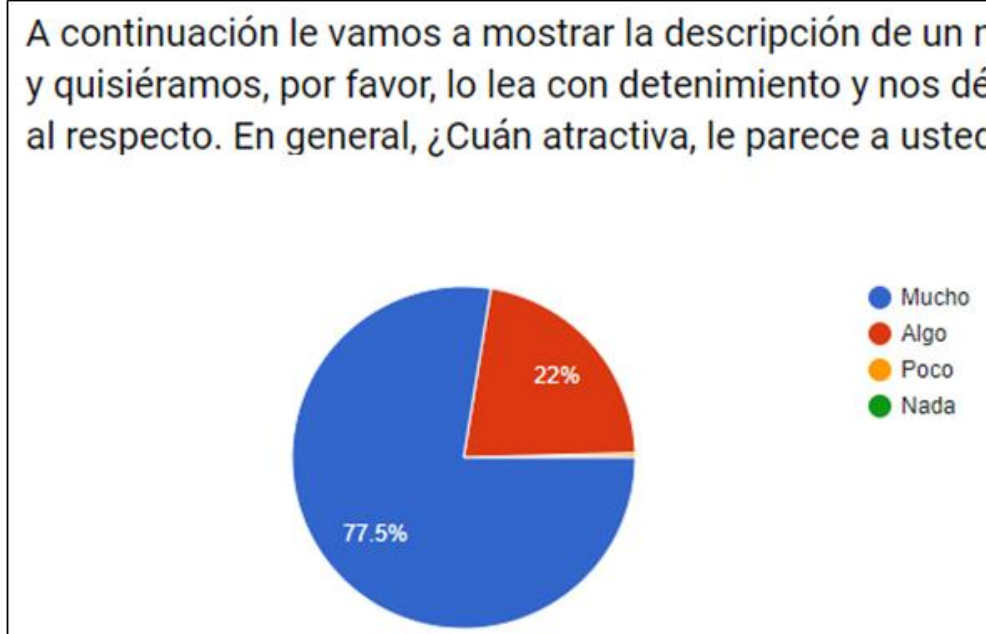

Figura 11. Evaluación de lo atractivo del proyecto.

Más de la mitad de los encuestados respondieron que les atraía mucho la idea. El $32.0 \%$ probablemente si lo compraría y el $60.2 \%$ indicó que definitivamente sí lo compraría. Éstos son datos importantes para el proyecto porque define el mercado efectivo (Ver Figura 12).

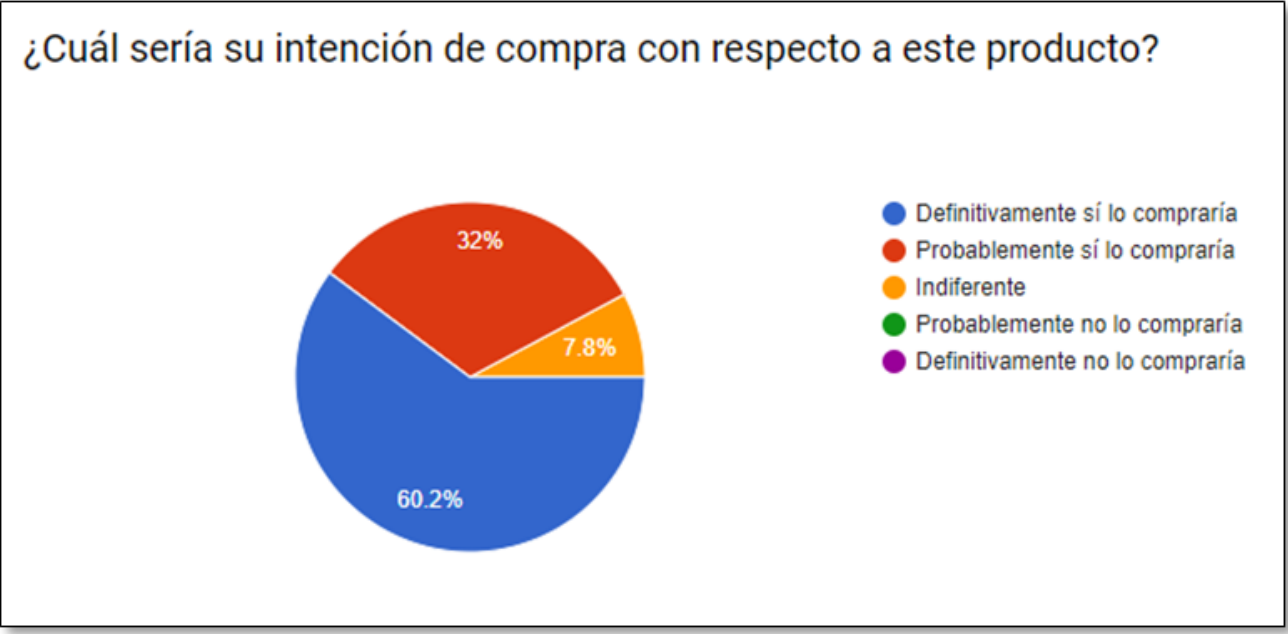

Figura 12. Intención de compra del nuevo concepto.

Con respecto a los lugares donde a los encuestados les gustaría encontrar el producto, dieron las siguientes respuestas: en un local independiente dentro de un centro comercial 
$(36,7 \%)$, en un patio de comidas de un centro comercial (20.6\%), cercano a centros comerciales (20.9\%), cerca de zonas de oficinas (11.1\%) y cercano a centro de estudios $(10.8 \%)$. El proyecto planea ubicar el producto en un local independiente dentro de un centro comercial, los cuales a la vez se encuentran cerca según las preferencias de los consumidores; por lo tanto, estas respuestas serán consideradas para determinar las ubicaciones correctas (Ver Figura 13).

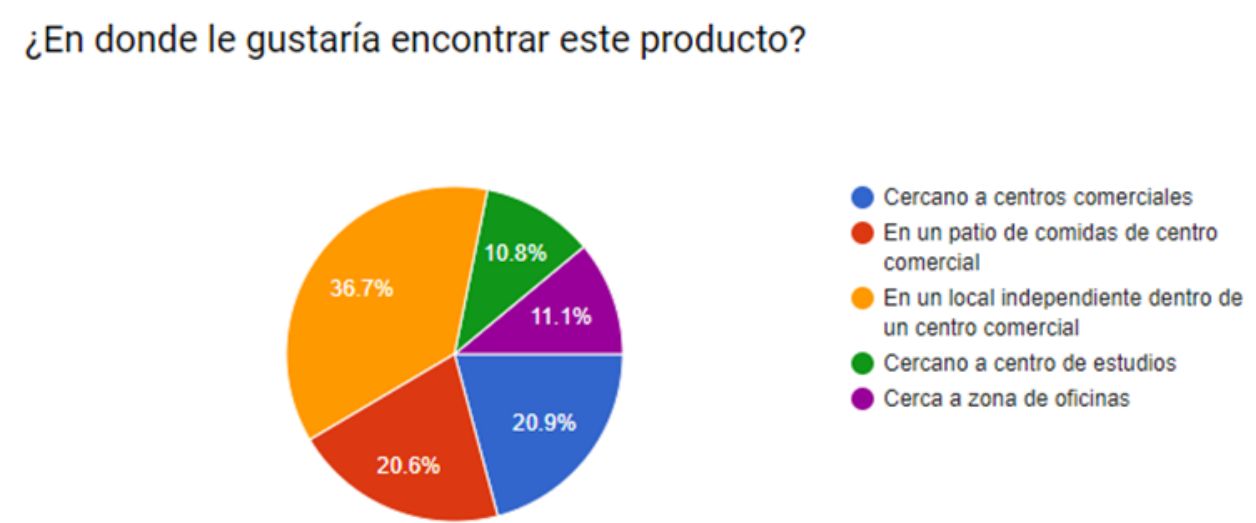

Figura 13. Principales lugares para encontrar el producto.

El resultado general de la muestra de NSE A, B y C, de 13 a 59 años, dice que el 42.7\% del total están dispuestos a pagar entre S/.20.01-S/.25.00. Existe una respuesta que representa el 36.6\% quienes indican que estarían dispuestos a pagar entre S/.15.01S/.20.00 y por el contrario el 14.6\% estarían dispuestos a pagar un precio más elevado de más de S/.25.01. Esta pregunta es vital para el proyecto, ya que ayuda a saber la perspectiva del cliente en la fijación de precios (Ver Figura 14). 
¿Cuánto estaría dispuesto a pagar por una pizza personalizada de 18 $\mathrm{cm}$ con los ingredientes a elegir?

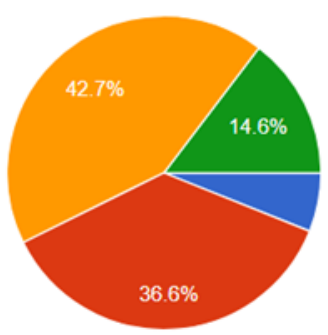

Figura 14. Monto dispuesto a pagar.

Con respecto a la frecuencia de consumo, un $34.4 \%$ de los encuestados respondieron que consumirán el producto de manera quincenal, y un $23.1 \%$ que consumirían el producto una vez a la semana, estos datos se usaron para la proyección de ventas (Ver Figura 15).

¿Con qué frecuencia consumiría el producto (pizza personal de $18 \mathrm{~cm}$ )?
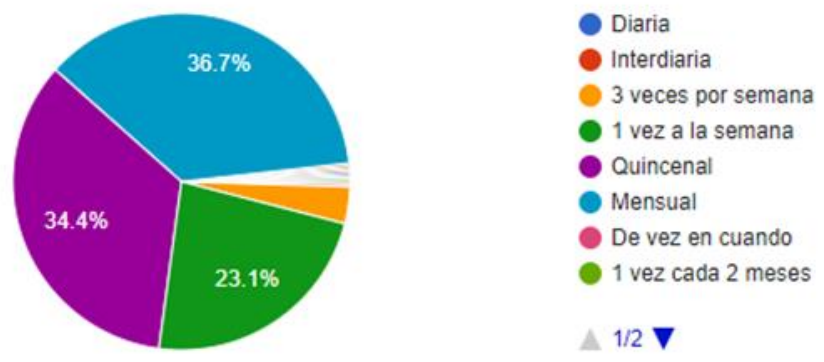

Figura 15. Frecuencia de Compra.

Éste resultado muestra que al $64.8 \%$ le gustaría encontrar una presentación personal de pizzas y al 32.2\% le gustaría una presentación personal (Ver Figura 16). 


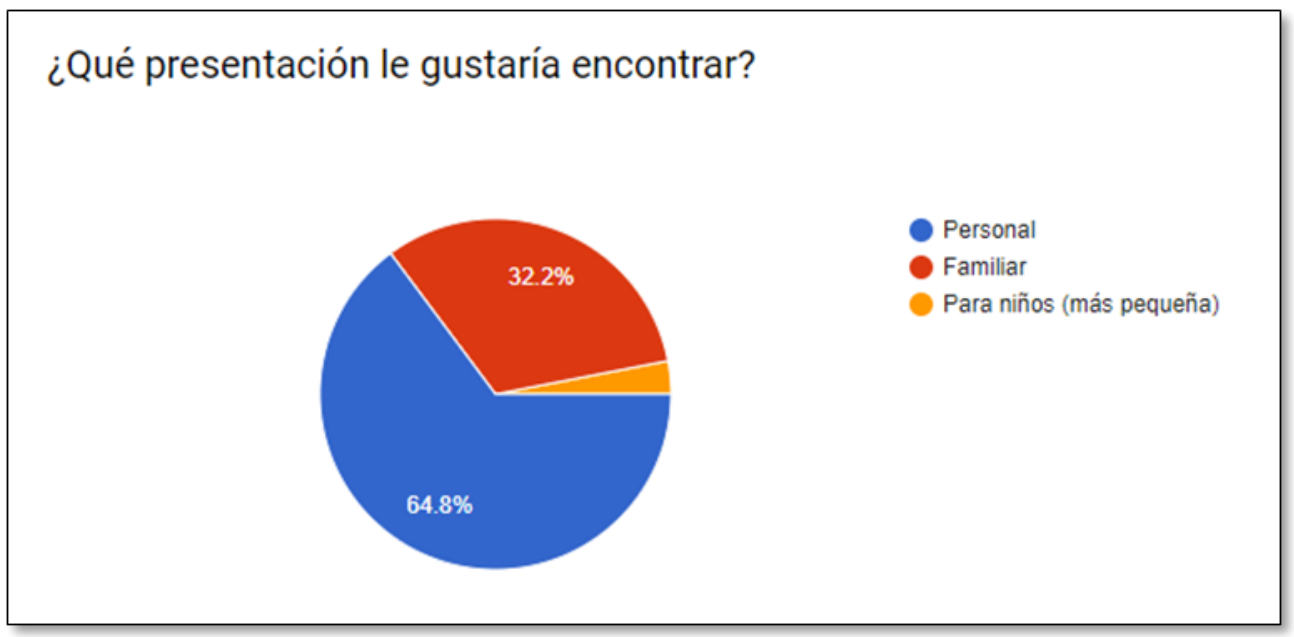

Figura 16. Presentación del producto.

Todas las respuestas de la encuesta se pueden visualizar en el Anexo 5: Resultados de Encuestas.

\subsection{Conclusiones y recomendaciones del Estudio Cualitativo y Cuantitativo}

Luego de realizar las investigaciones cualitativas y cuantitativas, se ha podido determinar diversas conclusiones, entre ellas:

- Ambos grupos del estudio cualitativo como cuantitativo son consumidores de pizza, ya sea para satisfacer las necesidades de hambre, en ocasiones diversas como celebraciones o salidas con amigos. Siendo un porcentaje considerable de personas los que prefieren asistir a establecimientos fuera de centros comerciales.

- Para la mayoría de personas el horario de consumo de pizza es por las noches, durante la cena, ya que consideran que es la hora ideal de consumo por las diversas ocasiones, como: reuniones con amigos o celebraciones.

- Ambos grupos consideran que para asistir a un establecimiento de pizzas, el local debe contar con una excelente infraestructura, calidad de productos y sobre todo que ofrezcan promociones constantes. 
- Para ambos grupos el nombre de la pizzería "PIZZA LAB", no fue de gran aceptación, ya que interpretaban que era otro tipo de negocio, que no era relacionado directamente a las pizzas sino a un laboratorio de medicina. Sin embargo al mostrarles el logo completo la percepción cambio ya que lo asociaban directamente al concepto.

- Con respecto al concepto y la opción de poder hacer sus propias combinaciones y armar una pizza al gusto, la aceptación fue muy positiva ya que muchas de las personas no encuentran combinaciones al gusto en pizzas tradicionales. Es por ello que indicaron que estarían dispuestos a asistir al nuevo establecimiento.

- Para la mayoría de personas, la ubicación del concepto en patio de comidas de centros comerciales no les pareció del todo atractivo, ya que la mayoría prefiere consumir pizzas en establecimientos privados ya sea dentro o fuera de centros comerciales. Porque se sienten más cómodos con mayor espacio y privacidad para consumir dicho plato.

Entre las recomendaciones de diversos estudios, indicaron:

- Con respecto a la idea de poder realizar libres combinaciones en la pizzería, preferirían que se cuente con personal especializado que les recomiende o guie en sus combinaciones, para que el cliente no quede insatisfecho.

- A la vez se recomendó que no solo se ofrezca pizzas, sino que se vendan adicionales, tales como: pastas, lasañas, postres y diversas bebidas.

- Con respecto a la infraestructura recomendaron que la decoración sea retro con colores de tonos amarillo y rojo, con luces bajas y música suave. Ya que consideran que es un ambiente cálido para disfrutar el momento.

- A la vez les gustaría enterarse del concepto por las redes sociales como Facebook e Instagram, ya que son las redes de mayor uso actualmente. $\mathrm{Y}$ en dichas publicaciones 
se recomendó que se anuncien las diversas promociones de la semana (como 2x1, $20 \%$ de descuento en la segunda pizza, entre otros.)

\subsection{Perfil de consumidor tipo y sus variantes}

Luego de realizar los estudios cualitativo y cuantitativo, para determinar el perfil del consumidor, de los 396 encuestados, se observa que el sexo que más predomina es el femenino con un 52.5\%. (Ver figura 17)

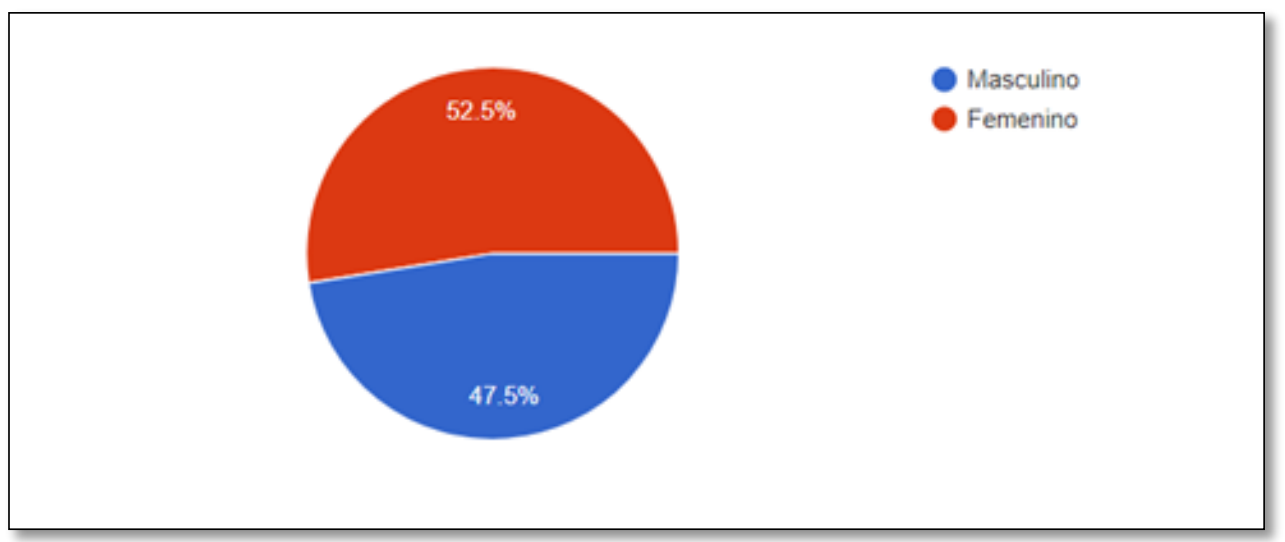

Figura 17. Géneros.

Para ambos grupos se consideraron las edades de 13 a 59 años de edad, dado que entre este rango de edad se encuentra la población económicamente activa (Ver tabla 6), ya que cada vez hay un mayor crecimiento. A la vez el grupo de personas que mayor predomina son de las edades de 21 a 35, dicho segmento son personas que estudian y trabajan, no disponen de tiempo para cenar en sus casas y prefieren comer fuera (Ver Figura 18).

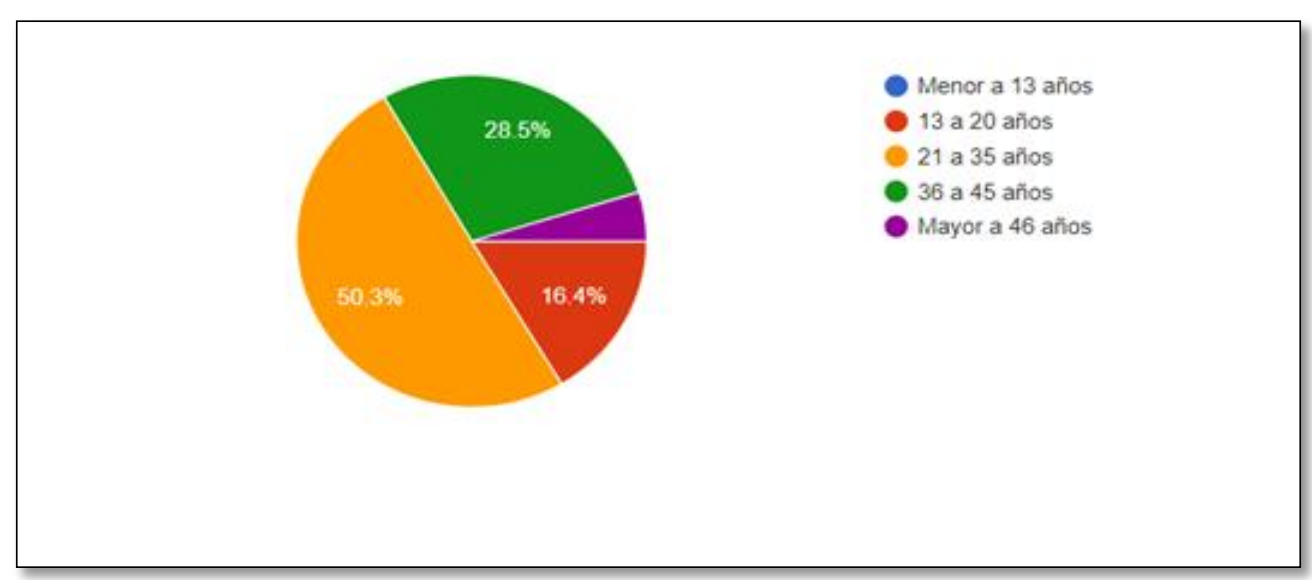

Figura 18. Grupos de Edad. 
Dicho segmento pertenece a los niveles socioeconómicos A, B y C, de todos los distritos de Lima Metropolitana, Lima Norte, Lima Este, Lima Centro, Lima Moderna y Lima Sur. Siendo personas que residen en los distintos distritos de las zonas antes mencionadas o que están visita en cualquier otro distrito de diversas zonas.

De la misma manera, del grupo de 396 encuestados, indicaron que consumen pizza por delivery (Ver Anexo 4). A la vez se puede mencionar según un estudio de Euromonitor (2016) sobre el modo de consumo de fast food, donde el $54 \%$ de personas prefieren comer en el restaurante y un $44 \%$ prefiere consumir por delivery. Lo mencionado anteriormente hace referencia a que más personas cada día consumen comida fast food mediante el canal de delivery.

Tabla 22

Ventas en Consumo de servicios Fast Food

Sales in Consumer Foodservice by Eat-in/Home Delivery/ Takeaway/Drive- Through: \% Foodservice Value 2016

$\%$ Value analysis

\begin{tabular}{lccccr}
\hline & $\begin{array}{c}\text { Eat } \\
\text { in }\end{array}$ & Home Delivery & Takeaway & Drive- Through & Total \\
\hline 100\% Home Delivery/ Takeaway & - & 95.2 & 4.8 & - & 100.0 \\
& & & & & \\
\hline Cafés/Bars & 77.2 & 9.0 & 13.8 & - & 100.0 \\
\hline Full- Service Restaurants & 93.2 & 6.7 & 0.1 & - & 100.0 \\
\hline Fast Food & 54.3 & 44.7 & 1.0 & - & 100.0 \\
\hline Self- Service Cafeterías & 100.0 & - & - & - & 100.0 \\
\hline Street Stalls / Kiosks & 18.4 & - & 81.6 & - & 100.0 \\
\hline Consumer Foodservice & 64.1 & 19.4 & 16.5 & - & 100.0 \\
\hline $\begin{array}{l}\text { Nota: Por Euromonitor International. Recuperado de http://www.euromonitor.com/100- } \\
\text { home-delivery-takeaway-in-the- } \text { us/report }\end{array}$ &
\end{tabular}

Como se mencionó anteriormente la frecuencia de consumo en dichos establecimientos es de manera diaria a quincenal. Siendo lo más valorado para los 
consumidores la calidad, sabor y precio. A la vez uno de los motivos principales de asistencia es el de reunirse con amigos o saciar el hambre por falta de tiempo. Las personas que consumen pizza, prefieren hacerlo por las noches como una cena o piqueo.

Es por ello que el perfil de consumidor para el presente proyecto son personas tanto mujeres como varones, de las edades de 13 a 59, entre estudiantes y personas que trabajan. Con un nivel de consumo diario a quincenal, principalmente con horario de consumo por las noches. 


\section{Capítulo IV. Proyección del mercado objetivo}

En el presente capítulo se determina la demanda proyectada que tendrá el restaurante de pizzas personalizadas, así como también, se realizará un pronóstico de ventas para los cinco años de estudio que tiene como duración el Plan de Negocios.

\subsection{El ámbito de la proyección}

La proyección de la demanda está basada en los resultados obtenidos del estudio de mercado, directamente relacionada con el estudio cuantitativo, es decir, las encuestas; así como también información demográfica relacionada con el segmento elegido para el proyecto. No se consideraron datos históricos, ya que el proyecto está basado en un concepto nuevo, sin precedentes en el Perú.

\subsection{Selección del método de proyección.}

“Un método de proyección es usado para prever compras, proyectar ventas, solicitar financiamiento o planificar su producción” (Kotler, 2016, p. 86).

Para el presente proyecto, la demanda se ha proyectado filtrando el mercado desde el mercado potencial hasta el mercado objetivo. Estos pasos se han podido realizar, con ayuda de bases estadísticas socioculturales y los resultados de la investigación cuantitativa.

Se usó el método de análisis de tendencia que es un método estadístico que usa las bases estadísticas con la finalidad de realizar proyecciones. En este caso, se usó para filtrar de acuerdo a segmentación para hallar el mercado potencial.

Además, para el mercado disponible y efectivo, se usó el método de sondeo de intenciones, la cual insiste en encuestar a los consumidores potenciales sobre expectativas de un producto o servicio. "Se usa para estimar la demanda de productos industriales o bienes de 
consumo; productos que cuyo lanzamiento requiere planificación anticipada o productos nuevos" (Kotler, 2016, p. 95).

\subsubsection{Mercado Potencial.}

"El mercado potencial es el grupo de consumidores que tienen el suficiente interés por la oferta de mercado, pero no necesariamente un interés directo de compra" (Kotler, 2016, p. 86).

Para hallar el mercado potencial y posteriormente la demanda, es necesario conocer la población de segmento al que se va a dirigir el proyecto. Para ello se requiere proyectar la población de Lima Metropolitana. Esto se basará en una proyección realizada por la INEI sobre la población proyectada de Lima Metropolitana. La proyección será para los siguientes cinco años, es decir, desde el año 2018 hasta el 2022, teniendo como año cero este año 2017. (Ver tabla 23)

Tabla 23

Población Proyectada de Lima Metropolitana

Año 2018 Población proyectada
de Lima Metropolitana
$9,166,222$

$9,261,220$

$9,354,942$

$9,447,470$

$9,539,112$

Nota. Las cantidades están estimadas en unidades de habitantes. Tomado de "Población de Lima Metropolitana”, por Instituto Nacional de Estadística e Informática (INEI), 2017. Recuperado de https://proyectos.inei.gob.pe/web/poblacion/

Luego de haber identificado la población de Lima Metropolitana proyectada, se realizó una segmentación geográfica, en la cual solo se tomó las zonas de Lima Metropolitana incluidas en la segmentación realizada, es decir: Lima Norte, Lima Sur, y Lima Moderna. (Ver Tabla 24) 
Tabla 24

Proporción de las zonas de Lima

\begin{tabular}{llllll}
\hline Lima Lima Lima Lima & Lima & Callao
\end{tabular}

Metropolitana Norte Este Centro Moderna

$\begin{array}{lllllll}100.00 \% & 25.25 \% & 24.40 \% & 7.99 \% & 13.13 \% & 18.98 \% & 10.25 \%\end{array}$

Nota. Adaptado de Estadística Poblacional NSE APEIM 2013. Tomado de: Perfiles Zonales de Lima Metropolitana, 2013 (p.10), por Ipsos Marketing (2012b), Lima, Perú: Depósito Legal N²012-08467.

Parte de la segmentación también incluye algunas características demográficas tomadas en consideración, las cuales son los niveles socioeconómicos A, B y C, y el grupo de edades desde 13 a 59 años. Los datos se sacaron de las tablas 25 y 26, las cuales expresan porcentualmente los niveles socioeconómicos y edades de Lima Metropolitana.

Tabla 25

Proporción de edades según zonas de Lima Metropolitana

\% de Personas según Edad y Zonas de Lima

Edad Zonas de Lima Metropolitana

Norte Este Centro Moderna Sur Callao

\begin{tabular}{lcccccc}
\hline Menos de 7 & $26.04 \%$ & $26.48 \%$ & $6.83 \%$ & $9.22 \%$ & $20.45 \%$ & $10.99 \%$ \\
\hline De 7 a 12 & $26.42 \%$ & $25.81 \%$ & $6.92 \%$ & $9.55 \%$ & $20.59 \%$ & $10.71 \%$ \\
\hline De 13 a 20 & $25.87 \%$ & $26.23 \%$ & $7.39 \%$ & $10.63 \%$ & $19.77 \%$ & $10.11 \%$ \\
\hline De 21 a 35 & $25.16 \%$ & $25.99 \%$ & $7.60 \%$ & $11.97 \%$ & $19.38 \%$ & $9.90 \%$ \\
\hline De 36 a 59 & $25.08 \%$ & $22.53 \%$ & $8.51 \%$ & $15.47 \%$ & $18.13 \%$ & $10.28 \%$
\end{tabular}

Nota. Adaptado de Estadística Poblacional por edaddes NSE APEIM 2013. Tomado de: Perfiles Zonales de Lima Metropolitana, 2013 (p.10), por Ipsos Marketing (2012b), Lima, Perú: Depósito Legal N²012-08467. 
Tabla 26

Proporción de NSE según zonas de Lima Metropolitana

\begin{tabular}{lcccc}
\hline \multirow{2}{*}{ Zonas } & \multicolumn{4}{c}{ Estructura económica } \\
\cline { 2 - 5 } & $\mathrm{AB}$ & $\mathrm{C}$ & $\mathrm{D}$ & $\mathrm{E}$ \\
\hline Lima Norte & $22.9 \%$ & $44.1 \%$ & $27.6 \%$ & $5.4 \%$ \\
\hline Lima Centro & $33.1 \%$ & $43.3 \%$ & $20.2 \%$ & $3.5 \%$ \\
\hline $\begin{array}{l}\text { Lima } \\
\text { Moderna }\end{array}$ & $76.8 \%$ & $17.4 \%$ & $4.5 \%$ & $1.3 \%$ \\
\hline Lima Este & $17.7 \%$ & $45.7 \%$ & $29.6 \%$ & $7.0 \%$ \\
\hline Lima Sur & $13.3 \%$ & $53.4 \%$ & $27.4 \%$ & $5.9 \%$ \\
\hline Callao & $21.7 \%$ & $45.9 \%$ & $23.6 \%$ & $8.8 \%$ \\
\hline
\end{tabular}

Nota. Adaptado de estructura económica por zonas de Lima Metropolitana. Tomado de: Marketreport Población 2018 (p.10), por Compañía peruana de estudios de mercados y opinión pública, Lima, Perú. Recuperado de:

http://cpi.pe/images/upload/paginaweb/archivo/26/mr_poblacional_peru_201905.pdf

Finalmente, tomando en cuenta que geográficamente las zonas de Lima representan el $57.36 \%$ de Lima Metropolitana, que los niveles socioeconómicos A, B y C forman el $73.5 \%$ en las zonas de Lima que se desarrollará el proyecto, y que el grupo de edades de 13 a 59 son el 68.62\% también en estas zonas, se realizó el cuadro filtrando la población de Lima Metropolitana con cada uno de estas variables, para finalmente, obtener el mercado potencial. (Ver Tabla 27)

Tabla 27

Mercado Potencial

\begin{tabular}{lccccc} 
Año & 2018 & 2019 & 2020 & 2021 & 2022 \\
\hline Población de Lima & & & & & \\
Metropolitana & $9,166,222$ & $9,261,220$ & $9,354,942$ & $9,447,470$ & $9,539,112$ \\
Zonas de Lima & $5,257,745$ & $5,312,236$ & $5,365,995$ & $5,419,069$ & $5,471,635$ \\
NSE & $3,861,951$ & $3,901,975$ & $3,941,463$ & $3,980,447$ & $4,019,058$ \\
Edad & $2,650,206$ & $2,677,672$ & $2,704,770$ & $2,731,522$ & $2,758,018$ \\
\hline Mercado potencial & $2,650,206$ & $2,677,672$ & $2,704,770$ & $2,731,522$ & $2,758,018$
\end{tabular}

Nota. Montos representados en unidades de personas. 


\subsubsection{Mercado Disponible}

"El mercado disponible representa el conjunto de consumidores que no solo tienen ingresos y acceso a la oferta, sino también, el interés sobre ésta” (Kotler, 2016, p. 86).

Para obtener el mercado disponible, se tomó como referencia algunos resultados de la investigación cuantitativa. La primera variable se obtuvo de la pregunta que nos indica cuántas personas son consumidores frecuentes de pizza; de acuerdo a los resultados fueron el 98.7\%. La segunda variable demuestra la intención de compra de una pizza personalizada sobre la que actualmente consume; de acuerdo a las estadísticas a un $98 \%$ de los encuestados preferirían una pizza personalizada. La tercera variable se obtuvo de los resultados de la pregunta de la encuesta sobre la atracción del concepto; se tomó en cuenta solo a aquellos que les gustó mucho, lo cual representa el 77.5\%; sin embargo, para reducir el optimismo en los resultados de las encuestas, se redujo este porcentaje a $73.2 \%$. Se redujo el porcentaje que representa el margen de error de la encuesta. Se determinó el mercado disponible usando las dos variables sobre el mercado potencial. (Ver tabla 28)

Tabla 28

Mercado Disponible

\begin{tabular}{lccccc} 
Año & 2018 & 2019 & 2020 & 2021 & 2022 \\
\hline $\begin{array}{l}\text { Consumidor de pizza } \\
\text { Pizza personalizada }\end{array}$ & $2,615,753$ & $2,642,862$ & $2,669,608$ & $2,696,012$ & $2,722,164$ \\
$\begin{array}{l}\text { vs pizza común } \\
\begin{array}{l}\text { Evaluación del } \\
\text { concepto }\end{array}\end{array}$ & $2,563,438$ & $2,590,005$ & $2,616,215$ & $2,642,092$ & $2,667,721$ \\
\hline Mercado Disponible & $1,914,731$ & $1,934,575$ & $1,954,153$ & $1,973,481$ & $1,992,624$ \\
\hline
\end{tabular}

Nota. Montos representados en unidades de personas. 


\subsubsection{Mercado Efectivo}

El mercado efectivo es aquel que tiene una intención directa de compra. Es el conjunto de consumidores que van a adquirir el producto de la empresa. (Kotler, 2016, p. 87)

El mercado efectivo se determina básicamente a la intención de compra luego de haber explicado el concepto y producto. En el caso de este proyecto, el resultado que se obtuvo de la encuesta fue que el $60.2 \%$ de la muestra concordó que definitivamente sí comprarían. Sin embargo, para reducir el optimismo en los resultados de las encuestas, se redujo este porcentaje a $52.5 \%$. En este caso también se redujo el porcentaje que representa el margen de error de la encuesta. Esta variable se aplicó sobre el mercado disponible, como se muestra en la tabla 29.

Tabla 29

Mercado Efectivo

\begin{tabular}{lccccc} 
Año & 2018 & 2019 & 2020 & 2021 & 2022 \\
\hline Mercado Disponible & $1,914,731$ & $1,934,575$ & $1,954,153$ & $1,973,481$ & $1,992,624$ \\
Intención de compra & $1,005,234$ & $1,015,652$ & $1,025,930$ & $1,036,077$ & $1,046,128$ \\
\hline Mercado Efectivo & $1,005,234$ & $1,015,652$ & $1,025,930$ & $1,036,077$ & $1,046,128$
\end{tabular}

Nota. Montos representados en unidades de personas.

\subsubsection{Mercado Objetivo}

"El mercado objetivo representa la parte del mercado que la empresa decide atender. Hacia este mercado es que van a dirigir sus esfuerzos de marketing y distribución” (Kotler, 2016, p. 87).

Para el mercado objetivo se proyectó un $2 \%$ del mercado efectivo. Las grandes compañías de pizza, ocupan el 92\% del mercado; con el 2\% del mercado efectivo, Pizza Lab 
planea abarcar el $0.3 \%$ de participación de mercado de este $8 \%$ que actualmente lo abarcan las pizzerías no muy conocidas o independientes. Este porcentaje es posible gracias a la gran afluencia de público que los Centros Comerciales brindarán a los locales; además, la capacidad instalada de los locales vuelve factible el crecimiento de la demanda sin necesidad de realizar grandes cambios en el servicio. Se debe considerar también que poco a poco la venta por delivery tendrá un crecimiento paulatino, lo cual no es una limitación ni operativa ni técnica, para crecer las ventas en los años siguientes. Otro de los motivos es que el proyecto no podría funcionar a su capacidad máxima de atención bajo supuestos como la existencia de los demás competidores con mayor tiempo y poder en el mercado. Se ha estimado crecimientos geométricos anuales del $8 \%$, teniendo en cuenta que el mercado es tan grande actualmente que posteriormente se pueden implementar más locales sin inconvenientes. Se ha tomado en cuenta un crecimiento lento de solo $8 \%$ geométrico, porque se trata de un nuevo concepto que tomará tiempo en hacerse conocido, además, la implementación de delivery y apertura de nuevas tiendas, se realizará con lentitud. Además, con este incremento del $8 \%$ geométrico, el proyecto habrá tenido un aumento en sus ventas de casi en un 50\% después de los primeros cinco años. (Ver tabla 30)

Tabla 30

Mercado Objetivo

\begin{tabular}{lrrrrr} 
Año & \multicolumn{1}{c}{2018} & \multicolumn{1}{c}{2019} & 2020 & \multicolumn{1}{c}{2021} & \multicolumn{1}{c}{2022} \\
\hline Mercado Efectivo & $\begin{array}{r}1,005,234 \\
1,015,652\end{array}$ & $\begin{array}{r}1,025,930 \\
1,036,077\end{array}$ & $1,046,128$ \\
Mercado Objetivo & 20,105 & 21,938 & 23,933 & 26,103 & 28,465 \\
\hline Crecimiento & $2.00 \%$ & $2.16 \%$ & $2.33 \%$ & $2.52 \%$ & $2.72 \%$ \\
Geometrico 8\% & & & &
\end{tabular}

Nota. Montos representados en unidades de personas. 


\subsection{Pronóstico de Ventas}

Para realizar la proyección de ventas, se debe tomar primero la frecuencia de compra, la cual se obtuvo de la encuesta, tomando en cuenta la pregunta sobre la frecuencia de consumo o asistencia al restaurante. Con los resultados se realizó una ponderación, para finalmente determinar que la frecuencia de venta mensual sería de 4.32 veces. (Ver tabla 31)

Tabla 31

Frecuencia de compra estimada

\begin{tabular}{lcc} 
Frecuencia de consumo & $\begin{array}{c}\text { Frecuencia } \\
\text { Mensual }\end{array}$ & Porcentaje \\
\hline Interdiaria & 15 & $5.82 \%$ \\
3 veces por semana & 12 & $11.39 \%$ \\
1 vez a la semana & 5 & $25.06 \%$ \\
Quincenal & 2 & $28.10 \%$ \\
Mensual & 1 & $24.05 \%$ \\
Otros & 0.5 & $5.57 \%$ \\
\hline Frecuencia Estimada & & 4.32
\end{tabular}

Para realizar una correcta proyección de ventas por unidad, se tomaron en cuenta dos variables: el mercado objetivo del proyecto y la frecuencia de compra anual. Finalmente las ventas se dividen entre el número de locales para de esa manera pronosticar de ventas por unidades de cada local. (Ver tabla 32) 
Tabla 32

Ventas expresadas en platos vendidos

\begin{tabular}{lrrrrr} 
Año & 2018 & 2019 & 2020 & 2021 & 2022 \\
\hline Ventas Anuales & 86852 & 94773 & 103390 & 112766 & 122968 \\
Ventas Mensuales & 7238 & 7898 & 8616 & 9397 & 10247 \\
Ventas Semanales & 1670 & 1823 & 1988 & 2169 & 2365 \\
Ventas Diarias & 239 & 260 & 284 & 310 & 338 \\
Ventas diarias por local & 80 & 87 & 95 & 103 & 113
\end{tabular}

Nota. Montos representados unidades de pizzas vendidas.

Finalmente para poder hallar la proyección de ventas en soles, se deben tomar en cuenta dos variables, el pronóstico de ventas por unidades y el ticket promedio. Este último dato se obtuvo de la encuesta, específicamente en la pregunta sobre qué tipo de presentación le gustaría encontrar, cabe mencionar que cada uno de los tipos de presentación tiene diferente precio promedio. Además, se está considerando que el ticket promedio de bebidas es de S/. 7.00, el cual se obtuvo luego del proceso de costeo de producto y fijación de precios. Entre estos obtendrá el ticket promedio de alimentos y bebidas. (Ver tabla 33)

Tabla 33

Ticket Promedio

\begin{tabular}{lccc} 
Tipo de Producto & Porcentaje & $\begin{array}{c}\text { Precio Promedio por } \\
\text { producto }\end{array}$ & $\begin{array}{c}\text { Precio } \\
\text { Ponderado }\end{array}$ \\
\hline Pizza Personal & $64.60 \%$ & S/. 25.00 & S/.16.15 \\
Pizza Familiar & $32.30 \%$ & S $/ .45 .00$ & S/.14.54 \\
Pizza Para niños & $3.10 \%$ & S/.12.00 & S/. 0.37 \\
\hline \multicolumn{3}{c}{ Sicket Promedio de Alimentos 31.06} \\
\hline \multicolumn{3}{c}{ Ticket Promedio de Bebidas } & S/. 7.00 \\
\hline \multicolumn{3}{c}{ Ticket Promedio } & S/. 38.06
\end{tabular}


Como se puede observar en la tabla 34, la venta proyectada en soles se calculó producto del ticket promedio y las unidades vendidas.

Tabla 34

Ventas proyectadas en Soles

\begin{tabular}{lrrlrrrrrrr} 
Año & \multicolumn{4}{r}{2018} & & 2019 & 2020 & 2021 & 2022 \\
\hline Ventas Anuales & S/. & $3,305,334$ & S/. & $3,606,758$ & S/. & $3,934,718$ & S/. & $4,291,526$ & S/. & $4,679,807$ \\
Ventas Mensuales & S/. & 275,445 & S/. & 275,445 & S/. & 275,445 & S/. & 275,445 & S/. & 275,445 \\
Ventas Semanales & S/. & 63,564 & S/. & 69,361 & S/. & 75,668 & S/. & 82,529 & S/. & 89,996 \\
Ventas Diarias & S/. & 9,081 & S/. & 9,909 & S/. & 10,810 & S/. & 11,790 & S/. & 12,857 \\
Ventas por local & S/. & 3,027 & S/. & 3,303 & S/. & 3,603 & S/. & 3,930 & S/. & 4,286
\end{tabular}

Nota. Montos representados en soles incluido IGV.

\subsection{Aspectos críticos que impactan el pronóstico de ventas}

Existen algunos factores que pueden afectar directamente al pronóstico de ventas realizado. Estos pueden ser factores externos, es decir, del macro entorno, como internos, es decir propios de la organización. A continuación, se mencionan los encontrados.

- Factores externos

- Ingreso per cápita

- Producto Bruto Interno

- Variaciones en la oferta del producto en el mercado.

- Variaciones en el precio de insumos principales.

-Desastres naturales

-Políticas de Centros Comerciales.

- Factores internos

- Cambios de la capacidad operativa 
-Por aumento o disminución del prestigio de la empresa o del producto que se ofrece.

- Acciones para mitigar el riesgo

- Contar con una organización totalmente flexible para adaptarse a las nuevas necesidades del entorno.

- Innovación de nuevos productos, servicios y operaciones; esto permitirá ampliar los horizontes del negocio en caso se presenten barreras o riesgos en el entorno.

- Inversión en procesos y capacitación; lo cual genera crear una organización más compacta y con mayor capacidad de resiliencia.

- Correcto uso de redes sociales; en caso se presenten casos que afecten el prestigio del negocio. 


\section{Capítulo V. Ingeniería del Proyecto}

En este capítulo se muestra todo lo relacionado a los procesos operativos de producción y servicio con los que contará el establecimiento, así como también las herramientas, equipos y maquinaria necesaria para que Pizza Lab pueda operar.

\subsection{Estudio de ingeniería}

En este punto se explican los procesos detalladamente por área, así como los detalles de los equipos y maquinaria que se usará en los establecimientos. También se mostrará el layout del local y la distribución de equipos y maquinarias. Todo esto se realizó con la finalidad de:

- Establecer los procesos de producción y definir las operaciones necesarias

- Elegir los estándares de producción, buscando que sean eficientes y logren satisfacer la demanda.

- Describir y elegir los recursos necesarios para el establecimiento, como los equipos, muebles, local e insumos.

\subsubsection{Modelamiento y selección de procesos productivos}

\subsubsection{Paquete de Servicio}

- Servicio Esencial

Este concepto brinda un servicio de alimentación en una línea de interacción personalizada por el mismo cliente, el cual consiste en elegir una proteína, sobre la cual está puesto el precio base. Posteriormente el cliente tendrá que elegir libremente entre diferentes opciones como el tipo de masa, la salsa base, el tipo de queso, verduras, proteínas, salsas, hortalizas, embutidos, frutas, y condimentos. Todos estos componentes de productos están 
elaborados en base a sabores clásicos de una pizza y por cantidades establecidas en cucharas medidoras.

- Servicios Facilitadores

Pizza Lab ofrece algunos servicios facilitadores, los cuales están compuestos por herramientas que permitan un mejor desempeño del servicio esencial, así como sistemas operativos. En este proyecto, se ofrecen los siguientes servicios facilitadores:

- Sistema de facturación: El Software cheff2000, permite realizar diferentes procesos operativos, como la toma y procesamiento de pedidos, facturaciones de venta, lleva sistemas de control de almacenes, data de precios de insumos, costeo de recetas, entre otras funciones.

- Sistema de pago POS: Esta es una opción extra de método de pago que mejora la eficiencia del restaurante en cuestión a métodos de pago para los clientes que optan por pagar con tarjetas de crédito o débito. Pizza Lab contará con Visa y MasterCard. Para ambos casos, piden como requisitos documentarios: un RUC activo, fotocopia de DNI vigente del representante legal, y fotocopia simple del documento bancario que acredite el número y titular de la cuenta donde se realizarán los abonos. En cuanto al sistema de cobro por parte de estas empresas son del $\mathbf{5 \%}$ aproximadamente de acuerdo a las ventas mensuales por estos métodos de pago. Solo tiene un costo único de instalación de S/. 60.00 y otro por el alquiler de la máquina POS de S/. 18.00 mensuales por POS.

- Aplicativo Móvil: Este aplicativo será un medio de compra del producto, que serán muy parecido a realizar una compra presencial. En esta, uno debe registrarse, y si desea realizar una compra, debe elegir el producto que desea comprar, posteriormente, elegir los ingredientes que desea poner en su pizza. Finalmente, elegir un medio de pago y elegir si desea recoger el pedido en tienda o desea servicio de Delivery. 
- Servicios de Apoyo

Estos servicios permiten a la operación dar valor agregado al servicio esencial. Los locales de Pizza Lab, tienen como servicio de apoyo al Centro Comercial. Esto debido a que permite estar en un lugar donde el cliente tiene la facilidad de encontrar muchos otros servicios, ya sea de compras, diversión, alimentación, servicios bancarios, entre otros. Además, estos Centros Comerciales poseen todas las facilidades que el cliente percibe como parte de la experiencia de Pizza Lab, como: los ascensores, estacionamientos, escaleras eléctricas y la facilidad de adquirir otros productos.

\subsubsection{Blueprint}

El proyecto cuenta con un Blueprint, que detalla sus operaciones desde que el cliente llega hasta que el servicio finaliza. Este proceso empieza cuando el cliente ingresa al establecimiento, para lo cual primero tiene que entrar al Centro Comercial; esto conlleva que interactúe con algunas de las facilidades de este, como el estacionamiento. Cuando el cliente ingresa a Pizza Lab, tiene el primer contacto con el personal del local, quien lo saluda y explica el sistema de servicio, en caso fuera su primera vez asistiendo al local. Cuando el cliente ha tomado una decisión en base a las opciones presentadas, se procede a la toma del pedido, en este punto se confirma el pedido para evitar errores posteriores. La comanda en este proyecto, será el individual, en donde se marcará las opciones que el cliente elija, para que quien sirva lo tenga presente, así como también quien cobra, sepa el precio que tiene que cobrar. En este último punto, se ofrece adicionales, extras y bebidas, con la finalidad de aumentar el ticket promedio. Luego, se procede a cancelar la cuenta, ya sea con tarjeta o con efectivo; se agradece al cliente por su compra y su visita. El cliente decide si consume su pedido en tienda, y posteriormente, el personal de limpieza se encarga de mantener limpio el área del comedor. Por otro lado, en la cocina se tendrán procesos de preparación y reposición 
constantes, con la finalidad de mantener los alimentos lo más frescos posible. Estos puntos, son considerados críticos, ya que se debe mantener un correcto control de temperaturas con la finalidad de garantizar un producto de calidad. (Ver Figura 19) 


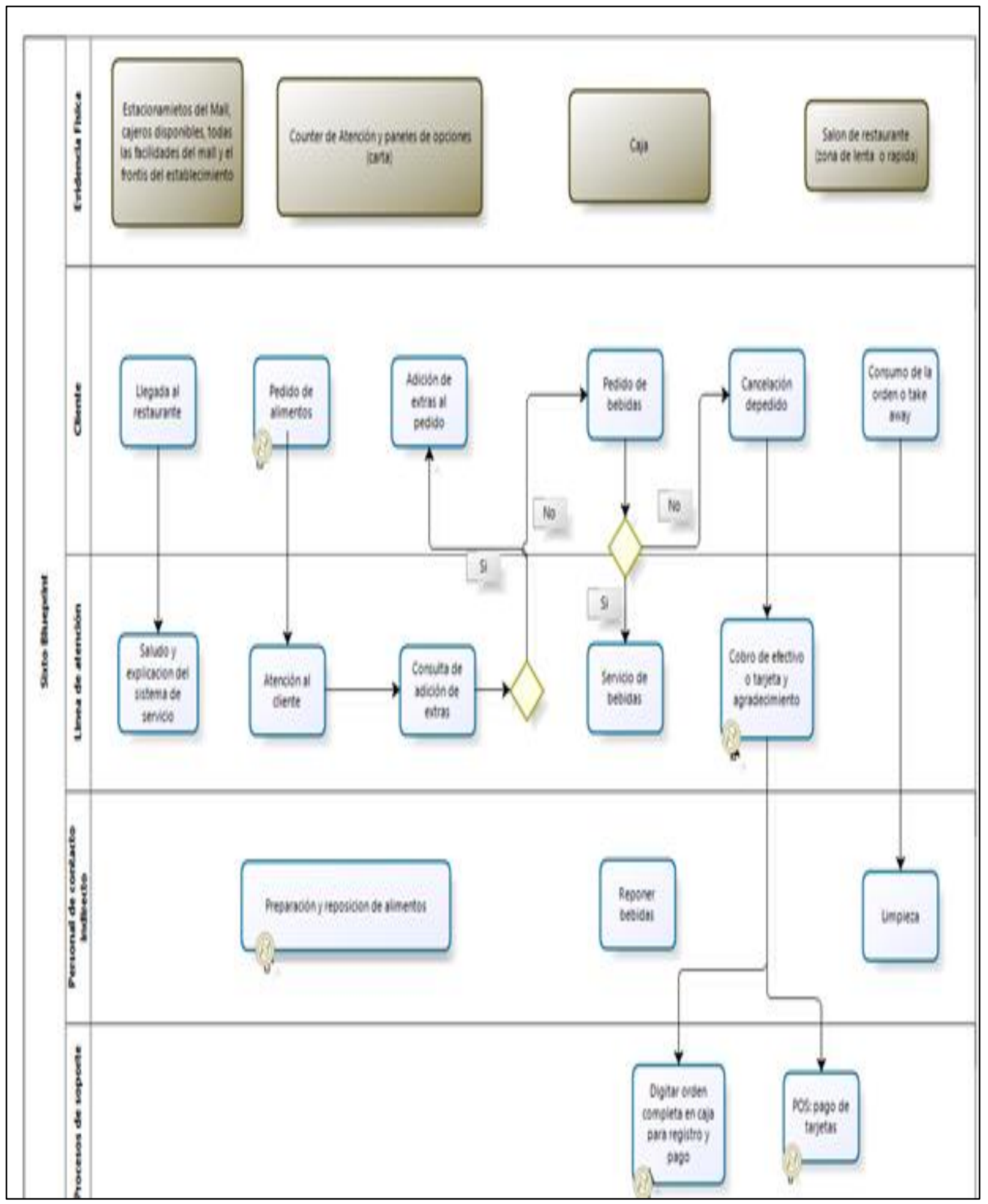

Figura 19. Blueprint 


\subsubsection{Flujos Independientes}

- Recepción de Mercadería

Para el proceso de recepción de mercadería es indispensable realizar diversos controles, ya que es el primer punto de control de calidad, que además, incluyen diferentes reglas de sanidad que por ley se deben cumplir. Primero, debe verificarse las condiciones del transporte. Cuando los insumos entran al área de recepción, se verifica la documentación. Si todo está conforme, se procede a medir la temperatura de los insumos que lo requieran, se realiza un chequeo físico, se pesa y se verifica que estos lleguen con los estándares requeridos. (Ver figura 20)

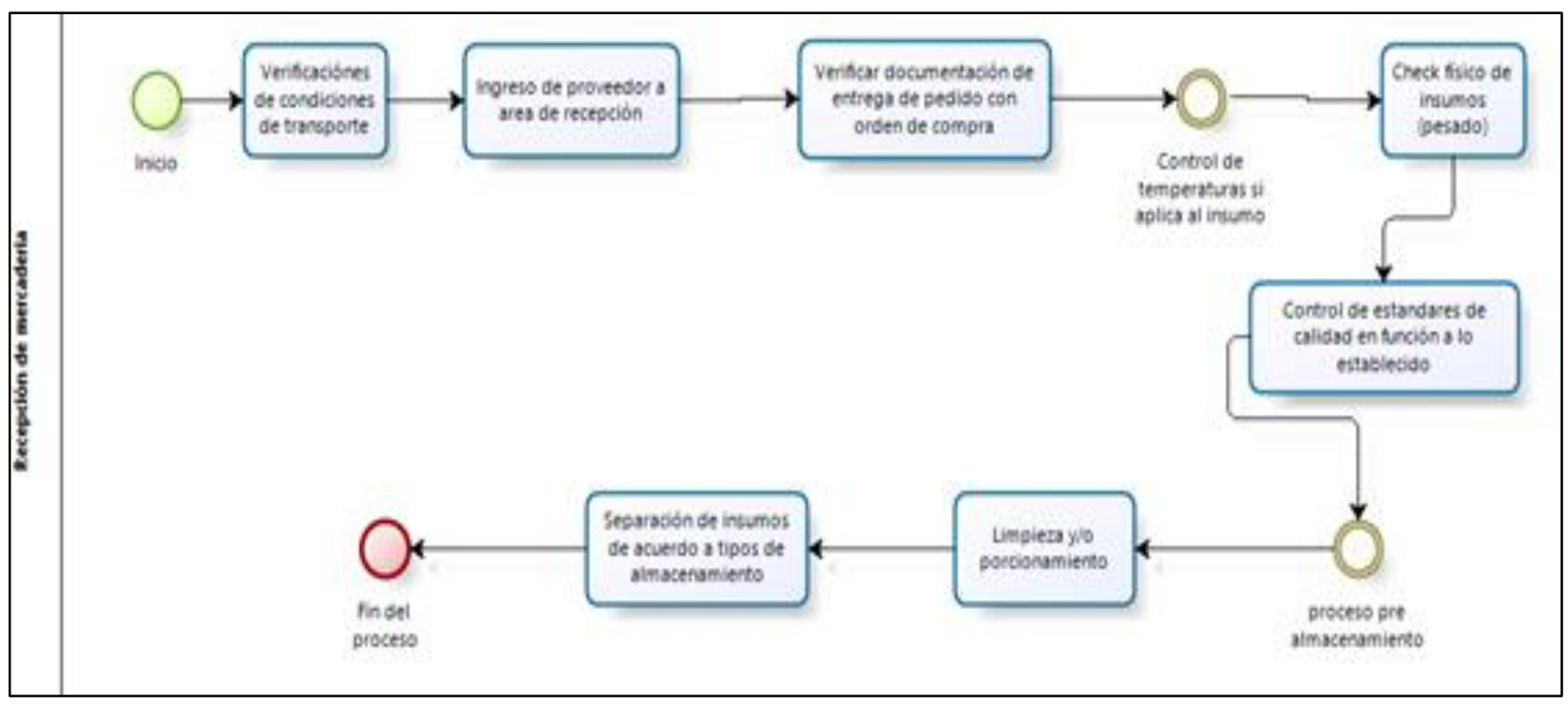

Figura 20. Flujo de Recepción de Mercadería. 
- Almacenamiento de productos perecibles

Luego que la mercadería llega al almacén, esta se separa por el tipo de insumo, y se realiza una rotulación con la fecha de ingreso. Se separan los alimentos por aquellos que requieren congelación y refrigeración. Posteriormente se registran para llevar un control de insumos. (Ver figura 21)

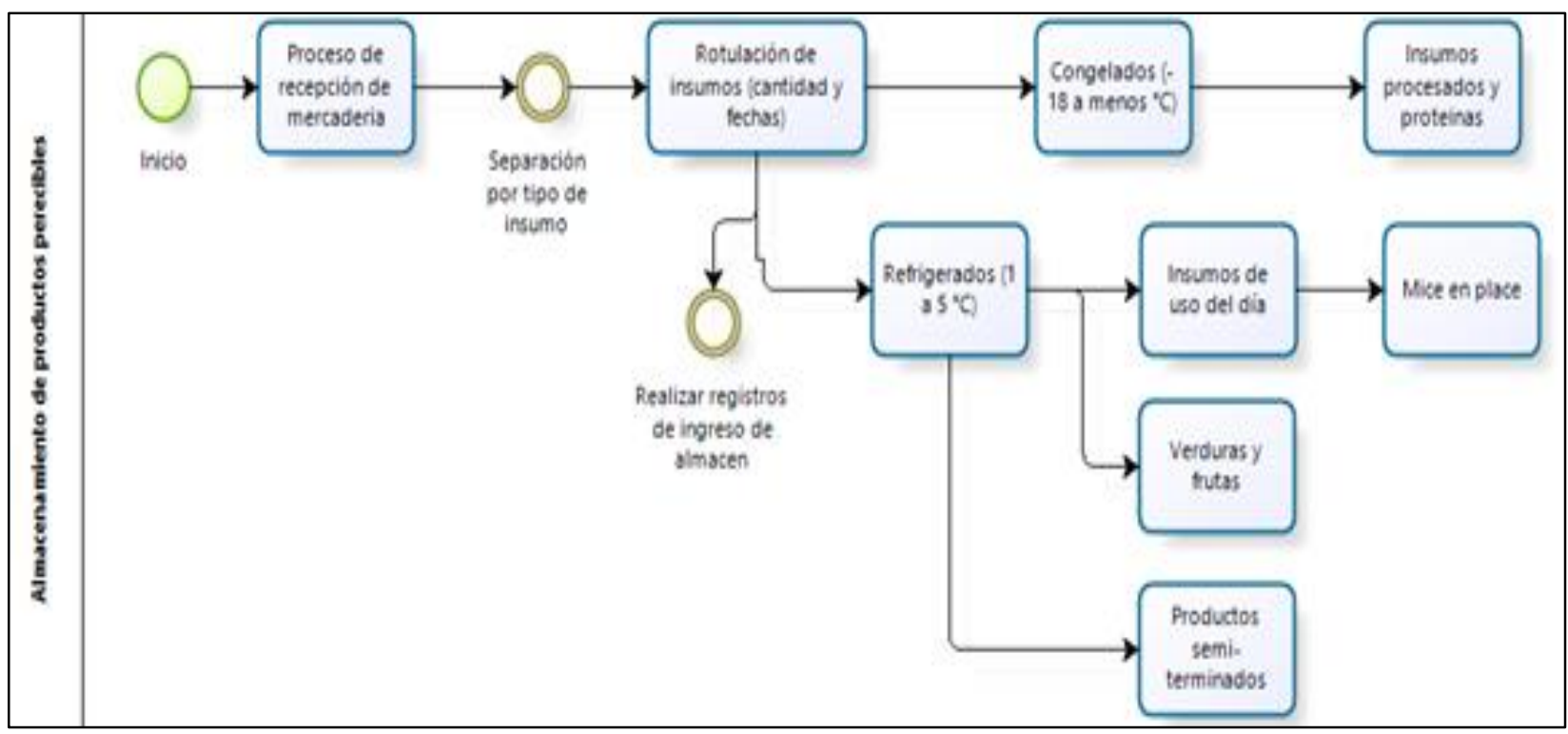

Figura 21. Flujo de Almacenamiento de productos perecibles.

- Almacenamiento de productos secos

Como se puede observar en la figura 22 , el proceso de almacenamiento de los insumos secos, es mucho más simple. Sin embargo, las BPM (Buenas Prácticas de Manufactura) se deben realizar continuamente para obtener los registros necesarios y así mantener el control de almacén. 


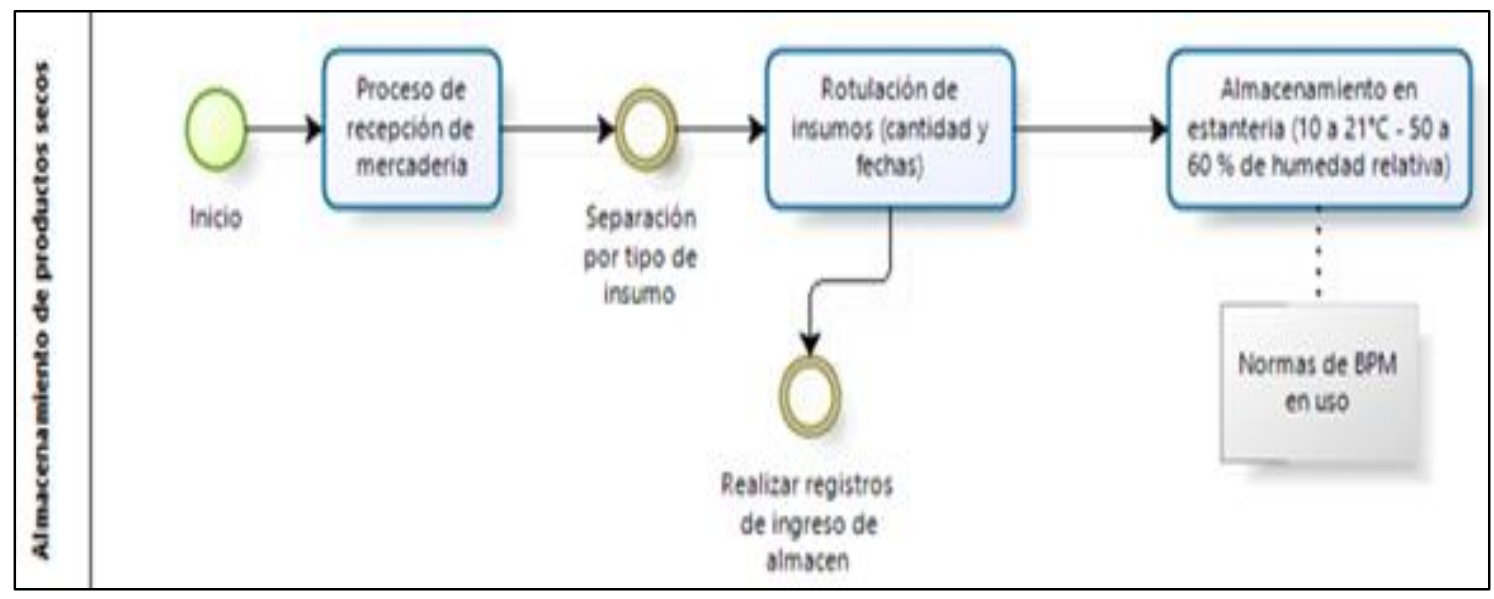

Figura 22. Flujo de Almacenamiento de Secos.

\section{- Preparación y reposición}

Las operaciones de cocina comienzan estableciendo la producción proyectada del día, de acuerdo a la necesidad del establecimiento. Se debe seguir la receta estándar de las preparaciones, y a la vez preparar el mice en place de los toppings. En el servicio, se colocan los alimentos en los contenedores de la línea de atención para realizar la correcta conservación de la temperatura. También se debe considerar el lavado de ollas y utensilios; así como la limpieza de la cocina para el cierre de turno. (Ver figura 23)

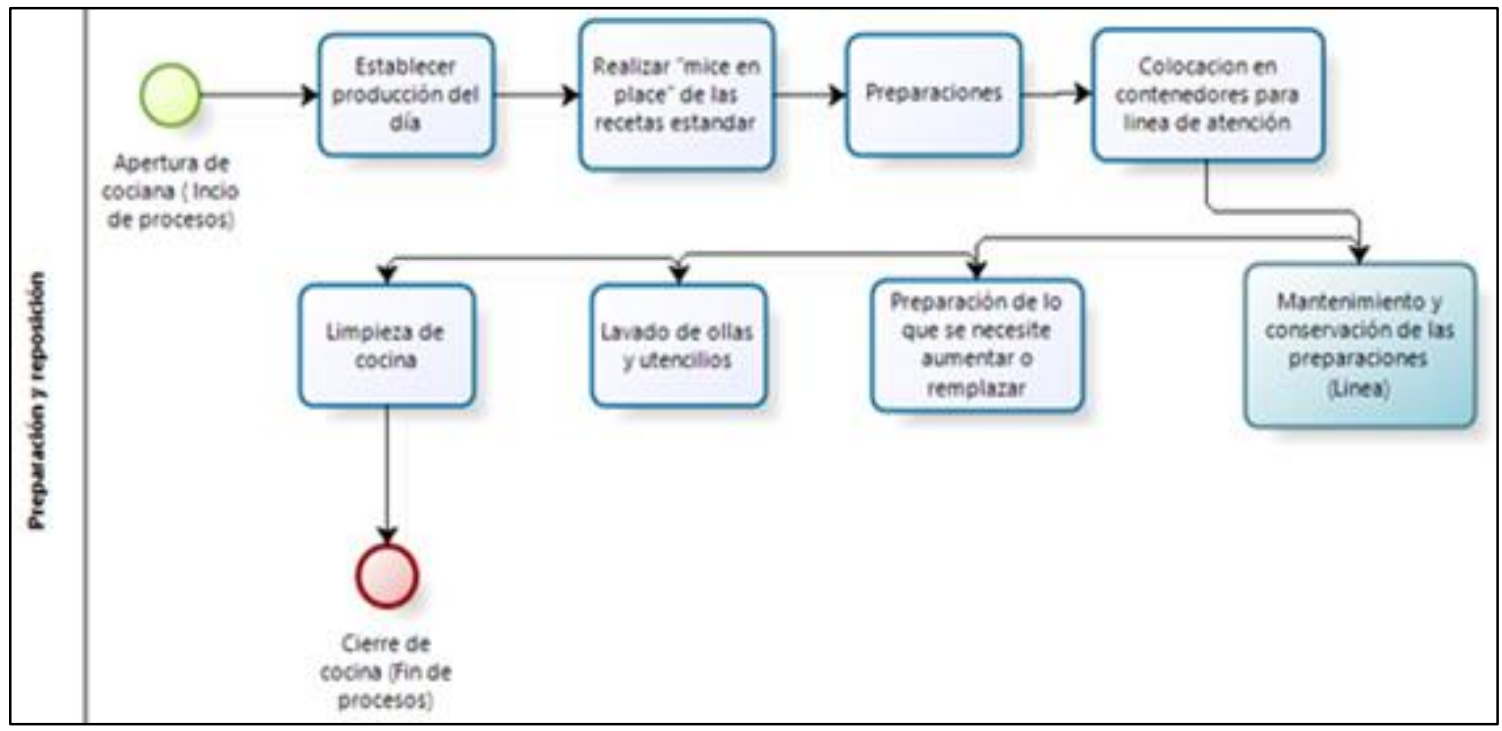

Figura 23. Flujo de Preparación y Reparación. 
- Atención al cliente

El primer contacto lo realiza el personal que saluda y explica el proceso de pedido del concepto. El cliente inicia su pedido y el personal guía al cliente a crear su pizza. Una vez creada la pizza, el personal busca vender adicionales y complementos. Finalmente, luego de los procesos de cobro, se entrega el pedido, se despide y agradece al cliente. (Ver figura 24)

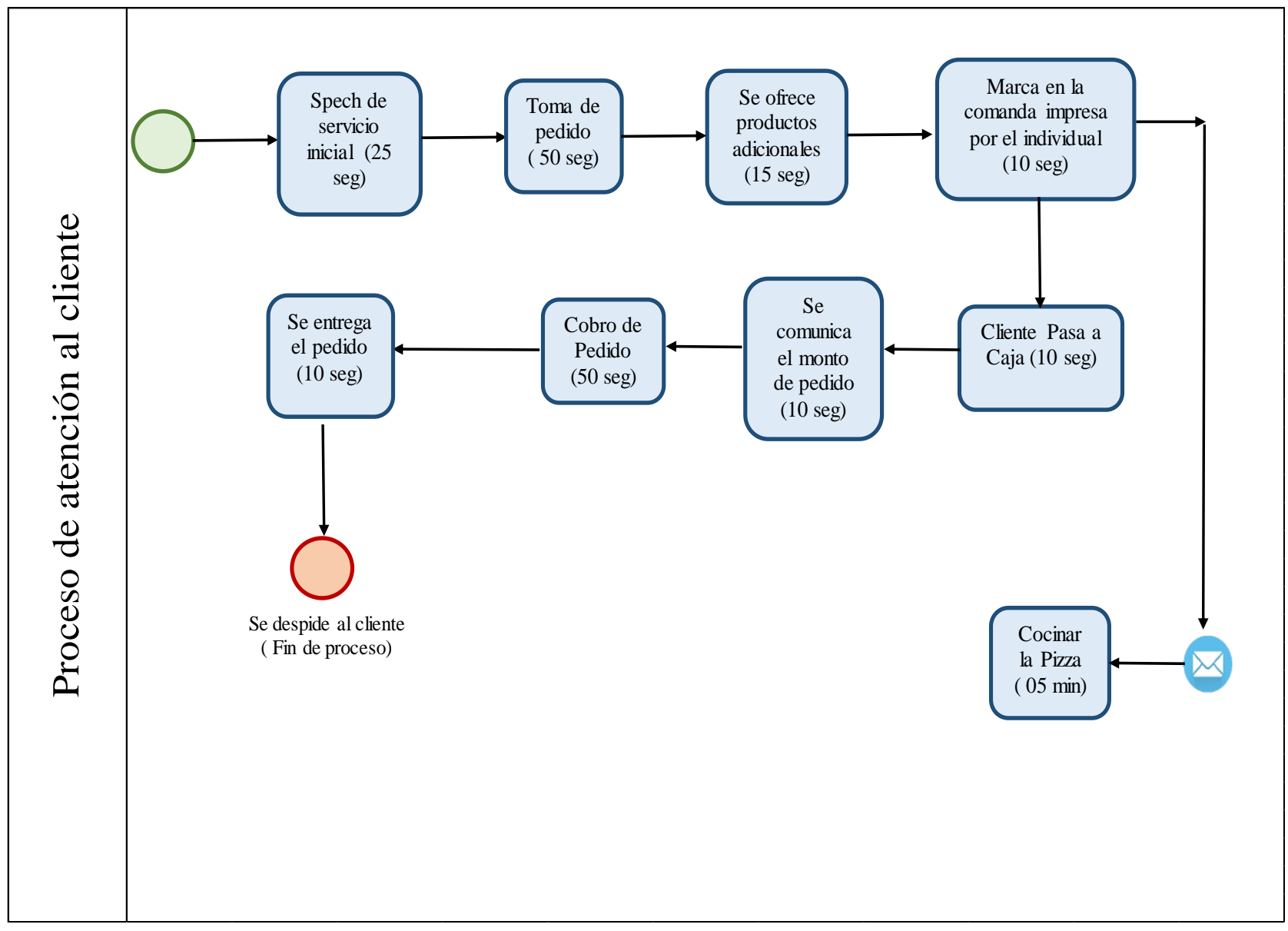

Figura 24. Flujo de Atención del Cliente.

\section{- Caja}

El proceso comienza con la apertura de la caja, en el cual se cuadra el fondo de caja, el cual debe ser el mismo al momento de liquidar o cerrar el turno. El responsable de la caja se encarga de realizar los cobros, y entregar los comprobantes de pago, ya sea boleta o factura. Al final del turno, se realiza el cuadre de caja, comparando el efectivo y voucher de pago que se tienen físicamente contra lo que indica el sistema. (Ver figura 25) 


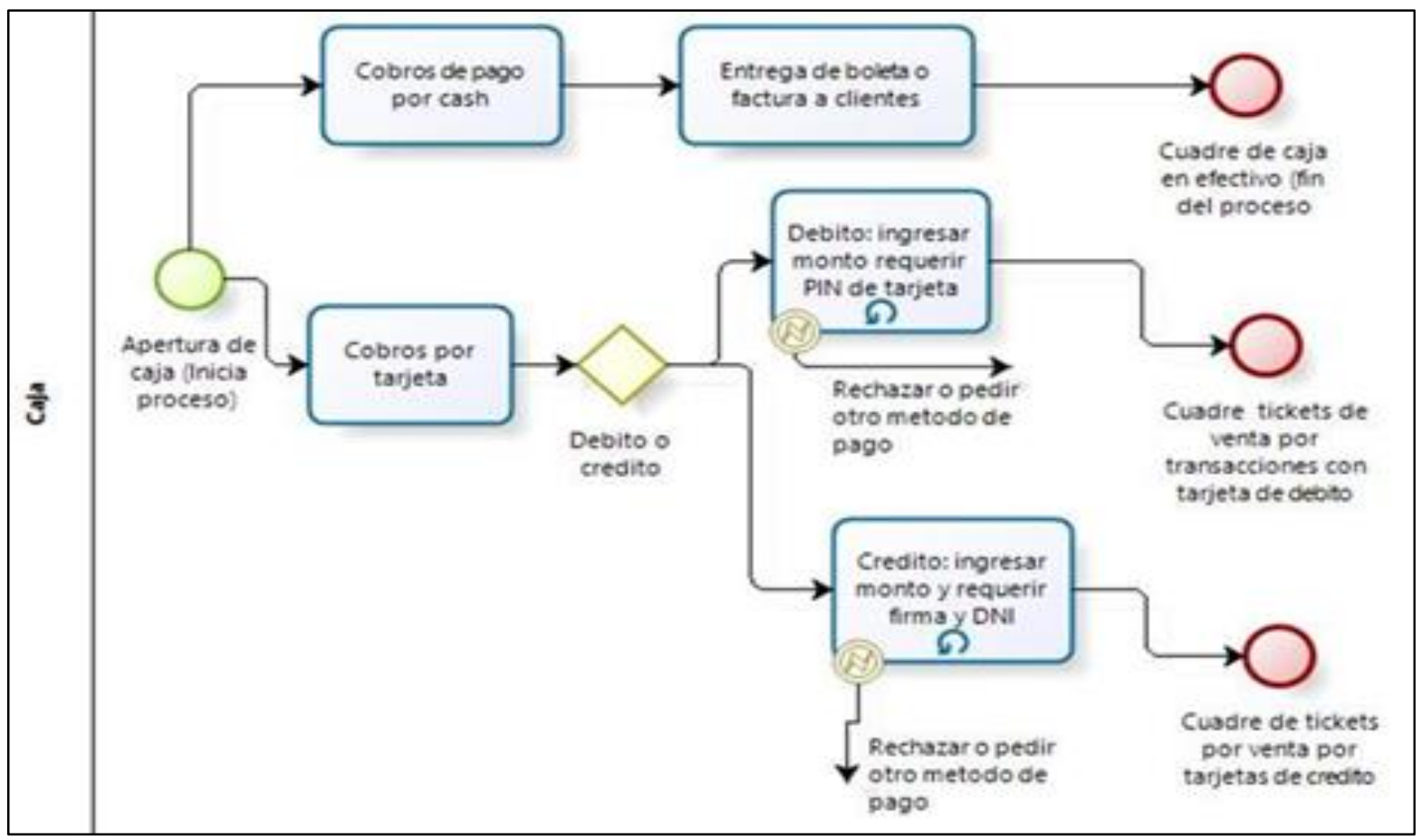

Figura 25. Flujo en la Caja.

\subsubsection{Selección del equipamiento}

En este punto se especificarán todos los equipos con los que contará el proyecto. Las proformas se pueden visualizar en el Anexo 7.

En la tabla 35, se detallan los equipos necesarios para comenzar con las operaciones del proyecto. 
Tabla 35

Equipamiento

\begin{tabular}{|c|c|c|c|c|c|c|}
\hline Equipo & \multicolumn{2}{|c|}{ Precio Unitario } & \multirow{2}{*}{$\frac{\text { Cantidad }}{6}$} & \multicolumn{2}{|c|}{ Precio Total } & Proveedor \\
\hline Salad Bar & $\mathrm{S} /$. & $3,136.00$ & & $\mathrm{~S} / \mathrm{s}$ & $18,816.00$ & Resinox \\
\hline Cocina de 2 Hornillas & $\mathrm{S} /$. & $1,555.20$ & 3 & $\mathrm{~S} / \mathrm{.}$ & $4,665.60$ & Frionox \\
\hline Horno & $\mathrm{S} / \mathrm{.}$ & $25,600.00$ & 3 & $\mathrm{~S} / \mathrm{.}$ & $76,800.00$ & Frionox \\
\hline Mesa Refrigerada de 3 Puertas & $\mathrm{S} / \mathrm{s}$ & $6,664.00$ & 3 & S/. & $19,992.00$ & Resinox \\
\hline Mesa de Trabajo dos niveles $0.65 \times 1.95$ & $\mathrm{~S} /$. & $1,744.00$ & 3 & S/. & $5,232.00$ & Siam \\
\hline Campana Extractora $1.25 \times 3.00$ & $\mathrm{~S} /$. & $5,086.40$ & 3 & $\mathrm{~S} / \mathrm{.}$ & $15,259.20$ & Frionox \\
\hline Motor Campana Extractora & $\mathrm{S} / \mathrm{.}$ & $4,448.00$ & 3 & $\mathrm{~S} / \mathrm{.}$ & $13,344.00$ & Resinox \\
\hline Mesa de Lavado de 2 Pozas & S/. & $2,012.80$ & 3 & S/. & $6,038.40$ & Frionox \\
\hline Refrigerador Vertical 1 puerta & $\mathrm{S} / \mathrm{.}$ & $4,841.60$ & 3 & $\mathrm{~S} / \mathrm{.}$ & $14,524.80$ & Frionox \\
\hline Congelador Vertical 1 puerta & $S /$. & $5,952.00$ & 3 & $S /$. & $17,856.00$ & Frionox \\
\hline Lavamanos & S/. & $1,312.00$ & 3 & $S /$. & $3,936.00$ & Resinox \\
\hline Licuadora & $\mathrm{S} / \mathrm{.}$ & $1,441.60$ & 3 & $\mathrm{~S} / \mathrm{.}$ & $4,324.80$ & Frionox \\
\hline Balanza de piso $150 \mathrm{KG}$ & $\mathrm{S} /$. & $1,836.00$ & 3 & $\mathrm{~S} / \mathrm{.}$ & $5,508.00$ & Makro \\
\hline Griferia tipo ducha & S/. & $1,373.28$ & 3 & S/. & $4,119.84$ & Isam \\
\hline All in EPSON (Pantalla y Ticketera) & $S /$. & $1,271.19$ & 3 & S/. & $3,813.56$ & Cheff 2000 \\
\hline Impresora Ticketera USB Bixolon SRP 270DUG & $\mathrm{S} /$. & 832.00 & 3 & $\mathrm{~S} / \mathrm{.}$ & $2,496.00$ & Cheff 2000 \\
\hline Trampas de Grasa & $\mathrm{S} /$. & 952.00 & 6 & S/. & $5,712.00$ & Frionox \\
\hline Carrito Portabandejas & S/. & $1,024.00$ & 3 & S/. & $3,072.00$ & Siam \\
\hline Bandejas GN 1/1 65mm & $\mathrm{S} /$. & 74.62 & 18 & $\mathrm{~S} / \mathrm{.}$ & $1,343.23$ & Food Service \\
\hline Bandejas GN 1/3 65mm & $\mathrm{S} / \mathrm{.}$ & 60.80 & 15 & S/. & 912.00 & Isam \\
\hline Bandejas GN 1/665mm & S/. & 28.32 & 24 & S/. & 679.68 & Frionox \\
\hline Olla recta $\mathrm{A} / \mathrm{I}$ fondo dif Nro. 20 (3.2 Lt) & S/. & 80.00 & 6 & S/. & 480.00 & Record \\
\hline Olla recta $\mathrm{A} / \mathrm{I}$ fondo dif Nro. 24 (5.4 Lt) & $\mathrm{S} /$. & 96.00 & 6 & $\mathrm{~S} / \mathrm{.}$ & 576.00 & Record \\
\hline Olla recta $\mathrm{A} / \mathrm{I}$ fondo dif Nro. 28 (9Lt) & $\mathrm{S} /$. & 128.00 & 6 & $\mathrm{~S} / \mathrm{.}$ & 768.00 & Record \\
\hline Parrilla de Acero Inoxidable & S/. & 153.60 & 3 & S/. & 460.80 & Food Service \\
\hline Bandeja Perforada & S/. & 94.14 & 2 & $S /$. & 188.29 & Food Service \\
\hline 24011/008 Cuchillo Century cheff Tramontina & $\mathrm{S} / \mathrm{.}$ & 88.42 & 9 & S/. & 795.81 & Multicosas \\
\hline 24011/004 Cuchillo Century oficio Tramontina & $\mathrm{S} /$. & 39.06 & 9 & $\mathrm{~S} / \mathrm{.}$ & 351.54 & Multicosas \\
\hline Tablas $60 \times 40$ color & $\mathrm{S} / \mathrm{.}$ & 64.00 & 12 & S/. & 768.00 & Multicosas \\
\hline Bolo ace Inox \#16 cm profes vinod & $\mathrm{S} /$. & 6.47 & 12 & $\mathrm{~S} / \mathrm{.}$ & 77.59 & Multicosas \\
\hline Bolo ace Inox \#20 cm profes vinod & $\mathrm{S} / \mathrm{.}$ & 10.12 & 15 & $\mathrm{~S} / \mathrm{.}$ & 151.75 & Multicosas \\
\hline Pallet Multiuso & S/. & 683.99 & 3 & S/. & $2,051.96$ & Multicosas \\
\hline Jabas de $18 \mathrm{~kg}$ & S/. & 31.45 & 12 & $S /$. & 377.40 & Multicosas \\
\hline Piso Antideslizante & S/. & 249.95 & 9 & S/. & $2,249.57$ & Multicosas \\
\hline Termometro & $\mathrm{S} /$. & 79.69 & 3 & $\mathrm{~S} / \mathrm{.}$ & 239.08 & Multicosas \\
\hline Cucharon de 20onz de Acero Inoxidable & $\mathrm{S} / \mathrm{.}$ & 36.73 & 6 & $\mathrm{~S} / \mathrm{.}$ & 220.37 & Multicosas \\
\hline Cucharon de 40 onz de Acero Inoxidable & $\mathrm{S} / \mathrm{.}$ & 42.34 & 6 & S/. & 254.02 & Multicosas \\
\hline Mandolina & $\mathrm{S} / \mathrm{.}$ & 307.90 & 3 & S/. & 923.71 & Multicosas \\
\hline Pelador & $\mathrm{S} /$. & 11.55 & 6 & $\mathrm{~S} / \mathrm{.}$ & 69.28 & Multicosas \\
\hline Pinzas de Acero Inoxidable & S/. & 6.06 & 6 & $S /$. & 36.35 & Multicosas \\
\hline Rallador & $\mathrm{S} / \mathrm{.}$ & 12.65 & 6 & $\mathrm{~S} / \mathrm{.}$ & 75.88 & Multicosas \\
\hline Bolo ace inox \#24 cm profes KB-400VINOD & $\mathrm{S} / \mathrm{.}$ & 12.17 & 15 & $\mathrm{~S} / \mathrm{.}$ & 182.60 & Multicosas \\
\hline Bolo ace inox \#26 cm profes KB-500VINOD & $\mathrm{S} / \mathrm{.}$ & 16.58 & 15 & $\mathrm{~S} / \mathrm{.}$ & 248.74 & Multicosas \\
\hline GUANTES PARA HORNEAR DE FELPA RESISTENTE 600"F. N 17 & $\mathrm{~S} / \mathrm{s}$ & 21.25 & 6 & S/. & 127.47 & Multicosas \\
\hline CUCHARON 12 OZ WINCO & $\mathrm{S} / \mathrm{.}$ & 16.93 & 6 & S/. & 101.61 & Multicosas \\
\hline CUCHARON 32 OZ WINCO & $\mathrm{S} / \mathrm{.}$ & 26.06 & 6 & S/. & 156.37 & Multicosas \\
\hline JARRAS MEDIDORAS POLICARBONATO $1.890 \mathrm{mI}$ WINCO & $\mathrm{S} /$. & 46.52 & 3 & S/. & 139.55 & Multicosas \\
\hline
\end{tabular}




\subsubsection{Energía y consumo del equipamiento}

La energía que se usará en este proyecto para los locales será electricidad y GLP. Es importante conocer el consumo de energía de cada equipo en el local.

\section{Electricidad}

En la tabla 36, se observa el consumo por hora de cada uno de los equipos que funcionan con electricidad.

Tabla 36

Consumo de energía eléctrica

Salad Bar

$$
\text { Equipo }
$$

Consumo por Hora (KW)

Mesa Caliente

$0.69 \mathrm{KW}$

Mesa mural refrigerada

$6.60 \mathrm{KW}$

Refrigeradora Vertical de 1 Puerta

$0.69 \mathrm{KW}$

Congelador Vertical de 1 Puerta

$0.80 \mathrm{KW}$

Licuadora Hamilton Beach

$1.60 \mathrm{KW}$

Abatidor Irinox EF 20.1

$0.60 \mathrm{KW}$

Motor de Extracción

$1.20 \mathrm{KW}$

Horno Combinado Rational

$1.80 \mathrm{KW}$

Consumo Total KW

$0.39 \mathrm{KW}$

$14.37 \mathrm{KW}$

\section{GLP}

En la tabla 37, se observa el consumo por hora de cada uno de los equipos que funcionan con GLP. 
Tabla 37

Consumo de energía de GLP

Equipo

Plancha Freidora Lisa

Cocina Isla de dos Quemadores

Horno de cúpula combinado

Consumo Total BTU
Consumo por Hora BTU

45,000 BTU

90,000 BTU

81,000 BTU

216,000 BTU

En ambos casos, la energía que se proyecta usar en cada uno de los locales es compatible con la capacidad que ofrece cada centro comercial para su correcto uso.

\subsubsection{Lay out}

El presente plan de negocios es una pizzería que presenta un diseño retro y cálido, tiene como principio básico la gama de colores amarillos y rojos, la iluminación baja y los revestimientos evocan la madera y lo rustico; es un concepto adaptable al entorno, el cual desarrolla un formato modular que se acopla a los distintos locales que cuenten con los siguientes requerimientos:

- $\quad$ Área Mínima: 80 metros cuadrados

- $\quad$ Área Máxima: 100 metros cuadrados

- $\quad$ Altura Mínima:4.40 metros

- $\quad$ Altura Máxima: 6.00 metros

- $\quad$ Frente del local mínimo: 4.8 metros

- $\quad$ Frente del local máximo: 8 metros 
- $\quad$ Profundidad del local mínima: 10 metros

- $\quad$ Profundidad del local máxima: 18.3 metros

Los locales deberán encontrarse en centros comerciales y espacios en los cuales transite el público. A la vez deberán mostrar las siguientes áreas en su diseño:

- Área de Tránsito

- Corredor Principal

- Corredores alternativos

- Área de Salón

- Área rápida de salón

- Área lenta de salón

- Estación de Masas

- Área de cocina

- Área de atención al público

- Área de preparación

- Área de Almacenamiento de toppings

- Área de Horneado

- Área de almacenamiento de productos refrigerados y congelados

- Área de almacenamiento de utensilios

- Área de Lavado

- Área de acopio de basura

A continuación se detallan las especificaciones para el desarrollo de cada área en el diseño de los locales. 


\section{- Área de Tránsito}

- Corredor Principal: Espacio destinado al tránsito principal de clientes que ingresan y salen del establecimiento, este corredor debe conectarse directamente con la puerta de ingreso y la barra de atención al público; se debe encontrar ubicado lateralmente y nunca de forma central. El ancho deberá ser 1.20 metros como mínimo y la longitud puede variar según el local, estará completamente limpio de obstáculos visuales y físicos que distraigan y/o dificulten el acceso del cliente hasta el counter de atención.

Los materiales a usar son los siguientes: piso-cemento pulido-, pared lateral (izquierda o derecha según el local) deberá estar decorada con paneles de revestimiento acústico de colores caoba, cerezo y encino, el techo deberá presentarse despejado pudiendo visualizarse el cableado propio de local. Sólo deberán presentarse luminarias colgantes que se encuentren a 2.10 metros sobre el suelo y deberán encontrarse siempre prendidas.

- Corredores Alternativos: estos corredores corresponden a todos aquellos destinados para los clientes que permanecen dentro del local para el consumo de alimentos y pueden ubicarse en las áreas lentas y rápidas del salón. Servirán exclusivamente para el tránsito de clientes, el tamaño mínimo con el deberá contar el pasillo es de 76 centímetros, pudiendo llegar a 1.20 metros para circulación de clientes.

La decoración del piso será cemento pulido, las paredes cercanas al corredor podrán quedar recubiertas de paneles o pintadas con la gama de colores predeterminada. El diseño de la iluminación será igual que en el corredor principal, presentando los mismos estándares de distancia del suelo.

\section{- Área de Salón}

- Área rápida de salón: Esta zona está dedicada para aquellos clientes que tenga un tiempo de permanencia corto en el local, está constituida por una barra larga de 
aproximadamente $65 \mathrm{~cm}$ de ancho por $450 \mathrm{~cm}$ de largo y cuenta con capacidad para 10 personas sentadas en banquillos altos. En este espacio el cliente deberá compartir la zona con otros comensales mientras consume las pizzas. El diseño pretende ser un ambiente de alta rotación de clientes.

Se encontrará cercano a la caja y al medio de local, se desmarcará por una pared medianera lateral del corredor principal con el fin de determinar la zona de esta área. Será la primera opción de asiento para los clientes que ya han sido atendidos con el fin de motivarlos al consumo rápido de alimentos y reducir el tiempo de permanencia en el local. La decoración presentará solamente iluminación correspondiente al salón de local.

- Área lenta de salón: Zona dedicada a los clientes que opten por tener un mayor tiempo de permanencia, se encuentra alejada del área de atención al público y la zona rápida de salón. Esta área presenta mesas cuadradas con tablero de melanina de 50x50 tipo Nogal y base de fierro y mesas rectangulares con tablero de melamina de 60x100 tipo Nogal y 2 Banquetas corrida de madera color pino 7.00 y 5.00 y sillas de madera tipo pino con capacidad aproximada para 46 clientes sentados en mesas de cuatro personas y mesas de dos personas. Para mejorar el aprovechamiento del espacio se han determinado asientos laterales empotrados contra la pared del local y la pared medianera que delimita el corredor principal del área lenta de salón.

Las medidas del corredor deberán contar con un mínimo de 76 cm y un máximo de un metro según la distribución del salón. El espacio entre mesa y mesa deberá ser mínimo de 45 cm para la circulación de clientes. En el espacio lateral de mesas más largo como parte del techo estará ubicado el mezzanine de almacenamiento de toppings. Cercana a la zona de salida del comedor lento de salón habrá una estación de desperdicio para el acopio de platos. 


\section{- Área de Cocina}

- Área de atención al público: Esta área se encuentra conectada directamente con el ingreso a través del corredor principal. En ella los clientes realizarán la selección del producto y cancelación del pedido a través de una línea de atención.

Está compuesta por una mesa de baño maría 2.00 metros de largo por 80 centímetros de profundidad y 90 centímetros de altura, en la que el cliente podrá visualizar a través de la vitrina, las 6 opciones de toppings en ollas de acero de 24 centímetros de diámetro y 3 opciones de masas en tabletas de 20 centímetros de diámetro.

- Área de preparación: Esta área se encuentra ubicada centralmente el horno a manera de isla, y a la vez está conformada por una mesa de trabajo de acero de doble nivel y una mesa refrigerada de 3 puertas que cuentan con las siguientes medidas 0.65 metros ancho por 1.95 metros de largo por 0.9 metros de alto. Esta zona está destinada a la realización del mise in place. Contará con iluminación fluorescente colgante y espacios de corredor de mínimo 0.7 metros entre los equipos y la isla central de trabajo.

- Área de Almacenamiento de toppings: El área de almacenamiento está conformada por un mezzanine ubicado en el salón del restaurante, el acceso será exclusivo para los empleados del local y se encontrara frente a la caja para mayor control de los insumos, está construida de acero galvanizado color negro con mínimo de ancho de 1.2 metros y a una altura máxima de 2.2 metros sobre el nivel del suelo del local. Para el almacenamiento contará con una estructura de ángulos ranurados que se encontrara a 0.15 metros desde el suelo hasta el primer panel como estándar mínimo y tienen paneles de almacenaje con 0.6 metros de profundidad, la distancia entre paneles. La altura máxima del andamio será de 2.00 metros y la longitud deberá adaptarse a las especificaciones del local. 
- Área de almacenamiento de productos refrigerados y congelados: se encontrará localizada dentro de la zona de cocina, ubicada lateralmente con respecto a la zona de preparación. Está compuesta por un refrigerador vertical 1 puerta de $0.75 \times 0.8$ x 2.08 metros, un congelador vertical de 1 puerta de $0.75 \times 0.8 \times 2.08$ metros y un abatidor de marca Irinox EF.20.1 con las siguiente dimensiones 0.79 x 0.771 x 0.870 metros. En esta área se almacenarán los productos pre elaborados con el fin de establecer una regeneración y preparación más rápida.

- Área de almacenamiento de utensilios: se encuentra dispuesta lateralmente al área de almacén de productos refrigerados y congelados a una distancia máxima de 0.6 metros del equipo de refrigeración, cuenta con un estante de acero inoxidable. La ubicación de este almacén deberá encontrarse cercana al área de preparación, regeneración y el área de lavado.

- Área de Lavado: esta zona está encargada de la limpieza de utensilios, equipos y cocina. Se encuentra ubicada de forma central en relación al área de preparación separada por una pared medianera de 0.9 metros de altura que evite la visualización directa del proceso de lavado y acopio de residuos sólidos. Para esta zona se cuenta con un lavadero de dos pozas con escurridor de $1.75 \times 0.65 \times 0.90$ metros, cada poza cuenta con el promedio estándar de 0.50x0.48x0.30 metros diseñados para el lavado de bandejas Gastronorm 1/1.

- Área de acopio de basura: se encuentra diferenciada de la cocina a través de una pared medianera ubicada en la parte lateral posterior del local. Cuenta con 0.6 metros de ancho por 0.6 metros de largo que permiten la colocación de un reservorio de plástico cerrado de 250 litros de capacidad para el acopio de la basura del local. Esta zona deberá tener un revestimiento de pintura esmaltada en el suelo y paredes para realizar una correcta limpieza y desinfección. 
A continuación se presenta la distribución de espacios del presente proyecto (Ver Figura 26 y 27). 


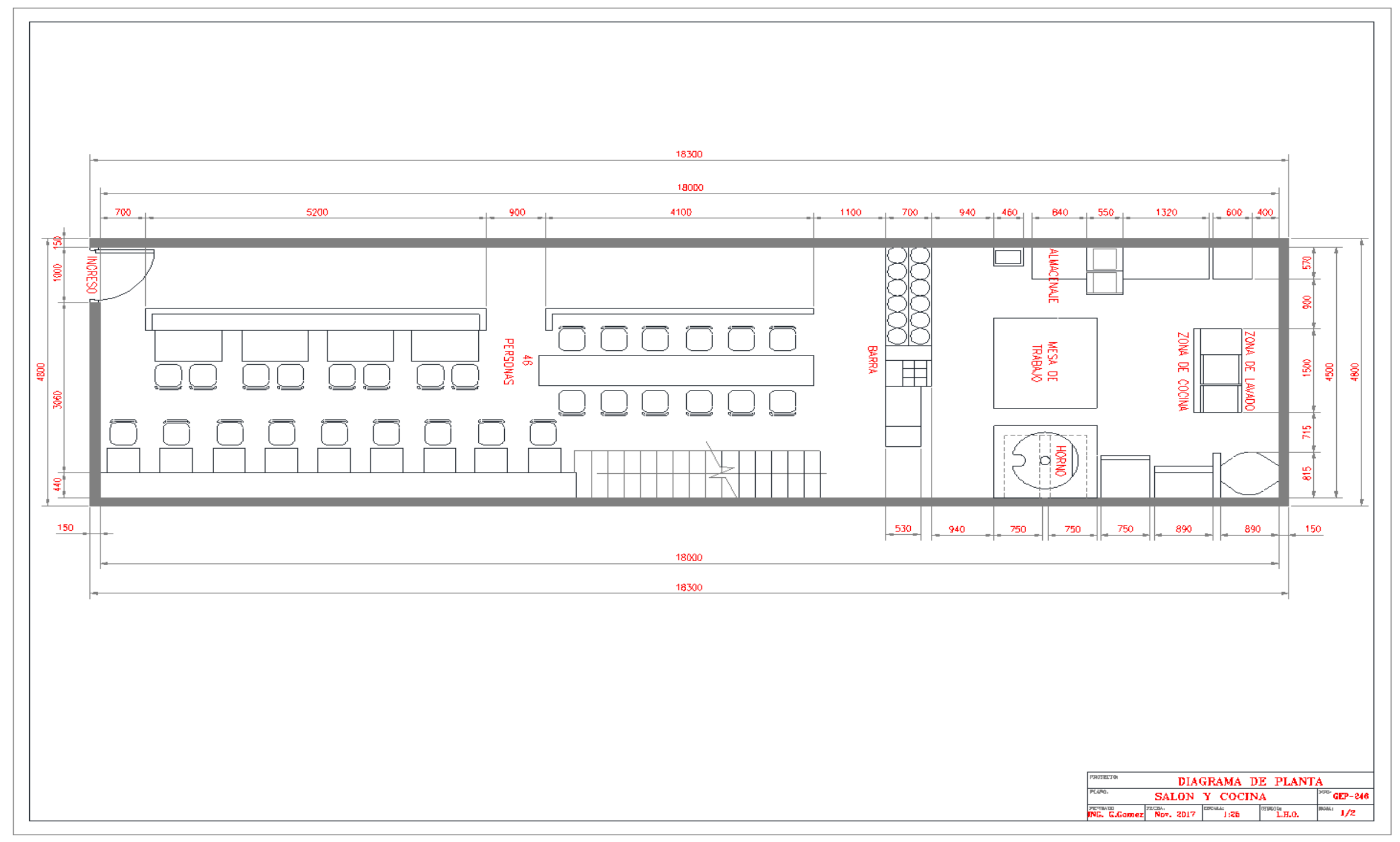

Figura 26. Lay out. 


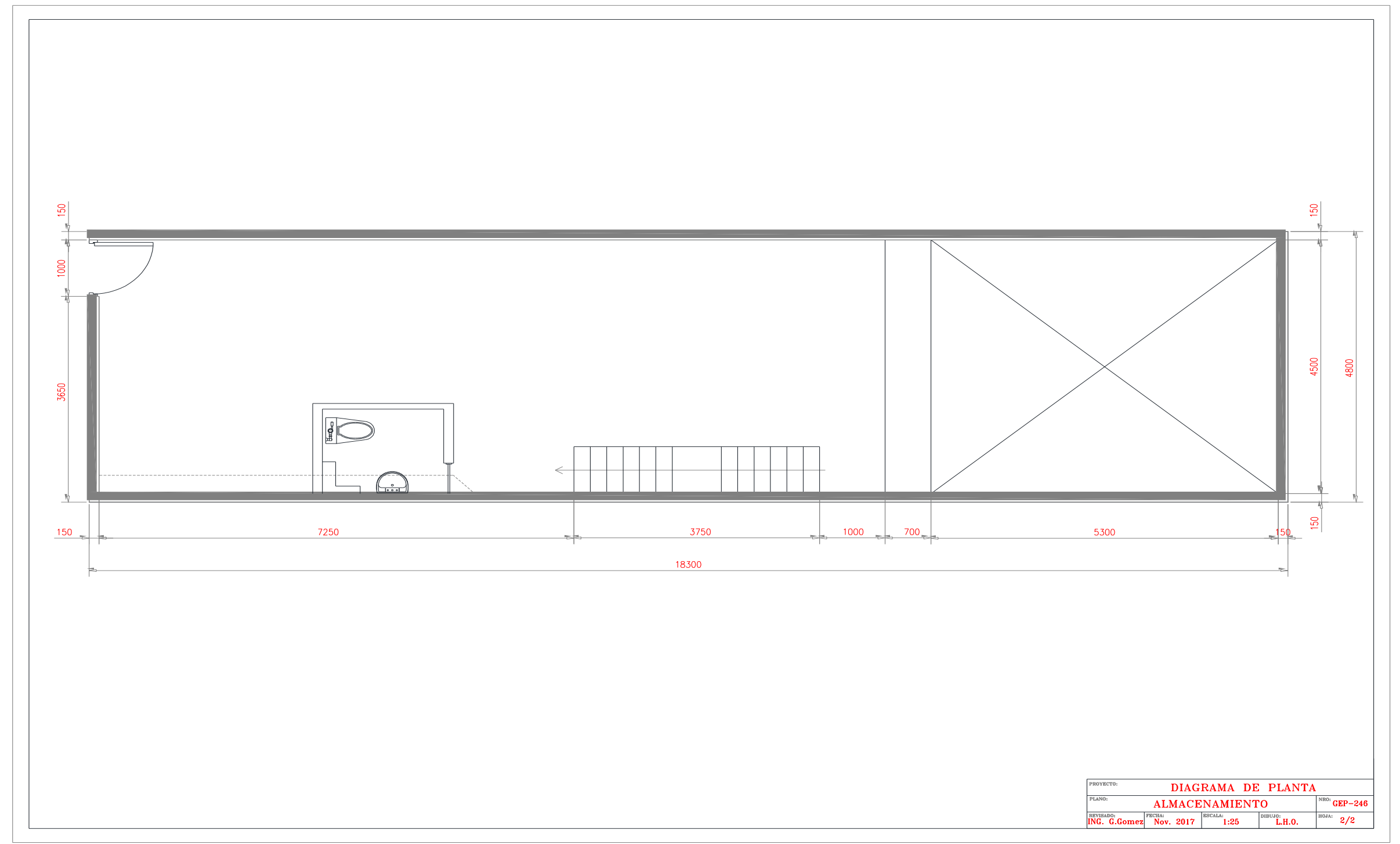

Figura 27. Lay out 


\subsubsection{Distribución de equipos y maquinarias}

Dentro del área de atención al público se encuentran la mesa de baño María de 2.00 metros de largo por 80 centímetros de profundidad, y 90 centímetros de altura. En esta se podrá visualizar todos los toppings, además de poder ver paso a paso el armado de las pizzas personalizadas. Dentro de estas se ubicarán envases de $28 \mathrm{~cm}$ de diámetro, donde se ubicarán ciertos toppings que requieren mantenimiento de temperaturas calientes.

También se ubicará un salad bar que cuenta con 80 centímetros de largo por 80 centímetros de profundidad y 90 centímetros de altura, con opciones de toppings que necesitan conservación en frío. Al final de esta línea de interacción de ubica una caja para el pago de los pedidos, además cuenta con un mueble en el cual estará ubicada la máquina dispensadora de bebidas.

En el área de preparación, que se ubica centralmente en la cocina a manera de isla está conformada por una mesa de trabajo de acero de doble nivel y una mesa refrigerada de 3 puertas que cuentan con las siguientes medidas 0.65 metros ancho por 1.95 metros de largo por 0.9 metros de alto. Esta zona está destinada a la realización de la pre-cocina.

En el área de regeneración y reposición de alimentos. Ubicada en un área lateral de la cocina, cuenta con toda la línea caliente de producción: la plancha, la campana extractora y la cocina tipo isla de dos hornillas).

El área de almacenamiento de productos refrigerados y congelados, ubicada dentro de la cocina, en uno de los laterales, está compuesta por un refrigerador vertical 1 puerta de $0.75 \times 0.8 \times 2.08$ metros, un congelador vertical de 1 puerta de $0.75 \times 0.8 \times 2.08$ metros. 
En la figura 28, se puede observar la distribución de la cocina, de manera, que se pueda entender mejor la distribución de los equipos.

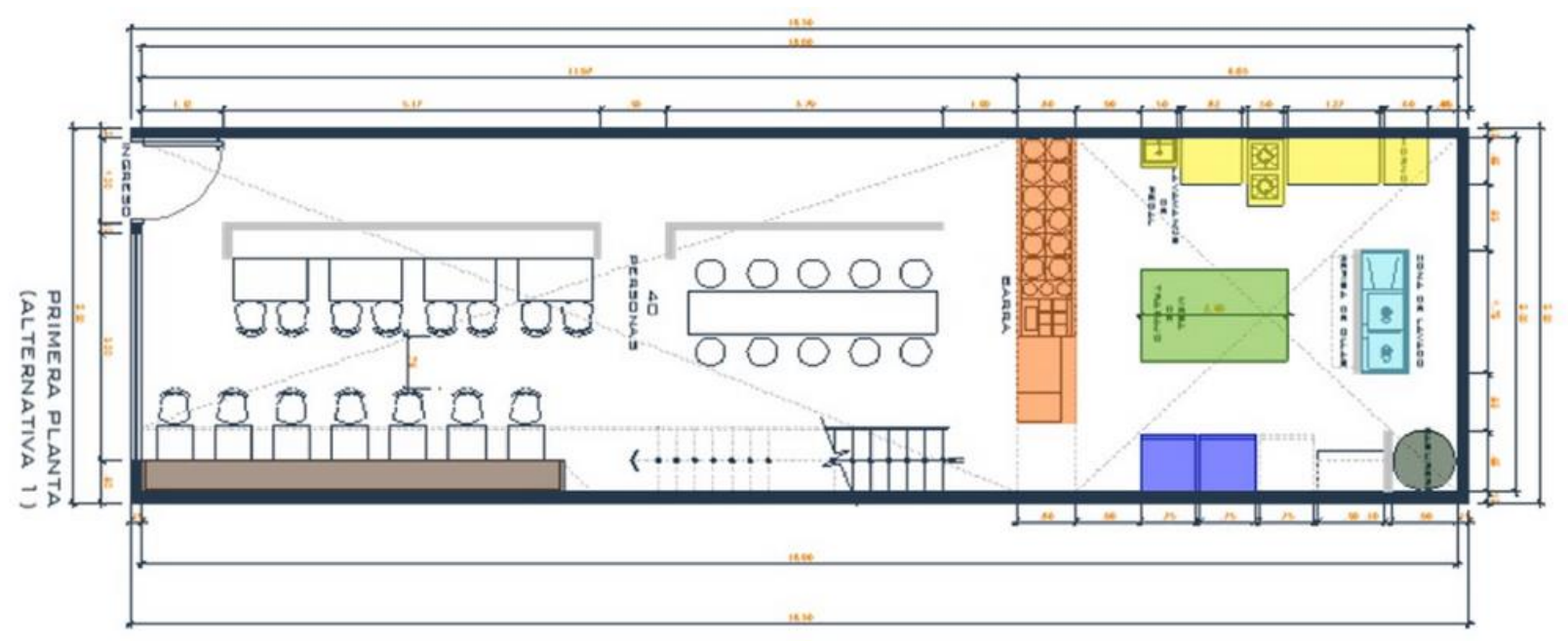

Figura 28. Áreas de cocina del local 


\subsection{Determinación del Tamaño}

\subsubsection{Proyección del crecimiento}

Se realizó la determinación del tamaño teniendo en cuenta los siguientes valores:

Tabla 38

Tamaño Óptimo de Pizza Lab

\begin{tabular}{|c|c|c|c|c|c|c|}
\hline \multicolumn{7}{|c|}{ Ventas expresadas en cantidad de pizzas } \\
\hline & $\begin{array}{c}\% \\
\text { participación }\end{array}$ & 2018 & 2019 & 2020 & 2021 & 2022 \\
\hline & & 86,852 & 94,773 & 103,390 & 112,766 & 122,968 \\
\hline Ventas anuales & $55.30 \%$ & 48,029 & 52,409 & 57,175 & 62,360 & 68,001 \\
\hline Consumo en el local & $44.70 \%$ & 38,823 & 42,364 & 46,215 & 50,406 & 54,967 \\
\hline $\mathrm{N}^{\circ}$ semanas & & 52 & 52 & 52 & 52 & 52 \\
\hline Consumo semanal & & 924 & 1008 & 1100 & 1199 & 1308 \\
\hline Lunes & $5 \%$ & 46 & 50 & 55 & 60 & 65 \\
\hline Martes & $5 \%$ & 46 & 50 & 55 & 60 & 65 \\
\hline Miércoles & $5 \%$ & 46 & 50 & 55 & 60 & 65 \\
\hline Jueves & $5 \%$ & 46 & 50 & 55 & 60 & 65 \\
\hline Viernes & $25 \%$ & 231 & 252 & 275 & 300 & 327 \\
\hline Sábado & $30 \%$ & 277 & 302 & 330 & 360 & 392 \\
\hline Domingo & $25 \%$ & 231 & 252 & 275 & 300 & 327 \\
\hline Horas pico (\%) & $67.40 \%$ & 187 & 204 & 222 & 242 & 264 \\
\hline Horas pico (hrs) & 3 & 62 & 68 & 74 & 81 & 88 \\
\hline Personas prom en mesa & 2 & 31 & 2 & 34 & 2 & 37 \\
\hline
\end{tabular}

Para realizar el cálculo de ventas anuales en unidades, se multiplicó con el porcentaje de personas que consumirían en el local, el cual dio un resultado de 55.3\% ya que según la tabla 20 donde el $44.7 \%$ de personas compra por delivery. Por consiguiente, lo que se obtuvo fue el consumo en unidades físicas en el establecimiento.

Para calcular el consumo semanal, se sabe por las entrevistas de profundidad que los días de semana la afluencia de consumidores es más baja y puede alcanzar un $10 \%$ y en caso, siendo pesimistas, se está considerando sólo a un 5\% a diferencia de los fines de semana (viernes, sábados y domingos) en donde la demanda puede alcanzar hasta el 90\%, sin embargo, solo se considerando una demanda de hasta el $80 \%$ teniendo en cuenta que los días viernes es de $25 \%$, sábado de $30 \%$ y domingo de $25 \%$. Para hallar la cantidad de pizzas vendidas por día, se multiplicó el consumo semanal por el porcentaje asignado para cada día. 
Así mismo, la mayoría de consumidores prefiere asistir en la noche a comprar el producto, por lo tanto, se toma como dato el porcentaje de $67.4 \%$ el cual fue resultado de las encuestas sobre el horario de preferencia y las horas pico que van desde las 7:00pm hasta las 10:00pm. Para hallar las horas pico en porcentaje, se hizo en base al 67.4\% y el día de más demanda, es decir el sábado. Posterior a ello, se tuvo que hallar las horas pico en cantidad de horas y por consecuencia se multiplicó las tres horas pico por el día de mayor demanda.

Se sabe además que los consumidores al menos van acompañados con una persona a cenar, es por ello se consideró a dos personas por mesa.

\subsubsection{Recursos}

\section{Insumos}

Los insumos que se utilizan para la preparación de pizzas no son estacionales, no existen inconvenientes para adquirir éstos productos como carnes y embutidos, verduras como cebolla, tomate, etc., así como los abarrotes para la preparación de masas.

\section{Cristalería y Menaje}

Para la presentación de las pizzas, se colocarán en bandejas redondas de madera con una medida de $20 \mathrm{~cm}$. Los vasos serán de vidrio, los cubiertos de acero inoxidable y los platos de un tamaño mediano y material de loza, con el fin de brindar una adecuada presentación del producto y cumplir con las exigencias del consumidor según las respuestas que brindaron en los diferentes focus group.

Los servilleteros serán de diseños elegantes que vayan acorde con la temática, no tan llamativo para que sea atractivo en un ambiente cálido. 


\subsubsection{Tecnología}

\section{Refrigerado}

Se tendrán que seleccionar los productos y envasarlas bien antes de refrigerarlos para evitar la contaminación cruzada. Los productos que tienen una vida útil menor como verduras, embutidos, abarrotes, estarán conservados a una temperatura adecuada para mantenerlos en el mejor estado y fresco.

En la congeladora, se ubicarán las carnes igual a la temperatura requerida para alargar su vida de uso.

\section{Cocción}

Para cocer la masa de las pizzas que se venderán, se debe contar con un horno que ofrezca la temperatura ideal para que esta parte del flujo no se convierta en un cuello de botella. Por ello, se considerará un horno de cúpula combinado que trabaja a gas y con carbón o leña, que es capaz de llegar a $500^{\circ} \mathrm{C}$ y cocer la pizza en un minuto; sin embargo, para darle una mejor cocción a la pizza, se trabajará con una temperatura de $300^{\circ} \mathrm{C}$ por cinco minutos. Este tipo de horno genera un calor exterior mínimo, lo cual genera un ambiente de trabajo fresco.

\subsubsection{Flexibilidad}

Las líneas de producción se van a dividir en pizzas y acompañamientos que son las bebidas.

En el futuro, se buscará que obtener mejor maquinaria para minimizar y optimizar los procesos de atención, de esa manera se podrá reducir en costos, mermas y generar mayor producción en menor venta. 


\subsubsection{Selección del tamaño ideal}

El tamaño para la localización del restaurante de pizza será de $100 \mathrm{~m} 2$, puesto que se debe considerar un espacio que cubra las necesidades de preparación en el que se debe tener toda la maquinaria e insumos así como espacio adecuado para la atención de los consumidores.

\subsection{Estudio de localización}

"El estudio de localización es importante ya que ayudará a determinar la ubicación más atractiva y ventajosa para la planta de producción o lugar de servicios para el desarrollo del proyecto" (Morales y Morales, 2009, p. 67).

El presente proyecto se encontrará ubicado en centros comerciales de Lima Metropolitana, es por ello que el estudio de localización ayudó a definir los centros comerciales óptimos para la apertura de establecimientos.

Del análisis de datos obtenidos en la investigación cuantitativa, que respondió a la pregunta de: ¿Dónde le gustaría encontrar este producto (pizzas personalizadas)? las personas encuestadas prefirieron que el establecimiento se encuentre en un local independiente dentro de un centro comercial con un $36.9 \%$. Teniendo en cuenta este tipo de zonificaciones es importante ubicar el proyecto en este tipo de establecimiento.

Para la correcta ubicación de los establecimientos, se realizaran los estudios de macro localización y micro localización.

\section{- Macro localización:}

Este aspecto permitirá identificar de manera específica donde se establecerá el local de prestación de servicios, a la vez ayudara a descartar diversos sectores geográficos que no 
cumplen con las condiciones que se requieren para el desarrollo del proyecto. (Morales y Morales, 2009)

Las alternativas elegidas para la macro localización son:

- Zona Norte:

Comprendido por ocho distritos como: Carabayllo, Ancón, Puente Piedra, San Martin de Porres, Santa Rosa, Coma, Independencia y los Olivos. En esta zona se concentran grandes centros comerciales como: Plaza Lima Norte, Mega Plaza Lima Norte y Royal Plaza, que hacen atractivo la selección de esta Zona.

\section{- Zona Sur:}

Comprendido por distritos como: Villa el Salvador. San Juan de Miraflores y Villa María del Triunfo. En esta zona se ubican centros comerciales como: Mall del Sur, Galaxy Plaza y Real Plaza donde acuden gran cantidad de personas lo cual hacen atractivo para la selección de esta zona.

\section{- Zona Centro:}

Formada por 13 distritos, entre ellos: Breña, La Victoria, Cercado de Lima, Rímac, San Luis, entre otros. En esta zona se concentran tres centros comerciales como: Real Plaza Centro Cívico, Centro Comercial La Concepción y Cyber Plaza. Lo que hace atractiva a la zona para ubicación del proyecto.

\section{- Zona Moderna:}

Conformada por doce distritos entre ellos: Barranco, La Molina, Miraflores, San Isidro, Santiago de Surco, entre otros. En esta zona se encuentran grandes comerciales como: Real Plaza Salaverry, La Rambla, Jockey Plaza, entre otros. Lo que hace atractivo a la zona para la ubicación del proyecto. 
De las zonas antes mencionadas, se puede afirmar que ofrecen muchas ventajas ya que todas cuentan y disponen de grandes e importantes centros comerciales para la ubicación e instalación del local para la pizzería, es por ello que se eligieron las zonas: Norte, Moderna y Sur. Por tanto la instalación de locales será en dichas zonas antes mencionadas.

\section{- Micro localización:}

Según Morales \& Morales (2009) la micro localización ayudará a identificar de manera específica en qué zona se ubicará las instalaciones del proyecto. A la vez indicará cuál es la mejor alternativa de instalación dentro de las zonas elegidas en la macro localización, es por ello que se dividieron los centros comerciales de las zonas Lima Norte, Lima Sur y Lima Moderna, para posteriormente establecer específicamente la localidad de emplazamiento.

Mediante la matriz de ponderación de puntos, se definirán el orden de los siguientes factores:

\subsubsection{Definición de factores locacionales}

Según Morales \& Morales (2009) para el desarrollo del proyecto y la elección de localización del lugar de servicios es necesario evaluar factores primarios como secundarios, dentro de los primarios se encuentran: mercado de consumo, fuentes de materias primas, entre otros. Y dentro de los factores secundarios se encuentran: la disponibilidad de infraestructura, mano de obra, y marco jurídico del país donde se establecerá el local.

Para sustentar la elección de los centros comerciales en los que se ubicará los locales del proyecto se ha determinado los siguientes factores con el fin de establecer si el concepto deber ser colado en distintos centros comerciales. 


\section{-Factores Cualitativos:}

- Afluencia de clientes: el flujo de personas permite determinar la cantidad de clientes potenciales que transitan en los centros comerciales. Se considera un factor importante dado la necesidad de asegurar un número sustancial de transacciones por día.

- Existencia de otros negocios que generan tráfico: la cercanía de negocios ancla en los centros comerciales es un considerado un factor importante ya que permitirán un flujo potencial de clientes.

- Seguridad: factor a tomar en cuenta ya que las distintas zonas de localización del negocio deben contar con la debida seguridad interna y externa, para los clientes y trabajadores de la empresa a fin de evitar robos o asaltos.

- Sistemas de Apoyo: otro punto a considerar es la disponibilidad y confiabilidad de los sistemas de apoyo, ya que los locales de la pizzería se encontrarán en centros comerciales, donde el cliente debe percibir la facilidad de encontrar muchos servicios en el mismo lugar, ya sea de compras, amplio estacionamiento, ascensores, servicios bancarios, diversión, entre otros.

\section{-Factores Cuantitativos}

- Costo de alquiler de local: factor que determinará el costo de alquilar un local, al seleccionar en base a los metros cuadrados disponibles según los centros comerciales principales.

- Facturación en millones de soles del centro comercial: factor que ayudará a determinar la rentabilidad que podría tener el negocio de acuerdo a la facturación de cada centro comercial. 
- Visitantes por mes del centro comercial (en millones): factor que ayudará a determinar la cantidad de clientes que podrían visitar el negocio en el mes de acuerdo al centro comercial elegido.

- Área arrendable y disponible (en miles de m2): factor que ayudará a determinar el espacio disponible de cada centro comercial para ubicación del negocio, así como también evaluar locales disponibles sin lista de espera.

A la vez con relación a la propuesta de valor que esta enfocada en la distribución por medio de venta directa en centros comerciales, se ha considerado tomar en cuenta los requerimientos para poder abrir un establecimiento dentro de un centro comercial, con el fin de establecer que puntos se tomaran cuenta para la apertura de locales en distintos centros comerciales, los pasos a seguir se muestran a continuación:

Requisitos Generales:

- Presentar Formulario Gratuito de Solicitud Declaración Jurada, consignando número de RUC debidamente llenado.

- Copia de Certificado de Seguridad en Edificaciones en Detalle, o del Informe de ITSE aprobatorio.

- Pago de la tasa correspondiente, indicar número de pago.

Requisitos específicos:

1. Certificado ITSE (Inspección Técnica de Seguridad en Edificaciones) acorde a las características del local: Este certificado verifica de manera integral el cumplimiento de la normativa en materia de seguridad en edificaciones, así como las condiciones de seguridad estructurales, no estructurales y funcionales, y del entorno inmediato que ofrecen los objetos de inspección, es realizada con la intervención de los Inspectores Técnicos de Seguridad en 
Edificaciones del Centro comercial. (Los 3 pasos para abrir un establecimiento dentro de un centro comercial en el Perú, 2017)

- ITSE Básicas Ex Post (hasta 100 m2).

2. Licencia de Funcionamiento: es la autorización que te otorga la municipalidad donde se ubica el centro comercial en el que operará el negocio. (Los 3 pasos para abrir un establecimiento dentro de un centro comercial en el Perú, 2017)

Requisitos para obtener la licencia de funcionamiento:

- Solicitud con carácter de declaración jurada que incluya número de RUC.

- Vigencia de poder del representante legal o carta poder con firma legalizada.

- Declaración jurada de observancia de condiciones de seguridad o inspección técnica de seguridad en defensa civil o multidisciplinaria, según corresponda al tamaño del local y giro del negocio.

\section{Autorización para instalación de elementos publicitarios}

- Presentar Formulario Gratuito de Solicitud-Declaración Jurada consignando número de RUC, debidamente llenado.

- Exhibir documento de identidad del representante.

- Pagar la tasa municipal correspondiente.

- Adjuntar fotomontaje del elemento de publicidad interior, que se instalará en el local, aparte de tres fotografías, una del inmueble sin anuncio, una con el fotomontaje y otra del entorno.

- Formato indicando tipo del anuncio, materiales, leyenda, colores, dimensiones y ubicación. 
- Presentar documento acreditando vigencia de poder del representante legal, en caso de personas jurídicas.

El método que se usó para definir los centros comerciales donde convendría ubicar el proyecto, fue el método de los factores ponderados por el autor Sapag (2011), que consta de definir factores cualitativos o subjetivos y factores cuantitativos u objetivos, dichos factores son importantes ya que la rentabilidad del proyecto puede verse perjudicada por algunos efectos en dichas variables. El método consta de los siguientes pasos:

- Definir los factores objetivos (FOi) y asignar un valor relativo a cada factor para cada localización en operación (Ver tabla 39 y tabla 40).

- Definir los factores subjetivos y estimar un valor relativo a cada factor (FSi) para cada localización en operación (Ver tabla 43 y tabla 44).

- Combinar los factores objetivos y subjetivos, con una ponderación relativa para así obtener la preferencia de localización (MPL) (Ver tabla 45).

- Para finalizar se selecciona la ubicación con mayor medida de preferencia.

La fórmula que se usó para calcular los valores es:

$$
F O_{t}=\frac{1 / C i}{\sum 1 / C i}
$$

A continuación se detallan los factores objetivos escogidos, los datos fueron obtenidos de informe anual del presente año de la Asociación de Centros Comerciales y de Entretenimiento del Perú. 
Tabla 39

Factores Objetivos

\section{DATOS ANUALES}

\begin{tabular}{|c|c|c|c|c|c|}
\hline Localización & $\begin{array}{l}\text { Facturación } \\
\text { (millones) }\end{array}$ & $\begin{array}{l}\text { Visitantes } \\
\text { por mes } \\
\text { (millones) }\end{array}$ & $\begin{array}{l}\text { Área } \\
\text { arrendable } \\
\text { (m2) }\end{array}$ & $\begin{array}{l}\text { Total } \\
\left(\mathrm{C}_{\mathrm{i}}\right)\end{array}$ & $\begin{array}{l}\text { Recíproco } \\
\left(1 / C_{i}\right)\end{array}$ \\
\hline Jockey Plaza & 2,046 & 2.50 & 165,026 & 169.70 & 0.00589 \\
\hline Mall de Sur & 1,500 & 6.00 & 229,187 & 238.15 & 0.00420 \\
\hline Plaza Norte & 1,500 & 6.00 & 229,187 & 238.15 & 0.00420 \\
\hline Plaza Lima Sur & 744 & 2.30 & 90,799 & 926.29 & 0.00108 \\
\hline
\end{tabular}

Tabla 40

Resumen de factores Objetivos Fo

\begin{tabular}{lcc}
\hline $\mathrm{FO}_{\text {Jockey }}=$ & $0.03247 / 0.09638=$ & 0.38339 \\
\hline FO $_{\text {Mall de Sur }}=$ & $0.03236 / 0.09638=$ & 0.27319 \\
\hline FO Plaza Lima Norte $=$ & $0.03115 / 0.09638=$ & 0.27319 \\
\hline FO $_{\text {Plaza Lima Sur }}=$ & $0.03115 / 0.09638=$ & 0.07024
\end{tabular}


- Factores Subjetivos:

Tabla 41

Factores Subjetivos $(F s)$

FACTORES

SUBJETIVOS

Factor $(\mathrm{j}) \quad$ Comparaciones pareadas $\quad$ Suma de $\quad$ Índice $\mathrm{W}_{\mathrm{j}}$

$\begin{array}{lllll}1 & 2 & 3 & 4 & \text { Preferencias }\end{array}$

$\begin{array}{llllll}\text { Afluencia de } & 1 & 1 & 2 & 2 / 4= & 0.50\end{array}$

Clientes

$\begin{array}{lllll}\text { Sistemas de } & 0 & 1 & 1 & 1 / 4=\end{array}$

Apoyo

\begin{tabular}{llllll}
\hline Seguridad & 0 & 1 & 1 & $1 / 4=$ & 0.25 \\
\hline Total & & & & 4 &
\end{tabular}


Tabla 42

Resumen de Factores Subjetivos

\section{FACTORES} Afluencia de Clientes

Sistemas de Apoyo

Seguridad

\section{SUBJETIVOS}

\begin{tabular}{|c|c|c|c|c|c|c|c|c|c|c|c|c|c|c|c|c|c|c|}
\hline \multirow[t]{2}{*}{ Localización } & \multicolumn{2}{|c|}{ Comp. } & \multicolumn{2}{|c|}{ Pareada } & \multirow{2}{*}{$\begin{array}{l}\text { Suma de } \\
\text { Pref. }\end{array}$} & \multirow[t]{2}{*}{$\mathrm{R}_{\mathrm{i} 1}$} & \multicolumn{4}{|c|}{ Comp. Pareada } & \multirow{2}{*}{$\begin{array}{l}\text { Suma de } \\
\text { Pref. }\end{array}$} & \multirow[t]{2}{*}{$\mathrm{R}_{\mathrm{i} 2}$} & \multicolumn{4}{|c|}{ Comp. Pareada } & \multirow{2}{*}{$\begin{array}{l}\text { Suma de } \\
\text { Pref. }\end{array}$} & \multirow[t]{2}{*}{$\mathrm{R}_{\mathrm{i} 3}$} \\
\hline & 1 & 2 & 3 & 4 & & & 1 & 2 & 3 & 4 & & & 1 & 2 & 3 & 4 & & \\
\hline Jockey Plaza & 1 & 0 & & & 1 & 0.20 & 0 & 1 & & & 1 & 0.17 & 1 & & 1 & & 2 & 0.40 \\
\hline Mall de Sur & 1 & & 0 & & 1 & 0.20 & 1 & & & 1 & 2 & 0.33 & 1 & & & 0 & 1 & 0.20 \\
\hline Plaza Norte & & 1 & 1 & & 2 & 0.40 & & 1 & & 1 & 2 & 0.33 & & & 1 & 0 & 1 & 0.20 \\
\hline Plaza Lima Sur & & 0 & & 1 & 1 & 0.20 & & 0 & 1 & & 1 & 0.17 & & 0 & 1 & & 1 & 0.20 \\
\hline Total & & & & & 5 & 1.00 & & & & & 6 & 1.00 & & & & & 5 & 1.00 \\
\hline
\end{tabular}


Tabla 43

Puntajes Relativos Factores Subjetivos

Puntaje Relativo Rij Índice

Factor $(\mathrm{j}) \quad$ Jockey Plaza $\quad$ Mall de Sur $\quad$ Plaza $\quad$ Plaza Lima $\quad W_{j}$

Norte Sur

$\begin{array}{llllll}\text { Afluencia de } & 0.20 & 0.20 & 0.40 & 0.20 & 0.50\end{array}$

Clientes

\begin{tabular}{cccccc} 
Sistemas de Apoyo & 0.17 & 0.33 & 0.33 & 0.17 & 0.25 \\
\hline Seguridad & 0.40 & 0.20 & 0.20 & 0.20 & 0.25
\end{tabular}

$$
\mathrm{FS}_{i}=\sum_{j=1}^{n}\left(\mathrm{R}_{i j} \mathrm{~W}_{j}\right)
$$

Tabla 44

Resumen de Factores Subjetivos

\begin{tabular}{lcc}
\hline FS $_{\text {Jockey Plaza }}=$ & $0.20 \times 0.50+0.17 \times 0.25+0.40 \times 0.25=$ & 0.2417 \\
\hline FS $_{\text {Mall Sur }}=$ & $0.20 \times 0.50+0.33 \times 0.25+0.20 \times 0.25=$ & 0.2333 \\
\hline FS Plaza Norte & $0.20 \times 0.50+0.17 \times 0.25+0.20 \times 0.25=$ & 0.3333 \\
\hline FS Plaza Lima Sur $=$ & $0.40 \times 0.50+0.33 \times 0.25+0.20 \times 0.25=$ & 0.1917
\end{tabular}


- Cálculo de la medida de preferencia de localización MPL

Asumiendo que los factores subjetivos son el doble de importante que los factores subjetivos:

$$
M P L=K\left(F O_{i}\right)+(1-K)(F S i)
$$

$$
\begin{aligned}
& \mathrm{MPL}=\mathrm{K}(\mathrm{FO} \mathrm{i})+(1-\mathrm{K})(\mathrm{FS} \text { i }) \\
& \mathrm{K}=2 \mathrm{x}(1-\mathrm{K}) \\
& \mathrm{K}=0.6667
\end{aligned}
$$

Tabla 45

Calculo MLP

\begin{tabular}{lcc}
\hline MLP Jockey Plaza & $(0.6667)(0.3833)+(1-0.6667)(0.2416)=$ & 0.33607139 \\
\hline MLP $_{\text {Mall del Sur }}=$ & $(0.6667)(0.2731)+(1-0.6667)(0.2333)=$ & 0.25983466 \\
\hline MLPPlaza Norte $=$ & $(0.6667)(0.2731)+(1-0.6667)(0.3333)=$ & 0.29316466 \\
\hline MLP Plaza Lima Sur $=$ & $(0.6667)(0.0702)+(1-0.6667)(0.1916)=$ & 0.11066262
\end{tabular}

\section{Selección de lugares:}

De acuerdo al método antes realizado, las alternativas elegidas para la localización del establecimiento de servicios son: C.C. Jockey Plaza con 33.6\%, C.C. Plaza Norte con $29.3 \%$ y C.C. Mall de Sur con $26 \%$ (Ver tabla 45). Entre los cuales se verá la disponibilidad de locales con las características del tamaño de la planta requerido para el presente proyecto. 


\subsubsection{Consideraciones legales}

Para la apertura y funcionamiento del presente proyecto, se deben proceder con diversos trámites administrativos y legales, que se mencionaran a continuación:

\subsubsection{Identificación del marco legal}

Dentro de los diversos tipos de sociedades, el proyecto pertenecerá a la Sociedad Anónima Cerrada. Conformada por tres personas naturales que conforman la sociedad, siendo sus aportes:

- Álvarez Meléndez Marycruz con $30 \%$ del total de acciones.

- Hurtado Lucero Vladimir con $40 \%$ del total de acciones.

- Vizcarra Hernández Andrea con 30\% del total de acciones.

La pizzería tendrá la formación de una persona jurídica. Una de las principales ventajas es que no existen límites para negociar con otras empresas, la responsabilidad de obligaciones con terceros sólo es respondida con el patrimonio de la empresa y no se incluye al patrimonio personal.

Dentro de los trámites a seguir para la conformación, están los siguientes:

- Registro de marca: En los registros de la Superintendencia Nacional de los Registros Públicos (SUNARP), se procederá a verificar el Título de reserva de Preferencia Registral. Es decir, se tendrá que registrar y reservar el nombre de la empresa y llenar un formulario. Se pagan dos conceptos, S/ 4.00 por la búsqueda del nombre y S/ 18.00 por reservar el nombre por 30 días, el trámite demora 24 horas.

- Descripción de la Actividad Económica: Se describirá la actividad a la que se dedicará la empresa y se presentará en una hoja suelta redactada y firmada por los socios. 
- Capital de la Empresa: Son los aportes de los socios en dinero (se abrirá una cuenta bancaria a nombre de la empresa) o con aportes de capital como máquinas, equipos, muebles o enseres, éstos deberán ser detallados en una declaración simple.

- Minuta de Constitución de la Empresa: se realizará en una notaría la elaboración de la minuta de constitución de la empresa en la cual el notario la transcribirá en una Escritura Pública.

- Elevación a registros públicos: El notario levantará la Escritura Pública en el Registro de Personas Jurídicas de la SUNARP. Se deberá abonar un monto de $1.08 \%$ de una UIT más el capital social.

- Inscripción de la empresa en la SUNAT: Antes de iniciar las operaciones de la empresa se deber sacar el número de 11 dígitos llamado RUC (Registro Único de Contribuyentes) en la SUNAT. El trámite es gratuito.

El presente Plan de Negocios se acogerá al Régimen General del Impuesto a la Renta, por lo cual requiere contar con libros contables, caja y bancos, registro de compras, ventas, ingresos, inventario y balances. De la misma manera, la empresa está obligada a la declaración mensual, declaración anual del Impuesto a la Renta y a efectuar las retenciones correspondientes a las rentas de cuarta, quinta categoría y aportes a la ONP.

\subsubsection{Ordenamiento jurídico de la empresa}

El tipo de sociedad seleccionada es la Sociedad Anónima Cerrada (S.A.C). Este tipo de sociedad podrá estar constituida por un máximo de 20 socios y por un mínimo de 2 socios; se constituye mediante escritura pública y se conforma mediante aportes dinerarios y no dinerarios. Se establece como persona jurídica y los socios no tienen responsabilidad sobre los pasivos de la misma. La conforman la junta de accionistas y un gerente general como estructura jurídica base. 
Para la apertura y funcionamiento de la pizzería, se deberán proceder los siguientes trámites administrativos

1. Elaboración de la minuta de constitución firmada por un abogado.

2. Elaboración de la Escritura Pública ante un Notario Público.

3. Inscripción en el registro de Personas Jurídicas, en el registro de sociedades.

4. Inscripción del Registro Único de Contribuyentes (RUC) realizada en la SUNAT.

5. Registro de trabajadores en ESSALUD mediante el programa de declaración telemática.

6. Autorización y legalización del libro de planillas en el Ministerio de Trabajo y Promoción del Empleo.

7. Legalización de libros contables ante un notario.

De los pasos antes mencionados, se desligan algunos puntos importantes para el inicio de funcionamiento, como:

- Licencias Municipales de Funcionamiento: la autorización que otorga la municipalidad con el fin de desarrollar cualquier actividad comercial como empresa. Se tiene la opción de elegir entre una licencia temporal, que tiene duración de un año o una licencia indeterminada, que será la que se obtendrá, ya que tiene una duración indefinida.

Dentro de la licencia de funcionamiento se encuentra unida a las condiciones de seguridad establecidas por INDECI (Instituto Nacional de Defensa Civil), la cual otorga un certificado de vigencia.

- Vigencia de poder del representante legal de la empresa: dentro de ellos se encuentra la Declaración Jurada de observancia de condiciones de seguridad hasta los 100 m2 de Defensa Civil., ya que local tendrá 100 m2. 
- Pago de derecho a trámite de S/. 100.00 en el año 2016 de acuerdo a lo especificado en el TUPA que es el $2.78 \%$ de una UIT que equivale a S/ 3950.00.

- Otro de los trámites administrativos a seguir es la Dirección de salud Lima Sur (DISA II LIMA SUR) ya que el presente Plan de Negocios siendo una pizzería, deberá seguir la Norma Sanitaria para el Funcionamiento de Restaurantes y Servicios Afines, Resolución Ministerial no 363-2005/MINSA. Todo ello con el fin de asegurar la calidad sanitaria de los alimentos y bebidas. Así como los requisitos sanitarios y buenas prácticas que debe cumplir la pizzería.

A la vez se considera la afectación tributaria como:

- Impuesto a la Renta

El presente Plan de Negocios se acogerá al Régimen General del Impuesto a la Renta, por lo cual requiere contar con libros contables, caja y bancos, registro de compras, ventas, ingresos, inventario y balances. De la misma manera, la empresa está obligada a la declaración mensual, declaración anual del Impuesto a la Renta y a efectuar las retenciones correspondientes a las rentas de cuarta, quinta categoría y aportes a la ONP.

- Otros Impuestos

Las actividades no estarán afectas al Impuesto Selectivo al Consumo, ya que es una empresa que no se dedica a la fabricación de bienes comerciales, y porque la adquisición de productos o insumos será del mercado local.

El desembolso y los pagos de las cuotas del préstamo bancario estarán gravados por el Impuesto a las Transacciones Financieras (ITF), la tasa vigente es de $0.005 \%$. 


\subsection{Determinación de Localización Óptima}

Según Baca (2013) "la localización óptima del proyecto es lo que ayuda en mayor medida para poder lograr la mayor tasa de rentabilidad sobre el capital, o desde el punto de vista social para obtener el costo unitario mínimo" (p.39).

Según el autor antes mencionado existe diversos métodos de localización óptima, para el presente proyecto se utilizó el método cuantitativo por puntos que consiste en asignar diversos factores cuantitativos a una serie de factores que se consideran relevantes para el proyecto, todo ello conduce a una comparación cuantitativa de los distintos sitios elegidos.

A continuación se desarrolla la matriz de localización para analizar y seleccionar la ubicación ideal de la cadena de pizzerías personalizadas en Lima Metropolitana, todos los sitios fueron elegidos ya que son centros comerciales con mayor tránsito de personas y a la vez por disponibilidad de infraestructura. (Ver Tabla 46)

Según el análisis, las mejores opciones son: el local del CC Jockey Plaza, ubicado en el distrito de Santiago de Surco con un puntaje de 6.0, el CC Mall de Sur ubicado en el distrito de San Juan de Miraflores con un puntaje de 5.30 y el CC Plaza Norte ubicado en Independencia con un puntaje de 5.10 (ver Tabla 46). 
Tabla 46

Método de Factores por Puntos

\begin{tabular}{|c|c|c|c|c|c|c|c|c|c|c|c|}
\hline \multirow[t]{2}{*}{ Factor } & \multirow[t]{2}{*}{ Peso } & \multicolumn{2}{|c|}{ Jockey Plaza } & \multicolumn{2}{|c|}{ Plaza Lima Sur } & \multicolumn{2}{|c|}{ Plaza Norte } & \multicolumn{2}{|c|}{ Mall del Sur } & \multicolumn{2}{|c|}{ Mega Plaza } \\
\hline & & Calificación & Ponderación & Calificación & Ponderación & Calificación & Ponderación & Calificación & Ponderación & Calificación & Ponderación \\
\hline $\begin{array}{l}\text { Afluencia } \\
\text { de Clientes }\end{array}$ & 0.20 & 5 & 1.00 & 4 & 0.80 & 6 & 1.20 & 5 & 1.00 & 4 & 0.80 \\
\hline $\begin{array}{l}\text { Costo de } \\
\text { Alquiler de } \\
\text { Local }\end{array}$ & 0.30 & 7 & 2.10 & 5 & 1.50 & 3 & 0.90 & 3 & 0.90 & 3 & 0.90 \\
\hline $\begin{array}{l}\text { Existencia } \\
\text { de otros } \\
\text { negocios }\end{array}$ & 0.20 & 6 & 1.20 & 5 & 1.00 & 6 & 1.20 & 7 & 1.40 & 4 & 0.80 \\
\hline Seguridad & 0.20 & 6 & 1.20 & 6 & 1.20 & 6 & 1.20 & 7 & 1.40 & 4 & 0.80 \\
\hline $\begin{array}{l}\text { Servicios de } \\
\text { Apoyo }\end{array}$ & 0.10 & 5 & 0.50 & 4 & 0.40 & 6 & 0.60 & 6 & 0.60 & 4 & 0.40 \\
\hline Total & 1.00 & & 6.00 & & 4.90 & & 5.10 & & 5.30 & & 3.70 \\
\hline
\end{tabular}

Nota. Adaptado de "Evaluación de proyectos," por Baca, G. 2013, p. 224. 


\section{Capítulo VI. Aspectos Organizacionales}

En el presente capítulo se determinaron las características de la cultura organizacional deseada como la misión, visión y principios. Así como también se diseñó la estructura organizacional, perfiles de puestos, remuneraciones, compensaciones y diversas políticas de recursos humanos con los que contará Pizza Lab.

\subsection{Caracterización de la cultura organizacional deseada}

Según Hitt, Black y Porter (2012) definieron a la cultura organizacional como el conjunto creencias, valores y conductas que los primeros miembros de una organización enfrentan al inicio (fundación) para posteriormente ser aceptadas y practicadas por todos los integrantes de la organización.

En relación al concepto anterior se puede deducir que la cultura organizacional es la manera en que actúan los integrantes de una organización y que se origina principalmente de un conjunto de creencias y valores compartidos, que son adoptados a lo largo del tiempo ya sea por la educación, experiencia o costumbres.

\subsubsection{Visión}

Según David (2013) "la declaración de visión debe responder a una pregunta fundamental: ¿En qué queremos convertirnos? Ya que una visión clara va a permitir desarrollar una misión detalla" (p.58).

Es por ello que la formulación de la visión organizacional será fundamental para el desarrollo e implementación de las principales estrategias del negocio, por lo que consta de elementos que se detallan en la tabla 47. 
Tabla 47

Elementos de la Visión

\begin{tabular}{ll}
\hline Elementos & Descripción \\
\hline Valores & Creatividad, Trabajo en Equipo, Compromiso. \\
\hline Propósito & $\begin{array}{l}\text { Lograr ser reconocidos como una de las pizzerías } \\
\text { líderes en Lima Metropolitana. }\end{array}$ \\
\hline Imagen & $\begin{array}{l}\text { Ser una pizzería innovadora logrando excelencia } \\
\text { en calidad, proporcionando a los clientes la mejor } \\
\text { experiencia. }\end{array}$ \\
\hline Recursos & $\begin{array}{l}\text { Continúa innovación y diferenciación en } \\
\text { tendencias fast food, con insumos de alta calidad. }\end{array}$
\end{tabular}

Luego de describir los elementos antes mencionados, la visión establecida para el negocio es:

“Ser la pizzería líder en vemtas en Lima Metropolitana, logrando excelencia en calidad y atención eficiente; a través de la continua innovación y diferenciación basada en tendencias más populares de fast food, proporcionando la mejor experiencia a los clientes".

\subsubsection{Misión}

David (2013) menciona que una declaración de misión es la expresión perdurable del propósito que distingue a una empresa de otras empresas similares, es decir, es la "razón de ser” de una organización, y es por ello que debe responder a la pregunta: ¿Cuál es el negocio?

La declaración de misión debe asegurar el propósito de una organización para tener una clara dirección. Para definir la misión el autor antes mencionado expone nueve componentes que se detallan a continuación en la tabla 48 . 
Tabla 48

Componentes de la Misión

\begin{tabular}{|c|c|}
\hline Componentes & Descripción \\
\hline Clientes & $\begin{array}{l}\text { Hombres y Mujeres entre } 13 \text { y } 59 \text { años de edad, de niveles } \\
\text { socioeconómicos A, B y C. }\end{array}$ \\
\hline Producto o Servicio & $\begin{array}{l}\text { Pizzas personalizadas, con diferentes ingredientes de alta } \\
\text { calidad. }\end{array}$ \\
\hline Mercados & $\begin{array}{l}\text { La pizzería está ubicada en Lima Sur, Lima Norte y Lima } \\
\text { Moderna, mediante una cadena de fast food en centros } \\
\text { comerciales, por lo que los principales competidores son las } \\
\text { grandes cadenas fast food como: Pizza Hut, Dominós Pizza, } \\
\text { Papa John's, Pizza Raúl. }\end{array}$ \\
\hline Tecnología & $\begin{array}{l}\text { Utilización de equipos de alta tecnología, para disminuir } \\
\text { tiempos de entrega de pedidos. }\end{array}$ \\
\hline $\begin{array}{l}\text { Preocupación por la } \\
\text { supervivencia, } \\
\text { crecimiento y la } \\
\text { rentabilidad }\end{array}$ & $\begin{array}{l}\text { Aprovechar las oportunidades del mercado fast food } \\
\text { buscando alcanzar una mayor tasa de crecimiento, para } \\
\text { lograr el rendimiento máximo del negocio. }\end{array}$ \\
\hline Filosofía & $\begin{array}{l}\text { Excelencia en servicio, trabajo en equipo, y compromiso } \\
\text { con clientes y trabajadores. }\end{array}$ \\
\hline Auto concepto & $\begin{array}{l}\text { La ventaja competitiva reside en la diferenciación del } \\
\text { producto mediante la personalización. }\end{array}$ \\
\hline $\begin{array}{l}\text { Preocupación por la } \\
\text { imagen pública }\end{array}$ & $\begin{array}{l}\text { La pizzería propone que el consumidor perciba un fast food } \\
\text { ecoamigable en el que puedan confiar, mediante la } \\
\text { aplicación de medidas sostenibles en sus procesos. }\end{array}$ \\
\hline $\begin{array}{l}\text { Preocupación por los } \\
\text { empleados }\end{array}$ & $\begin{array}{l}\text { Se cumplirá con las normas laborales exigidas por la ley, } \\
\text { brindando seguridad y bienestar a los empleados. }\end{array}$ \\
\hline
\end{tabular}

Nota. Adaptado de “Administración Estratégica” (14ta ed.) por David, F. 2013, p. 314.

Luego de describir los componentes antes mencionados, la misión establecida para el negocio es:

“Ofrecer a los clientes la experiencia de crear su propia pizza con los mejores y más frescos ingredientes, a través de un servicio rápido apoyados por la última tecnología. Se realiza con el compromiso hacia los empleados y consumidores." 


\subsubsection{Principios}

Bohlander, S., y Snell, S. (2013) definieron a los principios como los valores centrales de una organización, que son las creencias estables y perdurables, que refleja la forma de actuar hacia sus clientes, empleados y público en general.

Es por ello que los principios de una organización son la base para la toma de decisiones, ya que es la esencia de la cultura organizacional, ya que expresa la personalidad de todos los miembros de la organización.

Los principios establecidos para el negocio son:

- Creatividad: uno de los primordiales principios del negocio, ya que se busca continuamente la innovación mediante la creación de nuevos platos y combinaciones, a la vez buscando mejorar la forma de trabajo con el fin de lograr mejores resultados.

- Trabajo en equipo: representado por la coordinación y la integración de esfuerzos entre los miembros del equipo para lograr los mejores resultados, así mismo lograr la identificación con los objetivos, metas y las normas establecidas.

- Compromiso: el compromiso de la organización estará dirigido para los clientes internos y externos, demostrado por la vocación de servicio y ejercido por el liderazgo para dar cumplimiento a los objetivos organizacionales, respetando el medio ambiente.

- Dedicación: Aplicar todos los esfuerzos y dedicación diariamente para que los clientes estén contentos y satisfechos mediante la satisfacción de sus necesidades y requerimientos.

\subsection{Formulación de Estrategias del Negocio}

Para la determinación de estrategias del negocio se utilizó el modelo de Estrategias Competitivas Genéricas de Porter et.al (2013). Analizando el segmento de mercado con 
consumidores identificados y con gustos concretos, se pudo hacer notar que no se trata de una necesidad primaria, sino de una propuesta de valor para un determinado grupo de compradores y un específico mercado geográfico, es por ello que bajo este contexto se trata de un nicho de mercado basado en una necesidad, es por ello que usó la estrategia genérica de diferenciación (Ver Figura 29).

La estrategia de diferenciación se basa en el producto y servicio ofrecido, creando algo que en toda la industria se percibe como único.

Pizza Lab se basa en la estrategia de diferenciación, ya que ofrece una nueva alternativa para el segmento de mercado ya definido. Todo ello mediante la personalización de pizzas, con diversos ingredientes tanto tradicionales como saludables, generando que el cliente viva una experiencia gastronómica diferente a las existentes.

Bajo este enfoque Pizza Lab, deberá estar en constante innovación en nuevas tendencias fast food, así como la introducción de nuevos ingredientes de diversas especies, entre ellos ingredientes saludables, para así ofrecer nuevas pizzas y nuevas combinaciones, con el fin de generar fidelidad en los clientes a través de un producto diferenciado, para de esta manera crear una barrera de entrada para nuevos competidores.

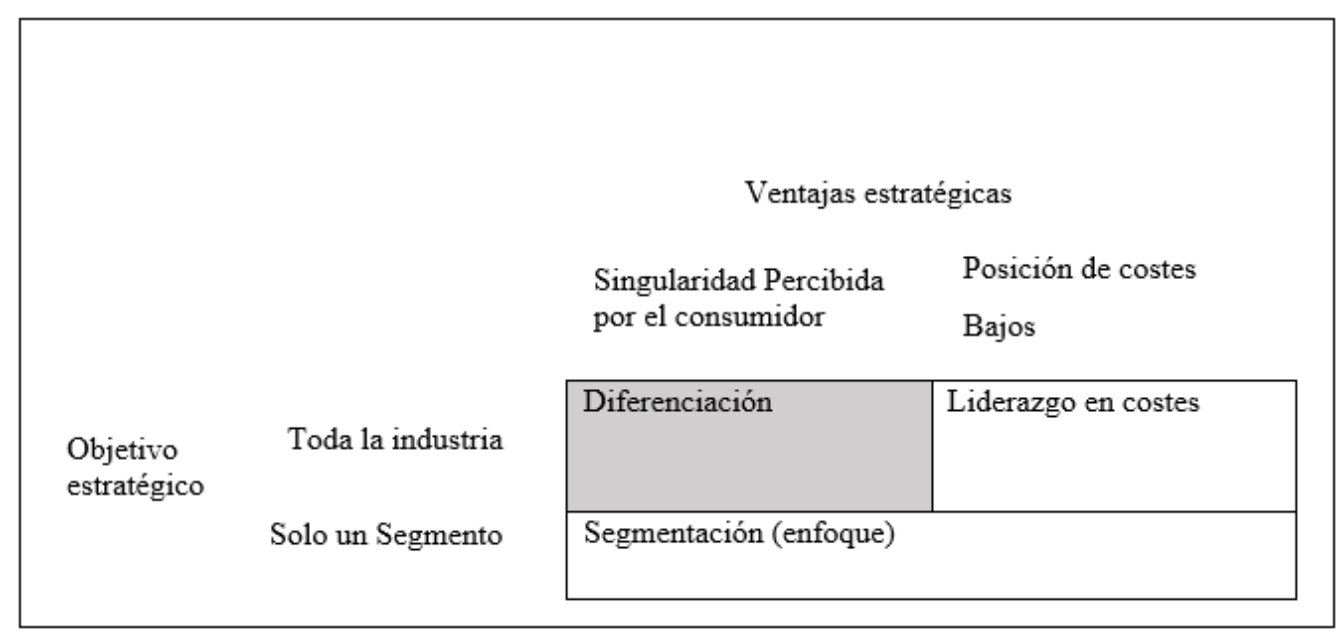

Figura 29. Tres estrategias genéricas de Porter 


\subsection{Determinación de las ventajas críticas}

Las empresas buscan alcanzar las estrategias genéricas para lograr sobresalir en el mercado, estas estrategias son liderazgo en costos, diferenciación y enfoque. Las dos primeras se basan en obtener ventajas competitivas en sector industrial y la de enfoque busca alcanzar una ventaja en costo (Porter, 2012, p. 72).

Según Hill y Jones (2009) indican que las ventajas competitivas se basan en cuatro pilares los cuales son eficiencia superior, innovación superior, calidad superior y respuesta al cliente, factores que distinguen a las empresas.

En cuanto a la eficiencia, éste factor dependerá también de la productividad de los trabajadores tanto operativo como administrativo optimizando recursos y minimizando costos. Por otro lado, los productos que se van a ofrecer son de excelente calidad en referencia a la competencia, por lo que los clientes serán quienes valorarán más éste atributo además de agregar rapidez, diseño y otras características como poder combinar diferentes ingredientes para personalizar las pizzas. Para lograr una innovación superior existe la ventaja de que el cliente es quien pueda agregar los ingredientes que prefieren, la entrega del producto será rápida puesto que se trabajará con maquinarias que estén a la vanguardia, en ambos se cuenta con innovación en producto y proceso. Finalmente, la capacidad de respuesta a los clientes es lo que generará la utilidad en la empresa, por lo que se ha previsto satisfacer sus necesidades de acuerdo al estudio de mercado que se realizó en donde se mejorará en ubicación, tiempo de espera en atención al cliente y entrega de pedidos así como excelencia en el producto.

El público objetivo es de 13 a 59 años, por lo que pueden ir entre amigos, parejas y familias. Así mismo, el personal estará capacitado para que brinden recomendaciones al momento de realizar las combinaciones por un factor que es el tipo y tiempo de preparación 
sin que ningún ingrediente se vea afectado y el resultado sea el mejor para los consumidores, logrando una diferenciación tanto en producto como frente a la competencia. Los insumos serán los tradicionales e inclusive se contará con productos light pensado para aquellos consumidores que hoy en día buscan alternativas saludables.

Para resumir el desarrollo de ventajas criticas se uso la matriz VRIO, detallada a continuación:

Tabla 49

Matriz VRIO

\begin{tabular}{|c|c|c|c|c|c|}
\hline Recurso & VALOR & RARO & INIMITABLE & ORGANIZADO & Implicancias \\
\hline Humano y Técnico & SI & $\mathrm{NO}$ & NO & SI & $\begin{array}{l}\text { El recurso humano es una ventaja que puede permanecer en el tiempo, } \\
\text { dependiendo de diferentes factores internos como inducción, }\end{array}$ \\
\hline Financiero & SI & NO & NO & SI & $\begin{array}{l}\text { Los recursos financieros aportan valor al proyecto de forma sostenida } \\
\text { sobre todo para el primer año de inversión. }\end{array}$ \\
\hline Tecnológico & SI & NO & SI & SI & $\begin{array}{l}\text { Uno de los principales factores porque aportará a la rapidez de atención } \\
\text { en cuanto al servicio y producto final. }\end{array}$ \\
\hline Producto & SI & SI & SI & SI & $\begin{array}{l}\text { El producto es importante, éste será de excelente calidad en donde los } \\
\text { clientes valorarán éste atributo. }\end{array}$ \\
\hline Personalización & SI & NO & SI & SI & $\begin{array}{l}\text { El cliente puede combinar los productos de su pizza según sus } \\
\text { preferencias. }\end{array}$ \\
\hline Ubicación & SI & NO & SI & SI & $\begin{array}{l}\text { Centros comerciales según estudio de mercado lo que aportará a la } \\
\text { marca, crecimiento y generar competencia. }\end{array}$ \\
\hline
\end{tabular}

\subsection{Diseño de la estructura organizacional deseada}

La estructura organizacional permite realizar divisiones de las áreas y el personal. En tal sentido se realiza una jerarquía según las funciones de los trabajadores designando responsabilidades a cada uno. La estructura organizacional que se usará para Pizza Lab será funcional ya que al contar con tres tiendas y al ofrecer una línea específica de producto (pizzas), dicha estructura hará posible aprovechar de manera eficiente los recursos y a la vez facilitará la supervisión de cada una de las tiendas, es por ello que se escogió una estructura simple, que se muestra a continuación en la figura 30: 


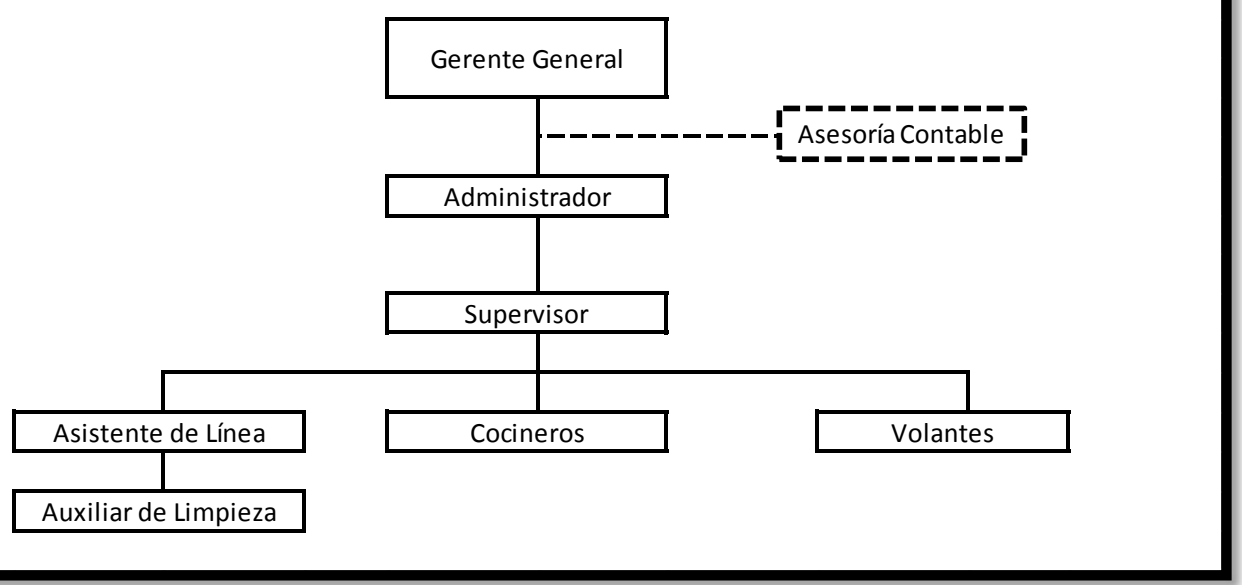

Figura 30: Organigrama

\subsection{Diseño de los Perfiles de puestos claves}

El restaurante estará a cargo de un administrador quien verificará las labores del supervisor, asistentes de línea, cocinero de producción y reposición, volante y limpieza.

Por otro lado, se tercerizará los servicios de áreas contables, legales y marketing.

Así mismo, se detallan los sueldos para aquellos puestos en donde se solicita una carrera técnica y aquellos que requieren de una carrera universitaria. (Ver anexo 9)

\section{Gerente General}

Sueldo: S/.12000

Funciones

- Dirigir, supervisar y evaluar el buen funcionamiento de los locales.

- Elaborar, supervisar y controlar los presupuestos anuales de los locales.

- Establecer políticas y estrategias para la mejora continua.

- Elaborar programas y objetivos a corto, mediano y a largo plazo.

- Proponer medidas y ajustes a sus actividades y elaborar informes para sus superiores.

- Auditar la documentación financiera.

- Representar a la Empresa en cualquier actividad pública y privada. 


\section{Administrador de Tienda}

Sueldo: S/.4500

Funciones:

- Coordinar y supervisar las tareas del personal.

- Gestionar la documentación interna del restaurante.

- Realizar indicadores de los diferentes procesos.

- Realizar las evaluaciones financieras de la Empresa.

\section{Supervisor de Tienda}

Sueldo: S/.3, 000

Funciones

- Responsable del control de los procesos.

- Verificar que los trabajadores cumplan con sus funciones, horarios, turnos y descansos.

- Asistir al cliente ante cualquier necesidad.

- Asistir al administrador en procesos administrativos.

4. Cocinero de Producción:

Sueldo: S/.1530

Funciones:

- Verificar el stock de insumos para la preparación de pizzas según la proyección del restaurante.

- Organizar los materiales, utensilios y equipos para la preparación de alimentos.

- Realizar la producción diaria garantizando los estándares de calidad.

- Verificar el buen funcionamiento y asegurarse de que los insumos se encuentren en óptimo estado. 


\section{Cocinero de Reposición:}

Sueldo: S/.1530

Funciones

- Verificar el stock de insumos para la preparación de pizzas

- Realizar la reposición de insumos según la salida de las pizzas

- Organizar los materiales y equipos para la preparación de alimentos

- Asegurar el buen estado de los ingredientes y que éstos sean almacenados correctamente.

- Mantener limpia el área de trabajo para garantizar las buenas prácticas de manipulación.

\section{Asistente de línea}

Sueldo: S/.1240

Funciones

- Cumplir con los estándares de atención al cliente

- Coordinar con los clientes sobre los métodos de pago.

- Asesorar a los clientes para la combinación de ingredientes.

- Atender a los clientes según sus requerimientos.

\section{Limpieza / Lavador}

Sueldo: S/. 930

Funciones

- Mantener limpias las áreas del restaurante.

- Asegurar el cuidado y limpieza de los utensilios y maquinaria para el uso correcto

- Cumplir con las medidas de seguridad para un trabajo eficiente 


\section{Volante}

Sueldo: S/. 1100

Funciones

- Cubrir los puestos del personal que se encuentre con descanso semanal

- Mantener las áreas limpias del restaurante

- Atender a los clientes ante cualquier requerimiento

- Apoyar a diferentes áreas según necesidad

\subsection{Remuneraciones Compensaciones e Incentivos}

De acuerdo al D.L N ${ }^{\circ} 728$ de la Ley de Fomento del Empleo, los contratos de trabajo para los colaboradores deberán indicar lo siguiente:

- Datos de la empresa (Razón social y RUC)

- Datos del representante legal (Nombres y apellidos y DNI)

- Datos del trabajador (Nombres y apellidos, DNI y dirección)

- Modalidad de contrato

- Tiempo de contrato

- Periodo de prueba (si una emisión de contrato)

- Horario de trabajo

- Sueldo

Así mismo, estos contratos deberán constar por escrito y por duplicado, para que tanto el trabajador como el empleador puedan firmarlos.

Los beneficios sociales que le corresponde por ley, son los siguientes:

- Gratificaciones (Julio y Diciembre)

- Vacaciones

- Seguro social de salud 
- Compensación por tiempo de servicio (CTS)

- $\quad$ Régimen pensionario (ONP o AFP)

- Utilidades

- Asignación familiar

- Seguro de vida ley (4to año)

A continuación, en la Tabla 50 se muestra la planilla de los trabajadores para el año 2018 y en la Tabla 51 se muestra los costos de las empresas a tercerizar:

Tabla 50

Sueldos de los Trabajadores

\begin{tabular}{|c|c|c|c|}
\hline Cargo & Cantidad & Monto Mes & Total mes \\
\hline Gerente de Marca & 1 & S/. $12,000.00$ & S/. $12,000.00$ \\
\hline Manager de Tienda & 3 & S/. $\quad 4,500.00$ & S/. $13,500.00$ \\
\hline Supervisor & 3 & S/. $\quad 3,000.00$ & S/. $\quad 9,000.00$ \\
\hline Cocinero de producción & 3 & S/. $\quad 1,530.00$ & S/. $\quad 4,590.00$ \\
\hline Cocinero de reposición & 3 & S/. $\quad 1,530.00$ & S/. $\quad 4,590.00$ \\
\hline Volante & 3 & S/. $\quad 1,100.00$ & $S / . \quad 3,300.00$ \\
\hline Lavador & 3 & 930.00 & S/. $\quad 2,790.00$ \\
\hline Asistente de Línea & 12 & S/. $\quad 1,240.00$ & S/. $14,880.00$ \\
\hline
\end{tabular}

Tabla 51

Inversión Anual en sueldos y salarios

\begin{tabular}{|c|c|c|c|c|c|c|c|}
\hline \multirow{2}{*}{$\begin{array}{c}\text { Cargo } \\
\text { Manager de Tienda }\end{array}$} & \multicolumn{2}{|c|}{ Total Mes } & \multicolumn{2}{|c|}{ Total (por 15 pagos) } & \multicolumn{2}{|c|}{$\begin{array}{l}\text { Pago a Essalud y } \\
\text { trabajador }(\mathrm{S} / .) \quad\left({ }^{*}\right)\end{array}$} & \multirow{2}{*}{$\begin{array}{c}\text { Total/año (S/.) } \\
\text { S/. 195,120.00 }\end{array}$} \\
\hline & $\mathrm{S} / \mathrm{s}$ & $12,000.00$ & $\mathrm{~S} /$. & $180,000.00$ & $\mathrm{~S} /$. & $15,120.00$ & \\
\hline Supervisor & $\mathrm{S} / \mathrm{s}$ & $3,000.00$ & S/. & $45,000.00$ & S/. & $3,780.00$ & S/. $\quad 48,780.00$ \\
\hline Cocinero de producción & S/. & $1,530.00$ & S/. & $22,950.00$ & $S /$. & $1,927.80$ & S/. $\quad 24,877.80$ \\
\hline Cocinero de reposición & S/. & $1,530.00$ & S/. & $22,950.00$ & S/. & $1,927.80$ & S/. $\quad 24,877.80$ \\
\hline Volante & $\mathrm{S} / \mathrm{.}$ & $1,100.00$ & S/. & $16,500.00$ & $\mathrm{~S} /$. & $1,386.00$ & S/. $\quad 17,886.00$ \\
\hline Lavador & $\mathrm{S} / \mathrm{.}$ & 930.00 & S/. & $13,950.00$ & $\mathrm{~S} /$. & $1,171.80$ & S/. $15,121.80$ \\
\hline Asistente de Línea & $\mathrm{S} /$. & $1,240.00$ & S/. & $18,600.00$ & S/. & $1,562.40$ & S/. $20,162.40$ \\
\hline
\end{tabular}




\subsubsection{Incentivos}

La Empresa brindará lo siguiente a los colaboradores:

1. Alimentación: Se brindará a los colaboradores el almuerzo o cena según corresponda el turno de horario.

2. Gift card por cumpleaños: para aquellos colaboradores que cumplen años se les otorgará un gift card de S/.70.

3. Trabajador del año: Se brindará un bono de S/.500 al trabajador del año, el cual se elegirá mediante una encuesta a los mismos trabajadores y en debate con los administradores de tienda y/o accionistas que estén involucrados en el proceso. El colaborador deberá tener mínimo 8 meses para ingresar a la lista de nominados.

\subsection{Política de Recursos Humanos}

El restaurante de pizzas tiene como objetivo organizar sus actividades con adecuados estándares de seguridad y eficiencia, con el fin de ser competitiva y rentable. Considerando que sus colaboradores son el capital más importante, por lo que se compromete a promover y cumplir lo siguiente:

- Cumplir y hacer cumplir la Ley de Productividad y Competitividad Laboral, aplicable a las actividades que se realizan, así como los procedimientos, normas y reglamentos establecidos por la empresa.

- Todos los colaboradores tienen las mismas oportunidades laborales, no se fomentará la discriminación por raza, religión, nacionalidad, sexo, edad, o cualquier otra causa; la cual será aplicada en el proceso de reclutamiento interno o externo.

- Proteger la salud y seguridad de los colaboradores, así como de los usuarios, visitantes y contratistas. 
- Implementar un Sistema de Seguridad y Salud en el Trabajo, basado en la prevención de riesgos y mejora continua; mediante el cual se involucra a los colaboradores en la identificación continua de los peligros y evaluación de sus riesgos, para poder tomar medidas para el control de los mismos.

- Capacitar y mejorar la participación del personal para obtener resultados e incrementar la competitividad laboral y línea de desarrollo. 


\section{Capítulo VII. Plan de Marketing}

El presente capítulo está basado en estrategias de posicionamiento, crecimiento y competencia las cuales se lograrán con la calidad del servicio al cliente y el excelente sabor de los insumos; creando así una ventaja competitiva que no tienen los fast foods del mercado, también se analizaron las cuatro P's de la mezcla de marketing, su forma de servicio y el contexto en general en el cual Pizza Lab se desarrollará. Finalmente, se establecieron los parámetros de comercialización: producto, plaza, precio y promoción, donde se detalló el grupo de productos que se comercializará, las promociones mensuales y el precio sugerido de cada producto.

\subsection{Estrategias de marketing}

La propuesta de valor es el grupo de diferentes beneficios que la empresa promete brindar a su público objetivo, por lo cual estas compañías deben ofrecer una oferta coherente cuyas características se refuercen entre sí. (Lovelock y Wirtz, 2015, p.80)

En este punto se analizarán las 4 P's de Pizza Lab, detallando estrategias de producto, distribución, precio, y promoción.

\subsubsection{Estrategia de Producto}

"El producto y servicio son el componente central que brinda los principales beneficios de solución al problema del cliente” (Lovelock y Wirtz, 2015, p.82).

\subsubsection{Producto}

El producto que ofrece Pizza Lab es una pizza de $18 \mathrm{~cm}$ (en su presentación personal) compuesta básicamente por ingredientes que el cliente elige, entre diferentes tipos de alimentos, como: el tipo de masa (tradicional o delgada), el tipo de queso (mozzarella o andino), el tipo de salsa base (marinara, salsa de tomate y salsa blanca), la proteína 
(pepperoni, carne, jamón, salchicha, tocino, pollo, chorizo, lomito ahumado y salame), y elegir de entre varios toppings (aceitunas, albahaca, alcachofa, alcaparras, arúgula, cebolla roja, cebolla blanca, champiñones, choclo, durazno, espárrago, espinaca, hongos portobello, papa, pimiento, piña, quinua, tomate, vainita y zanahoria). Además las pizzas pueden ser acompañadas con pan al ajo, o alguna bebida como: gaseosas, limonada, o chicha.

El nombre que lleva el negocio es Pizza Lab, el cual está compuesto por dos palabras: "Pizza", ya que el producto principal es la venta de pizzas; y "Lab" que significa laboratorio en inglés, esto debido a la relación que tiene un laboratorio con la creación, en este caso, de las pizzas. En la figura 31, se puede observar el logotipo que llevará el negocio.

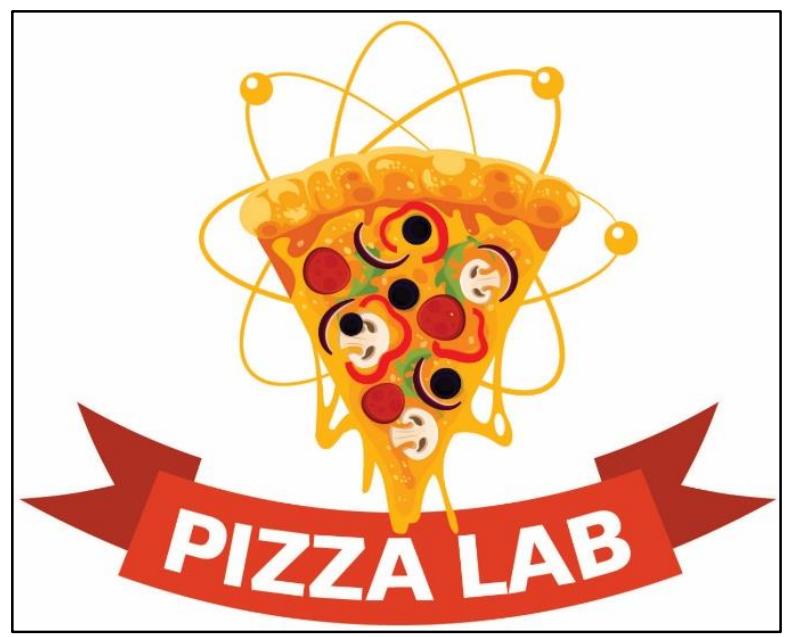

Figura 31. Logotipo

El producto busca diferenciarse, no solo por la capacidad de personalización, sino también por contar con ingredientes de alta calidad, respaldado por los procesos correctamente realizados. Por otro lado, la uniformidad que muestra el producto es una fortaleza, ya que todo será preparado bajo una receta estándar, la cual genera que el resultado de las preparaciones sea el mismo en cuestiones de textura, aroma, sabor, forma y color. Mantener los gramajes de servido en las pizzas, también es parte de la estandarización. 
Los envases que se usarán para los pedidos para llevar los alimentos y bebidas, serán proveídos por Darnel Perú S.A.C, quienes tienen stock permanente para la operación del restaurante. Se personalizarán los envases para llevar pizzas con los logos de Pizza Lab, e información de contacto. En la figura 32, se puede apreciar el envase de para pizzas de Pizza Lab.

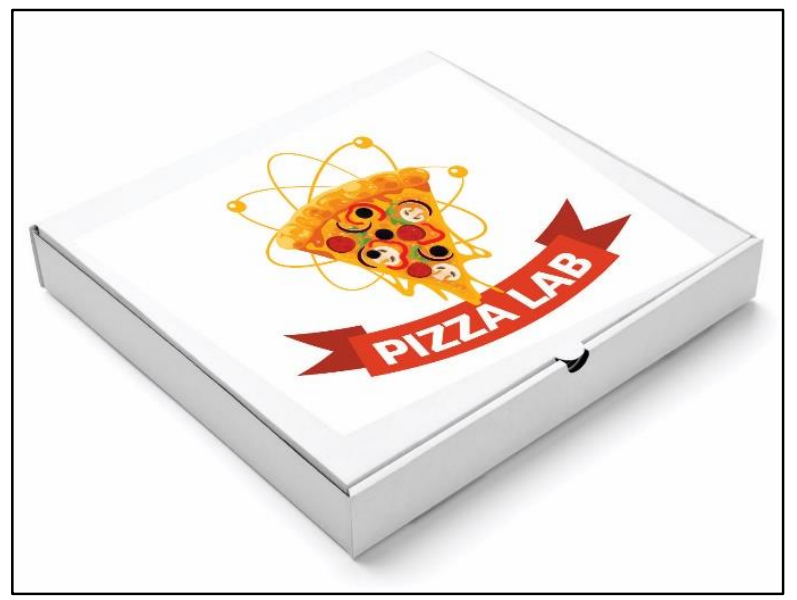

Figura 32. Envase

En cuanto a la confiabilidad del producto, el proyecto está diseñado para ofrecer un producto inocuo, es decir que no afecte a la salud del consumidor. Para lograr esto, se contará con proveedores de alimentos y bebidas que operan con certificaciones de sanidad e higiene. Además, el proyecto implementará filtros rigurosos de recepción de mercadería, control de temperaturas, BPM y correcto almacenamiento.

El producto debe lucir ordenado y apetitoso, a pesar que será el cliente quien arme la pizza eligiendo los ingredientes y cantidades, este no debe verse amontonado; por el contrario, debería tener una correcta proporción

\subsubsection{Servicio}

El servicio que propone el proyecto está organizado para que el cliente realice el pedido con toda facilidad, comenzando con el diseño del local y su distribución interna de la 
infraestructura. Se plantea que desde que el cliente inicia su pedido hasta que lo tiene listo para consumir, no deberían pasar más de 10 minutos, lo cual le dará al consumidor una opción rápida, pero a la vez de calidad y buena atención.

Para poder atender un restaurante de consumo masivo, el local debe estar preparado para atender las diferentes maneras de pago del cliente; por ello, Pizza Lab estará equipada con POS de Visa, MasteCard y Diners Club, para no perder a ningún cliente. Así como cuenta con un local, con el suficiente espacio, infraestructura cómoda y espacio necesario, para atender los pedidos de clientes que llegan al local a comer, como a los que solicitan pedidos para llevar o por delivery.

Parte del servicio, también es la atención que brinda el personal. Este debe ser correctamente seleccionado, entrenado, capacitado y motivado. Es sin duda una pieza importante para que el proyecto tenga éxito, debido a que un cliente no sólo debe quedar satisfecho con la comida, sino también bien tratado, piensa en volver pronto y recomendar.

La carta que será exhibida en el frontis de la barra de servicio, en la cual se mostrarán los tipos de pizza que se ofrecerán. Los precios están basados de acuerdo a la proteína que lleva cada pizza. Se tendrán tres diferentes precios de pizzas: las pizzas de S/ 25.00 son las que tienen de base pepperonni, jamón, salchicha, pollo o lomito ahumado; las de S/ 27.00 son las tienen base de carne, tocino, chorizo, o salame; y la pizza veggie tendrá un precio de S/ 22.00. También se mostrarán los precios de pizzas familiares, de niños y bebidas.

\subsubsection{Estrategias}

De acuerdo con Ferrel y Hartline (2012) las mejoras o revisiones de productos existentes, son aquellas que ofrecen a los usuarios un desempeño mejorado o un mayor valor percibido en ellos. En este caso, la personalización de la pizza en un lugar donde sólo puedes consumir este tipo de producto es la principal estrategia de producto. 


\subsubsection{Estrategia de Precio}

Según Ferrel y Hartline (2012), cuando se trata de comprar servicios, la gente tiene un dilema al determinar la calidad antes de realizar la compra. Por ello, la fijación de precios, es importante porque puede ser la única señal de calidad al alcance antes de adquirir un servicio.

El objetivo de la fijación de precio para el presente proyecto, es la maximización de la participación de mercado. Esto se refiere a entrar al mercado con un precio bajo-medio, con la finalidad que los clientes puedan probar el producto; a largo plazo, el incremento en el volumen de ventas permitirá bajar costos e incrementar utilidades.

La fijación de precios del producto principal del proyecto se determinó por el siguiente proceso. Lo primero que se realizó fue costear cada producto de los cinco tipos de alimentos de los cuales el cliente tendrá opción de elegir. Luego, en el caso del tipo de masa, la salsa base y el tipo de queso, se seleccionó el producto más con mayor costo de cada tipo, esto ya que el cliente es quien va a elegir la combinación, así que el costo se basa en los productos con costos más altos. En el caso de los toppings, se ha determinado un costo promedio por topping, ya que dentro de este grupo hay diferentes tipos de alimentos; se ha estimado que como máximo el cliente elegirá seis toppings, por lo cual, dentro del costeo se consideró seis veces el costo promedio de un topping. Adicionalmente, se agregaron los costos de envases y cubiertos, ya que se estima que habrá un alto porcentaje de clientes que soliciten su pedido para llevar, por delivery, o incluso para llevar lo que no pudieron terminar de comer. Todos los costos antes mencionados se consideraron fijos para cualquier tipo de pizza, lo que predomina o varía el precio es la proteína. Se agregó cada costo de proteína junto a todos los costos anteriores, dando como resultado el total del costo del plato. Para el proyecto se estimó que el porcentaje de costo de alimentos debería ser $40 \%$ en promedio, por lo tanto, en base a este se calcula el valor de venta. Finalmente a ese valor de venta se le 
agrega el IGV, que actualmente es el 18\%, para así llegar al precio de venta. Este precio de venta, se puede variar a un precio de venta real, siempre y cuando se mantenga la estructura de costos mencionada anteriormente.

Como se puede apreciar en el anexo 8: Costeo de Recetas, las pizzas personales de Pepperoni, Jamón, Salchicha, Pollo y Lomito Ahumado, tienen un precio de venta de S/. 25.00; mientras que las de Carne, Tocino, Chorizo y Salame, tienen un precio de venta de S/. 27.00. Se plasmó también la opción Veggie, que no lleva ninguna proteína, y el cliente puede llenar su pizza solo de toppings por S/. 22.00; para este caso, se costeó con un máximo de 8 opciones de toppings a elegir por el cliente.

Adicionalmente, previo a fijar los precios se realizó un benchmarking con los competidores más cercanos, identificando que los precios del proyecto se encontraban dentro del rango de intervalo entre los precios de fast foods de pizzas y los restaurantes de servicio que ofrecen pizza como una de sus opciones.

Cabe mencionar que el precio no será fijo, en el sentido que los productos solo se venderán a ese precio, ya que dependiendo a los descuentos, estos pueden verse alterados en beneficio del consumidor. Este punto se toca con mayor detalle en el tema de Promoción, que se encuentra en el presente capítulo.

\subsubsection{Estrategia de distribución}

Las respuestas al qué, cómo, cuándo y dónde, forman parte de las bases para cualquier estrategia de distribución. La experiencia de servicio y los encuentros, dependen de la forma en que se distribuyen o entregan los diferentes productos, a través de canales físicos o electrónicos (Lovelock \& Wirtz, 2015) 
El proyecto está preparado para empezar con tres establecimientos. Cada uno de estos estará ubicado en los siguientes centros comerciales: Jockey Plaza, Mall del Sur, y Plaza Norte. Estos tres locales, serán los únicos establecimientos que realizarán ventas directas.

La venta dentro del establecimiento se realizará de dos maneras, dependiendo, si el comensal entrará al establecimiento para consumir en una de las mesas, o si el cliente llegará al local para realizar un pedido para llevar. Ambos tienen el mismo proceso de venta, e incluso el mismo precio, la diferencia en el proceso, es el envase, ya que éste estará diseñado de manera diferente si es un pedido para la mesa o para llevar, pues se buscará la comodidad para ambos casos.

Por otro lado, Pizza Lab generará dos vías de distribución adicionales, las cuales son: vía aplicativo/web y vía telefónica; en ambos casos, podría ser solicitado para delivery o para recoger en tienda. La aplicación de Pizza Lab, la que podrá ser usada en móviles y ordenadores, servirá para que el cliente pueda pre-ordenar su pedido como si estuviera en tienda, realizar su combinación y saber su precio; luego de esto, pagarlo con una tarjeta de crédito o débito, y elegir entre recogerlo o pedirlo por delivery. Mientras que la venta vía telefónica, será exclusivamente para delivery; sin embargo, se intentará que esta sea mínima, ya que tomará bastante tiempo tomar una orden por el concepto que se tiene, además que se perderá la interacción e imagen visual del proyecto. Se buscará informar e incentivar a estos consumidores sobre la opción del aplicativo, con la finalidad de mejorar los tiempos operativos, y el cliente tenga una mejor experiencia.

Los canales de distribución podrían variar con el tiempo; no obstante, solo los canales mencionados se tomarán en cuenta para el presente proyecto. Fácilmente, Pizza Lab podría adaptarse a otras distribuciones, como por ejemplo: ferias gastronómicas, food trucks u ofrecer servicio para eventos corporativos o sociales. 


\subsubsection{Estrategia de promoción y publicidad}

Las empresas usan comunicaciones de marketing para atraer a clientes y mostrarles que su producto o servicio es la mejor opción con respecto a las ofertas de la competencia. (Lovelock \& Wirtz, 2015)

El presente proyecto usará diferentes tipos de comunicación comercial con diferentes propósitos para cada una de las etapas del proyecto. Estas tres etapas serán realizadas en el siguiente orden: la etapa de intriga (dos meses de duración antes de la apertura), la etapa de lanzamiento (un mes de duración desde la apertura), y la etapa de mantenimiento (desde la finalización de la etapa de lanzamiento)

\subsubsection{Etapa de Intriga}

Esta etapa se pondrá en marcha dos meses antes del lanzamiento o la apertura de los locales de Pizza Lab. El principal propósito de esta etapa es dar a conocer el concepto, que se conozca previamente el producto, y que cause expectativa en los clientes potenciales por conocer los locales y probar el producto. Para esta etapa, los medios que se usarán, serán con el uso de internet y redes sociales.

En esta etapa, Facebook se usará para dar a conocer todo sobre la marca, realizando publicaciones de interés de los consumidores potenciales, y manteniendo una constante comunicación con ellos. Este sirve también para resolver consultas y dudas, y a la vez conocer las expectativas de los usuarios. No sólo se realizarán publicaciones escritas y con imágenes, sino también se compartirán videos promocionales de la marca que serán publicados en YouTube; así como también se promocionará la página web y la aplicación para celulares inteligentes. Se contará con un Community Manager que se encargará de la realización gráfica de las publicaciones y de responder asertivamente a las consultas y comentarios de los usuarios; este encargado de las redes tendrá un sueldo mensual de S/. 
1200.00. Las publicaciones se realizarán por lo menos dos veces al día, mínimo una en hora de almuerzo y de cena. Se buscará promocionar esta página dentro de Facebook, para lo cual se realizará inversión en publicidad en esta plataforma, previa segmentación del mercado objetivo del proyecto, con la finalidad de obtener más número de likes en esta etapa y más gente pueda conocer el proyecto antes de la apertura. Habrá un presupuesto de S/ 2155.00 mensual para publicitar por Facebook.

El proyecto también planea abrir un canal de YouTube, en el cual se publicará un video de aproximadamente un minuto, que explicará de manera interactiva y explícita, el concepto de Pizza Lab. Se explicará tanto el sistema de toma de pedidos, se mostrará la evidencia física y se mostrarán las opciones de producto. Este video tendrá un presupuesto de S/ 500.00. Además, se usará este medio y a través de Google Adwords se realizará publicidad en YouTube, para que más personas puedan ver el video como parte de publicidad. Habrá un presupuesto de S/ 1643.00 para publicitar por Youtube.

A la vez, en esta etapa se lanzará la página web, que será www.pizzalabrestaurante.com, cuyo dominio está actualmente libre, por lo tanto, solo se tendrá que realizar el gasto de creación de la página web. La página web será bastante interactiva y se dividirá en secciones como: Nosotros, donde se puede encontrar información de la empresa; Historia, donde se puede apreciar la historia de Pizza Lab; Locales, muestra dónde están ubicados y cómo contactarse con ellos; Arma tu Pizza, en donde se podrá armar la pizza de manera interactiva e incluso se puede apreciar el resultado final; Videos, donde se publicará material de la empresa; y Contáctanos, donde se muestra las formas de contactar a la empresa. Entre el dominio y el diseño web, se realizará un gasto de S/ 2563.00. 
En esta etapa también se creará el aplicativo móvil, que será una aplicación gratuita, tiene la misma función de "Arma tu Pizza" de la página web. Esta aplicación se promocionará por los tres medios de comunicación antes mencionados.

En la tabla 52 se muestran los gastos de marketing pre-operativos, o de la etapa de intriga.

Tabla 52

Gastos en la etapa de intriga

\begin{tabular}{lrr}
\multicolumn{1}{c}{ Actividad } & \multicolumn{2}{c}{ Gasto } \\
\hline Publicidad y Promocion Facebook & S/. & 3,355 \\
Community Manager & S/. & 1,200 \\
Gasto en publicidad en Facebook & S/. & 2,155 \\
Publicidad y Promocion Youtube & S/. & 2,143 \\
Producción del video & S/. & 500 \\
Gasto en publicidad en Youtube & S/. & 1,643 \\
Diseño de Pagina Web y Aplicación & S/. & 2,563 \\
Dominio & S/. & 1,000 \\
Branding Sot. & 9,000 \\
Diseño de web & S/. & 1,563 \\
\hline \multicolumn{1}{c}{ Total } & S/. & 25,122
\end{tabular}

Nota. Los montos mostrados son por mes. La etapa de intriga dura dos meses

\subsubsection{Etapa de Lanzamiento}

Esta etapa empieza desde el primer día en que Pizza Lab abre sus puertas, y tiene como duración un mes. Su principal objetivo es generar por todos los medios posibles que el cliente entre al establecimiento y la vez vuelva pronto. Se caracteriza principalmente por tener diferentes promociones de venta e incluso algunos días de degustación gratuita.

Se realizará una campaña de cupones de descuento, los cuales se entregarán de dos maneras: directamente en el centro comercial y los que serán vendidos en Groupon. Estos cupones llevarán promociones especiales como: “Arma tu pizza con Pepperoni y llévate una 
bebida gratis”, “Arma tu Pizza hoy por S/. 20.00”, “2x1 en Pizzas Veggies”. Se entregarán un total de 200 cupones por día, y se entregarán cerca a los locales. Los cupones en Groupon serán 100 unidades, y se pondrán a la venta por todo el mes.

Para esta etapa, habrá gente que quizás sienta interés por acudir al local; sin embargo, siempre existe cierta intriga cuando se trata de un producto o servicio nuevo. Por ello, Pizza Lab, plantea hacer un sampling, para que estos clientes entren a probar el producto. Este se dará un día por cada semana del primer mes, y será desde la apertura, teniendo un stock limitado de 50 pizzas. Este día será entre lunes y jueves, y será en base a la proteína elegida por el restaurante. Será anunciado por Facebook para que los seguidores tengan la preferencia de adquirir la promoción. Esta inversión se verá reflejada como un gasto, dentro de los cuadros financieros.

En esta etapa las redes sociales deben mantener una constancia manteniendo informado a todos los usuarios, especialmente de las promociones de venta y todo lo que está pasando en los locales.

Junto con todo lo expuesto, la presencia de la marca y el concepto se verán reflejados dentro de cada local de Pizza Lab. Las paredes internas y externas tendrán viniles con diseños relacionados a los colores y los ventajas competitivas del concepto. La marca estará presente en diferentes puntos del servicio tanto tangible como intangiblemente. Estos gastos se ven reflejado en el acondicionamiento de local, en los gastos pre-operativos.

En la tabla 53, se muestran los gastos de marketing en la etapa de intriga lanzamiento. 
Tabla 53

Gasto en la etapa de lanzamiento

\begin{tabular}{|c|c|c|}
\hline Actividad & \multicolumn{2}{|c|}{ Gastos } \\
\hline Hosting & $\mathrm{S} /$. & 350 \\
\hline Dominio (actualización web) & $\mathrm{S} /$. & 500 \\
\hline Impresión de publicidad & $\mathrm{S} /$. & 1,620 \\
\hline Facebook y página web & $\mathrm{S} /$. & 14,400 \\
\hline Sorteos & $\mathrm{S} /$. & 1,200 \\
\hline Concursos & $\mathrm{S} /$. & 1,500 \\
\hline Cupones & $\mathrm{S} /$. & 3,600 \\
\hline Branding & $\mathrm{S} /$. & 9,000 \\
\hline Sampling & $\mathrm{S} /$. & 12,000 \\
\hline
\end{tabular}

Nota. Los gastos expresados son por el mes de la etapa de lanzamiento.

\subsubsection{Etapa de Mantenimiento}

Esta etapa tiene lugar después de la etapa de lanzamiento, es decir luego del primer mes de haber abierto los locales. Su objetivo principal es mantener a los clientes informados, ofrecer promociones de ventas, e impulsar ventas de productos. Además, se busca una mayor interacción con el comensal, ya que una vez que haya probado el concepto, incluso se le puede ofrecer descuentos o promociones a cambio de interacción con la marca.

En esta etapa, las promociones ya no llegarán fácilmente a los clientes, ya que lo que se busca es interactuar con ellos, esperando que ellos realicen algún esfuerzo primero. Se realizarán campañas promocionales como; "No todos somos iguales", en el cual el cliente debe comprar una pizza personalizada, tomarle una foto y colgarla en su biografía de Facebook, etiquetando a la cuenta de Facebook de Pizza Lab, y participar por premios; "Ven Acompañado", que sería una propuesta que en realidad es un $2 \times 1$ de pizzas, en ciertos productos, se dará una vez cada dos meses, en un día considerado de ventas bajas; "Ponle color a la vida", que consiste en asistir al establecimiento con una prenda de vestir de un 
color en específico para obtener un descuento especial; además, se planea tener promociones específicas para universitarios.

El proyecto también plantea realizar concursos y sorteos, como: "Mi Creación”, en la cual el cliente toma foto a su creación, le toma una foto y la sube a las redes sociales, poniéndole un nombre y los ingredientes que se usaron. La idea de este concurso es que el cliente muestre su creatividad para generar una buena combinación y ponerle un nombre creativo de acuerdo a los ingredientes. Se publican todas las creaciones en un álbum de fotos y se definen los ganadores mediante cantidad de likes de la gente. Los ganadores recibirán premios diversos que giran en torno al negocio.

Por supuesto, el uso de redes sociales y página web debe seguir siendo constante y poco a poco seguir aumentando el número de likes de la página de Facebook, ya que mediante esta cuenta es que se comunicarán los diversos concursos, promociones y cualquier tipo de actualización.

En la tabla 54, se muestran los gastos de marketing en la etapa de intriga lanzamiento.

Tabla 54

Gasto en la etapa de mantenimiento

\begin{tabular}{|c|c|c|}
\hline Actividad & \multicolumn{2}{|c|}{ Gastos } \\
\hline Hosting & $\mathrm{S} /$. & 350 \\
\hline Dominio (actualización web) & $\mathrm{S} /$. & 500 \\
\hline Impresión de publicidad & $\mathrm{S} /$. & 1,620 \\
\hline Facebook y página web & $\mathrm{S} /$. & 14,400 \\
\hline Sorteos & $\mathrm{S} /$. & 2,400 \\
\hline Concursos & $\mathrm{S} /$. & 3,000 \\
\hline Branding & $\mathrm{S} /$. & 5,000 \\
\hline Cupones & $\mathrm{S} /$. & 3,600 \\
\hline Total & $\mathrm{S} /$. & 30,870 \\
\hline
\end{tabular}

Nota. Los gastos expresados por cada mes de la etapa de mantenimiento. 


\subsubsection{Branding}

El Branding para este tipo de conceptos es vital, teniendo en cuenta que este tipo de establecimientos y productos son nuevos en el mercado. Lo que se busca es dar a conocer al cliente no solo el logo y la marca, sino también en concepto en sí y entrar en la mente de consumidor. Desde la etapa de intriga en adelante es importante que se realice el branding adecuado para dar a conocer la marca desde antes que comiencen las operaciones. Es por ello, que cada una de las etapas de promoción y publicidad tienen un presupuesto de branding. El objetivo principal de la estrategia de branding es mostrarlo como un laboratorio en donde los clientes pueden venir a crear su propia pizza; es la idea que se quiere vender. Se creará una identidad teniendo como pilares la diversidad, la creatividad y la atención personalizada. Posterior a esto, se debe consolidar toda esta idea en la operación del día a día, ya que de nada sirve vender una imagen, que realmente no se ofrecerá, para lo cual se debe capacitar correctamente a todo el personal. Paso siguiente, se debe marcar diferencias con la competencia, evidenciando las ventajas competitivas que tiene el negocio. Finalmente, lo que se espera es generar mayor credibilidad y prestigio; de la mano con un crecimiento en resultados.

\subsection{Estrategia de ventas}

La planificación y creación de una estrategia de ventas efectiva, requiere mirar a largo plazo las metas de ventas y análisis del ciclo de negocios, la primera etapa es la fase introductoria, seguida por las fases de crecimiento, estacionaria, maduración y de declive. (Lambin, 2009, p. 54).

A continuación se detalla cada frase:

\section{Fase introductoria.}

- Estrategia 1: Realizar un sampling, testeo de producto gratis. 
- Duración: Dos meses antes del lanzamiento.

- Objetivo: Atraer al cliente potencial a que pruebe el producto y concepto.

- Acción 1: Publicación en redes sociales que cierto día desde que se apertura el local, se estará regalando una pizza personalizada de degustación gratis.

- Acción 2: Atender a las primeras 50 personas que lleguen al local, con una pizza personalizada cuya base proteica será elegida por la empresa. Se realizará solo una vez a la semana, entre lunes y jueves, de las cuatro primeras semanas de apertura.

- Acción 3: Se realizará una encuesta de satisfacción para realizar mejoras y obtener recomendaciones.

- Estrategia 2: Ofrecer cupones de descuento a quienes transitan los centros comerciales.

- Objetivo: Captar compradores potenciales para el local.

- Acción 1: Se repartirán volantes que contienen cupones de descuento en los locales de Pizza Lab.

- Acción 2: Se buscará aumentar las ventas con estos descuentos, se procurará brindar el mejor servicio, ya que serán los primeros clientes.

\section{Fase de crecimiento.}

En esta etapa, el proyecto deberá contar con clientes que asistan con mayor frecuencia, y por consecuencia ya conocen el producto. La finalidad es que se dé el marketing boca a boca, y se influya a otros clientes por recomendación; con el objetivo de incrementar las ventas.

- Estrategia 1: Poner en marcha la campaña "No todos somos iguales"

- Duración: Un mes desde el lanzamiento. 
- Objetivo: Tener mayor interacción con los clientes.

- Acción 1: Informar por la página web y redes sociales sobre la campaña, que en este caso consiste en que el cliente debe tomarse una foto en el local con su pizza personalizada y etiquetar la página de Facebook, usando un hashtag específico.

- Acción 2: Revisar las fotos y publicarlas, cada cliente que participe en la campaña, tendrá un $20 \%$ en su próxima compra en el local.

- Estrategia 2: Lanzar el concurso "Mi Creación"

- Objetivo: Generar mayor posicionamiento en el cliente.

- Acción 1: Informar a los clientes de la promoción. Para participar, el cliente debe realizar una compra en el local, tomarle una foto a su creación y ponerle un nombre. Existe un plazo de un mes para poder participar.

- Acción 2: Publicar los participantes, y luego de una semana, establecer tres finalistas; estos se medirán por números de likes.

- Acción 3: Nombrar un ganador luego de una semana más de competencia. El ganador se ganará una tarjeta de consumo en Pizza Lab por un mes. Podrá adquirir una pizza personal al día en cualquier establecimiento de Pizza Lab.

\section{Fase estacionaria.}

Las pizzas no están dentro de una tendencia estacionaria marcada, las ventas crecen y decrecen en los meses comunes para todos los negocios. Sin embargo, en los meses más bajos, es cuando el clima competitivo se torna más agresivo. El objetivo que tiene el proyecto para estas épocas es posicionar la marca en la mente de los consumidores; creando lealtad. Se analizará los puntos más vulnerables de la competencia y se buscará fortificar el punto en el que la competencia es más débil. 


\section{Fase de madurez.}

En esta etapa lo que se busca es defenderse, y si es posible, seguir expandiéndose en el mercado. Para seguir esta estrategia, se debe prestar atención a los flancos más débiles, pues es por donde los competidores buscarán atacar. Lo ideal es realizar una evaluación cuidadosa de cualquier amenaza potencial.

En esta etapa el objetivo prioritario de la pizzería será defender y de ser posible expandir la participación de mercado, así como ganar una ventaja competitiva sustentable sobre los competidores directos.

\subsubsection{Plan de ventas}

Al abrir las tiendas de Pizza Lab, que estarán ubicadas en los centros comerciales Jockey Plaza, Lima Sur y Plaza Norte; se proyecta llegar a vender hasta el año 2022 la cantidad de S/. 15'115,670.25, desde su apertura en el año 2018. Esta proyección de ventas se realizó en el programa de ventas en el capítulo IV.

A continuación se detallan las ventas anuales en soles, de los productos que se van a ofrecer en Pizza Lab. (Ver Tabla 55)

Tabla 55

Proyección de ventas por productos

\begin{tabular}{|c|c|c|c|c|c|c|}
\hline Productos & & 2018 & 2019 & 20220 & 2021 & 2022 \\
\hline Pizza personal & $\mathrm{s} / \mathrm{s}(\mathrm{s}-\mathrm{s}$ & 1,188,697.56 s/. & $1,297,098.49 \mathrm{~S} /$ & S/. $1,415,042.85 \mathrm{~S} /$ & $1,543,361.80 \mathrm{~s} /$ & 1,682,999.38 \\
\hline Pizza familiar & $s /$. & $1,069,827.80 \mathrm{~s} /$. & $1,167,388.64 \mathrm{~S} / \mathrm{L}$ & S/. $1,273,538.56 \mathrm{~S} /$ & $1,389,025.62 \mathrm{~s} /$ & 1,514,699.44 \\
\hline Pizza niño & $s /$. & $27,380.53 \mathrm{~s} /$. & $29,877.44 \mathrm{~S} /$ & $32,594.18 \mathrm{~s} /$ & $35,549.88 \mathrm{~s} /$ & $38,766.30$ \\
\hline Bebidas & $S /$. & $515,224.95 \mathrm{~S} /$. & $562,209.87 \mathrm{~S} /$ & $613,331.27 \mathrm{~S} /$ & $668,949.39 \mathrm{~S} /$ & $729,473.42$ \\
\hline
\end{tabular}




\subsubsection{Políticas de servicios y garantías}

El proyecto establecerá sus políticas de acuerdo a la responsabilidad que ejerce al ser vendedor de alimentos y bebidas, es decir, debe cuidar de la salubridad e higiene, los procesos de control, y la relación con el cliente.

Las políticas que se implementarán son las siguientes:

- Realizar mantenimientos preventivos y correctivos a equipos de cocina, siempre que corresponda.

- Mantener las áreas internas totalmente limpias y con los parámetros que indica la ley; es decir, mantenerlas en óptimas condiciones de higiene y cuidar la cadena de frío para conservar los alimentos en su mejor estado.

- Realizar fumigaciones preventivas bimensualmente, o siempre que haya un indicio que sea necesario.

- Tener una política de lavado de manos cada media hora para todo el personal, para lo cual se les brindarán los utensilios necesarios.

- Mantener la limpieza en general de la tienda, desde las mesas desocupadas, hasta los servicios higiénicos del local.

\section{Política de compras.}

- Trabajar con los proveedores aceptados por la empresa, que cumplan con las normas de salubridad e higiene; mantener relaciones contractuales, a fin de no tener irregularidades con los precios de los productos y calidad de los mismos.

- Se deben seguir los procesos establecidos en caso se desee contratar a un nuevo proveedor tal y como se describió en el capítulo V.

- Los ingredientes deben tener las características que el proyecto requiere para lograr alimentos inocuos al ser consumidos. 
- Los proveedores, deberán llegar al local trayendo los insumos requeridos, dentro de los plazos establecidos.

\section{Políticas de ventas.}

- Los precios de venta estarán siempre al alcance del cliente, en un lugar visible dentro del local. Al momento de realizar un pedido se respetarán los precios de la carta. Sin embargo, los precios estarán afectos a cambios sin aviso, en caso ocurra algún factor que vaya contra el margen de ganancia de la empresa, como por ejemplo: un mayor costo de los insumos por desastres naturales, inflación o escasez.

- En el local también se realizarán cobros por POS, el cual no tendrá ningún cargo adicional para el cliente.

- La persona que tomará el pedido del cliente y creará la pizza a su medida, preguntará si es la primera vez que viene a consumir, de manera que le explicará detalladamente el procedimiento de compra.

- Los pedidos no deberían demorar más de 10 minutos, contando con un establecimiento a tope y embotellamiento en ciertos puntos de la cadena.

- En caso de que alguna fruta o producto esté agotado, se indicará a todos los clientes, además de verse reflejado en la carta. 


\section{Capítulo VIII. Planificación Financiera}

En el presente capítulo se realizará el análisis financiero de Pizza Lab, con la finalidad de determinar los costos e inversiones que se asumirán para llevar a cabo el proyecto, así como también los gastos administrativos y de ventas, y diferentes presupuestos. Finalmente, se presentará el estado de ganancias y pérdidas, el balance general, y flujos de proyección.

\subsection{La Inversión}

"Las inversiones de un proyecto se deben realizar antes de empezar a operar, aunque también es necesario agregar las que se necesitarán durante la operación, como para reemplazar o por aplicación de la demanda” (Sapag, 2011, p. 87).

\subsubsection{Inversión pre-operativa}

Esta inversión se dividió en dos partes: la inversión en maquinaria y equipos, y la inversión necesaria para operar antes de la apertura del proyecto (Ver tabla 56 y tabla 57). El detalle de estas inversiones se puede observar en la tabla 35.

Tabla 56

Inversión en maquinaria, equipos y acondicionamiento

\begin{tabular}{llr}
\multicolumn{1}{c}{ Descripción } & \multicolumn{2}{c}{ Monto Neto } \\
\hline Equipos y maquinaria & $\mathrm{S} /$. & 240,517 \\
Acondicionamiento & $\mathrm{S} /$. & 143,338 \\
Equipos de oficina & $\mathrm{S} /$. & 27,936 \\
\hline \multicolumn{1}{c}{ Total } & $\mathrm{S} /$. & 411,791
\end{tabular}


Tabla 57

Gastos pre-operativos

\begin{tabular}{|c|c|c|c|}
\hline Tipo de Gasto & Descripciones & \multicolumn{2}{|c|}{ Precio sin IGV } \\
\hline \multirow{5}{*}{ Constitución de la empresa } & Constitución de la empresa & $\mathrm{S} /$. & 763 \\
\hline & Gastos notariales & $\mathrm{S} /$. & 300 \\
\hline & Trámites municipales & $\mathrm{S} /$. & 1,742 \\
\hline & Libros contables & $\mathrm{S} /$. & 13 \\
\hline & Legalización de libros contables & $\mathrm{S} /$. & 153 \\
\hline \multirow{2}{*}{ Alquiler del local } & Monto de entrada Real Plaza & $\mathrm{S} /$. & - \\
\hline & Monto de entrada Jockey Plaza & $\mathrm{S} /$. & - \\
\hline \multirow{4}{*}{ Marketing Pre-operativo } & Publicidad y Promocion Facebook & $\mathrm{S} /$. & 3,355 \\
\hline & Publicidad y Promocion Youtube & $\mathrm{S} /$. & 2,143 \\
\hline & Branding & $\mathrm{S} /$. & 12,000 \\
\hline & Diseño de Pagina Web y Aplicación & $\mathrm{S} /$. & 2,563 \\
\hline \multirow{3}{*}{ Sistema operativo } & Licencia Cheff 2000 & $\mathrm{~S} /$. & 3,254 \\
\hline & Sistema por tres tienda & $\mathrm{S} /$. & 678 \\
\hline & Marcha Blanca & $\mathrm{S} /$. & 5,375 \\
\hline \multirow[t]{2}{*}{ Preparación operativa } & Capacitaciones & $\mathrm{S} /$. & 2,200 \\
\hline & Total & $\mathrm{S} /$. & 34,538 \\
\hline
\end{tabular}

\subsubsection{Inversión en capital de trabajo}

Para determinar el capital de trabajo, se revisó la estacionalidad en ventas de centros comerciales semejantes. Posteriormente se hallaron los costos y gastos que se tendrán mensualmente. Este tipo de proyectos requiere de una información más exacta en temas de gastos y costos, por lo tanto, se realizó un análisis de las primeras cuatro semanas, y con ello se llegó a la conclusión que el capital de trabajo era equivalente al costo que se necesitará para la primera semana de ventas. Como se puede observar en la tabla 58, el capital de trabajo para el primer año es de S/ 55,420.00, debido a que es lo que requiere el proyecto para comenzar sus operaciones. 
Tabla 58

Capital de trabajo

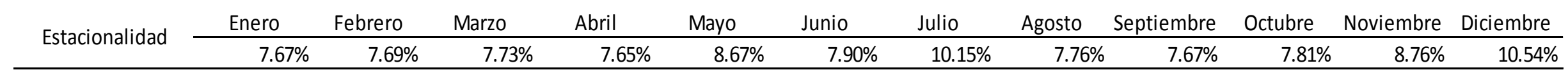

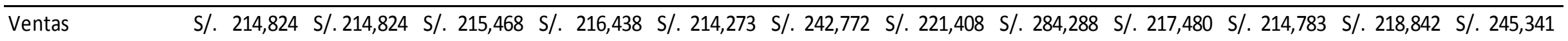

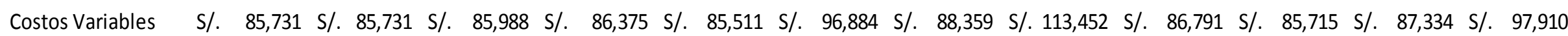
Costos Fijos S/. 125,191 S/.125,191 S/. 125,191 S/. 125,191 S/. 125,191 S/. 150,766 S/. 125,191 S/. 176,341 S/. 125,191 S/. 125,191 S/. 125,191 S/. 150,766

Total Egresos S/. 210,922 S/. 210,922 S/. 211,179 S/. 211,566 S/. 210,702 S/. 247,650 S/. 213,549 S/. 289,793 S/. 211,982 S/. $210,906 \quad$ S/. 212,525 S/. 248,676

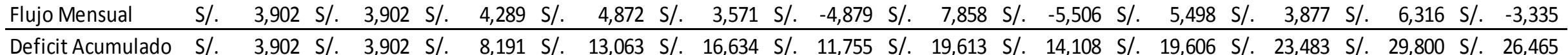

\begin{tabular}{|c|c|c|c|c|c|c|c|c|}
\hline \multirow{2}{*}{ Estacionalidad } & \multicolumn{2}{|c|}{ Semana 1} & \multicolumn{2}{|c|}{ Semana 2} & \multicolumn{2}{|c|}{ Semana 3} & \multicolumn{2}{|c|}{ Semana 4} \\
\hline & & $15.00 \%$ & & $20.00 \%$ & & $30.00 \%$ & & $35.00 \%$ \\
\hline Ventas & $\mathrm{S} /$. & 32,224 & $\mathrm{~S} /$. & 42,965 & $\mathrm{~S} / \mathrm{.}$ & 64,447 & $\mathrm{~S} /$. & 75,188 \\
\hline Costos Variables & $\mathrm{S} /$. & 12,860 & $S /$. & 17,146 & S/. & 25,719 & $\mathrm{~S} /$. & 30,006 \\
\hline Costos Fijos & $\mathrm{S} /$. & - & S/. & 2,441 & S/. & 2,441 & $\mathrm{~S} /$. & - \\
\hline Total Egresos & $\mathrm{S} /$. & 12,860 & S/. & 19,587 & S/. & 28,160 & S/. & 30,006 \\
\hline
\end{tabular}

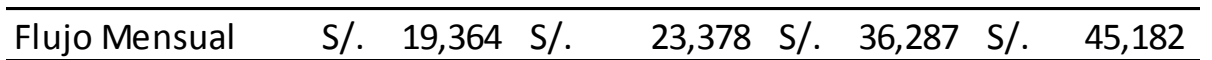

Deficit Acumulado S/. 19,364 S/. 42,742 S/. $79,029 \quad$ S/. 124,211 


\subsubsection{Costo del proyecto}

Se ha determinado a partir de la inversión de los activos (ver tabla 56 y tabla 57) y el capital de trabajo (Ver tabla 58), así como los otros gastos pre-operativo. (Ver tabla 59)

Tabla 59

Costo del proyecto

\begin{tabular}{llr} 
Inversiones & \multicolumn{2}{c}{ Gasto del proyecto } \\
\hline Maquinaria y Equipos & $\mathrm{S} /$. & $411,790.79$ \\
Constitución de la empresa & $\mathrm{S} /$. & $2,969.49$ \\
Alquiler del local & $\mathrm{S} /$. & $80,000.00$ \\
Marketing pre-operativo & $\mathrm{S} /$. & $20,061.04$ \\
Sistema operativo & $\mathrm{S} /$. & $3,932.37$ \\
Capital de trabajo & $\mathrm{S} /$ & $55,419.64$ \\
\hline Total & $\mathrm{S} /$. & $574,173.33$
\end{tabular}

\subsubsection{Inversiones futuras}

Se determinó un calendario de inversiones, considerando 4 años de vida útil a los equipos de oficina y 5 años a los equipos y maquinaria diversos del proyecto.

Tabla 60

Calendario de Inversiones

\begin{tabular}{|c|c|c|c|c|c|}
\hline \multirow[t]{2}{*}{ Reposición } & 1 & 2 & 3 & 4 & 5 \\
\hline & 2018 & 2019 & 2020 & 2021 & 2022 \\
\hline Equipo y maquinaria & & & & & S/. $240,516.85$ \\
\hline Equipo de oficina & & & & S/. 27,936.00 & \\
\hline Imprevistos (5\% del sub-total) & & & & $1,396.80$ & S/. $12,025.84$ \\
\hline
\end{tabular}

\subsection{Financiamiento}

\subsubsection{Endeudamiento y Condiciones}

Luego de haber concluido con la planificación de inversiones tanto pre- operativa como capital de trabajo, entre otras. Se procederá a evaluar la capacidad de endeudamiento para financiar parte de la inversión total. 
Después de evaluar varias entidades la elegida fue el BBVA Continetal, por el financiamiento de Línea de Préstamo comercial Negocios, ya que la inversión inicial es alta. Es por ello que se elegido la entidad ya que brinda facilidades con créditos efectivos con diversas garantías (Ver tabla 61).

Para la disposición del crédito, se necesitarán los siguientes requisitos:

- Copia de DNI de los socios.

- Buena experiencia crediticia en el sistema financiero.

- Recibo de luz, agua o teléfono.

- Documentos del negocio de residencia del representante legal apoderado y avales.

- Vigencia de poderes actualizada con antigüedad no mayor a 8 días.

- Documentos de propiedad del inmueble que será otorgado en garantía.

- Contar con BBVA Net Cash (para la modalidad Fast Cash).

- Pagos de IGV/Renta a Sunat

A continuación se detallaran los datos de la estructura de financiamiento:

Tabla 61

Estructura del Financiamiento

\begin{tabular}{lll}
\hline Inversión Total & S/. & $758,949.52$ \\
\hline Capital Propio & S/. & $455,369.71$ \\
\hline Porcentaje a Financiar & S/. & $758,949.52$ \\
\hline Monto Financiado & S/. & $455,369.71$ \\
\hline Capital Propio & S/. & $303,579.81$ \\
\hline Entidad Bancaria & BBVA & \\
\hline TCEA & $27 \%$ & \\
\hline TCEM & $2.01 \%$ & \\
\hline Tiempo (t) años & 5 \\
\hline Tiempo (t) meses & 60 \\
\hline
\end{tabular}




\subsubsection{Capital y costo de oportunidad}

Según Sapag (2011) el costo de capital está representado por la tasa de retorno exigida a la inversión realizada el proyecto, para compensar el costo de Oportunidad. Donde el costo de oportunidad, es la rentabilidad que obtendría el inversionista en otras inversiones posibles que dejaría de hacer para realizar el proyecto.

Para el presente plan de negocios se utilizó la metodología de valoración de activos de capital (CAPM), utilizando el beta apalancado y una prima nueva de negocio. Donde para medir la rentabilidad el objetivo es calcular el costo de capital desapalancado, que está asociado por la beta $(\beta)$ el cual es un factor que servirá para medir el riesgo sistemático de invertir en la industria. La beta que se usó para el proyecto es la de la industria de Restaurantes, los datos para calcular el costo de capital fueron tomados de Damodaran (2018) (Ver Tabla 62).

Se usó la siguiente formula:

$$
K u=R f+\beta \mathrm{u}(\mathrm{Rm}-\mathrm{R})
$$


Donde:

Tabla 62

Costo de Capital

$\beta$ del sector: $\quad 0.68$

\begin{tabular}{ll}
\hline $\mathrm{Rm}:$ & $10.27 \%$
\end{tabular}

Rf: $\quad 4.29 \%$

$\begin{array}{ll}\text { Deuda } & 70 \%\end{array}$

$\begin{array}{ll}\text { Patrimonio } & 30 \%\end{array}$

Beta apalancado $\quad 1.40 \%$

Tasa de Impuesto a la renta $\quad 30 \%$

Riesgo País $1.22 \%$

Desarrollo de formula

$$
\begin{aligned}
& K u=R f+\beta \mathrm{u}(\mathrm{Rm}-\mathrm{R}) \\
& K u=4.29 \%+0.68 \%(10.27 \%-4.29 \%) \\
& K u=4.29 \%+0.68 \%(5.98 \%) \\
& K u=4.29 \%+4.06 \% \\
& K u=8.35+\text { riesgo pais } \\
& K \boldsymbol{u}=\mathbf{9 . 5 7} \%
\end{aligned}
$$

Se obtuvo un costo de capital de $9.57 \%$. Es decir, que el presente proyecto debe contar con un rendimiento como mínimo de $9.57 \%$ para que sea rentable en comparación al mercado. 


\subsubsection{Costo de Capital Promedio Ponderado}

El presente proyecto se financiara con deuda y con aportes de capital propio, por lo que se debe estimar la tasa de descuento como el costo promedio ponderado del capital (CPPC) tanto de deudas y de aportes propios, considerando que se financiará un $40 \%$ con capital propio y el otro $60 \%$ a través de un crédito bancario, tal y como se mencionó anteriormente. Se obtuvo un CPPC de $15.25 \%$ (Ver tabla 63)

Se utilizó la fórmula del CPP según Sapag (2011), que se detalla a continuación:

$$
C P C C=K e \frac{E_{t-1}}{\left(E_{t-1}+D_{t-1}\right)}+K d(1-t) \frac{D_{t-1}}{\left(E_{t-1}+D_{t-1}\right)}
$$

\section{Tabla 63}

\section{Costo de Capital}

Fondos Propios (E) S/. 455,369.71

\begin{tabular}{ll}
\hline Nivel de Endeudamiento (D) & S/. 303,579.81 \\
\hline Tasa Impositiva (T) & $30 \%$ \\
\hline Coste Financiero (Kd) & $27 \%$ \\
\hline Coste de Capital (Ke) & $9.57 \%$
\end{tabular}

$$
C P C C=9.57 \% \frac{455,369.71}{(455,369.71+303,579.81)}+27 \%(1-29.5 \%) \frac{303,579.81}{(455,369.71+303,579.81)}
$$

\section{$\mathrm{CPCC}=15.25 \%$}


Significa que la rentabilidad anual del proyecto debe ser superior o igual a $\mathbf{1 5 . 2 5 \% ,}$ ya que si el proyecto proporciona un $15.25 \%$ será capaz de pagar exactamente la rentabilidad exigida por los financiadores: un $27 \%$ al banco $(\mathrm{Kd})$ y $9,57 \%(\mathrm{Ke})$ a los accionistas.

\subsection{Presupuestos Base}

\subsubsection{Presupuesto de ventas}

Estos están de acuerdo a la proyección de ventas que se vieron en los capítulos anteriores. Se muestran las ventas detalladas por tipo de producto. (Ver tabla 64)

Tabla 64

Pronóstico de ventas

\begin{tabular}{|c|c|c|c|c|c|c|c|c|}
\hline roductos & & 2018 & & 2019 & & 20220 & 2021 & 2022 \\
\hline zza & & 97.56 & $S$ & $297,098.49$ & S/. & 1,41 & S/. 1,543,361.80 & S/. 1, \\
\hline zza & & 7.80 & S/. & 88.64 & S/. & 56 & 5.62 & $\mathrm{~S} /$. \\
\hline zza & & 80.53 & $\mathrm{~S} / \mathrm{.}$ &, 877.44 & S/. &,, 594.18 & $35,549.88$ & $8,766.30$ \\
\hline$D_{-1}+2$ & & $5,224.95$ & $\mathrm{~S} /$. & $2,209.87$ & $\mathrm{~S} /$. & $613,331.27$ & S/. $\quad 668,949.39$ & $729,473.42$ \\
\hline tol $\operatorname{cin} 1$ & & 80113081 & & 3 & & $4,506.85$ & $3,636,886.69$ & $6502-2$ \\
\hline
\end{tabular}

\subsubsection{Presupuesto de costos de producción}

Se tomaron en cuenta para este punto todos los gastos que tienen relación con las operaciones del restaurante. La variación del costo de materia prima será equivalente a la variación de las ventas. Los demás gastos tendrán un aumento mínimo debido a que el incremento de las ventas, requerirá de un aumento de mano de obra, uniformes, material de limpieza, gas, luz y agua. (Ver tabla 65) 
Tabla 65

Presupuesto de costos de producción

\begin{tabular}{|c|c|c|c|c|c|c|c|c|c|}
\hline Costos de producción & & 2018 & & 2019 & 20220 & & 2021 & & 2022 \\
\hline Materia prima & $\mathrm{S} /$. & 947,342 & $\mathrm{~S} /$. & $1,033,733$ & S/. $1,127,730$ & S/. & $1,229,995$ & $\mathrm{~S} /$. & $1,341,280$ \\
\hline Mano de obra directa & $\mathrm{S} /$. & 490,239 & $\mathrm{~S} /$. & 497,593 & 505,056 & $\mathrm{~S} /$. & 512,632 & $\mathrm{~S} /$. & 520,322 \\
\hline Costos indirectos de fabricación & $\mathrm{S} /$. & 282,797 & $\mathrm{~S} /$. & 288,453 & 294,222 & S/. & 300,106 & $\mathrm{~S} /$. & 306,108 \\
\hline Uniformes & $\mathrm{S} /$. & 2,119 & $\mathrm{~S} /$. & 2,161 & 2,204 & $\mathrm{~S} /$. & 2,248 & $\mathrm{~S} /$. & 2,293 \\
\hline Material de limpieza & $\mathrm{S} /$. & 30,508 & $\mathrm{~S} /$. & 31,119 & 31,741 & $\mathrm{~S} /$. & 32,376 & $\mathrm{~S} /$. & 33,023 \\
\hline Gas & $\mathrm{S} /$. & 97,627 & $\mathrm{~S} /$. & 99,580 & 101,571 & $\mathrm{~S} /$. & 103,603 & $\mathrm{~S} /$. & 105,675 \\
\hline Agua y enegría eléctrica & $\mathrm{S} /$. & 152,542 & S/. & 155,593 & 158,705 & $\mathrm{~S} /$. & 161,879 & $\mathrm{~S} /$. & 165,117 \\
\hline
\end{tabular}

\subsubsection{Presupuesto de compras}

Se detallaron los montos destinados a las compras en cada tipo de producto. (Ver tabla $66)$.

Tabla 66

Presupuesto de compras

\begin{tabular}{lrrrrrrrrrr} 
Compras & \multicolumn{2}{c}{2018} & & 2019 & 20220 & 2021 & 2022 \\
\hline $\begin{array}{l}\text { Compra de ingredientes } \\
\text { para pizzas }\end{array}$ & S/. & 773,093 & S/. & 843,594 & S/. & 920,302 & S/. & $1,003,756$ & S/. & $1,094,573$ \\
$\begin{array}{l}\text { Compra de ingredientes } \\
\text { para bebidas }\end{array}$ & S/. & 174,249 & S/. & 190,139 & S/. & 207,429 & S/. & 226,239 & S/. & 246,708 \\
\hline Total & S/. & 947,342 & S/. & $1,033,733$ & S/. & $1,127,730$ & S/. & $1,229,995$ & S/. & $1,341,280$
\end{tabular}

\subsubsection{Presupuesto de gastos administrativos}

Se consideraron los siguientes gastos administrativos, como se puede apreciar en la tabla 67. 
Tabla 67

Gastos administrativos

\begin{tabular}{|c|c|c|c|c|c|}
\hline Gasto & 2018 & 2019 & 20220 & 2021 & 2022 \\
\hline Alquiler de local & S/. 510,720 & S/. 510,720 & S/. 510,720 & S/. 510,720 & S/. 510,720 \\
\hline Teléfono e Internet & 7,200 & 7,200 & 7,200 & 7,200 & 7,200 \\
\hline Sueldo Aministrativo & S/. 341,460 & S/. 344,875 & S/. 351,772 & S/. 358,808 & S/. 365,984 \\
\hline Movilidad & 4,320 & 4,406 & 4,495 & 4,584 & 4,676 \\
\hline Contabilidad externa & S/. $\quad 16,800$ & S/. $\quad 16,800$ & S/. $\quad 16,800$ & S/. $\quad 16,800$ & S/. $\quad 16,800$ \\
\hline Total & S/. 880,500 & S/. 884,001 & S/. 890,987 & S/. 898,112 & S/. 905,380 \\
\hline
\end{tabular}

\subsubsection{Presupuesto de marketing y ventas}

Se consideraron los siguientes gastos de marketing y ventas, como se puede apreciar en la tabla 68 .

Tabla 68

Gastos de marketing y ventas

\begin{tabular}{|c|c|c|c|c|c|c|c|c|c|c|}
\hline Gastos & & 2018 & & 2019 & & 20220 & & 2021 & & 2022 \\
\hline Hosting & $\mathrm{S} /$. & 350 & $\mathrm{~S} /$. & 350 & $\mathrm{~S} /$. & 350 & $\mathrm{~S} /$. & 350 & $\mathrm{~S} /$. & 350 \\
\hline Comisión de tarjetas & $\mathrm{S} /$. & 42,017 & $\mathrm{~S} /$. & 45,849 & $\mathrm{~S} /$. & 50,018 & $\mathrm{~S} /$. & 54,553 & $\mathrm{~S} /$. & 59,489 \\
\hline Dominio (actualización web) & $\mathrm{S} /$. & 500 & $\mathrm{~S} /$. & 500 & S/. & 500 & $\mathrm{~S} /$. & 500 & $\mathrm{~S} /$. & 500 \\
\hline Impresión de publicidad & $\mathrm{S} /$. & 12,000 & $\mathrm{~S} /$. & 12,240 & $\mathrm{~S} /$. & 12,485 & $\mathrm{~S} /$. & 12,734 & $\mathrm{~S} /$. & 12,989 \\
\hline Facebook y página web & $\mathrm{S} /$. & 14,400 & $\mathrm{~S} /$. & 14,400 & $\mathrm{~S} /$. & 14,400 & $\mathrm{~S} /$. & 14,400 & $\mathrm{~S} /$. & 14,400 \\
\hline Sorteos & $\mathrm{S} /$. & 2,400 & $\mathrm{~S} /$. & 2,448 & $\mathrm{~S} /$. & 2,497 & $\mathrm{~S} /$. & 2,547 & S/. & 2,598 \\
\hline Concursos & $\mathrm{S} /$. & 3,000 & S/. & 3,060 & S/. & 3,121 & $\mathrm{~S} /$. & 3,184 & $\mathrm{~S} /$. & 3,247 \\
\hline Cupones & $\mathrm{S} /$. & 3,600 & S/. & 3,672 & S/. & 3,745 & $\mathrm{~S} /$. & 3,820 & S/. & 3,897 \\
\hline Branding & $\mathrm{S} /$. & 23,000 & $\mathrm{~S} /$. & 18,000 & $\mathrm{~S} /$. & 18,000 & $\mathrm{~S} /$. & 18,000 & $\mathrm{~S} /$. & 18,000 \\
\hline Sampling & $\mathrm{S} /$. & 12,000 & S/. & - & S/. & - & $\mathrm{S} /$. & - & $\mathrm{S} /$. & - \\
\hline Total & $\mathrm{S} /$. & 113,267 & S/. & 0,519 & $\mathrm{~S} /$ & 55,116 & S/. & 10,089 & $\mathrm{~S} /$. & 115,470 \\
\hline
\end{tabular}

\subsubsection{Presupuesto de gastos financieros.}

El presente proyecto estará financiado tanto con capital propio como deuda financiera. Es por ello que se proyectó todos los intereses del préstamo. Se generó un cronograma de pagos para el préstamo de S/ 416,295 financiado a 5 años con pagos mensuales (Ver tabla 69) 
Tabla 69

Amortización de préstamo

\begin{tabular}{|c|c|c|c|c|c|c|c|c|}
\hline \multirow{2}{*}{$\frac{\text { Periodo }}{O}$} & \multicolumn{2}{|c|}{ Cuota } & \multicolumn{2}{|c|}{ Interés } & \multicolumn{2}{|c|}{ Amortización } & \multicolumn{2}{|r|}{ Saldo } \\
\hline & & & & & & & S/. & $455,369.71$ \\
\hline 1 & $\mathrm{~S} /$. & $13,137.44$ & $\mathrm{~S} /$. & $9,161.02$ & $\mathrm{~S} / \mathrm{.}$ & $3,976.42$ & S/. & $451,393.29$ \\
\hline 2 & $\mathrm{~S} /$. & $13,137.44$ & S/. & $9,081.02$ & $\mathrm{~S} /$. & $4,056.42$ & $\mathrm{~S} /$. & $447,336.88$ \\
\hline 3 & $\mathrm{~S} /$. & $13,137.44$ & $\mathrm{~S} /$. & $8,999.42$ & $\mathrm{~S} / \mathrm{.}$ & $4,138.02$ & $\mathrm{~S} /$. & $443,198.86$ \\
\hline 4 & $\mathrm{~S} /$. & $13,137.44$ & S/. & $8,916.17$ & $\mathrm{~S} /$. & $4,221.27$ & $\mathrm{~S} /$. & $438,977.59$ \\
\hline 5 & $\mathrm{~S} /$. & $13,137.44$ & $\mathrm{~S} /$. & $8,831.25$ & $\mathrm{~S} / \mathrm{s}$ & $4,306.19$ & $\mathrm{~S} /$. & $434,671.40$ \\
\hline 6 & $\mathrm{~S} /$. & $13,137.44$ & $\mathrm{~S} /$. & $8,744.62$ & $\mathrm{~S} / \mathrm{s}$ & $4,392.82$ & $\mathrm{~S} /$. & $430,278.57$ \\
\hline 7 & $\mathrm{~S} /$. & $13,137.44$ & $\mathrm{~S} /$. & $8,656.24$ & $\mathrm{~S} / \mathrm{.}$ & $4,481.20$ & S/. & $425,797.38$ \\
\hline 8 & $\mathrm{~S} / \mathrm{s}$ & $13,137.44$ & $\mathrm{~S} / \mathrm{.}$ & $8,566.09$ & $\mathrm{~S} / \mathrm{s}$ & $4,571.35$ & $\mathrm{~S} / \mathrm{.}$ & $421,226.03$ \\
\hline 9 & $\mathrm{~S} /$. & $13,137.44$ & $\mathrm{~S} / \mathrm{.}$ & $8,474.13$ & $\mathrm{~S} /$. & $4,663.31$ & $\mathrm{~S} /$. & $416,562.72$ \\
\hline 10 & $\mathrm{~S} /$. & $13,137.44$ & $\mathrm{~S} /$. & $8,380.31$ & $\mathrm{~S} / \mathrm{.}$ & $4,757.13$ & $\mathrm{~S} /$. & $411,805.59$ \\
\hline 11 & $\mathrm{~S} /$. & $13,137.44$ & $\mathrm{~S} /$. & $8,284.61$ & $\mathrm{~S} / \mathrm{.}$ & $4,852.83$ & $\mathrm{~S} /$. & $406,952.76$ \\
\hline 12 & $\mathrm{~S} /$. & $13,137.44$ & $\mathrm{~S} /$. & $8,186.98$ & $\mathrm{~S} /$. & $4,950.46$ & $\mathrm{~S} /$. & $402,002.30$ \\
\hline 13 & $\mathrm{~S} /$. & $13,137.44$ & $\mathrm{~S} /$. & $8,087.39$ & $\mathrm{~S} / \mathrm{.}$ & $5,050.05$ & S/. & $396,952.25$ \\
\hline 14 & $\mathrm{~S} /$. & $13,137.44$ & $\mathrm{~S} /$. & $7,985.79$ & $\mathrm{~S} / \mathrm{.}$ & $5,151.65$ & S/. & $391,800.60$ \\
\hline 15 & $\mathrm{~S} / \mathrm{s}$ & $13,137.44$ & $\mathrm{~S} /$. & $7,882.15$ & $\mathrm{~S} / \mathrm{s}$ & $5,255.29$ & $\mathrm{~S} / \mathrm{.}$ & $386,545.31$ \\
\hline 16 & $\mathrm{~S} /$. & $13,137.44$ & $\mathrm{~S} /$. & $7,776.43$ & $\mathrm{~S} / \mathrm{s}$ & $5,361.01$ & S/. & $381,184.30$ \\
\hline 17 & $\mathrm{~S} /$. & $13,137.44$ & $\mathrm{~S} /$. & $7,668.58$ & $\mathrm{~S} / \mathrm{s}$ & $5,468.86$ & $\mathrm{~S} /$. & $375,715.44$ \\
\hline 18 & $\mathrm{~S} /$. & $13,137.44$ & $\mathrm{~S} /$. & $7,558.55$ & $\mathrm{~S} / \mathrm{.}$ & $5,578.88$ & $\mathrm{~S} /$. & $370,136.55$ \\
\hline 19 & $\mathrm{~S} /$. & $13,137.44$ & S/. & $7,446.32$ & $\mathrm{~S} /$. & $5,691 \cdot 12$ & $\mathrm{~S} /$. & $364,445.43$ \\
\hline 20 & $\mathrm{~S} /$. & $13,137.44$ & $\mathrm{~S} /$. & $7,331.83$ & S/. & $5,805.61$ & S/. & $358,639.82$ \\
\hline 21 & $\mathrm{~s} /$. & $13,137.44$ & $\mathrm{~S} /$. & $7,215.03$ & $\mathrm{~S} / \mathrm{s}$ & $5,922.41$ & $\mathrm{~S} / \mathrm{s}$ & $352,717.41$ \\
\hline 22 & $\mathrm{~S} /$. & $13,137.44$ & $\mathrm{~S} /$. & $7,095.89$ & $\mathrm{~S} / \mathrm{.}$ & $6,041.55$ & S/. & $346,675.86$ \\
\hline 23 & $\mathrm{~S} / \mathrm{s}$ & $13,137.44$ & $\mathrm{~S} / \mathrm{.}$ & $6,974.34$ & $\mathrm{~S} / \mathrm{s}$ & $6,163.10$ & $\mathrm{~S} / \mathrm{.}$ & $340,512.76$ \\
\hline 24 & $\mathrm{~S} /$. & $13,137.44$ & $\mathrm{~S} /$. & $6,850.36$ & $\mathrm{~S} / \mathrm{s}$ & $6,287.08$ & $\mathrm{~S} /$. & $334,225.68$ \\
\hline 25 & $\mathrm{~S} /$. & $13,137.44$ & $\mathrm{~S} /$. & $6,723.87$ & $\mathrm{~S} / \mathrm{s}$ & $6,413.57$ & $\mathrm{~S} /$. & $327,812.11$ \\
\hline 26 & $\mathrm{~S} /$. & $13,137.44$ & $\mathrm{~S} /$. & $6,594.85$ & $\mathrm{~S} / \mathrm{.}$ & $6,542.59$ & $\mathrm{~S} /$. & $321,269.52$ \\
\hline 27 & $\mathrm{~S} /$. & $13,137.44$ & $\mathrm{~S} /$. & $6,463.22$ & $\mathrm{~S} /$ & $6,674.21$ & $\mathrm{~S} /$. & $314,595.31$ \\
\hline 28 & $\mathrm{~S} /$. & $13,137.44$ & $\mathrm{~S} /$. & $6,328.95$ & $\mathrm{~S} /$. & $6,808.48$ & $\mathrm{~S} /$. & $307,786.82$ \\
\hline 29 & $\mathrm{~S} /$. & $13,137.44$ & $\mathrm{~S} /$. & $6,191.98$ & $\mathrm{~S} / \mathrm{.}$ & $6,945.46$ & S/. & $300,841.37$ \\
\hline 30 & $\mathrm{~S} /$. & $13,137.44$ & $\mathrm{~S} /$. & $6,052.26$ & $\mathrm{~S} / \mathrm{s}$ & $7,085.18$ & $\mathrm{~S} /$. & $293,756.18$ \\
\hline 31 & $\mathrm{~S} /$. & $13,137.44$ & $\mathrm{~S} /$. & $5,909.72$ & $\mathrm{~S} / \mathrm{s}$ & $7,227.72$ & S/. & $286,528.46$ \\
\hline 32 & $\mathrm{~S} / \mathrm{.}$ & $13,137.44$ & $\mathrm{~S} /$. & $5,764.31$ & $\mathrm{~S} / \mathrm{s}$ & $7,373.13$ & $\mathrm{~S} /$. & $279,155.34$ \\
\hline 33 & $\mathrm{~S} /$. & $13,137.44$ & $\mathrm{~S} /$. & $5,615.98$ & $\mathrm{~S} /$. & $7,521.46$ & $\mathrm{~S} /$. & $271,633.88$ \\
\hline 34 & $\mathrm{~S} /$. & $13,137.44$ & $\mathrm{~S} /$. & $5,464.67$ & $\mathrm{~S} /$. & $7,672.77$ & $\mathrm{~S} /$. & $263,961.10$ \\
\hline 35 & $\mathrm{~S} /$. & $13,137.44$ & $\mathrm{~S} /$. & $5,310.31$ & $\mathrm{~S} /$. & $7,827.13$ & $\mathrm{~S} /$. & $256,133.97$ \\
\hline 36 & $\mathrm{~S} /$. & $13,137.44$ & $\mathrm{~S} /$. & $5,152.84$ & $\mathrm{~S} / \mathrm{.}$ & $7,984.60$ & S/. & $248,149.38$ \\
\hline 37 & $\mathrm{~S} /$. & $13,137.44$ & $\mathrm{~S} /$. & $4,992.21$ & $\mathrm{~S} / \mathrm{s}$ & $8,145.23$ & $\mathrm{~S} /$. & $240,004.15$ \\
\hline 38 & $\mathrm{~S} /$. & $13,137.44$ & $\mathrm{~S} /$. & $4,828.35$ & $\mathrm{~S} / \mathrm{.}$ & $8,309.09$ & S/. & $231,695.06$ \\
\hline 39 & $\mathrm{~S} /$. & $13,137.44$ & $\mathrm{~S} /$. & $4,661.19$ & $\mathrm{~S} /$. & $8,476.25$ & $\mathrm{~S} /$. & $223,218.80$ \\
\hline 40 & $\mathrm{~S} /$. & $13,137.44$ & $\mathrm{~S} /$. & $4,490.66$ & $\mathrm{~S} / \mathrm{s}$ & $8,646.78$ & $\mathrm{~S} /$. & $214,572.03$ \\
\hline 41 & $\mathrm{~S} /$. & $13,137.44$ & $\mathrm{~S} /$. & $4,316.71$ & $\mathrm{~S} / \mathrm{s}$ & $8,820.73$ & $\mathrm{~S} /$. & $205,751.30$ \\
\hline 42 & $\mathrm{~S} /$. & $13,137.44$ & $\mathrm{~S} /$. & $4,139.26$ & $\mathrm{~S} /$ & $8,998.18$ & $\mathrm{~S} /$. & $196,753.12$ \\
\hline 43 & $\mathrm{~S} /$. & $13,137.44$ & $\mathrm{~S} /$. & $3,958.23$ & $\mathrm{~S} /$ & $9,179.21$ & S/. & $187,573.91$ \\
\hline 44 & $\mathrm{~S} /$. & $13,137.44$ & $\mathrm{~S} /$. & $3,773.57$ & $\mathrm{~S} / \mathrm{.}$ & $9,363.87$ & S/. & $178,210.04$ \\
\hline 45 & $\mathrm{~S} /$. & $13,137.44$ & $\mathrm{~S} /$. & $3,585.19$ & $\mathrm{~S} / \mathrm{.}$ & $9,552.25$ & S/. & $168,657.79$ \\
\hline 46 & $\mathrm{~S} /$. & $13,137.44$ & $\mathrm{~S} /$. & $3,393.02$ & $\mathrm{~S} / \mathrm{.}$ & $9,744.42$ & S/. & $158,913.37$ \\
\hline 47 & $\mathrm{~S} / \mathrm{.}$ & $13,137.44$ & $\mathrm{~S} /$. & $3,196.98$ & $\mathrm{~S} /$ & $9,940.46$ & $\mathrm{~S} /$. & $148,972.91$ \\
\hline 48 & $\mathrm{~S} / \mathrm{.}$ & $13,137.44$ & $\mathrm{~S} /$. & $2,997.00$ & S/. & $10,140.44$ & S/. & $138,832.47$ \\
\hline 49 & $\mathrm{~S} /$. & $13,137.44$ & $\mathrm{~S} /$. & $2,793.00$ & S/. & $10,344.44$ & $\mathrm{~S} /$. & $128,488.03$ \\
\hline 50 & $\mathrm{~S} /$. & $13,137.44$ & $\mathrm{~S} /$. & $2,584.89$ & S/. & $10,552.55$ & S/. & $117,935.48$ \\
\hline 51 & $\mathrm{~S} /$. & $13,137.44$ & $\mathrm{~S} /$. & $2,372.60$ & S/. & $10,764.84$ & S/. & $107,170.64$ \\
\hline 52 & $\mathrm{~S} /$. & $13,137.44$ & $\mathrm{~S} /$. & $2,156.03$ & $\mathrm{~S} /$ & $10,981.41$ & S/. & $96,189.24$ \\
\hline 53 & S/. & $13,137.44$ & $\mathrm{~S} /$. & $1,935.11$ & S/. & $11,202.33$ & $\mathrm{~S} /$. & $84,986.91$ \\
\hline 54 & $\mathrm{~S} /$. & $13,137.44$ & $\mathrm{~S} /$. & $1,709.75$ & S/. & $11,427.69$ & $\mathrm{~S} /$. & $73,559.22$ \\
\hline 55 & $\mathrm{~S} /$. & $13,137.44$ & $\mathrm{~S} /$. & $1,479.85$ & $\mathrm{~S} /$ & $11,657.59$ & S/. & $61,901.63$ \\
\hline 56 & $\mathrm{~S} /$. & $13,137.44$ & S/. & $1,245.32$ & $\mathrm{~S} /$ & $11,892.12$ & $\mathrm{~S} /$. & $50,009.51$ \\
\hline 57 & $\mathrm{~S} / \mathrm{s}$ & $13,137.44$ & $\mathrm{~S} /$. & $1,006.08$ & S/. & $12,131.36$ & $\mathrm{~S} /$. & $37,878.15$ \\
\hline 58 & $\mathrm{~S} /$. & $13,137.44$ & S/. & 762.02 & S/. & $12,375.42$ & S/. & $25,502.74$ \\
\hline 59 & $\mathrm{~S} /$. & $13,137.44$ & $\mathrm{~S} /$. & 513.06 & S/. & $12,624.38$ & S/. & $12,878.36$ \\
\hline 60 & $\mathrm{~S} /$. & $13,137.44$ & $\mathrm{~S} /$. & 259.08 & S/. & $12,878.36$ & $\mathrm{~S} /$. & 0.00 \\
\hline
\end{tabular}




\subsection{Presupuestos de Resultados}

\subsubsection{Estado de ganancias y pérdidas proyectado}

Para este estado financiero se tomó en cuenta la proyección de ingresos, costos y gastos dentro del horizonte del proyecto, es decir, para los próximos cinco años (Ver

Tabla 70)

Tabla 70

Estado de resultados

Estado de Ganancias y Pérdidas

\begin{tabular}{|c|c|c|c|c|c|c|c|c|c|}
\hline Ventas & S/. $\quad 2,801,131$ & S/. & $3,056,574$ & S/. & $3,334,507$ & S/. & $3,636,887$ & S/. & $3,965,939$ \\
\hline Costo de Ventas & S/. $\quad 947,342$ & S/. & $1,033,733$ & S/. & $1,127,730$ & S/. & $1,229,995$ & S/. & $1,341,280$ \\
\hline $\begin{array}{l}\text { Gastos } \\
\text { Administración }\end{array}$ & S/. 880,500 & S/. & 884,001 & S/. & 890,987 & $\mathrm{~S} /$. & 898,112 & S/. & 905,380 \\
\hline Gastos de Ventas & S/. $\quad 113,267$ & S/. & 100,519 & S/. & 105,116 & S/. & 110,089 & S/. & 115,470 \\
\hline $\begin{array}{l}\text { Utilidad } \\
\text { Operativa }\end{array}$ & S/. 860,021 & S/. & $1,038,321$ & S/. & $1,210,674$ & S/. & $1,398,691$ & S/. & $1,603,808$ \\
\hline
\end{tabular}

Tabla 71

\section{Balance Proyectado}

\begin{tabular}{|c|c|c|c|c|c|}
\hline 3alance General & 2018 & 2019 & 20220 & 2021 & \\
\hline aja & S/. $-79,092.55$ & S/. $\quad 36,358.52$ & S/. 147,468.67 & S/. 240,027.52 & S/. 149,365.19 \\
\hline cuentas por cobrar & S/. & $\mathrm{S} /$. & S/. & $\mathrm{S} /$. & S/. \\
\hline ive & S/. 273,671.47 & S/. 555,347.86 & S/. 466,090.97 & S/. 382,676.97 & S/. 464,478.78 \\
\hline ver & /. $55,419.64$ & S/. $\quad 58,621.70$ & S/. $\quad 62,075.96$ & S/. $\quad 65,803.88$ & S/. $\quad 69,829.85$ \\
\hline eti & S/. 121,212.00 & S/. 121,212.00 & S/. 121,212.00 & S/. 121,212.00 & 212.00 \\
\hline qui & 90.79 & S/. $59,387.94$ & S/. $59,387.94$ & S/. $59,387.94$ & S/. $59,387.94$ \\
\hline tro & $104,281.85$ & S/. $89,872.65$ & S/. $71,572.96$ & S/. $\quad 48,332.36$ & S/. $\quad 18,816.80$ \\
\hline ctiv & . $62,357.33$ & S/. 124 & S/. 187,072.00 & 29.34 & 86.67 \\
\hline & 9.19 & $\mathrm{~S} / .2$ & 644.97 & 1.70 & 03.47 \\
\hline Tota & S/. 540, & S/. 58 & S/. 613,811.53 & S/. 626,684.31 & S/. $621,849.75$ \\
\hline uen & $s$ & $\mathrm{~S} /$. & $\mathrm{S} /$. & S/. & S/. \\
\hline eu & . 402,002.30 & S/. 334,225.68 & S/. $248,149.38$ & S/. 138,832.47 & S/. \\
\hline & $402,002.30$ & S/. 334,225.68 & S/. $248,149.38$ & $8,832.47$ & S/. \\
\hline & S/. 126,378.62 & S/. 126,378.62 & S/. 126,378.62 & S/. 126,378.62 & S/. 126,378.62 \\
\hline esultados a & $12,196.44$ & S/. 127,899.72 & S/. 239,283.53 & S/. 361,473.22 & S/. 495,471.13 \\
\hline & $138,575.06$ & S/. 254,278.34 & S/. 365,662.15 & S/. 487,851.84 & S/. $621,849.75$ \\
\hline $1 \mathrm{D}$ & 7.36 & $588,504.02$ & S/. 613,811.53 & S/. 626,684.31 & S/. $621,849.75$ \\
\hline
\end{tabular}




\subsubsection{Flujo de caja proyectado}

Dentro del siguiente flujo de caja se puede determinar la utilidad económica del proyecto, así como la financiera (Ver tabla 72).

\section{Tabla 72}

Flujo de caja proyectado

\begin{tabular}{|c|c|c|c|c|c|c|c|c|c|c|c|c|}
\hline Flujo de caja & & 2017 & & 2018 & & 2019 & & 2020 & & 2021 & & 2022 \\
\hline Ingresos por Ventas & & & $\mathrm{S} /$. & $2,801,131$ & $\mathrm{~S} /$. & $3,056,574$ & $\mathrm{~S} /$. & $3,334,507$ & $\mathrm{~S} /$. & $3,636,887$ & $\mathrm{~S} /$. & $3,965,939$ \\
\hline Ingresos Totales & & & S/. & $2,801,131$ & S/. & $3,056,574$ & S/. & $3,334,507$ & S/. & $3,636,887$ & $\mathrm{~S} /$. & $3,965,939$ \\
\hline Costos de venta & & & S/. & $1,720,378$ & S/. & $1,819,779$ & $\mathrm{~S} /$. & $1,927,008$ & $\mathrm{~S} /$. & $2,042,733$ & $\mathrm{~S} /$. & $2,167,710$ \\
\hline Costos fijos $(*)$ & & & S/. & 993,767 & $\mathrm{~S} /$. & 984,520 & S/. & 996,103 & S/. & $1,008,201$ & $\mathrm{~S} /$. & $1,020,850$ \\
\hline Depreciación & & & $\mathrm{S} /$. & 62,357 & $\mathrm{~S} /$. & 62,357 & $\mathrm{~S} /$. & 62,357 & $\mathrm{~S} /$. & 62,357 & $\mathrm{~S} /$. & 62,357 \\
\hline Amortización Intang. & & & $\mathrm{S} /$. & 7,205 & $\mathrm{~S} /$. & 7,205 & $\mathrm{~S} /$. & 7,205 & $\mathrm{~S} /$. & 7,205 & $\mathrm{~S} /$. & 7,205 \\
\hline Egresos Totales & & & $\mathrm{S} /$. & $2,783,707$ & S/. & $2,873,861$ & S/. & $2,992,673$ & S/. & $3,120,496$ & $\mathrm{~S} /$. & $3,258,123$ \\
\hline Utilidad antes Imp. & & & $\mathrm{S} /$. & 17,423 & $\mathrm{~S} /$. & 182,714 & $\mathrm{~S} /$. & 341,834 & $\mathrm{~S} /$. & 516,390 & $\mathrm{~S} /$. & 707,816 \\
\hline Impuestos & & & S/. & $5,227.05$ & $\mathrm{~S} /$. & 54,814 & S/. & 102,550 & S/. & 154,917 & $\mathrm{~S} /$. & 212,345 \\
\hline Utilidad neta & & & $\mathrm{S} /$. & 12,196 & $\mathrm{~S} /$. & 127,900 & $\mathrm{~S} /$. & 239,284 & $\mathrm{~S} /$. & 361,473 & $\mathrm{~S} /$. & 495,471 \\
\hline Depreciación & & & $\mathrm{S} /$. & 62,357 & $\mathrm{~S} /$. & 62,357 & $\mathrm{~S} /$. & 62,357 & $\mathrm{~S} /$. & 62,357 & $\mathrm{~S} /$. & 62,357 \\
\hline Amortización Intang. & & & $\mathrm{S} /$. & 7,205 & $\mathrm{~S} /$. & 7,205 & $\mathrm{~S} /$. & 7,205 & S/. & 7,205 & $\mathrm{~S} /$. & 7,205 \\
\hline Inversión inicial $(* *)$ & S/. & 526,329 & & & & & & & & & & \\
\hline Inversión de reemplazo & & & S/. & - & S/. & - & S/. & - & $\mathrm{S} /$. & 29,333 & $\mathrm{~S} /$. & 252,543 \\
\hline $\begin{array}{l}\text { Inversión capital trabajo } \\
\text { Valor residual }\end{array}$ & S/. & 55,420 & S/. & 3,202 & S/. & 3,454 & S/. & 3,728 & S/. & $4,025.96$ & S/. & $5,476.32$ \\
\hline Flujo de Caja Operativo & $\mathrm{S} /$. & $-581,748$ & $\mathrm{~S} /$. & 78,557 & $\mathrm{~S} /$. & 194,008 & $\mathrm{~S} /$. & 305,118 & $\mathrm{~S} /$. & 397,677 & $\mathrm{~S} /$. & 307,014 \\
\hline Préstamo & S/. & 455,370 & & & & & & & & & & \\
\hline Amortización de deuda & & & S/. & 53,367 & S/. & 67,777 & S/. & 86,076 & S/. & 109,317 & $\mathrm{~S} /$. & 138,832 \\
\hline Interés del préstamo & & & $\mathrm{S} /$. & 104,282 & $\mathrm{~S} /$. & 89,873 & $\mathrm{~S} /$. & 71,573 & $\mathrm{~S} /$. & 48,332 & $\mathrm{~S} /$. & 18,817 \\
\hline Flujo de Caja del Inversio & S/. & $-126,379$ & $\mathrm{~S} /$. & $-79,093$ & $\mathrm{~S} /$. & 36,359 & $\mathrm{~S} /$. & 147,469 & $\mathrm{~S} /$. & 240,028 & $\mathrm{~S} /$. & 149,365 \\
\hline
\end{tabular}




\section{Capítulo IX. Evaluación Económica Financiera}

En el presente capítulo se determina la viabilidad de Pizza Lab, se utilizaron diversos indicadores de rentabilidad, entre ellos: tasa interna de retorno, valor actual neto, entre otros. Para así definir la rentabilidad financiera de la pizzería.

Así como también se elaboró análisis de riesgo, determinando el punto de equilibrio con diversos escenarios de sensibilidad que pueden generarse a lo largo del desarrollo del presente plan de negocios.

\subsection{Evaluación Financiera}

El presente proyecto tiene un horizonte de cinco años, por lo cual se generó los flujos a futuro, de acuerdo al crecimiento del mercado, donde se consideró un $10 \%$.

\subsubsection{TIR}

Según Sapag (2011) "la tasa interna de retorno es uno de los criterios de evaluación que mide la rentabilidad del proyecto como porcentaje" (p. 32).

La tasa Interna de Rendimiento que obtuvo el proyecto es de $27 \%$ y una TIRF de $35 \%$, los resultados son mayores que el costo de capital que es de $15.25 \%$, por lo que el proyecto se acepta.

\subsubsection{VAN}

“El valor actual neto mide el excedente resultante después de obtener la rentabilidad deseada y después de recuperar toda la inversión” (Sapag, 2011, p. 34)

El VAN que se obtuvo en el proyecto es S/. 208,214.27; el cual es positivo, por lo tanto indica que el proyecto es suficiente para recuperar el capital invertido, ya que el VAN es mayor a 0 , por lo que el proyecto es rentable para que los accionistas reciban el rendimiento requerido. 
En la tabla 73 se muestra la evaluación de TIR y el VAN

Tabla 73

Calculo de TIR y VAN

\begin{tabular}{cl}
\hline VANE & S/. 208,214.27 \\
\hline TIRE & $27 \%$ \\
\hline VANF & S/. 138,219.84 \\
\hline TIRF & $35 \%$ \\
\hline
\end{tabular}

\subsubsection{ROE}

El ROE (Return On Assets) mide la rentabilidad obtenida de la empresa sobre sus fondos propios (Sapag, 2011). De acuerdo a los resultados se puede apreciar un ROE con una tendencia creciente, lo que significa que para el año 2018, por cada S/1.00 invertido en el patrimonio, este habrá rendido el 13\% en el resultado neto (Ver Tabla 74).

Tabla 74

Calculo del ROE

\begin{tabular}{cccccc}
\hline INDICADORES & 2018 & 2019 & 2020 & 2021 & 2022 \\
\hline ROE & $13 \%$ & $27 \%$ & $28 \%$ & $29 \%$ & $32 \%$ \\
\hline
\end{tabular}

\subsubsection{Ratios}

Para el proyecto se utilizaron diversos ratios como ROE, ROA, margen neto y apalancamiento financiero. (Ver Tabla 75) 
Tabla 75

Ratios Financieros

\begin{tabular}{lccccc}
\hline Indicadores & 2018 & 2019 & 2020 & 2021 & 2022 \\
\hline ROA & $13 \%$ & $27 \%$ & $28 \%$ & $29 \%$ & $32 \%$ \\
\hline ROE & $22 \%$ & $28 \%$ & $31 \%$ & $23 \%$ & $39 \%$ \\
\hline Margen Operativo & $31 \%$ & $34 \%$ & $36 \%$ & $38 \%$ & $40 \%$ \\
\hline Margen Neto & $21 \%$ & $24 \%$ & $25 \%$ & $27 \%$ & $28 \%$ \\
\hline
\end{tabular}

- ROA (Return On Assets): de acuerdo a los resultados anteriores se puede apreciar un ROA estable en el primer año, lo que significa que para el año 2018, por cada S/1.00 invertido en activos, se obtendrá $13 \%$ de la utilidad neta.

- ROE (Return On Assets): de acuerdo a los resultados anteriores se puede apreciar un ROE con una tendencia creciente, lo que significa que para el año 2018, por cada S/1.00 invertido en el patrimonio, este habrá rendido el $22 \%$ en el resultado neto.

- Margen Operativo: La utilidad operativa de Pizza Lab en el 2018 es de 31\% y para el último año es de $40 \%$.

- Margen Neto: El margen neto para Pizza Lab para el 2018 es de 21\% y para último año es $28 \%$.

\subsection{Análisis de Riesgos}

Según Gitman y Zutter (2016) al hacer el análisis de riesgo se evalúa el grado de variabilidad de los flujos de efectivo. 


\subsubsection{Análisis de Punto de Equilibrio}

Para el análisis del punto de equilibrio, se utilizó los costos fijos y variables del proyecto, así como también el costo de ticket promedio, ya que los precios de cada pizza son distintos. Es por ello que las unidades vendidas se basaran el ticket promedio de consumo.

Se obtuvo un resultado de 39457 unidades de pizza que se deben vender durante un año, para así cubrir todos los costos y no tener pérdidas ni ganancias. (Ver Tabla 76)

Tabla 76

Análisis de Punto de Equilibrio

\begin{tabular}{ll}
\hline \multicolumn{2}{c}{ Punto de Equilibrio } \\
\hline Costo Fijo & $\mathrm{S} / .993,767$ \\
\hline Ingresos por Ventas & $\mathrm{S} / .2,801,131$ \\
\hline Ticket Promedio & $\mathrm{S} / .38$ \\
\hline Número de Tickets & 86852 \\
\hline Ventas por tickets & $\mathrm{S} / .3,305,334$ \\
\hline Ventas sin IGV & $\mathrm{S} / .2,801,131$ \\
\hline Costo Variable Unitario & $\mathrm{S} / .13$ \\
\hline Equilibro por Tickets en unidades & 39457 \\
\hline
\end{tabular}

\subsubsection{Análisis de Sensibilidad}

El análisis de sensibilidad es un método que permite agregar información que posibilite decidir más adecuadamente respecto a la inversión. Siendo el método más común el modelo se sensibilización de Hertz, el cual analizar la variación del VAN cuando se modifica una o más variables susceptibles de cambiar durante el periodo de evaluación. (Sapag, 2011, p. 38).

Para el presente proyecto se utilizó el método antes mencionado, donde se tiene por finalidad mostrar los efectos del VAN y TIR del flujo del proyecto y del flujo del inversionista. Para el análisis se consideró dos variables: Precio, cantidad vendida y costo variables. (Ver tabla 77, tabla 78 y tabla 79) 
Tabla 77

Sensibilidad por Precio

\begin{tabular}{|c|c|c|}
\hline & Precio & \\
\hline Variación del Precio & $-4.24 \%$ & $-6.45 \%$ \\
\hline VANE & 0 & S/. $\quad 69,753.01$ \\
\hline TIRE & $15.00 \%$ & $19.00 \%$ \\
\hline VANF & S/. $\quad-69,631.39$ & 0 \\
\hline TIRF & $5.00 \%$ & $5.00 \%$ \\
\hline
\end{tabular}

Tabla 78

Sens ibilidad por Cantidad Vendida

\begin{tabular}{|c|c|c|}
\hline \multicolumn{3}{|c|}{ Cantidad Vendida } \\
\hline $\begin{array}{l}\text { Variación de cantidad } \\
\text { Vendida }\end{array}$ & $-4.26 \%$ & $7.31 \%$ \\
\hline VANE & 0 & S/. 71,305.40 \\
\hline TIRE & $14.60 \%$ & $20.00 \%$ \\
\hline VANF & S/. $-70,256.40$ & 0 \\
\hline TIRF & $6.00 \%$ & $14.00 \%$ \\
\hline
\end{tabular}

Tabla 79

Sensibilidad por Costo Variable

\begin{tabular}{|c|c|c|}
\hline \multicolumn{3}{|c|}{ Costo Variable } \\
\hline $\begin{array}{l}\text { Variación de Costo } \\
\text { Variable }\end{array}$ & $7.59 \%$ & $17.64 \%$ \\
\hline VANE & 0 & S/. $-70,449.07$ \\
\hline TIRE & $15.00 \%$ & $19.00 \%$ \\
\hline VANF & S/. 70,681.57 & 0 \\
\hline TIRF & $5.00 \%$ & $15.00 \%$ \\
\hline
\end{tabular}




\subsubsection{Análisis de escenarios}

Para el análisis de escenarios se consideró la matriz EFE (Ver figura 8), donde se detallan las oportunidades y amenazas del sector. El escenario optimista se basó en un aumento de ventas debido a que el ingreso promedio del consumidor peruano va aumentando así como el gasto por comer fuera de casa. A la vez en el escenario pesimista las ventas pueden bajar debido al alza de la inflación, ya que los costos de materias primas pueden aumentar afectando el precio del producto final, así como también se consideraron los desastres naturales que pueden generarse en el tiempo.

Las variaciones en las ventas y costos, de los escenarios: (a) pesimista y (b) optimista, se muestran en la tabla 80 .

Tabla 80

Análisis de Escenarios

\begin{tabular}{|c|c|c|c|}
\hline \multicolumn{4}{|c|}{$\begin{array}{l}\text { Resumen del } \\
\text { Escenario }\end{array}$} \\
\hline & Valores Actuales & Optimista & Pesimista \\
\hline \multicolumn{4}{|c|}{ Celdas cambiantes: } \\
\hline Precio & S/. 38.057 & S/. 41.86 & $\mathrm{~S} / 34.44$ \\
\hline Ventas & S/. 2,801,131 & S/. 3,081,045 & S/. 2,612,927 \\
\hline \multicolumn{4}{|l|}{$\begin{array}{l}\text { Celdas de } \\
\text { resultado: }\end{array}$} \\
\hline VANE & S/. 208,214.27 & S/. 700,613.00 & S/. - $122,850.41$ \\
\hline TIRE & $27 \%$ & $51 \%$ & $8 \%$ \\
\hline VANF & S/. 138,219.84 & S/. 629,760.05 & S/. -192,267.61 \\
\hline TIRF & $35 \%$ & $110 \%$ & $-15 \%$ \\
\hline
\end{tabular}




\subsubsection{Matriz de Riesgos Financieros}

Tabla 81

Matriz de Riesgos

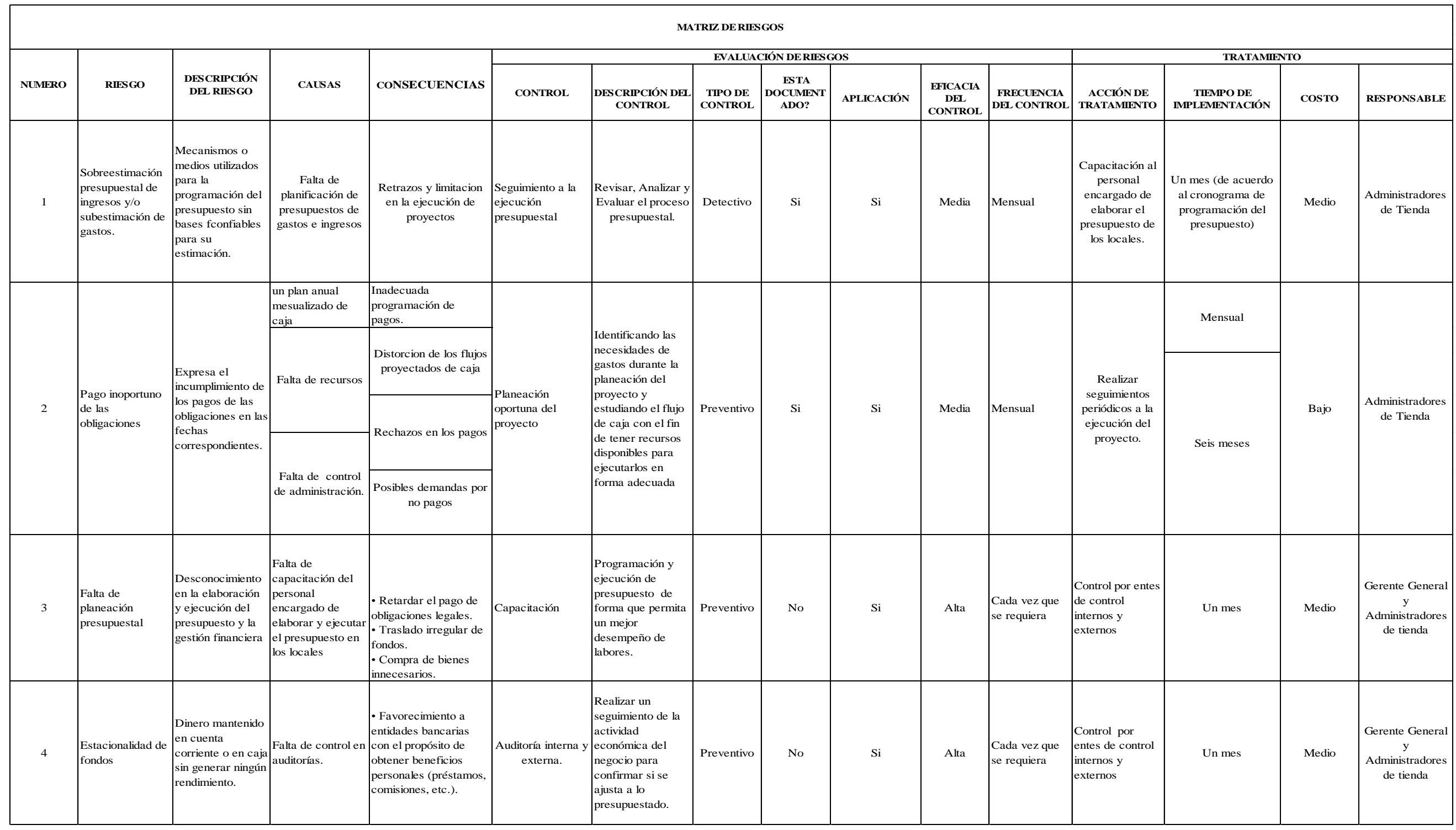




\section{Conclusiones y Recomendaciones}

\section{Conclusiones}

- La idea del plan de negocios fue innovar con un restaurante de pizzas en el cual los consumidores puedan disfrutar la experiencia de realizar sus propias combinaciones con variedad ingredientes. Es por ello que la principal ventaja competitiva es la diferenciación.

- La infraestructura y localización demostraron aceptación por parte del público objetivo puesto que se encuentra dentro de los centros comerciales los cuales están estratégicamente ubicados.

- Se implementó un plan operativo en el cual se pudo determinar los procesos productivos y operacionales, hacia la optimización de los diferentes recursos.

- Se realizó un estudio y análisis del mercado en donde se obtuvo resultados viables y factibles en temas financieros. Por lo tanto, se puede concluir que se obtuvo una TIR del $27 \%$ y una TIRF del $35 \%$ y El VAN que se obtuvo en el proyecto es S/. 208,214.27; el cual es positivo, por lo tanto indica que el proyecto es suficiente para recuperar el capital invertido.

- El restaurante cuenta con tecnología especializada, lo que garantiza tiempos óptimos en atención al cliente. A la vez se cuenta con personal capacitado para uso de maquinaria especializada.

\section{Recomendaciones}

- Se debe continuar con la evaluación del proyecto para abrir más locales en Lima Metropolitana, puesto que los estudios fueron positivos en temas financieros y a la vez indican que el público objetivo está dispuesto a consumir el producto. 
- Realizar diferentes procesos para mejorar y optimizar los recursos materiales y humanos de la empresa, de esa forma reducir diferentes costos.

- Innovar constantemente en tecnología y capacitaciones al personal, e ir ajustando el concepto a las necesidades del mercado en cuanto a precios, preferencias, etc.

- Invertir en publicidad y promociones, en redes sociales como volanteo dentro de centros comerciales, a medida que la pizzería tenga una creciente demanda para ampliar la venta de productos y fijar estrategias de fidelización de clientes, ya que el posicionamiento de marca será crucial el primer año.

- Actualmente las ventas por delivery por aplicativo significan un gran porcentaje para los restaurantes. Pizza lab tiene un concepto y producto que es fácilmente adaptable operativamente para trabajar con delivery por aplicativo.

- Los octógonos en los productos alimenticios empaquetados, representan una amenaza para las empresas, y en algún momento llegará a los restaurantes. Pizza lab tiene la suficiente variedad y adaptabilidad para hacer frente ante un hecho como este; considerando que tiene productos veganos y vegetarianos para captar a un público más saludable. 


\section{Referencias:}

Arbaiza, L., Cánepa, M., Cortez, O., y Lévano, G. (2014). Análisis prospectivo del sector de comida rápida en Lima 2014- 2030. Recuperado de https://www.esan.edu.pe/publicaciones/2014/11/06/Comida\%20rapida\%20para\%20w eb.pdf

Arbaiza, L. (2015). Como elab<orar un plan de negocio. Lima, Perú: Esan Ediciones.

Aizega, J.M. (2016). La cocina como motor de cambio. Recuperado de http://www.bculinary.com/es/noticias/la-cocina-como-motor-de-cambio-articulo-dejoxe-mari-aizega-director-general-de-basque-culinary-center

Amiel, J. (2014). Metodología y Diseño de la Investigación Científica. Lima, Perú: Fondo Editorial de la Universidad Científica del Sur.

Andrade, N., Morales, M., y Andrade, C. (2008). Segmentación del mercado como base para el posicionamiento de las franquicias de comida rápida en el municipio Maracaibo. Revista: Multiciencias. Tomado de http://www.redalyc.org/pdf/904/90480111.pdf

Amaro J. (2015). Uso de Smartphone en Perú es uno de los más crecientes en Latinoamérica. Recuperado de http://larepublica.pe/marketing/4540-uso-de-smartphones-en-peru-esuno-de-los-mas-crecientes-en-latinoamerica

Arellano Marketing (2017). Estilos de Vida. Recuperado de http://www.arellanomarketing.com/inicio/estilos-de-vida/

Ávila, F., Orellana, J., y Vera, S. (2016). Implementación de fast food con enfoque de comida rápida a base de pastas - “FASTTAS” (Tesis de maestría). Universidad Peruana de Ciencias Aplicadas, Lima, Perú. 
Baca, G. (2013). Evaluación de Proyectos (7ma ed.). México, D.F: Interamericana Editores, S.A

Barki, J. (2010). Conoce las 10 cadenas de fast food más grandes del mundo. Recuperado de https://www.planetajoy.com/?page=ampliada\&id=1699

Bernal, C.A. (2010). Metodología de la Investigación (3ra ed.).Bogotá, Colombia: Pearson Education

BCRP (2017). Inflación. Recuperado de https://estadisticas.bcrp.gob.pe/estadisticas/series/mensuales/inflacion

Bohlander, S., y Snell, S. (2013). Administración de Recursos Humanos (16a ed.). México, DF: Cengage Learning, Inc.

Cépeda, L., y Javier, C. (2006). Estudio de pre-factibilidad para la implementación de una cadena de comidas rápidas en base a pollo en Lima Norte. (Tesis de licenciatura). Pontificia Universidad Catolice del Perú, Lima, Perú

Chipotle (2017, Marzo 25.). Comida con Integridad. Recuperado de https://www.chipotle.com/food-with-integrity

Código.pe (2017, febrero 28), Fast food en Perú: con rentabilidad del $20 \%$ y con ventas de US\$700 millones este año. Recuperado de https://codigo.pe/marcas/fast-food-perurentabilidad-del-20-ventas-us700-millones-este-ano

Contreras C. (2015). Joxe Mari Aizega: La innovación es casi una actitud. Recuperado de http://elcomercio.pe/gastronomia/internacional/joxe-mari-aizega-innovacion-actitud38872 
Cuesta, M., y Herrero, F. (2014): Introducción al Muestreo. Recuperado de http://mey.cl/apuntes/muestrasunab.pdf

David, F. (2013). Administración Estratégica (14ta ed.). México. DF: Pearson Educación

Diaz, D., Merino, E.P., y Salas, G. (2015). Plan de Negocio Para La Implementación de un Restaurante Pizzería Fusión Italo-Andina (Tesis de maestría inédita). Universidad Del Pacifico, Lima, Perú.

Digesa (2005). Norma sanitaria sobre el procedimiento para la aplicación del sistema HACCP en la fabricación de alimentos y bebidas. Recuperado de http://www.digesa.minsa.gob.pe/norma_consulta/proy_haccp.htm

El Comercio (2010, Marzo 28), El paso a paso para abrir un restaurante. Recuperado de http://elcomercio.pe/gastronomia/peruana/paso-paso-abrir-restaurante-noticia-453275

El comercio (2017, agosto 01), Top10: Conoce las marcas que dominan el mercado peruano de comida rápida, el comercio. Recuperado de http://elcomercio.pe/economia/negocios/fast-food-peru-10-marcas-dominan-mercadonoticia-446415

El Comercio (2018, Agosto 29), MEF proyecta una mayor inflación que el BCR al 2022. Recuperado de: https://elcomercio.pe/economia/peru/mef-proyecta-mayor-inflacionbcr-2022-noticia-551682

El Pino (2017, Setiembre 7), Los 3 pasos para abrir un establecimiento dentro de un centro comercial en el Perú. Recuperado de: https://www.elpino.com.pe/los-3-pasos-abrirestablecimiento-comercial-peru/ 
Euromonitor (2016). Passport de Comida rápida en Perú: 2016. Recuperado de http://www.euromonitor.com/

Ferrell O.C., y Hartline M. (2012). Estrategia de Marketing (5ta ed.). México: Cengace Learning.

Francés, A. (2006). Estrategia y Planes para la Empresa con el Cuadro de Mando Integral. México, México: Pearson Education.

Gestión (2017, Julio 31). El pollo se impone: Norky's, Roky's y KFC lideran ventas de restaurantes y fast food. Recuperado de http://gestion.pe/empresas/pollo-se-imponenorkys-rokys-y-kfc-lideran-ventas-restaurantes-y-fast-food-2196423

Gestión (2017). CCL proyecta crecimiento económico para Perú de $2.6 \%$ en 2017 y $3.5 \%$ en el 2018. Recuperado de http://gestion.pe/economia/ccl-proyecta-crecimientoeconomico-peru-26-2017-y-35-2018-2198845

Gestión (2016). IGV: Perú es la cuarta economía con la tasa más alta en la región. Recuperado de http://gestion.pe/economia/igv-peru-cuarta-economia-tasa-mas-altaregion-2165771

Gestión (2015, abril 01), Más del 70\% de limeños acude cada quince días a los fast food. Recuperado de http://gestion.pe/mercados/mas-70-limenos-acude-cada-quince-diasfast-food-2127840

Gestión (2017, Junio 20), SNI advierte: Ley de Alimentación Saludable no contempla a 'fast food' ni restaurantes. Recuperado de https://gestion.pe/economia/sni-advierte-leyalimentacion-saludable-contempla-fast-food-restaurantes-137647 
Gestión (2018, Agosto 24), MEF elevó su proyección de crecimiento del PBI de $3.6 \%$ a 4\% para 2018. Recuperado de: https://gestion.pe/economia/mef-elevo-3-6-4-proyeccioncrecimiento-pbi-2018-nndc-242539

Gitman, L. J., y Zutter, C. J. (2016). Administración Financiera (14ta ed.). México, D.F: Pearson Education

Hernández, R., Fernández, C., y Baptista, P. 2014). Metodología de la investigación (6ta ed.). México: McGraw-Hill / Interamericana Editores, S.A. DE C.V.

Hill, C., y Jones, G. (2009). Administración Estratégica (8va ed.). México D.F, México: McGraw-Hill/Interamericana Editores, SA de C.V.

Hitt, M., Black, S., y Porter, L. (2012). Administración. México, DF: Pearson Educación

INEI (2017 a). Boletín Estadístico Encuesta Mensual del Sector Servicios Julio 2017.

Recuperado de http://m.inei.gob.pe/biblioteca-virtual/boletines/

INEI (2010 b). Clasificación Industrial Internacional Uniforme de todas las actividades económicas Revisión 4. Recuperado de https://www.inei.gob.pe/media/MenuRecursivo/publicaciones_digitales/Est/Lib0883/ Libro.pdf

INEI (2017 c). Comportamiento de la Economía Peruana en el Segundo Trimestre de 2017. Recuperado de https://www.inei.gob.pe/media/MenuRecursivo/boletines/03-informetecnico-n03_producto-bruto-interno-trimestral-2017ii.pdf

INEI (2017 d). Lima Metropolitana: Remuneraciones mínima vital mensual. Recuperado de https://www.inei.gob.pe/estadisticas/indice-tematico/salaries/

INEI (2015 e). Población económicamente activa, según ámbitos geográficos. Recuperado de https://www.inei.gob.pe/estadisticas/indice-tematico/ocupacion-y-vivienda/ 
INEI (2017 f). Población total al 30 de junio de cada año, según sexo y grupos de edad. Recuperado de https://www.inei.gob.pe/estadisticas/indice-tematico/poblacion-yvivienda/

INEI (2017 g). Población total al 30 de junio de cada año, según sexo y grupos de edad. Recuperado de https://www.inei.gob.pe/estadisticas/indice-tematico/poblacion-yvivienda/

INEI (2017 h). Precios Promedio al Consumidor de Cereales y Derivados. Recuperado de http://iinei.inei.gob.pe/iinei/siemweb/publico/

INEI (2017 i). Producto Bruto Interno Total y por Habitante 1994-2016 (Valores a precios corrientes). Recuperado de https://www.inei.gob.pe/estadisticas/indicetematico/economia/

IPSOS (2013 c). Distribución de Lima Metropolitana según Nivel Socioeconómico. Recuperado de https://www.ipsos.com/es-pe/niveles-socieconomicos-de-la-gran-lima

IPSOS (2014 d). Estadística Poblacional 2014. Recuperado de https://www.ipsos.com/sites/default/files/publication/201402/Estadistica_poblacional_2014.pdf

IPSOS (2013 e). Gasto Mensual Familiar destinado a Alimentación por NSE en Lima Metropolitana. Recuperado de https://www.ipsos.com/espe/search?search=gasto+mensual

IPSOS (2017 a). Mapa con Información Socioeconómica de Lima Metropolitana. https://www.ipsos.com/es-pe/mapinse-lima-2017

IPSOS (2012 b). Perfiles Zonales de Lima Metropolitana, 2013. Lima, Perú: Depósito Legal $\mathrm{N}^{\circ} 2012-08467$. 
IPSOS (2016 f). Perfil del adulto joven. https://www.ipsos.com/es-pe/perfil-del-adulto-joven2016

Juárez, J., \& Palomino, S. (2016). Pizza Express (Tesis de Licenciatura). Universidad de Lima, Lima, Perú.

Kotler, P., y Armstrong, G. (2012). Marketing (14ta ed.). México D.F, México: Pearson Education

Kotler, P., y Keller, K. (2012). Dirección de Marketing (14ta ed.). México D.F, México: Pearson Education

Kotler, P., \& Keller, K. (2016). Dirección de Marketing (15ta ed.). México D.F, México: Pearson Education

Lambin, J. (2009). Dirección de Marketing (2da ed.). México D.F, México: Mcgraw Hill.

La República (2019, Enero 25), ¿Cómo deducir gastos en hoteles, restaurantes y bares, y pagar menos Impuesto a la Renta? Recuperado de: https://larepublica.pe/economia/1387289-conoce-pasos-deducir-gastos-restauranteshoteles-bares

Lovelock C., Wirtz J. (2015). Marketing de Servicios (6ta ed.). México, D.F: Pearson.

Malhotra N. (2008). Investigación de mercados (5ta ed.). México: Pearson Educación

Mott.pe (2015). Conoce como se está moviendo el mercado de los fast food en el Perú.

Recuperado de https://mott.pe/noticias/conoce-como-se-esta-moviendo-el-mercadode-los-fast-food-en-el-peru

Morales, A., y Morales, J.A. (2009). Proyectos de Inversión Evaluación y Formulación. México, DF: Interamericana Editores, S.A 
Munlima (2016). Ley de seguridad y salud en el trabajo. Recuperado de http://www.munlima.gob.pe/images/descargas/Seguridad-Salud-en-elTrabajo/Ley\%2029783\%20_\%20Ley\%20de\%20Seguridad\%20y\%20Salud\%20en\%2 0e1\%20Trabajo.pdf

Núñez J. (2016). Se imponen los restaurantes sostenibles, ecológicos. Recuperado de http://diariodegastronomia.com/pagariamos-mas-comer-restaurante-sostenible/

Ochoa, V. (2015). Más del 70\% de limeños acude cada quince días a los fast food. Recuperado de http://gestion.pe/mercados/mas-70-limenos-acude-cada-quince-diasfast-food-2127840

Papa John`s (2017). Historia. Recuperado de http://papajohns.com.pe/conocenos/

Peña, E. (2017). Las mejores aplicaciones móviles de delivery para Android e iOS en Perú. Recuperado de https://www.vexsoluciones.com/apps-moviles/mejores-aplicacionesde-delivery-android-ios-peru/

Pino, R. (2010). Manual de Investigación Científica. Lima, Perú: Biblioteca Nacional del Perú

Pizza Hut (2017). Nuestra historia. Recuperado de https://www.pizzahut.com.pe/Online

Pizza Raúl (2017). Quienes somos. Recuperado de http://www.pizzasraul.com/nosotros.html

Ponte en carrera (2016 a) Remuneración promedio mensual, mínima, máxima de jóvenes profesionales técnicos, según familia de carreras, 2016. Recuperado de https://www.ponteencarrera.pe/como-va-el-empleo\#cuanto-ganan

Ponte en carrera (2016 b) Remuneración promedio mensual, mínima, máxima de jóvenes profesionales universitarios, según familia de carreras, 2016. Recuperado de https://www.ponteencarrera.pe/como-va-el-empleo\#cuanto-ganan 
Porter, M. (2010). Ventaja Competitiva Creación y Sostenibilidad de un Rendimiento Superior. Madrid, España: Editorial Continental, S.A.

Porter, M. (2013). Estrategia Competitiva Técnicas Para El Análisis De La Empresa y Sus Competidores. Madrid, España: Editorial Continental, S.A.

PlanetaJoy (2010, Junio 24). Conoce las 10 cadenas de fast food más grandes del mundo. Recuperado de https://www.planetajoy.com/?page=ampliada\&id=1699

Prialé, J. (2017). Pulso Perú: Un 56\% de peruanos dispuestos a gastar más en malls en próximos 12 meses. Recuperado de http://gestion.pe/economia/crecen-43-56peruanos-dispuestos-gastar-mas-malls-proximos-12-meses-2197611

PerúRetail (2015, Diciembre 03). Panorama del mercado fast food en el Perú. Recuperado de http://www.peru-retail.com/panorama-del-mercado-fast-food-en-el-peru/

PerúRetail (2016, Octubre 31). ¿Cómo se desarrolla el mercado de la pizza en el Perú? Recuperado de http://www.peru-retail.com/estudio-investigacion/como-se-desarrollael-mercado-de-la-pizza-en-peru/

PerúRetail (2017, Junio 02). Cadenas de fast food superan las 800 tiendas en Perú. Recuperado de http://www.peru-retail.com/cadenas-fast-food-superan-800-tiendasperu/

PerúRetail (2017, Abril 24). El negocio de los "fast food" en el mercado peruano. Recuperado de http://www.peru-retail.com/negocio-fast-food-mercado-peruano/

Rodríguez, M., y Lamas, A. (2011). El consumo de Comida Rápida Situación en el Mundo y acercamiento autonómico. Recuperado de http://www.abc.es/gestordocumental/uploads/Sociedad/comida-rapida.pdf 
Salas L. (2016). El mercado de las pizzas se prepara para la guerra. Recuperado de http://elcomercio.pe/economia/dia-1/mercado-pizzas-prepara-guerra-274099

Sapag, N. (2011). Proyectos de Inversión: Formulación y Evaluación (2da ed.). México: Pearson.

Subway (2016). La Historia de los Restaurantes Subway. Recuperado de http://www.subway.pe/quienes_somos.php\#

Sunat (2017 a). Consulta RUC. Recuperado de www.sunat.gob.pe/cl-ti-itmrconsruc/jcrS00Alias

Sunat (2016 b). Régimen de Percepciones del IGV. Recuperado de http://orientacion.sunat.gob.pe/index.php/empresas-menu/regimen-de-percepcionesdel-igv-empresas/regimen-de-percepciones-informacion-general/3458-01-regimen-depercepciones-del-igv

Sunat (2016 c). Texto único ordenado de la ley del impuesto a la renta. Recuperado de http://www.sunat.gob.pe/legislacion/renta/ley/fdetalle.htm

Telepizza (2017). Nuestra historia. Recuperado de https://www.telepizza.com/compania/ Wheelen, T. y Hunger, D. (2013). Administración Estratégica y Política de Negocios (13ra ed.). México: Pearson Education. 


\section{Anexos}

Anexo 1. Guía de Pautas Entrevistas a profundidad

\section{a. Entrevista para experto en la Industria de Fast Food}

\section{Introducción}

Buenos días/tardes. Mi nombre es Vladimir y estamos realizando un estudio sobre un restaurante fast food. La idea es poder conocer distintas opiniones para colaborar con el desarrollo e implementación de este restaurante. En este sentido, siéntase libre de compartir sus ideas en este espacio. Aquí no hay respuestas correctas o incorrectas, lo que importa es justamente su opinión sincera. Cabe aclarar que la información es sólo para el trabajo, sus respuestas serán unidas a otras opiniones de manera anónima y en ningún momento se identificará qué dijo cada participante. Para agilizar la toma de la información, esta conversación será grabada. Tomar notas a mano demora mucho tiempo y se pueden perder información importante. El uso de la grabación es sólo a los fines de análisis. Desde ya muchas gracias por su tiempo.

\section{Investigación sobre el sector}

¿Considera que aún existe mercado en la industria de fast food?

¿Con tantos nuevos conceptos de restaurantes y servicios que se crean, los fast food mantendrán sus ventas en los próximos años?

¿Qué tan altas son las barreras de entradas para ubicar el restaurante en un centro comercial? ¿Qué es lo primero que se te viene a la mente cuando escuchas "pizzas personalizadas"?

\section{Estudio en profundidad}

A continuación le hablaré del proyecto que estamos desarrollando. Se trata de un restaurante de comida rápida que busca integrar todos los ingredientes de una pizza con una línea de 
servicio interactiva en la que el cliente podrá personalizar su pedido, mediante la selección de los ingredientes que se ofrecen, entre los que se encuentran el tipo de masa, el tipo de queso, verduras, proteínas, salsas, hortalizas, embutidos, frutas, y condimentos. El nombre del negocio será Pizza Lab.

¿Qué tipo de local se te viene a la mente luego de haber escuchado el concepto?

¿Qué opina sobre esta idea de negocio?

¿Hasta qué segmento de mercado cree que pueda abarcar este producto/servicio?

¿Con qué asoció el nombre "Pizza Lab"?

¿Qué sensación le brindan los colores?

¿Dónde le gustaría encontrar este concepto?

¿Cuál es el mejor medio de comunicación para enterarse de un restaurante nuevo?

¿Cree que este restaurante debe vender solo pizzas o debería tener algún alimento adicional complemento?

¿Considera que el concepto se relaciona más con una ubicación en un patio de comidas o $\mathrm{n}$ restaurante cerrado?

¿Considera algún centro comercial en especial para ubicar el concepto?

¿Cuál debería ser el rango de precios del producto?

¿Considera que solo debería vender pizzas personales o también familiares?

¿Operativamente, a grandes rasgos, crees que podría haber algún inconveniente?

¿La opción de comprar por delivery sería factible?

¿Considera que es buena opción vincular esta idea con un app de Smartphone?

\section{Cierre}

¿Qué tan interesado está en asistir a este establecimiento? ¿Por qué?

¿Qué no le gustó del proyecto? o ¿En qué podría mejorar? 
¿Desea compartir una opinión como conclusión? ¿Alguna sugerencia?

\section{b. Entrevista para experto en la elaboración de proyectos de restaurante}

\section{Introducción}

Buenos días/tardes. Mi nombre es Vladimir y estamos realizando un estudio sobre un restaurante fast food. La idea es poder conocer distintas opiniones para colaborar con el desarrollo e implementación de este restaurante. En este sentido, siéntase libre de compartir sus ideas en este espacio. Aquí no hay respuestas correctas o incorrectas, lo que importa es justamente su opinión sincera. Cabe aclarar que la información es sólo para el trabajo, sus respuestas serán unidas a otras opiniones de manera anónima y en ningún momento se identificará qué dijo cada participante. Para agilizar la toma de la información, esta conversación será grabada. Tomar notas a mano demora mucho tiempo y se pueden perder información importante. El uso de la grabación es sólo a los fines de análisis. Desde ya muchas gracias por su tiempo.

\section{Investigación sobre el sector}

¿Considera que aún existe mercado en la industria de fast food?

¿Con tantos nuevos conceptos de restaurantes y servicios que se crean, los fast food mantendrán sus ventas en los próximos años?

¿Qué tan altas son las barreras de entradas para abrir un fast food?

¿Qué es lo primero que se te viene a la mente cuando escuchas "pizzas personalizadas"?

\section{Estudio en profundidad}

A continuación le hablaré del proyecto que estamos desarrollando. Se trata de un restaurante de comida rápida que busca integrar todos los ingredientes de una pizza con una línea de 
servicio interactiva en la que el cliente podrá personalizar su pedido, mediante la selección de los ingredientes que se ofrecen, entre los que se encuentran el tipo de masa, el tipo de queso, verduras, proteínas, salsas, hortalizas, embutidos, frutas, y condimentos. El nombre del negocio será Pizza Lab.

¿Qué tipo de local se te viene a la mente luego de haber escuchado el concepto?

¿Qué opina sobre esta idea de negocio?

¿Con qué asoció el nombre "Pizza Lab”?

¿Cuál sería el área por m2 mínima para que pueda operar este restaurante?

¿Cuál es el equipamiento necesario para abrir un restaurante de este tipo?

¿Qué tipos de permisos se requieren para comenzar este tipo de proyectos?

¿Cuánto tiempo tomaría armar este establecimiento físicamente hablando?

¿Dónde le gustaría encontrar este concepto?

¿Considera que el concepto se relaciona más con una ubicación en un patio de comidas o un restaurante cerrado?

¿Considera algún centro comercial en especial para ubicar el concepto?

¿Operativamente, a grandes rasgos, crees que podría haber algún inconveniente?

¿La opción de comprar por delivery sería factible?

¿Considera que es buena opción vincular esta idea con un app de Smartphone?

\section{Cierre}

¿Qué tan interesado está en asistir a este establecimiento? ¿Por qué?

¿Qué no le gustó del proyecto? o ¿En qué podría mejorar?

¿Desea compartir una opinión como conclusión? ¿Alguna sugerencia? 


\section{c. Entrevista para experto en cocina}

\section{Introducción}

Buenos días/tardes. Mi nombre es Vladimir y estamos realizando un estudio sobre un restaurante fast food. La idea es poder conocer distintas opiniones para colaborar con el desarrollo e implementación de este restaurante. En este sentido, siéntase libre de compartir sus ideas en este espacio. Aquí no hay respuestas correctas o incorrectas, lo que importa es justamente su opinión sincera. Cabe aclarar que la información es sólo para el trabajo, sus respuestas serán unidas a otras opiniones de manera anónima y en ningún momento se identificará qué dijo cada participante. Para agilizar la toma de la información, esta conversación será grabada. Tomar notas a mano demora mucho tiempo y se pueden perder información importante. El uso de la grabación es sólo a los fines de análisis. Desde ya muchas gracias por su tiempo.

\section{Investigación sobre el sector}

¿Considera que aún existe mercado en la industria de fast food?

¿Con tantos nuevos conceptos de restaurantes y servicios que se crean, los fast food seguirán evolucionando su producto?

¿Qué tan difícil es entrar a competir con productos de comida rápida ya establecidos?

¿Qué es lo primero que se te viene a la mente cuando escuchas “pizzas personalizadas”?

\section{Estudio en profundidad}

A continuación le hablaré del proyecto que estamos desarrollando. Se trata de un restaurante de comida rápida que busca integrar todos los ingredientes de una pizza con una línea de servicio interactiva en la que el cliente podrá personalizar su pedido, mediante la selección de los ingredientes que se ofrecen, entre los que se encuentran el tipo de masa, el tipo de queso, 
verduras, proteínas, salsas, hortalizas, embutidos, frutas, y condimentos. El nombre del negocio será Pizza Lab.

¿Qué tipo de local se te viene a la mente luego de haber escuchado el concepto?

¿Qué opina sobre esta idea de negocio?

¿Qué tipos de ingredientes considera que se debería ofrecer?

¿Cuántas opciones se debería tener para armar la pizza?

¿Cree que este restaurante debe vender solo pizzas o debería tener algún alimento adicional complemento?

¿Qué tamaño debería tener una pizza personal?

¿Cuál es el espacio mínimo que debería tener el proyecto para operar?

¿Qué tipo de equipamiento de cocina es necesario para este tipo de restaurante?

¿Considera que solo debería vender pizzas personales o también familiares?

En su experiencia, ¿Cuánto tiempo tomaría preparar una de estas pizzas?

¿Dónde le gustaría encontrar este concepto?

¿Con qué tipo de bebidas se combinaría este producto?

¿La opción de comprar por delivery sería factible?

¿Considera que el concepto se relaciona más con una ubicación en un patio de comidas o un restaurante cerrado?

¿Operativamente, a grandes rasgos, crees que podría haber algún inconveniente?

\section{Cierre}

¿Qué tan interesado está en asistir a este establecimiento? ¿Por qué?

¿Qué no le gustó del proyecto? o ¿En qué podría mejorar?

¿Desea compartir una opinión como conclusión? ¿Alguna sugerencia? 
Anexo 2. Guía de Pautas Focus Group

\section{Introducción}

Buenos días/tardes mi nombre es Andrea/Vladimir/Marycruz. Como verán, les hemos pedido poner su nombre, les agradecemos, porque eso hará que podamos mantener una mejor comunicación. Nos gustaría que cada uno de ustedes nos indique su edad y en dónde viven. Muchas gracias

¿Quisiera saber si saben para qué estamos reunidos?

Les comento. Estamos reunidos para discutir sobre un tema que ustedes conocen bien, por este motivo nos gustaría pedirles que sean totalmente sinceros y no se dejen influenciar por nadie. Además, nos gustaría comunicarles que no existen respuestas correctas ni incorrectas, todas las respuestas son totalmente válidas. También nos gustaría solicitar su autorización para que esta sesión sea grabada, ya que sus opiniones son muy importantes y probablemente por la fluidez no se podrán hacer algunos apuntes, y la memoria es frágil. Finalmente, tengo que pedirles que apaguen o pongan en vibrador sus celulares.

\section{Calentamiento}

\section{- Hábitos de consumo de pizza}

¿Nos gustaría saber si suelen consumir pizza?

¿Por qué consumen pizza?

¿Lo hacen en alguna ocasión en especial?

¿Cuál es el tipo de pizza de su preferencia?

¿Con qué complemento sueles acompañar tu pizza?

¿Con qué frecuencia consumes pizza?

¿Suelen consumirla de noche o por el día?

¿Suele consumir en tienda o por delivery? 
¿Con qué frecuencia lo hace en ambos casos?

\section{- Hábitos de consumo general}

¿Al momento de un almuerzo prefieren un fast food o un restaurante tradicional? ¿Por qué? ¿Cuánto presupuesto destinan diariamente a un almuerzo o cena fuera de casa?

¿En los últimos doce meses, que tipo de restaurante considera que son a los que más ha concurrido y con qué frecuencia?

¿Cuál es el momento del día más importante para la visita de un restaurante?

Si pudiese mencionar los principales factores que influyen en su decisión por un restaurante ¿Cuáles serían?

¿Qué nuevas ideas podría aportar para un restaurante? ¿Qué le gustaría que existiese en un restaurante?

¿Estaría dispuesto a visitar diariamente un solo restaurante que ofrece diversas opciones de comida?

¿A qué lugares fast food suele ir con mayor frecuencia? ¿Por qué?

¿Les agrada la decoración de los fast food a los que ha asistido? ¿Qué nuevas ideas podrían proponer?

¿Suelen visitar centros comerciales para comer? ¿Por qué?

\section{- Competencia}

¿Qué restaurantes de pizzas conocen?

¿Pueden hacer un ranking de sus pizzerías preferidas? ¿Por qué?

¿Qué atributos valoran más en una pizzería?

Para ustedes, ¿cómo sería la pizzería ideal? En cuanto a la música, ambientación, iluminación y ubicación. 


\section{Estudio en profundidad}

\section{- Evaluación de Concepto}

¿Ha oído hablar del concepto de comidas personalizadas?

A continuación les hablaremos del proyecto que estamos desarrollando. Se trata de un restaurante de comida rápida que busca integrar todos los ingredientes de una pizza con una línea de servicio interactiva en la que el cliente podrá personalizar su pedido, mediante la selección de los ingredientes que se ofrecen, entre los que se encuentran el tipo de masa, el tipo de queso, verduras, proteínas, salsas, hortalizas, embutidos, frutas, y condimentos. El nombre del negocio será Pizza Lab.

¿Estaría interesado en este concepto?

\section{- MOSTRAR IMÁGENES DE LOCAL, COMIDA Y TIPO DE SERVICIO}

¿Qué características les parece la más importante del concepto en general?

¿Con qué frecuencia irían?

¿Dónde les gustaría encontrar este concepto?

¿En qué momento del día irían al local?

¿Qué nombre le darían al concepto o con qué lo relacionarían?

¿Les gustaría encontrar solo opciones personales, o también familiares?

¿Consideran que debe venderse otro tipo de alimentos junto a este concepto?

¿Pedirían estas pizzas por delivery?

\section{- Evaluación de Marca}

¿Con qué asociaron el nombre Pizza Lab?

¿Cuál de los tres siguientes logos tiene más relación con el concepto? 
¿Qué sensaciones les brindan los colores?

¿Por qué medio de comunicación les gustaría enterarse de este restaurante?

\section{Cierre}

¿Qué tan interesados están en asistir a este establecimiento? ¿Por qué?

¿Qué no les gustó del proyecto? o ¿En qué podría mejorar?

¿Desean compartir una opinión como conclusión? ¿Alguna sugerencia? 
Anexo 3. Filtro de Nivel Socioeconómico

Sr. / Sra. /Joven, Con la finalidad de agrupar sus respuestas con las de otras personas de similares características a las de usted, nos gustaría que responda a las siguientes preguntas.

1. ¿Quién es la persona que aporta MÁS al sostenimiento económico de su hogar? (E: 1. Si identifica a dos personas o más, preguntar por la de mayor edad. 2. Si la persona que más aporta no vive en el hogar, preguntar por la que administra los ingresos que recibe de la persona ausente.)

2. Las siguientes preguntas se refieren a... que es la persona que aporta MÁS al sostenimiento de su hogar (E: según pregunta 1)

N1 ¿Cuál es el nivel de instrucción del jefe de hogar (E: mencione a la persona que aporta más al sostenimiento del hogar)? (ACLARAR “COMPLETA O INCOMPLETA”) 
Sin educación

Superior no universitaria

Completa

Educación inicial / Primaria Incompleta

Superior universitaria

incompleta

Primaria completa/ Secundaria incompleta/

Secundaria completa

Superior universitaria

completa

Superior No Universitaria Incompleta

Post-Grado universitario

N2. ¿Cuál de estos bienes tiene en su hogar que esté funcionando?

O I

Computadora o laptop en funcionamiento

Lavadora en funcionamiento

Teléfono fijo en funcionamiento

Refrigeradora / congeladora en funcionamiento

Horno microondas en funcionamiento

N3.

a. ¿Cuántas personas viven permanentemente en el hogar? (sin incluir el servicio doméstico) (ANOTAR)

b. ¿Cuántas habitaciones tiene en su hogar (no vivienda) que actualmente use exclusivamente para dormir (incluir la de servicio doméstico)? 


\begin{tabular}{|c|c|c|c|c|c|c|c|c|c|c|c|}
\hline $\begin{array}{l}\text { b. Habitaciones } \\
\text { exclusivamente para } \\
\text { dormir incluyendo la del }\end{array}$ & $\begin{array}{l}\text { c. Miembros del } \\
\text { hogar sin incluir } \\
\text { el servicio } \\
\text { doméstico }\end{array}$ & & & & & & & & & & \\
\hline & $1-2$ & 3 & 4 & $\begin{array}{l}5- \\
6\end{array}$ & $\begin{array}{l}\text { 7- } \\
8\end{array}$ & 9 & 10 & $\begin{array}{l}11- \\
12\end{array}$ & $\begin{array}{l}13- \\
14\end{array}$ & 15 & 16 \\
\hline 0 habitaciones & 0 & 0 & 0 & 0 & 0 & 0 & 0 & 0 & 0 & 0 & 0 \\
\hline 1 habitación & 7 & 4 & 2 & 1 & 0 & 0 & 0 & 0 & 0 & 0 & 0 \\
\hline 2 habitaciones & 7 & 7 & 7 & 4 & 2 & 1 & 1 & 1 & 0 & 0 & 0 \\
\hline 3 habitaciones & 7 & 7 & 7 & 7 & 4 & 4 & 2 & 2 & 1 & 1 & 1 \\
\hline 4 habitaciones & 7 & 7 & 7 & 7 & 7 & 4 & 4 & 4 & 2 & 2 & 2 \\
\hline 5 habitaciones & 7 & 7 & 7 & 7 & 7 & 7 & 7 & 4 & 4 & 4 & 2 \\
\hline 6 habitaciones & 7 & 7 & 7 & 7 & 7 & 7 & 7 & 7 & 4 & 4 & 4 \\
\hline 7 habitaciones & 7 & 7 & 7 & 7 & 7 & 7 & 7 & 7 & 7 & 4 & 4 \\
\hline 8 habitaciones & 7 & 7 & 7 & 7 & 7 & 7 & 7 & 7 & 7 & 7 & 7 \\
\hline
\end{tabular}

N4. ¿Cuál es el material predominante en los pisos de su vivienda? (CONSIDERAR ÁREA CONSTRUIDA) 
Tierra/arena/tablones sin pulir

Laminado tipo madera, láminas

asfálticas o similares

Cemento sin pulir o pulido/ madera Parquet/madera pulida y similares;

(entablados)/ tapizón

porcelanato, alfombra, mármol

Losetas/terrazos, mayólicas, cerámicos,

vinílicos, mosaico o similares

Si la vivienda es multihogar, considerar para la evaluación de pisos TODA la vivienda, así el hogar encuestado ocupe una parte.

TOTAL: SUMAR N1, N2, N3 Y N4:

ANOTAR RESULTADO Y MARCAR NSE =

\begin{tabular}{llll}
\hline PUNTAJE & NSE & PUNT
\end{tabular}

AJE SE

50 puntos

A1 (1)

De 28 a

37 puntos

$1(5)$

\begin{tabular}{|c|c|c|c|c|}
\hline De 48 a 49 & A2 (2) & \multicolumn{2}{|c|}{ De 23 a } & ( \\
\hline puntos & & 27 puntos & $2(6)$ & \\
\hline De 43 a 47 & B1 (3) & \multicolumn{2}{|c|}{ De $11 \mathrm{a}$} & ] \\
\hline puntos & & 22 puntos & (7) & \\
\hline De 38 a 42 & B2 (4) & \multicolumn{2}{|c|}{ De $0 \mathrm{a}$} & I \\
\hline puntos & & 10 puntos & (8) & \\
\hline
\end{tabular}


Anexo 4: Ficha de Reclutamiento

\section{FICHA DE RECLUTAMIENTO}

\section{Presentación}

Estamos realizando un estudio de mercado a través de focus group, por lo cual, solicitamos la participación de personas que tengan hábitos y costumbres de vida similares. Por ello, se les invita a la sesión de grupo que se realizará el día , desde las En la siguiente dirección:

\section{Filtro \#1 (hábitos de consumo)}

¿Usted ha consumido pizza en el último mes?

SÍ ( )

NO ( ) pasar a pregunta 3.

¿Qué tipo de pizza pidió?

¿Usted consume pizza?

SÍ ( )

NO ( )

Si su respuesta fue no finalice el cuestionario, si su respuesta fue sí continúe el cuestionario. 
¿En qué lugar suele consumir pizza? Marcar más de una alternativa:

( ) Restaurantes

( ) Patio de comidas

( ) Delivery

( ) Otros (especifique)

\section{Filtro \#2 (NSE)}

El formato de filtro de NSE es el mismo que se encuentra en los anexos.

\section{Datos de Control}

Nombre y Apellidos:

Edad:

Sexo: Masculino ( ) Femenino ( )

Distrito donde vive:

Distrito donde trabaja o estudia:

A continuación, se detallan las edades y distritos de residencia de cada uno de los participantes de cada focus:

\begin{tabular}{|c|c|c|}
\hline FOCUS 1 & EDAD & $\begin{array}{c}\text { DISTRITO DE } \\
\text { RESIDENCIA }\end{array}$ \\
\hline PARTICIPANTE 1 & 33 & LA MOLINA \\
\hline PARTICIPANTE 2 & 28 & MIRAFLORES \\
\hline PARTICIPANTE 3 & 35 & SURCO \\
\hline PARTICIPANTE 4 & 25 & SURCO \\
\hline PARTICIPANTE 5 & 22 & SAN MIGUEL \\
\hline PARTICIPANTE 6 & 27 & SAN BORJA \\
\hline
\end{tabular}




\begin{tabular}{|c|c|c|}
\hline FOCUS 2 & EDAD & $\begin{array}{c}\text { DISTRITO DE } \\
\text { RESIDENCIA }\end{array}$ \\
\hline PARTICIPANTE 1 & 25 & SAN MIGUEL \\
\hline PARTICIPANTE 2 & 19 & LOS OLIVOS \\
\hline PARTICIPANTE 3 & 23 & LINCE \\
\hline PARTICIPANTE 4 & 28 & LOS OLIVOS \\
\hline PARTICIPANTE 5 & 22 & LINCE \\
\hline PARTICIPANTE 6 & 26 & SURCO \\
\hline
\end{tabular}

\begin{tabular}{|c|c|c|}
\hline FOCUS 3 & EDAD & $\begin{array}{c}\text { DISTRITO DE } \\
\text { RESIDENCIA }\end{array}$ \\
\hline PARTICIPANTE 1 & 23 & SURCO \\
\hline PARTICIPANTE 2 & 27 & SAN BORJA \\
\hline PARTICIPANTE 3 & 21 & SURCO \\
\hline PARTICIPANTE 4 & 31 & SAN MIGUEL \\
\hline PARTICIPANTE 5 & 30 & MIRAFLORES \\
\hline PARTICIPANTE 6 & 28 & SURCO \\
\hline
\end{tabular}

\begin{tabular}{|c|c|c|}
\hline FOCUS 4 & EDAD & $\begin{array}{c}\text { DISTRITO DE } \\
\text { RESIDENCIA }\end{array}$ \\
\hline PARTICIPANTE 1 & 18 & ATE \\
\hline PARTICIPANTE 2 & 23 & LOS OLIVOS \\
\hline PARTICIPANTE 3 & 24 & SAN MIGUEL \\
\hline PARTICIPANTE 4 & 27 & LINCE \\
\hline PARTICIPANTE 5 & 30 & SAN MARTÍN DE PORRES \\
\hline PARTICIPANTE 6 & 27 & SURCO \\
\hline
\end{tabular}


Anexo 5: Resultados de Encuestas

Marque el género al que pertenece.

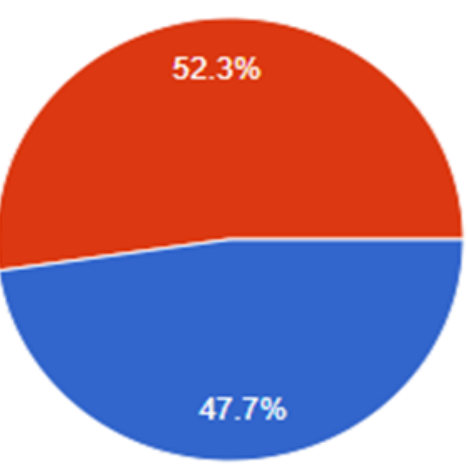

Marque el grupo de edad al que pertenece

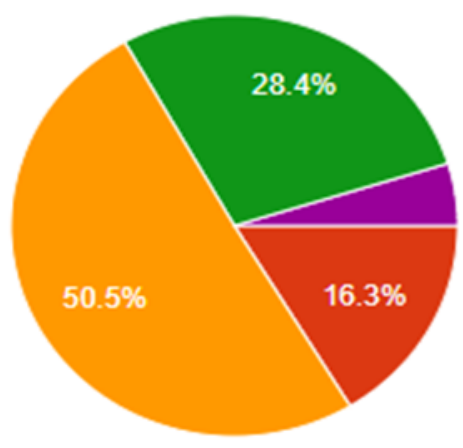

Menor a 13 años

13 a 20 años

21 a 35 años

36 a 45 años

Mayor a 46 años

En los últimos 12 meses ¿En qué zona de Lima Metropolitana ha residido permanentemente?

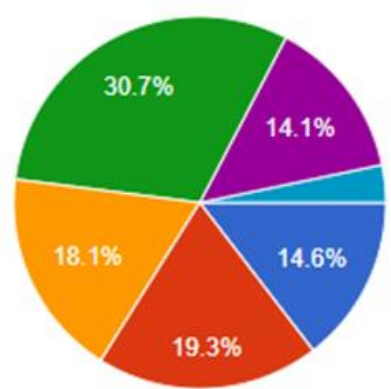

Lima Norte (Los Olivos, Comas, San Martin de Porres, Independencia, C..

- Lima Este (Ate, Chaclacayo, Cieneguilla, El Agustino, Luriganch..

- Lima Centro (Breña, La Victoria, Lima, Rimac, San Luis)

- Lima Moderno (Barranco, Jesús Maria, La Molina, Lince, Magdalena. - Lima Sur (Chorrillos, Lurín, Pachac.. Otro 
Indique el grado de instruccion que posee el jefe de hogar.

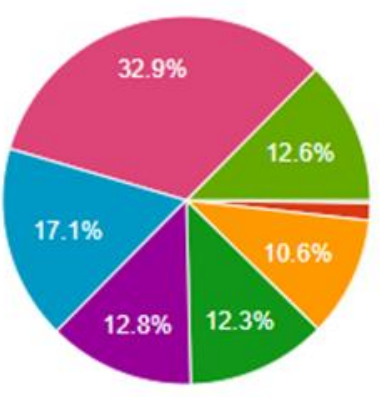

Sin Educación

- Educación Inicial/ Primaria Incompleta

- Primaria Completa/ Secundaria Incompleta/ Secundaria Completa

- Superior No Universitaria Incompleta

- Superior No universitaria Completa

- Superior Universitaria Incompleta

- Superior Universitaria Completa

- Post-Gradouniversitario

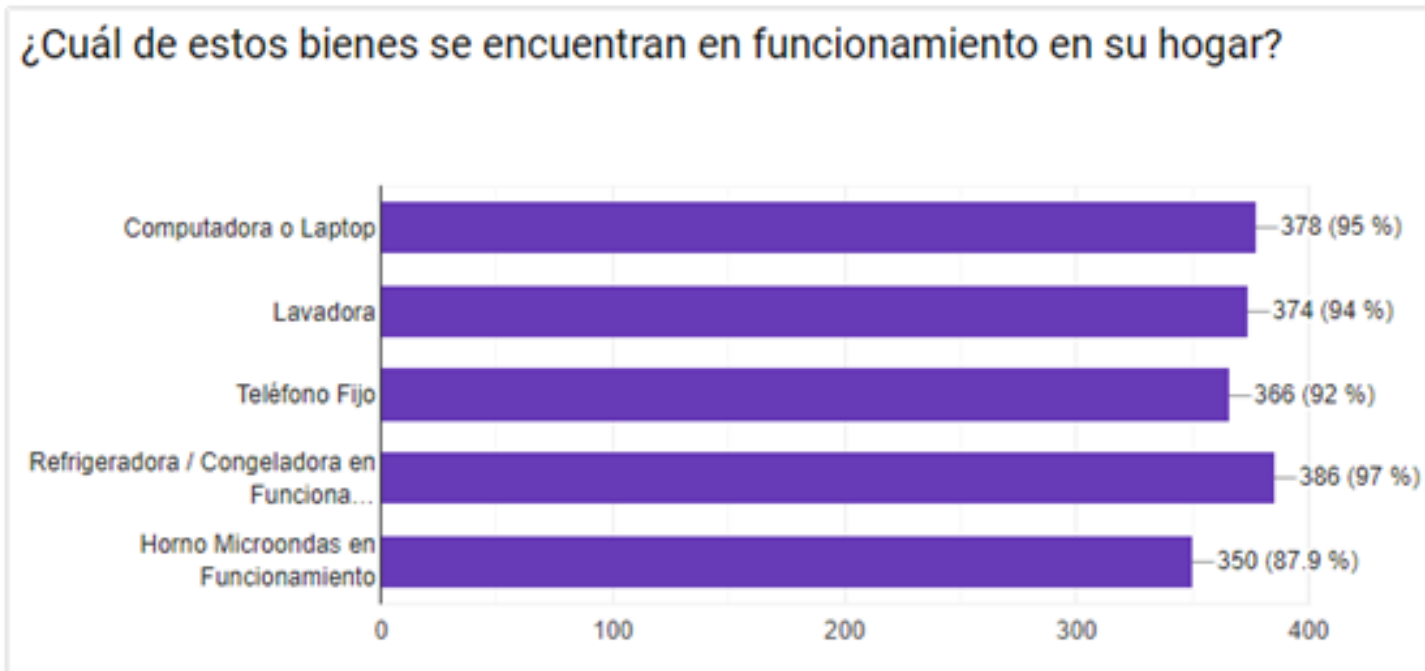

¿Cuántas personas viven en su hogar permanentemente?! ¿Cuántas

habitaciones tiene su hogar(exclusivamente para dormir)?

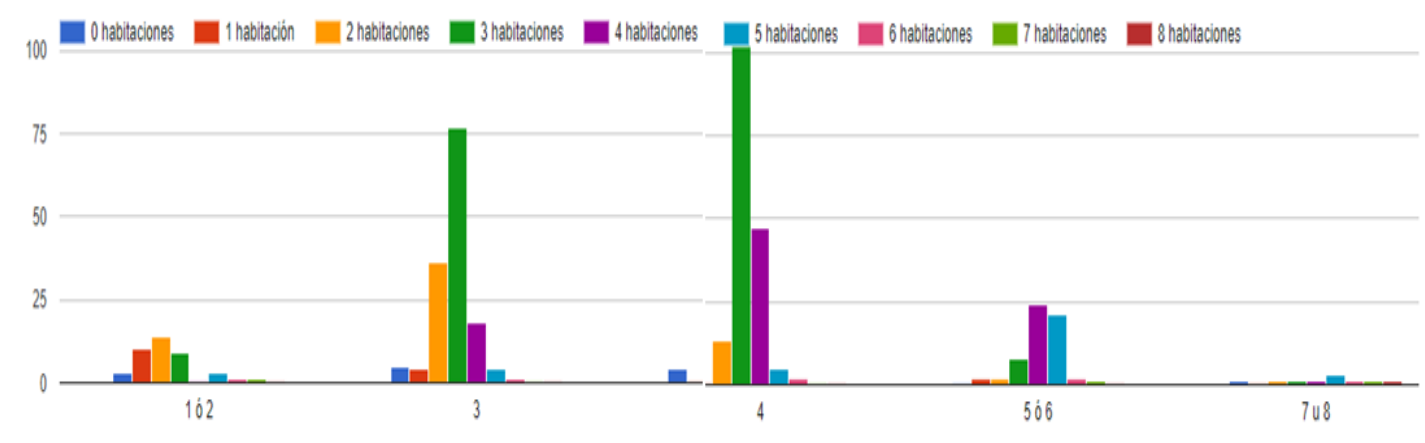


¿Cuál es el material predominante en el piso de vivienda?

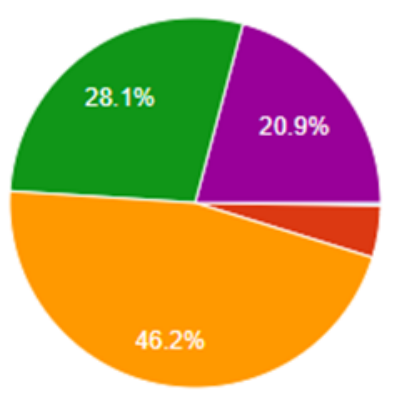

Tierra/arena/tablones sin pulir

Cemento sin pulir o pulido/ madera (entablados)/ tapizón

Losetas/terrazos, mayólicas, cerámicos, vinílicos, mosaico 0 similares

Laminado tipo madera, láminas asfálticas 0 similares

- Parquet/madera pulida y similares; porcelanato, alfombra, mármol

\section{¿Es usted consumidor de pizza?}

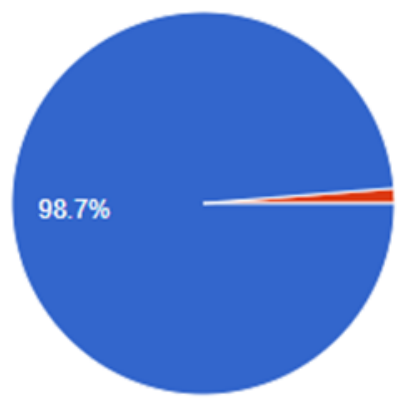

¿Aproximadamente, cuánto suele gastar en una visita a una pizzeria?

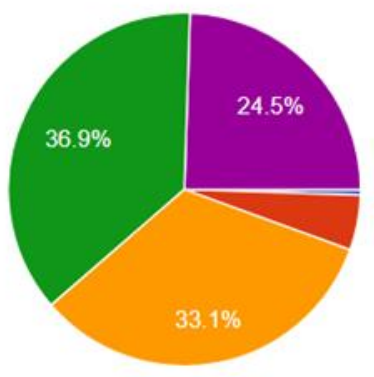

S/.25.01 a más 


\section{¿Con qué frecuencia suele consumir pizza?}

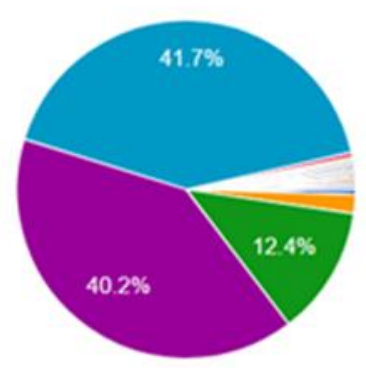

Todos los dias

Interdiaria

3 veces por semana

1 vez por semana

Quincenal

- Mensual

- De vez en cuando

- Para el antojo no muy seguido

A $1 / 3 \mathbf{\nabla}$

¿En qué momento del día suele consumir pizza?

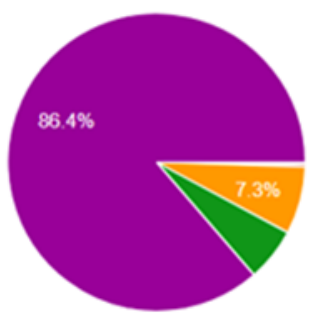

Mañana(Desayuno)

- Media Mañana

- Tarde(Almuerzo)

- Media Tarde

- Noche(Cena)

- Madrugada

¿Cuál de las siguientes alternativas de respuesta, representa cuán

importante o no son para usted las siguientes caracteristicas de una

pizza?

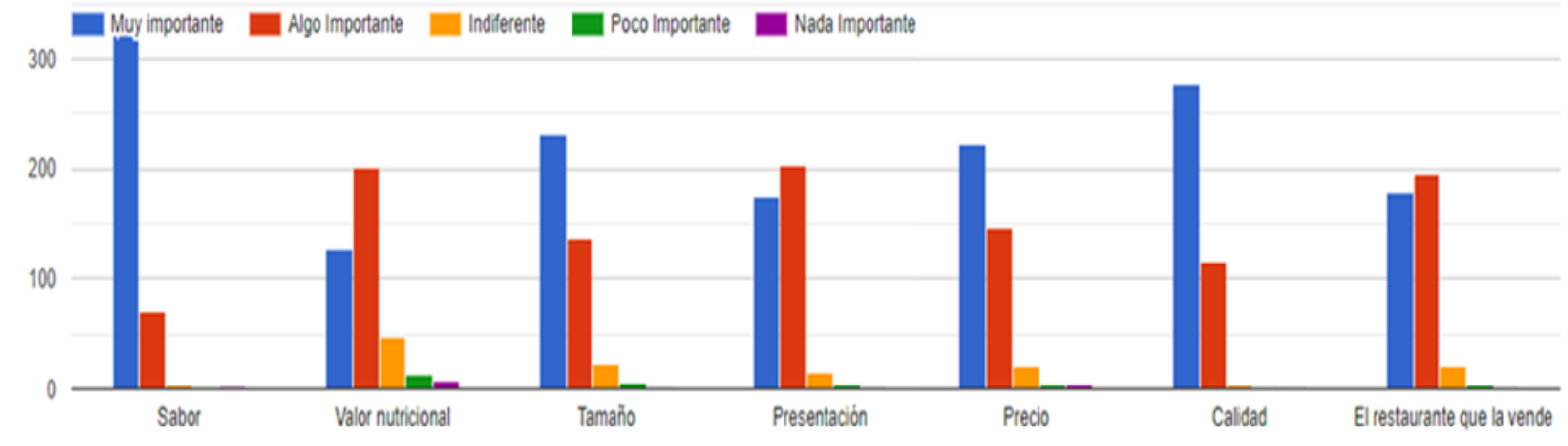


245

En general, ¿Es usted fiel a una sola marca de pizza?
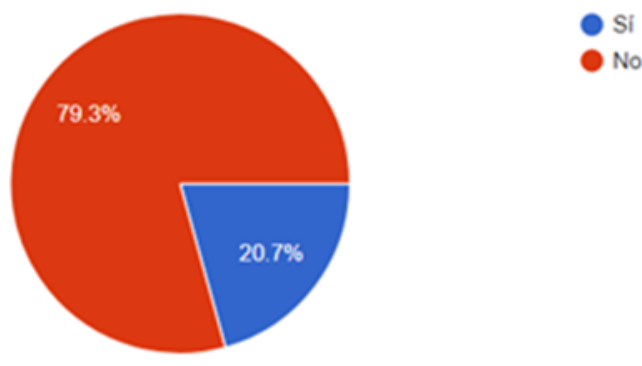

¿Ha oído hablar sobre restaurantes de comida personalizada?
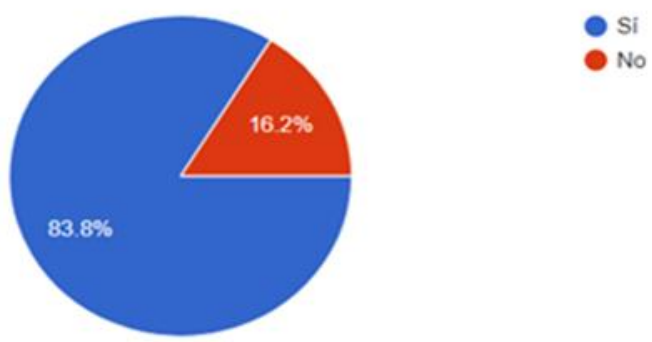

¿Optaría usted por comprar una pizza personalizada por la que actualmente consume?

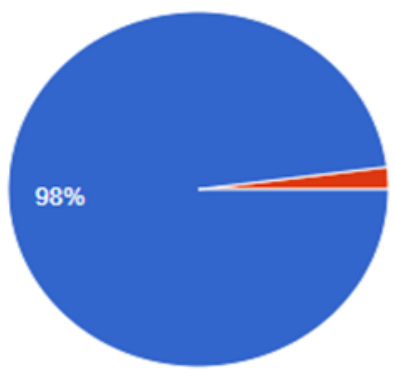

Sí

No 
A continuación le vamos a mostrar la descripción de un nuevo negocio y quisiéramos, por favor, lo lea con detenimiento y nos dé sus opiniones al respecto. En general, ¿Cuán atractiva, le parece a usted esta idea?

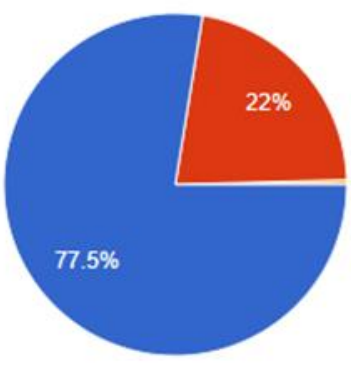

Mucho

- Algo

Poco

- Nada

Según los elementos del concepto, seleccione usted la característica que considera más importante.

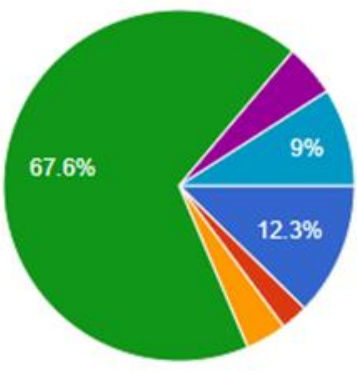

La interacción con el cliente

Presentación

Precio

- Posibilidad de combinación

- Tamaño

Rapidez

¿Cuánto estaría dispuesto a pagar por una pizza personalizada de 18 $\mathrm{cm}$ con los ingredientes a elegir?

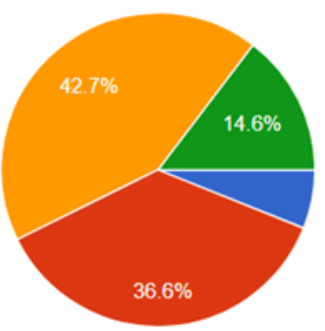


¿Cuál sería su intención de compra con respecto a este producto?

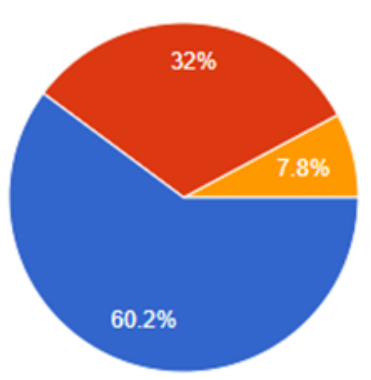

Definitivamente sí lo compraria

Probablemente sí lo compraría

Indiferente

Probablemente no lo compraría

- Definitivamente no lo compraria

¿En qué momento del día comería esta pizza?

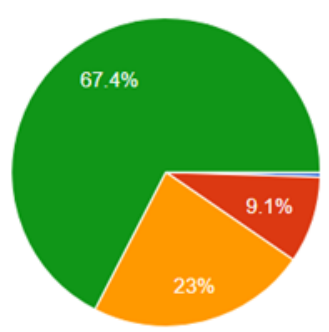

- Mañana (Desayunos)

- Almuerzos

Media Tarde

Cenas

¿En donde le gustaría encontrar este producto?

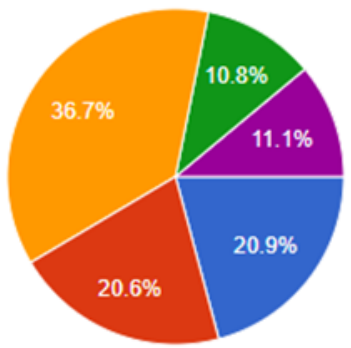

Cercano a centros comerciales

En un patio de comidas de centro comercial

En un local independiente dentro de

un centro comercial

Cercano a centro de estudios

- Cerca a zona de oficinas 
¿Con qué frecuencia consumiría el producto (pizza personal de $18 \mathrm{~cm}$ )?

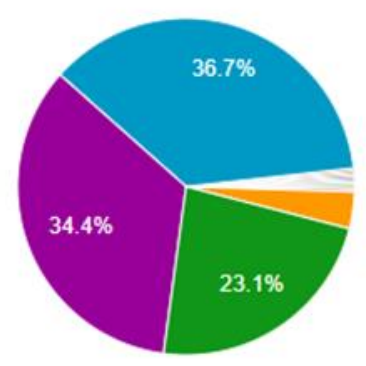

Diaria

- Interdiaria

3 veces por semana

1 vez a la semana

- Quincenal

Mensual

De vez en cuando

1 vez cada 2 meses

$1 / 2 \nabla$

¿Estaría interesado en obtener este producto por delivery?

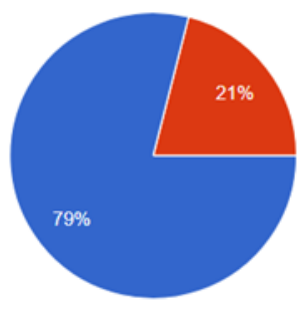

No

¿Cuál de los siguientes logotipos le agrada más para este concepto?

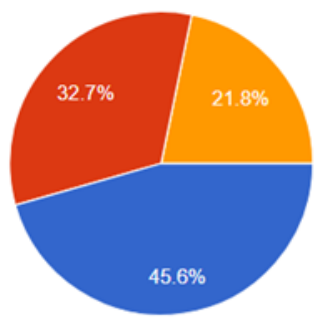

A

C 
¿Qué presentación le gustaría encontrar?

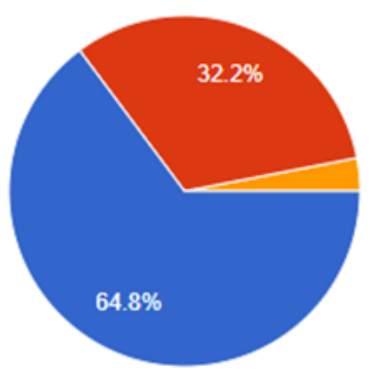

Personal

- Familiar

Para niños (más pequeña)

¿Cómo le gustaría enterarse de las promociones de este nuevo restaurante?

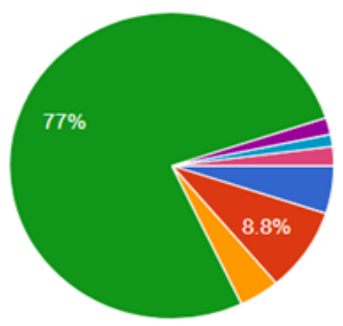

- Televisión

Página Web

E-mail

- Facebook

Twitter

Volantes

Por otras personas

Radio 


\section{Anexo 6. Respuestas Entrevistas en profundidad}

\begin{tabular}{|c|c|}
\hline Entrevistado & Alejandro Villa-García \\
\hline Puesto Actual & Gerente de proyectos en Acurio Restaurantes \\
\hline Experiencia & $\begin{array}{l}\text { Lleva } 3 \text { años aperturando restaurantes en Acurio Restaurantes, ha aperturado } \\
\text { más de } 8 \text { restaurantes incluyendo marcas importantes como Tanta, Panchita, } \\
\text { Barra Chalaca, El Bodegón y Papachos. Se encarga de ver los proyectos des de } \\
\text { su pre-inversión hasta su equipamiento y operatividad. }\end{array}$ \\
\hline Preguntas & Respuestas \\
\hline $\begin{array}{l}\text { ¿Considera que aún existe mercado en la } \\
\text { industria de fast food? }\end{array}$ & $\begin{array}{l}\text { Todavía hay mercado, pero a mi percepción la comida peruana ha pasado a } \\
\text { segundo plano. Ahora se busca conceptos innovadores, generando nuevas } \\
\text { experiencias. }\end{array}$ \\
\hline $\begin{array}{l}\text { ¿Con tantos nuevos conceptos de restaurantes } \\
\text { y servicios que se crean, los fast food } \\
\text { mantendrán sus ventas en los próximos años? }\end{array}$ & $\begin{array}{l}\text { Se podrá vender, pero los fast food deberán entrar a la nueva tendencia de } \\
\text { comida sana, porque los consumidores de hoy en día son más conscientes de lo } \\
\text { que comen. }\end{array}$ \\
\hline $\begin{array}{l}\text { ¿Qué tan altas son las barreras de entradas } \\
\text { para abrir un fast food? }\end{array}$ & $\begin{array}{l}\text { Dependerá de la ubicación que es muy importante, también el tema conceptual } \\
\text { para salir de lo común y por último, el financiamiento. }\end{array}$ \\
\hline $\begin{array}{l}\text { ¿Qué es lo primero que se te viene a la mente } \\
\text { cuando escuchas "pizzas pers onalizadas"? }\end{array}$ & Me suena a hacer pizzas a mi manera. \\
\hline $\begin{array}{l}\text { ¿Qué tipo de local se te viene a la mente luego } \\
\text { de haber escuchado el concepto? }\end{array}$ & $\begin{array}{l}\text { Dependiendo de la complejidad de la infraestructura, si vas a tercerizar o realizar } \\
\text { la producción dentro del local. Al ser una marca que se inicia implica empezar en } \\
\text { un centro comercial no tan recurrido. }\end{array}$ \\
\hline ¿Qué opina sobre esta idea de negocio? & $\begin{array}{l}\text { Creo que la sensación que genera ver tu pizza horneándose, ver el proceso } \\
\text { productivo, ver como hacen la pizza frente a ti, es algo satisfactorio. }\end{array}$ \\
\hline $\begin{array}{l}\text { ¿Cuál sería el área por m2 mínima para que } \\
\text { pueda operar este restaurante? }\end{array}$ & $\begin{array}{l}\text { En un espacio de } 90 \mathrm{~m} 2 \text { estaría bien tomando en cuenta el almacenaje de los } \\
\text { insumos, la producción que realicen. }\end{array}$ \\
\hline $\begin{array}{l}\text { ¿Cuál es el equipamiento neces ario para abrir } \\
\text { un restaurante de este tipo? }\end{array}$ & $\begin{array}{l}\text { Todo el equipamiento de producción, mesas de trabajo, equipos de refrigeración, } \\
\text { equipo de congelación. Un horno importado. }\end{array}$ \\
\hline $\begin{array}{l}\text { ¿Qué tipos de permisos se requieren para } \\
\text { comenzar este tipo de proyectos? }\end{array}$ & $\begin{array}{l}\text { Un certificado de parámetros de la municipalidad, garantizar la agotación de } \\
\text { estacionamiento necesaria y por último el tema eléctrico. }\end{array}$ \\
\hline $\begin{array}{l}\text { ¿Cuánto tiempo tomaría armar este } \\
\text { establecimiento fís icamente hablando? }\end{array}$ & $\begin{array}{l}\text { Para un local de } 70 \mathrm{~m} 2 \text {, debería ser de } 45 \text { a } 60 \text { días de obra, dependiendo mucho } \\
\text { de cómo encuentres el local. Aparte de los permis os municipales que se deben } \\
\text { dar a la par ya que tardan de } 30 \text { a } 60 \text { días. Y luego inspección de Indeci, si } \\
\text { apruebas te dan la licencia de funcionamiento luego de } 7 \text { días. }\end{array}$ \\
\hline $\begin{array}{l}\text { ¿Considera que el concepto se relaciona más } \\
\text { con una ubicación en un patio de comidas o un } \\
\text { restaurante cerrado? }\end{array}$ & $\begin{array}{l}\text { Depende del concepto, si operativamente priorizan las ventas podrían estar } \\
\text { dentro de un centro comercial. }\end{array}$ \\
\hline $\begin{array}{l}\text { ¿Considera algún centro comercial en especial } \\
\text { para ubicar el concepto? }\end{array}$ & Podrían empezar en los conos, hay bastante demanda. \\
\hline $\begin{array}{l}\text { ¿Operativamente, a grandes rasgos, crees que } \\
\text { podría haber algún inconveniente? }\end{array}$ & $\begin{array}{l}\text { Entrar a un centro comercial no es fácil, además, tienen que adaptarse a lo que } \\
\text { ellos, y las municipalidades soliciten. }\end{array}$ \\
\hline $\begin{array}{l}\text { ¿La opción de comprar por delivery sería } \\
\text { factible? }\end{array}$ & $\begin{array}{l}\text { Sí es factible, pero se debe buscar el mejor proceso, ya que harían el delivery } \\
\text { des de un Centro Comercial. }\end{array}$ \\
\hline $\begin{array}{l}\text { ¿Considera que es buena opción vincular esta } \\
\text { idea con un app de smartphone? }\end{array}$ & Sí, ya en estos tiempos, existe es a opción y a las empres as les funciona. \\
\hline $\begin{array}{l}\text { ¿Qué factores considera más importates para } \\
\text { este tipo de concepto? }\end{array}$ & $\begin{array}{l}\text { Considero que la rapidez en que se sirva el producto es el factor más importante, } \\
\text { así como poder realizar una propia pizza. La ubicación de los locales y el } \\
\text { reconocimiento tienen cierta importancia también. }\end{array}$ \\
\hline $\begin{array}{l}\text { En comparación con la competencia, ¿En qué } \\
\text { podría diferenciarse este proyecto? }\end{array}$ & $\begin{array}{l}\text { Creo que la diferenciación está en las opciones a elegir y la libertad de crear una } \\
\text { pizza. Pizza Hut tiene mejores ubicaciones, además de varias tiendas, también } \\
\text { tiene muchas opciones de pizzas, y tiene a favor que ya es conocido. Telepizza } \\
\text { tiene opciones más cómodas. En general, todas son rápidas por ser fast foods. } \\
\text { Papa Jonh tiene mayor interacción con el cliente, por el servicio que tiene. }\end{array}$ \\
\hline $\begin{array}{l}\text { ¿Qué tan interesado está en asistir a este } \\
\text { establecimiento? ¿Por qué? }\end{array}$ & Sí lo probaría. \\
\hline $\begin{array}{l}\text { ¿Qué no le gustó del proyecto? o ¿En qué } \\
\text { podría mejorar? }\end{array}$ & $\begin{array}{l}\text { Mejorar el concepto de la marca, como una marca socialmente responsable, una } \\
\text { marca con un aspecto tecnológico específico, una marca que vaya más allá del } \\
\text { producto. }\end{array}$ \\
\hline $\begin{array}{l}\text { ¿Des ea compartir una opinión como } \\
\text { conclusión? ¿Alguna sugerencia? }\end{array}$ & $\begin{array}{l}\text { Les suguiero que los clientes se identifiquen con su pizza, vender la pizza como } \\
\text { su creación, vender la pizza como su obra maestra. Trabajar en el marketing y la } \\
\text { marca. }\end{array}$ \\
\hline
\end{tabular}




\begin{tabular}{|c|c|}
\hline Entrevistado & Mónica Ortega \\
\hline Puesto Actual & Gerente de Restaurante Papachos \\
\hline Experiencia & $\begin{array}{l}\text { Lleva más de } 8 \text { años administrando restaurantes. Ha administrado en } \\
\text { marcas como Mc Donalds y Paseo Colón, teniendo el completo control } \\
\text { de las operaciones. Ha trabajado en diferentes puestos operativos en } \\
\text { fast foods. }\end{array}$ \\
\hline Preguntas & Respuestas \\
\hline $\begin{array}{l}\text { ¿Considera que aún existe mercado en la industria de } \\
\text { fast food? }\end{array}$ & Está en constante expansión. \\
\hline $\begin{array}{l}\text { ¿Con tantos nuevos conceptos de restaurantes y } \\
\text { servicios que se crean, los fast food mantendrán sus } \\
\text { ventas en los próximos años? }\end{array}$ & $\begin{array}{l}\text { Considero que sí, porque las generaciones cambian constantemente de } \\
\text { gustos, ahora es más importante la rapidez que ofrecen los Fast Food. }\end{array}$ \\
\hline $\begin{array}{l}\text { ¿Qué tan altas son las barreras de entradas para } \\
\text { ubicar el restaurante en un centro comercial? }\end{array}$ & $\begin{array}{l}\text { Dependiendo al impacto que tenga en las personas, se debe ir acorde al } \\
\text { estatus social y al conocimiento que tenga el público de lo que ofreces. }\end{array}$ \\
\hline $\begin{array}{l}\text { ¿Qué es lo primero que se te viene a la mente cuando } \\
\text { escuchas "pizzas personalizadas"? }\end{array}$ & $\begin{array}{l}\text { Que yo estoy viendo todo el proceso, desde el origen de la masa, ver } \\
\text { los ingredientes que escogí colocándolos y ver como se hornea. }\end{array}$ \\
\hline $\begin{array}{l}\text { ¿Qué tipo de local se te viene a la mente luego de } \\
\text { haber escuchado el concepto? }\end{array}$ & $\begin{array}{l}\text { Lo que hace Dominos, por el inconveniente que tuvo, regresan } \\
\text { mostrándole al cliente todo el proceso de elaboración. }\end{array}$ \\
\hline ¿Qué opina sobre esta idea de negocio? & $\begin{array}{l}\text { Es muy buena, porque me llama la atención ver como hacen mi } \\
\text { producto, también porque me dan la opción de escoger que es lo que } \\
\text { quiero para mi pizza. }\end{array}$ \\
\hline $\begin{array}{l}\text { ¿Hasta qué segmento de mercado cree que pueda } \\
\text { abarcar este producto/servicio? }\end{array}$ & Creo que para todos. \\
\hline ¿Con qué asoció el nombre "Pizza Lab”? & Un lugar donde se hacen creaciones \\
\hline ¿Qué sensación le brindan los colores? & Son muy llamativos, típicos de pizzerías fast food. \\
\hline ¿Dónde le gustaría encontrar este concepto? & $\begin{array}{l}\text { En un centro comercial, porque sería una idea innovadora, con un } \\
\text { público notable. }\end{array}$ \\
\hline $\begin{array}{l}\text { ¿Cuál es el mejor medio de comunicación para } \\
\text { enterarse de un restaurante nuevo? }\end{array}$ & Actualmente creo que las redes sociales. \\
\hline $\begin{array}{l}\text { ¿Cree que este restaurante debe vender solo pizzas o } \\
\text { debería tener algún alimento adicional complemento? }\end{array}$ & $\begin{array}{l}\text { Lo acompañaría con un complemento como bebidas refrescantes, } \\
\text { también un postre pequeño. También pensaría en la opción de un } \\
\text { combo pero poco a poco. }\end{array}$ \\
\hline $\begin{array}{l}\text { ¿Considera que el concepto se relaciona más con una } \\
\text { ubicación en un patio de comidas o un restaurante } \\
\text { cerrado? }\end{array}$ & $\begin{array}{l}\text { En un patio de comidas se relaciona más el concepto. Pero si lo veo en } \\
\text { un local también podría entrar a probarlo. }\end{array}$ \\
\hline $\begin{array}{l}\text { ¿Considera algún centro comercial en especial para } \\
\text { ubicar el concepto? }\end{array}$ & Sería buena opción abrir más de uno, y ubicarte en conos. \\
\hline ¿Cuál debería ser el rango de precios del producto? & $\begin{array}{l}\text { Dependiendo a los ingredientes que utilices, yo no pagaría más de } 25 \\
\text { soles. }\end{array}$ \\
\hline $\begin{array}{l}\text { ¿Considera que solo debería vender pizzas personales } \\
\text { o también familiares? }\end{array}$ & $\begin{array}{l}\text { También debes tener opciones de pizzas familiares, para parejas, sin } \\
\text { darle limitaciones al cliente. }\end{array}$ \\
\hline $\begin{array}{l}\text { ¿Operativamente, a grandes rasgos, crees que podría } \\
\text { haber algún inconveniente? }\end{array}$ & $\begin{array}{l}\text { No, ninguno, porque no hablamos de una mano de obra alta, y las } \\
\text { maquinarias son accesibles. }\end{array}$ \\
\hline ¿La opción de comprar por delivery sería factible? & Sí claro, tomando en cuenta como llegará la pizza a casa. \\
\hline $\begin{array}{l}\text { ¿Considera que es buena opción vincular esta idea } \\
\text { con un app de smartphone? }\end{array}$ & $\begin{array}{l}\text { La tecnología está avanzando rápido, y las personas cuentan con varios } \\
\text { aplicativos de todo. Esta opción sería una buena alternativa, para } \\
\text { escoger desde la casa, el trabajo, el carro. }\end{array}$ \\
\hline $\begin{array}{l}\text { ¿Qué factores considera más importates para este tipo } \\
\text { de concepto? }\end{array}$ & $\begin{array}{l}\text { Poder crear una pizza, la ubicación, el posicionamiento que pueda tener, } \\
\text { la calidad del producto, la interacción que se pueda tener con el cliente } \\
\text { y la rapidez en el servicio. }\end{array}$ \\
\hline $\begin{array}{l}\text { En comparación con la competencia, ¿En qué podría } \\
\text { diferenciarse este proyecto? }\end{array}$ & $\begin{array}{l}\text { Considero que tienen mayor exclusividad, por ejemplo Telepizza y Pizza } \\
\text { Raúl tienen mayor rapidez y precios más bajos.Pizza Hut tiene locales } \\
\text { con servicio a la mesa, lo cual genera mayor interacción con el cliente, } \\
\text { como su proyecto. En ambiente, los mejores son Papa Johns, los demás } \\
\text { son básicos; Telepizza y Pizza Raúl, incluso son inferiores en ambiente. }\end{array}$ \\
\hline $\begin{array}{l}\text { ¿Qué tan interesado está en asistir a este } \\
\text { establecimiento? ¿Por qué? }\end{array}$ & $\begin{array}{l}\text { Anteriormente tuve una mala experiencia en otro establecimiento similar, } \\
\text { pero si tú me das una nueva opción, junto con un buen servicio, si } \\
\text { asistiría. No basta con un buen producto, sino también con un buen } \\
\text { servicio. }\end{array}$ \\
\hline $\begin{array}{l}\text { ¿Qué no le gustó del proyecto? o ¿En qué podría } \\
\text { mejorar? }\end{array}$ & Nada, creo que la idea está bien. \\
\hline $\begin{array}{l}\text { ¿Desea compartir una opinión como conclusión? } \\
\text { ¿Alguna sugerencia? }\end{array}$ & $\begin{array}{l}\text { Como sugerencia los precios deben ir acorde a los productos de calidad } \\
\text { que tendrás, siempre tener estandarizados los precios de todos los } \\
\text { locales. }\end{array}$ \\
\hline
\end{tabular}




\begin{tabular}{|c|c|}
\hline Entrevis tado & Eduardo Verano \\
\hline Puesto Actual & Gerente de marca Papachos \\
\hline Experiencia & $\begin{array}{l}\text { Lleva más de } 15 \text { en el rubro, tiene experiencia siendo gerente de Mc Donalds, } \\
\text { Pizza Hut y KFC. También ha sido administrador de tiendas de fast foods por } \\
\text { más de } 5 \text { años. }\end{array}$ \\
\hline Pregunta & Respuestas \\
\hline $\begin{array}{l}\text { ¿Considera que aún existe mercado en la industria } \\
\text { de fast food? }\end{array}$ & $\begin{array}{l}\text { Sí, de hecho el porcentaje más alto de consumidores de fast food son los } \\
\text { niños y jóvenes entre } 10 \text { a } 20 \text { años. Los que toman la decisión en que comer } \\
\text { un fin de semana. }\end{array}$ \\
\hline $\begin{array}{l}\text { ¿Con tantos nuevos conceptos de restaurantes y } \\
\text { servicios que se crean, los fast food mantendrán } \\
\text { sus ventas en los próximos años? }\end{array}$ & $\begin{array}{l}\text { Creo que sí, porque el mercado está en una situación económica sostenida. } \\
\text { Hay una tendencia de marcas establecidas en Lima, de expandirse en } \\
\text { provincia. }\end{array}$ \\
\hline $\begin{array}{l}\text { ¿Qué tan altas son las barreras de entradas para } \\
\text { ubicar el restaurante en un centro comercial? }\end{array}$ & $\begin{array}{l}\text { Es complicado encontrar un buen local para un restaurante de alimentos y } \\
\text { bebidas, por los precios que se han elevado demasiado, y sobre todo en los } \\
\text { distritos que el estilo de vida es alto. Para poder entrar es difícil porque los } \\
\text { grandes consorcios como, Delosi, NGR, están posicionados y tienen } \\
\text { exclusividad con centros comerciales. }\end{array}$ \\
\hline $\begin{array}{l}\text { ¿Qué es lo primero que se te viene a la mente } \\
\text { cuando escuchas "pizzas personalizadas"? }\end{array}$ & Entiendo que uno puede armar su pizza. \\
\hline $\begin{array}{l}\text { ¿Qué tipo de local se te viene a la mente luego de } \\
\text { haber escuchado el concepto? }\end{array}$ & $\begin{array}{l}\text { Para empezar está bien un fast food en un patio de comida. De hecho la } \\
\text { experiencia de servicio en un patio de comida es muy diferente al de un } \\
\text { restaurante, por el modelo que ofreces. }\end{array}$ \\
\hline ¿Qué opina sobre esta idea de negocio? & $\begin{array}{l}\text { La idea de negocio si es importante, porque directamente está diciendo que } \\
\text { vengas y armes tu pizza, y esa oferta no la tenemos en las marcas conocidas. } \\
\text { Sí me parece interesante. }\end{array}$ \\
\hline $\begin{array}{l}\text { ¿Hasta qué segmento de mercado cree que pueda } \\
\text { abarcar este producto/s ervicio? }\end{array}$ & Todos. No le veo límite. \\
\hline ¿Con qué asoció el nombre “Pizza Lab”? & Aseguras que la pizza que armas estaría buena para mi gusto. \\
\hline ¿Qué sensación le brindan los colores? & $\begin{array}{l}\text { Independiente del color, creo que tiene que ver con la imagen que quieren } \\
\text { dar. El laboratorio normalmente es blanco, podrían jugar con el blanco, rojo, } \\
\text { amarillo. }\end{array}$ \\
\hline ¿Dónde le gustaría encontrar este concepto? & $\begin{array}{l}\text { Lo que mejor se asocia al proyecto es un centro comercial o un patio de } \\
\text { comidas. }\end{array}$ \\
\hline $\begin{array}{l}\text { ¿Cuál es el mejor medio de comunicación para } \\
\text { enterarse de un restaurante nuevo? }\end{array}$ & $\begin{array}{l}\text { Definitivamente las redes sociales como Facebook, Instagram, Snapchat, etc. } \\
\text { Hasta los negocios exitosos en el país de más de } 30 \text { años se han tenido que } \\
\text { acoplar a ello, por la comunicación directa que exis te y la penetración que } \\
\text { tienen en el mercado. }\end{array}$ \\
\hline $\begin{array}{l}\text { ¿Cree que este restaurante debe vender solo } \\
\text { pizzas o debería tener algún alimento adicional } \\
\text { complemento? }\end{array}$ & Es importante la tendencia de comida sana, podría ser una pizza vegetariana. \\
\hline $\begin{array}{l}\text { ¿Considera que el concepto se relaciona más con } \\
\text { una ubicación en un patio de comidas o un } \\
\text { restaurante cerrado? }\end{array}$ & $\begin{array}{l}\text { Abrir inicialmente un local, para personas que tienen el tiempo para poder } \\
\text { elegir su pizza y para este caso estaría mejor en un centro comercial. }\end{array}$ \\
\hline $\begin{array}{l}\text { ¿Considera algún centro comercial en especial } \\
\text { para ubicar el concepto? }\end{array}$ & $\begin{array}{l}\text { Para comenzar creo que estaría bien que es te ubicado en centro comerciales } \\
\text { de los conos. }\end{array}$ \\
\hline $\begin{array}{l}\text { ¿Cuál debería ser el rango de precios del } \\
\text { producto? }\end{array}$ & Pagaría 25 soles, si me llena. \\
\hline $\begin{array}{l}\text { ¿Considera que solo debería vender pizzas } \\
\text { personales o también familiares? }\end{array}$ & $\begin{array}{l}\text { Por el concepto que tienes, es probable que sean personales por lo que son } \\
\text { personalizables. Puede ser una buena idea una pizza familiar y personalizarla } \\
\text { mitad, mitad o entre tres. }\end{array}$ \\
\hline $\begin{array}{l}\text { ¿Operativamente, a grandes rasgos, crees que } \\
\text { podría haber algún inconveniente? }\end{array}$ & $\begin{array}{l}\text { No, hoy en día existen variedad de proveedores, inclusive nacionales que } \\
\text { ofrecen variedad en máquinas. Lo más complicado sería conseguir el horno } \\
\text { artesanal, por los ladrillos italianos que llevan. }\end{array}$ \\
\hline ¿La opción de comprar por delivery sería factible? & $\begin{array}{l}\text { Hoy en día el } 60 \% \text { de las personas pide las pizzas en delivery y de ese } 60 \% \text {, el } \\
59 \% \text { lo pide online, es decir entra a la web y la pide. Sí sería factible. }\end{array}$ \\
\hline $\begin{array}{l}\text { ¿Considera que es buena opción vincular esta } \\
\text { idea con un app de smartphone? }\end{array}$ & $\begin{array}{l}\text { Creo que es importante, por el porcentaje que mencione las personas la piden } \\
\text { online. }\end{array}$ \\
\hline $\begin{array}{l}\text { ¿Qué factores considera más importates para este } \\
\text { tipo de concepto? }\end{array}$ & $\begin{array}{l}\text { En este caso, se debe buscar un servicio muy rápido, porque la gente } \\
\text { tampoco puede esperar tanto por una pizza. La opción de crear una pizza } \\
\text { propia y la fuerte relación e interacción con la gente también son puntos } \\
\text { importantes. }\end{array}$ \\
\hline $\begin{array}{l}\text { En comparación con la competencia, ¿En qué } \\
\text { podría diferenciarse este proyecto? }\end{array}$ & $\begin{array}{l}\text { La diferencia la marca la libertad de crear una pizza, aunque Pizza Hut tiene } \\
\text { una opción parecida; creo que es el máximo competidor, porque también tiene } \\
\text { la mayor participación de mercado. En rapidez me parece que Telepizza y Pizza } \\
\text { Raúl tienen ventaja. Sin duda, Pizza Hut tiene las mejores ubicaciones, ya que } \\
\text { está dentro de centros comerciales. }\end{array}$ \\
\hline $\begin{array}{l}\text { ¿Qué tan interesado está en as istir a este } \\
\text { establecimiento? ¿Por qué? }\end{array}$ & Sí estoy interesado. \\
\hline $\begin{array}{l}\text { ¿Qué no le gustó del proyecto? o ¿En qué podría } \\
\text { mejorar? }\end{array}$ & Por el momento, no tengo comentarios \\
\hline $\begin{array}{l}\text { ¿Des ea compartir una opinión como conclusión? } \\
\text { ¿Alguna sugerencia? }\end{array}$ & $\begin{array}{l}\text { Definan bien los procesos, ya que me preocupa el tiempo que puedan esp } \\
\text { los clientes. }\end{array}$ \\
\hline
\end{tabular}




\begin{tabular}{|c|c|}
\hline Entrevistado & Edwin Cahuana \\
\hline Puesto Actual & Gerente de Cocina Acurio Restaurantes \\
\hline Experiencia & $\begin{array}{l}\text { Lleva más de } 20 \text { años en el rubro de restaurantes como jefe de cocina, ha } \\
\text { trabajado en restaurantes de comida italiana y es gran conocedor de pizzas } \\
\text { artesanales. }\end{array}$ \\
\hline Pregunta & Respuestas \\
\hline $\begin{array}{l}\text { ¿Con tantos nuevos conceptos de restaurantes y } \\
\text { servicios que se crean, los fast food seguirán } \\
\text { evolucionando su producto? }\end{array}$ & $\begin{array}{l}\text { Considero que sí, siguen evolucionando, siguen saliendo más opciones, y } \\
\text { siguen abriendo nuevos conceptos. Creo que va a seguir creciendo el mercado }\end{array}$ \\
\hline $\begin{array}{l}\text { ¿Qué tan difícil es entrar a competir con productos de } \\
\text { comida rápida ya establecidos? }\end{array}$ & $\begin{array}{l}\text { Es complicado, pero el peruano es ingenioso, y siempre innova en el producto. } \\
\text { Siempre busca nuevas fusiones o combinaciones para ofrecer. }\end{array}$ \\
\hline $\begin{array}{l}\text { ¿Qué es lo primero que se te viene a la mente cuando } \\
\text { escuchas "pizzas personalizadas"? }\end{array}$ & Armar una pizza con sus propios ingredientes, al gusto que uno quiera. \\
\hline ¿Qué opina sobre esta idea de negocio? & $\begin{array}{l}\text { Me gusta la idea de ir a comer una pizza que uno desee, está buena la idea. Te } \\
\text { sugeriría que aumentes unos piqueos, una pasta, alguna comida italiana. }\end{array}$ \\
\hline $\begin{array}{l}\text { ¿Qué tipos de ingredientes considera que se debería } \\
\text { ofrecer? }\end{array}$ & $\begin{array}{l}\text { Como armas una pizza clásica, queso mozarella, chorizo, jamón. También podrías } \\
\text { aumentar trozos de pollo a la brasa o una pizza de lomo saltado. También es } \\
\text { considerable las opciones de verduras y frutas, porque el peruano también } \\
\text { busca comer sano con ingredientes como, champiñones, piña, alcachofas, } \\
\text { esnárragos }\end{array}$ \\
\hline $\begin{array}{l}\text { ¿Cuántas opciones se debería tener para armar la } \\
\text { pizza? }\end{array}$ & Que tengas entre 20 a 30 ingredientes a escoger del cliente. \\
\hline $\begin{array}{l}\text { ¿Cree que este restaurante debe vender solo pizzas o } \\
\text { debería tener algún alimento adicional complemento? }\end{array}$ & $\begin{array}{l}\text { La pizza seria el plato fuerte de la casa, pero debería tener un acompañamiento, } \\
\text { como unas tradicionales focaccias. Darle la alternativa que mientras llegue la } \\
\text { pizza ofrecerle focaccias o pan al ajo, como un adicional mientras que espera el } \\
\text { cliente. }\end{array}$ \\
\hline ¿Qué tamaño debería tener una pizza personal? & $\begin{array}{l}\text { Creo que una pizza con } 4 \text { tajadas de } 20 \mathrm{~cm} \text {. Porque armar una pizza grande no } \\
\text { podrías acabártela sola, y la comerías entre dos o tres personas pero tendrías } \\
\text { que personalizar tu pizza para todos. }\end{array}$ \\
\hline $\begin{array}{l}\text { ¿Qué tipo de equipamiento de cocina es necesario para } \\
\text { este tipo de restaurante? }\end{array}$ & $\begin{array}{l}\text { Un horno artesanal, que normalmente llegue a los } 500^{\circ} \text {. Donde la masa de pizza } \\
\text { cocinada sale en } 6 \text { minutos, y pueden entrar hasta } 12 \text { pizzas medianas. También } \\
\text { debes tener conservadores, y un horno más pequeño para los piqueos, como el } \\
\text { pan al ajo. }\end{array}$ \\
\hline $\begin{array}{l}\text { ¿La masa de la pizza se puede mantener congelada o } \\
\text { refrigerada y usarla cuando es necesario? }\end{array}$ & $\begin{array}{l}\text { Lo que yo te recomendaría es que la masa sea del día, porque la masa tiene que } \\
\text { reposar durante } 30 \text { minutos para que tenga buena textura. Te recomiendo } \\
\text { trabajar con una masa fresca, y quizás dos o tres variedades de masa. Podrías } \\
\text { poner opciones de masa, como por ejemplo: masa con maíz morado. }\end{array}$ \\
\hline $\begin{array}{l}\text { ¿Considera que solo debería vender pizzas personales } \\
\text { o también familiares? }\end{array}$ & $\begin{array}{l}\text { Las familiares no las consideraría, porque puede haber discrepancia entre } \\
\text { gustos. }\end{array}$ \\
\hline $\begin{array}{l}\text { En su experiencia, ¿Cuánto tiempo tomaría preparar } \\
\text { una de estas pizzas? }\end{array}$ & $\begin{array}{l}\text { Unos } 8 \text { minutos como máximo, horneadas y con todos los ingredientes que el } \\
\text { cliente pide. }\end{array}$ \\
\hline ¿Dónde le gustaría encontrar este concepto? & Creo que la opción de ponerla en un centro comercial es buena \\
\hline $\begin{array}{l}\text { ¿Con qué tipo de bebidas se combinaría este } \\
\text { producto? }\end{array}$ & $\begin{array}{l}\text { Con una chica, una limonada de hierba luisa, tal vez con diferentes opciones de } \\
\text { té helado o zumos de frutas. }\end{array}$ \\
\hline ¿La opción de comprar por delivery sería factible? & Si vería factible la opción. \\
\hline $\begin{array}{l}\text { ¿Considera que el concepto se relaciona más con una } \\
\text { ubicación en un patio de comidas o un restaurante } \\
\text { cerrado? }\end{array}$ & $\begin{array}{l}\text { Dentro de un patio de comidas de un centro comercial, porque encuentras más } \\
\text { público. }\end{array}$ \\
\hline $\begin{array}{l}\text { ¿Operativamente, a grandes rasgos, crees que podría } \\
\text { haber algún inconveniente? }\end{array}$ & $\begin{array}{l}\text { No lo creo. Porque si tienes la pizza marcada, pre cocinada saldría en menos } \\
\text { minutos. }\end{array}$ \\
\hline $\begin{array}{l}\text { ¿Qué factores considera más importates para este tipo } \\
\text { de concepto? }\end{array}$ & $\begin{array}{l}\text { Tiene varios factores, pero deben concentrarse en la rapidez, las opciones } \\
\text { variadas, el ambiente, la calidad de producto y buscar el posicionamiento } \\
\text { rápido. }\end{array}$ \\
\hline $\begin{array}{l}\text { En comparación con la competencia, ¿En qué podría } \\
\text { diferenciarse este proyecto? }\end{array}$ & $\begin{array}{l}\text { Crear la pizza es la mayor diferencia. No sé cómo lo harán, pero el ambiente de } \\
\text { Papa Johns y Pizza Hut son mejores. Pizza Raúl casi no tiene interacción con el } \\
\text { cliente. Todas tienen rapidez y reconocimiento, al menos en Lima, aunque } \\
\text { tienen diferencias en su público objetivo. }\end{array}$ \\
\hline $\begin{array}{l}\text { ¿Qué tan interesado está en asistir a este } \\
\text { establecimiento? ¿Por qué? }\end{array}$ & Sí me gustaría armar mi propia pizza, saliendo un poco de lo común. \\
\hline $\begin{array}{l}\text { ¿Qué no le gustó del proyecto? o ¿En qué podría } \\
\text { mejorar? }\end{array}$ & Nada, me gusta el proyecto de armar mi propia pizza. \\
\hline $\begin{array}{l}\text { ¿Desea compartir una opinión como conclusión? } \\
\text { ¿Alguna sugerencia? }\end{array}$ & $\begin{array}{l}\text { Mi sugerencia seria que mientras espero me gustaría ir comiendo algo, una } \\
\text { entrada como pan al ajo o unas focaccias de sabores, y la espera no sería larga. }\end{array}$ \\
\hline
\end{tabular}




\begin{tabular}{|c|c|}
\hline Entrevistado & Carlos Camino \\
\hline Puesto Actual & Empresario de Restaurantes \\
\hline Experiencia & $\begin{array}{l}\text { En restaurantes, ha sido propietario y creador de Bembos, actualmente maneja la } \\
\text { marca Papachos. }\end{array}$ \\
\hline $\begin{array}{l}\text { ¿Cómo ve el rubro de restaurantes en } \\
\text { general? ¿Qué oportunidades se pueden } \\
\text { encontrar en el entorno? }\end{array}$ & $\begin{array}{l}\text { En general, veo que el rubro de restaurantes sigue creciendo, ya no a pasos gigantes } \\
\text { como hace unos años, pero es importante que siga habiendo crecimiento. Los } \\
\text { restaurantes que venden pizzas son aún una gran oportunidad, el peruano consume } \\
\text { bastante pizza, y no hay edad para este producto. }\end{array}$ \\
\hline $\begin{array}{l}\text { ¿Qué puntos económicos cree que podrían } \\
\text { tener impacto en el proyecto? }\end{array}$ & $\begin{array}{l}\text { Actualmente el peruano tiene mayor ingreso promedio, lo cual genera que pueda } \\
\text { realizar más gastos, y pueda aumentar su capacidad de comer fuera de casa; lo negativo } \\
\text { de esto es que en algún punto esto genera inflación, lo cual ataca directamente al rubro } \\
\text { de restaurantes, ya que los alimentos son de las cosas que más elevan sus precios. }\end{array}$ \\
\hline $\begin{array}{l}\text { ¿Qué amenazas o trabas puede encontrar un } \\
\text { establecimiento de restauración? }\end{array}$ & $\begin{array}{l}\text { Como te comenté anteriormente, la inflación es un hecho que pasará y afectará a los } \\
\text { restaurantes. Además, nunca estamos libres de algún desastre natural, eso también } \\
\text { afecta los precios, en especial de los productos perecibles. Consideraría también las } \\
\text { normas sanitarias y municipales, que constantemente están fiscalizando los } \\
\text { restaurantes, y generan que constantemente se generen gastos por sus } \\
\text { requerimientos. }\end{array}$ \\
\hline $\begin{array}{l}\text { Viendo las siguientes oportunidades, ¿Cuál } \\
\text { considera que tiene mayor impacto para este } \\
\text { proyecto? }\end{array}$ & $\begin{array}{l}\text { Considero que el alto consumo de pizzas en Lima es una gran oportunidad para este } \\
\text { proyecto, después podría considerar el aumento en el gasto del consumidor peruano, } \\
\text { seguido por el aumento en el ingreso promedio del consumidor. Los demás considero } \\
\text { que son variables secundarias. }\end{array}$ \\
\hline $\begin{array}{l}\text { Viendo las siguientes amenazas, ¿Cuál } \\
\text { considera que tiene mayor impacto para este } \\
\text { proyecto? }\end{array}$ & $\begin{array}{l}\text { En mi punto de vista, la desaceleración económica es lo más importante, ya que esta } \\
\text { conlleva a otras variables que también afectan. El otro punto que afecta directamente } \\
\text { es la inflación, esto puede mover todo presupuesto de gestión que se haya podido } \\
\text { realizar, ya que los costos se mueven mucho. Las normas sanitarias y los fenómenos } \\
\text { naturales, son relativos, simplemente hay que estar preparados para estos. }\end{array}$ \\
\hline
\end{tabular}


Anexo 7. Encuesta

\section{Encuesta}

Estamos realizando una investigación sobre un nuevo tipo de restaurante. Nos gustaría saber qué opina sobre diferentes aspectos de este nuevo proyecto, así como recibir sus sugerencias. Esto nos ayudará a realizar mejoras en el producto y servicio que se está desarrollando. La encuesta solo le tomará entre cinco y diez minutos, y sus respuestas son totalmente anónimas.

¡Valoramos sus comentarios!

Marque el género al que pertenece.

Masculino

Femenino

\section{Marque el grupo de edad al que pertenece *}

Menor a 13 años

13 a 20 años

21 a 35 años

36 a 45 años

Mayor a 46 años

\section{En los últimos 12 meses ¿En qué zona de Lima Metropolitana ha residido permanentemente?}

Lima Norte (Los Olivos, Comas, San Martin de Porres, Independencia, Carabayllo, Puente Piedra)

Lima Este (Ate, Chaclacayo, Cieneguilla, El Agustino, Lurigancho, San Juan de Lurigancho, Santa Anita)

Lima Centro (Breña, La Victoria, Lima, Rimac, San Luis)

Lima Moderno (Barranco, Jesús María, La Molina, Lince, Magdalena del Mar, Miraflores, Pueble Libre, San Borja, San I:

Lima Sur (Chorrillos, Lurín, Pachacamac, San Juan de Miraflores, Villa el Salvador, Villa María del Triunfo)

Otro 
Indique el grado de instruccion que posee el jefe de hogar. *

Jefe de Hogar: Persona que tiene un mayor aporte en el hogar y que toma las principales decisiones para el sostenimiento del mismo

Sin Educación

Educación Inicial/ Primaria Incompleta

Primaria Completa/ Secundaria Incompleta/ Secundaria Completa

Superior No Universitaria Incompleta

Superior No universitaria Completa

Superior Universitaria Incompleta

Superior Universitaria Completa

Post-Gradouniversitario

¿Cuál de estos bienes se encuentran en funcionamiento en su hogar?*

Solo marcar aquellos que se encuentren operativos

Computadora o Laptop

Lavadora

Teléfono Fijo

$\square$ Refrigeradora / Congeladora en Funcionamiento

$\square$ Horno Microondas en Funcionamiento 
¿Cuántas personas viven en su hogar permanentemente?/¿Cuántas habitaciones tiene su hogar(exclusivamente para dormir)?

Cantidad de Personas: Sin incluir el servicio doméstico

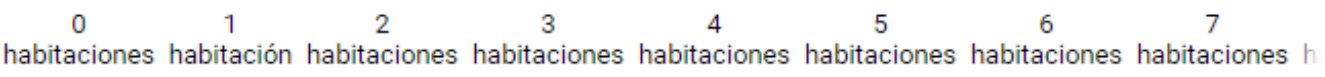
1 ó 2
3
4
5 ó 6
7 u 8
9
10
11 ó 12
13 ó 14
15

¿Cuál es el material predominante en el piso de vivienda? *
Tierra/arena/tablones sin pulir
Cemento sin pulir o pulido/ madera (entablados)/ tapizón
Losetas/terrazos, mayólicas, cerámicos, vinílicos, mosaico o similares
Laminado tipo madera, láminas asfálticas o similares
Parquet/madera pulida y similares; porcelanato, alfombra, mármol

¿Es usted consumidor de pizza? ${ }^{\star}$
Si
No 
¿Podría escribir TRES (3) pizzerias en las que suele consumir? *

Texto de respuesta largo

¿Aproximadamente, cuánto suele gastar en una visita a una pizzeria? *
Menos de $\mathrm{S} / .10 .00$
S/.10.01-S/.15.00
S/.15.01-s/.20.00
S/.20.01-S/.25.00
S/.25.01 a más

¿Con qué frecuencia suele consumir pizza? *
Todos los días
Interdiaria
3 veces por semana
1 vez por semana
Quincenal
Mensual
Otra... 
¿En qué momento del día suele consumir pizza? *

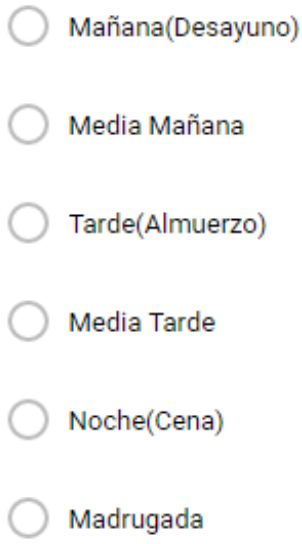

¿Cuál de las siguientes alternativas de respuesta, representa cuán importante o no son para usted las siguientes características de una pizza?

Muy importante Algo Importante Indiferente Poco Importante Nada Importante

Sabor
Valor nutricional
Tamaño
Presentación
Precio
Calidad
El restaurante que la
vende


En general, ¿Es usted fiel a una sola marca de pizza? *

Sí

No

¿Ha oído hablar sobre restaurantes de comida personalizada? *

Comida personalizada: Concepto en el que se ofrece un producto base, y el cliente se encarga de elegir la combinación a su gusto entre diferentes ingredientes, para obtener un producto final hecho a la medida. Ejemplo: Subway, Pinkberry, etc.

Sí

No

¿Optaría usted por comprar una pizza personalizada por la que actualmente consume?

Pizza personalizada: aquella en la cual el cliente puede agregar los ingredientes a la pizza a su gusto, con la finalidad que el cliente pueda comer su creación.

Sí

No

A continuación le vamos a mostrar la descripción de un nuevo negocio y quisiéramos, por favor, lo lea con detenimiento y nos dé sus opiniones al respecto. En general, ¿Cuán atractiva, le parece a usted esta idea?

Se trata de un restaurante de comida rápida que busca integrar todos los ingredientes de una pizza con una línea de servicio interactiva en la que el cliente podrá personalizar su pedido, mediante la selección de los ingredientes que se ofrecen, entre los que se encuentran el tipo de masa, el tipo de queso, verduras, proteínas, salsas, hortalizas, embutidos, frutas, y condimentos. Podrán elegir diferentes ingredientes hasta llenar la superficie de la pizza. El nombre del negocio será Pizza Lab.

Mucho

Algo

Poco

Nada 
Según los elementos del concepto, seleccione usted la característica que considera más importante.

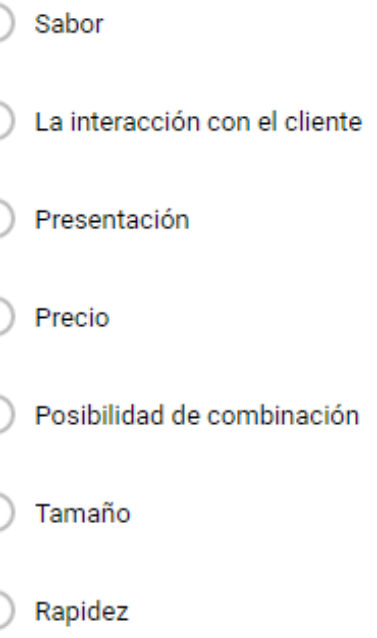

¿Cuánto estaría dispuesto a pagar por una pizza personalizada de $18 \mathrm{~cm}$ con * los ingredientes a elegir?
Menos de S/. 15.00
S/.15.01-S/. 20.00
$\mathrm{S} / .20 .01-\mathrm{S} / .25 .00$
Mas de $\mathrm{S} / .25 .01$

¿Cuál sería su intención de compra con respecto a este producto? *
Definitivamente sí lo compraría
Probablemente sí lo compraría
Indiferente
Probablemente no lo compraría
Definitivamente no lo compraría 
¿En qué momento del día comería esta pizza? *

Mañana (Desayunos)

Almuerzos

Media Tarde

Cenas

¿En donde le gustaría encontrar este producto? *

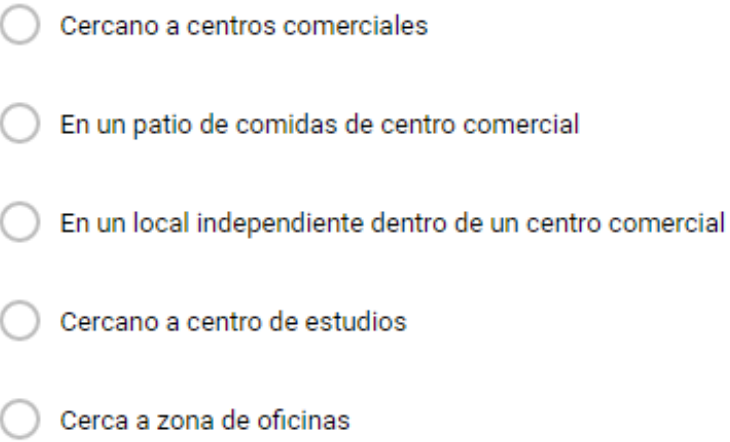

¿Con qué frecuencia consumiría el producto (pizza personal de $18 \mathrm{~cm}$ )?

Diaria

Interdiaria

3 veces por semana

1 vez a la semana

Quincenal

Mensual

Otra.

¿Estaría interesado en obtener este producto por delivery?

Sí

No 
¿Cuál de los siguientes logotipos le agrada más para este concepto?
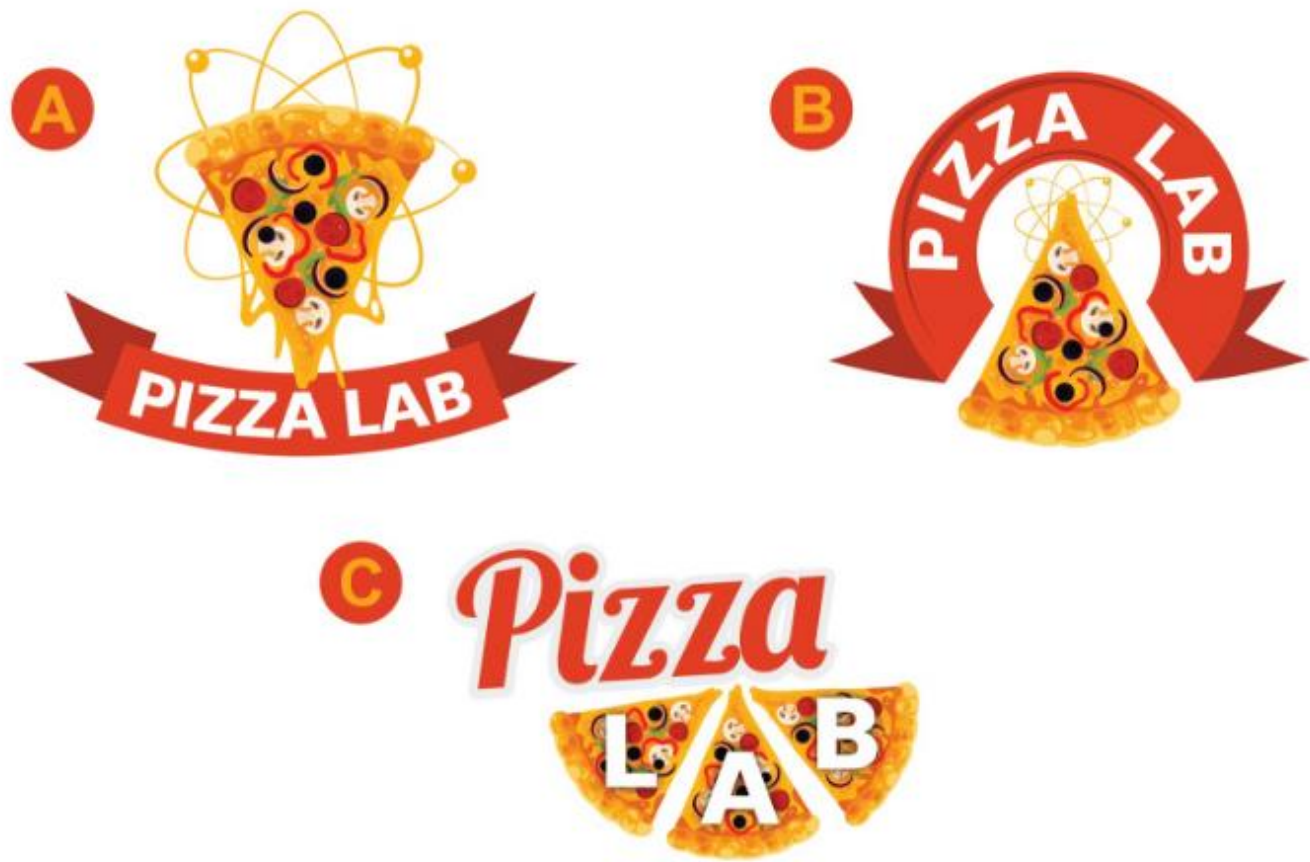

¿Qué presentación le gustaría encontrar?

Personal

Familiar

Para niños (más pequeña)

¿Cómo le gustaría enterarse de las promociones de este nuevo restaurante? ${ }^{\star}$
Televisión
Página Web
E-mail
Facebook
Twitter
Volantes
Por otras personas
Radio 
Anexo 8. Cotizaciones

Equipos

\section{FRIONOX}

Cotización \#

9941

Dirección : Calle Los Taladros $N^{\circ} 200$ Independencia, Lima, Peru

Ruc: $20460436771 \quad$ Telefono: (511) 522-1181/522-7081

Razón Social : $\quad$ ALIMENTOS Y BEBIDAS GROUP PERU S.A.C.

RUC: 20557724878

Direccion : $\quad$ Pasaje MONTE AZUL 120 LIMA - SURCO - LIMA, LIMA, PERU

Referencia :

Item Cant. UM Descripción Precio sin Igv Total

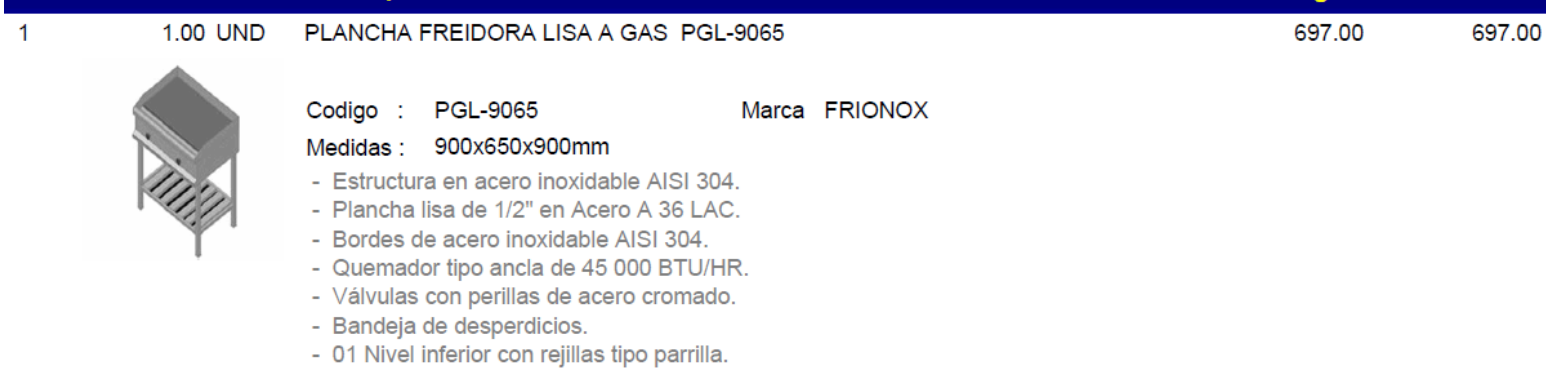

Codigo : PGL-9065 Marca FRIONOX

Medidas : $900 \times 650 \times 900 \mathrm{~mm}$

- Estructura en acero inoxidable AISI 304

- Plancha lisa de 1/2" en Acero A 36 LAC.

- Bordes de acero inoxidable AISI 304.

Quemador tipo ancla de 45000 BTU/HR.

Válvulas con perillas de acero cromado.

- Bandeja de desperdicios.

- 01 Nivel inferior con rejillas tipo parrilla.

\begin{tabular}{|c|c|c|c|c|}
\hline \multirow[t]{3}{*}{2} & \multirow[t]{3}{*}{1.00 UND } & MANGUERA PARA GLP CONECTORES ROSCADOS Ø3/4" Genérica & \multirow[t]{3}{*}{60.00} & \multirow[t]{3}{*}{60.00} \\
\hline & & Codigo : $7132-75354$ & & \\
\hline & & $\begin{array}{l}\text { Medidas Exteriores (mm): Diametro } Ø 3 / 4 ", \text { Longitud de } 600 \mathrm{~mm} \text { a } \\
1000 \mathrm{~mm}\end{array}$ & & \\
\hline \multirow[t]{3}{*}{3} & 1.00 UND & COCINA ISLA A GAS DE 02 QUEMADORES CI2 & 486.00 & 486.00 \\
\hline & & Marca FRIONOX & & \\
\hline & & $\begin{array}{l}\text { Medidas: 450x1050x900mm } \\
\text { - Estructura integral en acero inoxidable AISI } 304 . \\
\text { - Tablero superior de 1/16" de espesor. } \\
\text { - Quemadores a gas de Fe. Fdo. de } \varnothing 5^{\prime \prime}(41500 \text { Btu/Hr c/u) } \\
\text { - Presión de trabajo } 15 \text { Psi (Alta Presión). } \\
\text { - Parrillas de fierro fundido de } 380 \times 380 \mathrm{~mm} \text {. } \\
\text { - Válvulas con perillas de acero cromado. } \\
\text { - Bandeja de desperdicios. } \\
\text { - } 01 \text { Nivel inferior con rejilla tipo parrilla. } \\
\text { - Patas de tubo cuadrado de } 11 / 2 " x 1.5 \mathrm{~mm} \text { de espesor. }\end{array}$ & & \\
\hline \multirow[t]{3}{*}{4} & 1.00 UND & $\begin{array}{l}\text { MANGUERA REFORZADA CON CONECTORES ROSCADOS Ø1/2 } \\
\text { Genérica. }\end{array}$ & 65.00 & 65.00 \\
\hline & & Codigo : MGR1/2 & & \\
\hline & & Medidas : Diametro $\varnothing 1 / 2$ & & \\
\hline
\end{tabular}




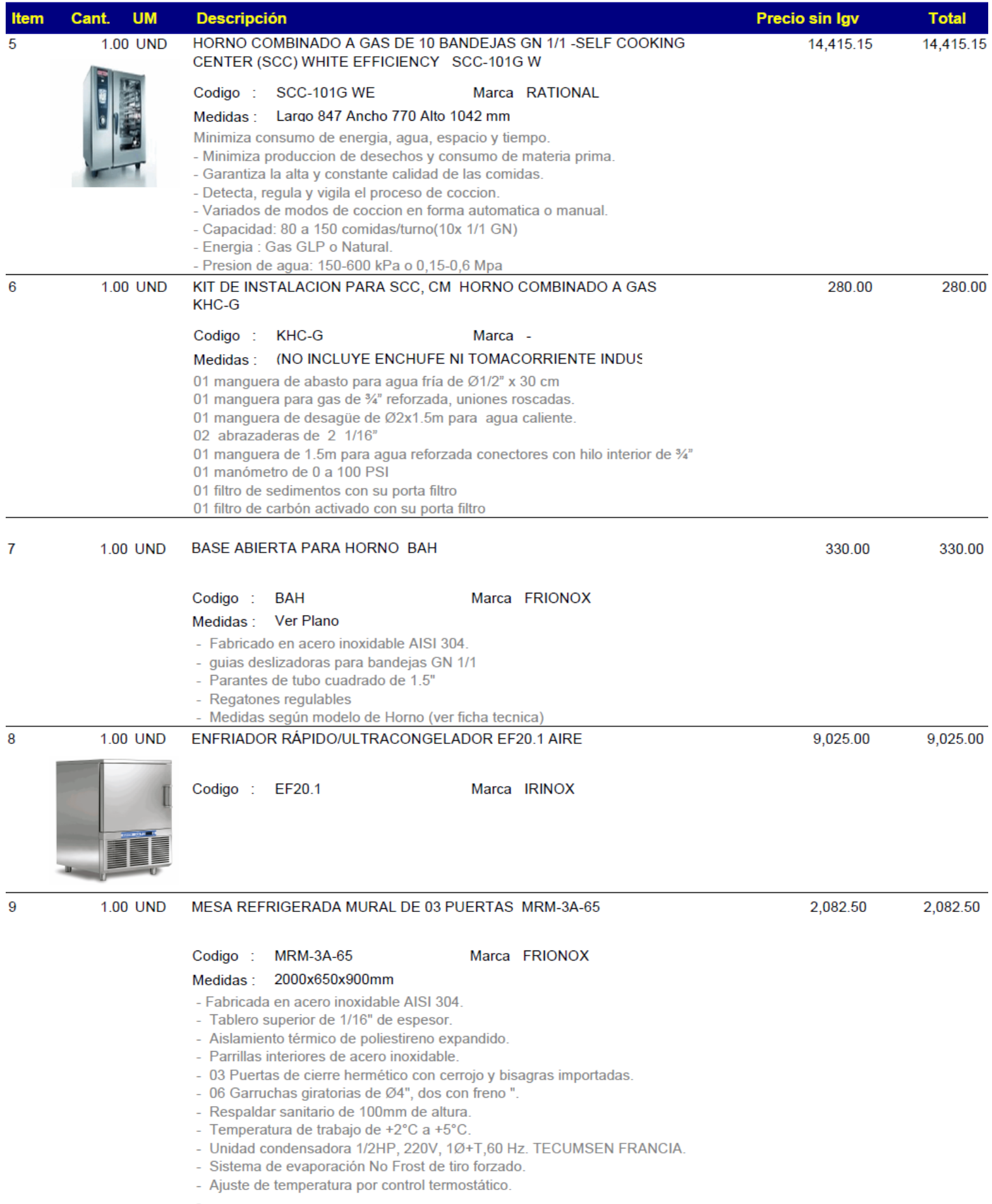




\begin{tabular}{|c|c|c|c|c|}
\hline \multirow[t]{2}{*}{10} & \multirow[t]{2}{*}{$1.00 \mathrm{UND}$} & MESA MURAL CON 01 NIV. INFERIOR MM19065-1N & \multirow[t]{2}{*}{587.35} & \multirow[t]{2}{*}{587.35} \\
\hline & & $\begin{array}{l}\text { Codigo : MM19065-1N Marca FRIONOX } \\
\text { Medidas: } 1900 \times 650 \times 900 \mathrm{~mm} \\
\text { - Fabricado en acero inoxidable AISI } 304 \text {. } \\
\text { - Tablero superior de } 1 / 16^{\prime \prime} \text { de espesor con bordes redondeados. } \\
\text { - } 01 \text { Nivel inferior de } 1 / 20^{\prime \prime} \text { de espesor. } \\
\text { - Patas tubulares de } \varnothing 11 / 2^{\prime \prime} \text { con regatones regulables. } \\
\text { - Respaldar sanitario de } 100 \mathrm{~mm} \text { de altura. }\end{array}$ & & \\
\hline \multirow[t]{2}{*}{11} & \multirow[t]{2}{*}{$1.00 \mathrm{UND}$} & CAMPANA EXTRACTORA EN AC. INOX. U. SOLDADAS CEX300120-AIS & \multirow[t]{2}{*}{$1,589.50$} & \multirow[t]{2}{*}{$1,589.50$} \\
\hline & & $\begin{array}{l}\text { - Fabricada en acero inoxidable AISI } 304 \\
\text { - Plancha de } 1 / 27^{\prime \prime} \text { de espesor. } \\
\text { - Reforzados en los laterales con plancha de } 1 / 20 " \\
\text { - Incluye } 6 \text { filtros lavables de grasa tipo bafle. } \\
\text { - Uniones soldadas mediante proceso TIG de fino acabado* NO INCLUYE } \\
\text { DUCTERIA, EXTRACTOR Y ACCESORIOS POR CONFIRMAR SEGUN VISITA } \\
\text { EN OBRA. }\end{array}$ & & \\
\hline \multirow[t]{2}{*}{12} & \multirow[t]{2}{*}{$1.00 \mathrm{UND}$} & LAVADERO DE 02 POZAS ESCURRIDERO A LA DERECHA L-2A-D & \multirow[t]{2}{*}{629.00} & \multirow[t]{2}{*}{629.00} \\
\hline & & $\begin{array}{l}\text { Codigo : L-2A-D Marca FRIONOX } \\
\text { Medidas: } 1750 \times 650 \times 900 \mathrm{~mm} \\
\text { - Fabricado en acero inoxidable AISI } 304 \text {. } \\
\text { - Uniones fijas por soldadura TIG, con fino acabado. } \\
\text { - Tablero superior de } 1 / 16^{\prime \prime} \text { de espesor con bordes antirrebose redondeado. } \\
\text { - Poza(s) sanitaria(s) de } 500 \times 480 \times 300 \mathrm{~mm} \text { soldada al tablero. } \\
\text { - Patas tubulares fijas } \varnothing 11 / 2 " \text { AISI } 304 \mathrm{~L} \text { con regatones regulables. } \\
\text { - Amarre tubular de } \varnothing 1 " \text { AISI } 304 \mathrm{~L} \text {. } \\
\text { - Respaldar sanitario de } 200 \mathrm{~mm} \text { de altura. }\end{array}$ & & \\
\hline \multirow[t]{3}{*}{13} & \multirow[t]{3}{*}{$2.00 \mathrm{UND}$} & GRIFERIA DE AGUA FRIA AL TABLERO & 90.00 & 180.00 \\
\hline & & Codigo : GF-T & & \\
\hline & & INCLUYE MANGUERA DE ABASTO & & \\
\hline \multirow[t]{2}{*}{14} & \multirow[t]{2}{*}{2.00 UND } & $\begin{array}{l}\text { SISTEMA DE DRENAJE : CANASTILLA DE ACERO } \varnothing 4^{\prime \prime} / \text { TRAMPA DE PVC } \\
\varnothing 2\end{array}$ & 45.00 & 90.00 \\
\hline & & Codigo : SD-4 & & \\
\hline \multirow[t]{2}{*}{15} & \multirow[t]{2}{*}{1.00 UND } & REFRIGERADOR VERTICAL 01 PUERTA RV-1A-75 & $1,513.00$ & $1,513.00$ \\
\hline & & $\begin{array}{l}\text { Codigo : } \text { RV-1A-75 Marca FRIONOX } \\
\text { Medidas: } 750 \times 750 \times 2080 \mathrm{~mm} \\
\text { - Fabricada en acero inoxidable AISI } 304 . \\
\text { - Capacidad } 19 \text { Pie3. } \\
\text { - Aislamiento térmico de poliestireno expandido. } \\
\text { - } 01 \text { puerta de cierre hermético con bisagras y cerrojos importados. } \\
\text { - } 04 \text { Garruchas giratorias de } \varnothing 5^{\prime \prime}, 02 \text { con freno. De alto tránsito, para trabajo } \\
\text { pesado } \\
\text { - Temperatura de trabajo en conservación de }+2^{\circ} \mathrm{C} \text { a }+5^{\circ} \mathrm{C} \text {. } \\
\text { - Unidad de conservacion de } 1 / 3 \mathrm{HP}, 220 \mathrm{~V}, 1 \varnothing+\mathrm{T}, 60 \mathrm{~Hz} \text {. TECUMSEN } \\
\text { FRANCIA. } \\
\text { - Sistema de evaporación No Frost a tiro forzado, tuberia de Cu. y aletas de AI. } \\
\text { - Aiuste de temperatura por control termostático. }\end{array}$ & & \\
\hline
\end{tabular}




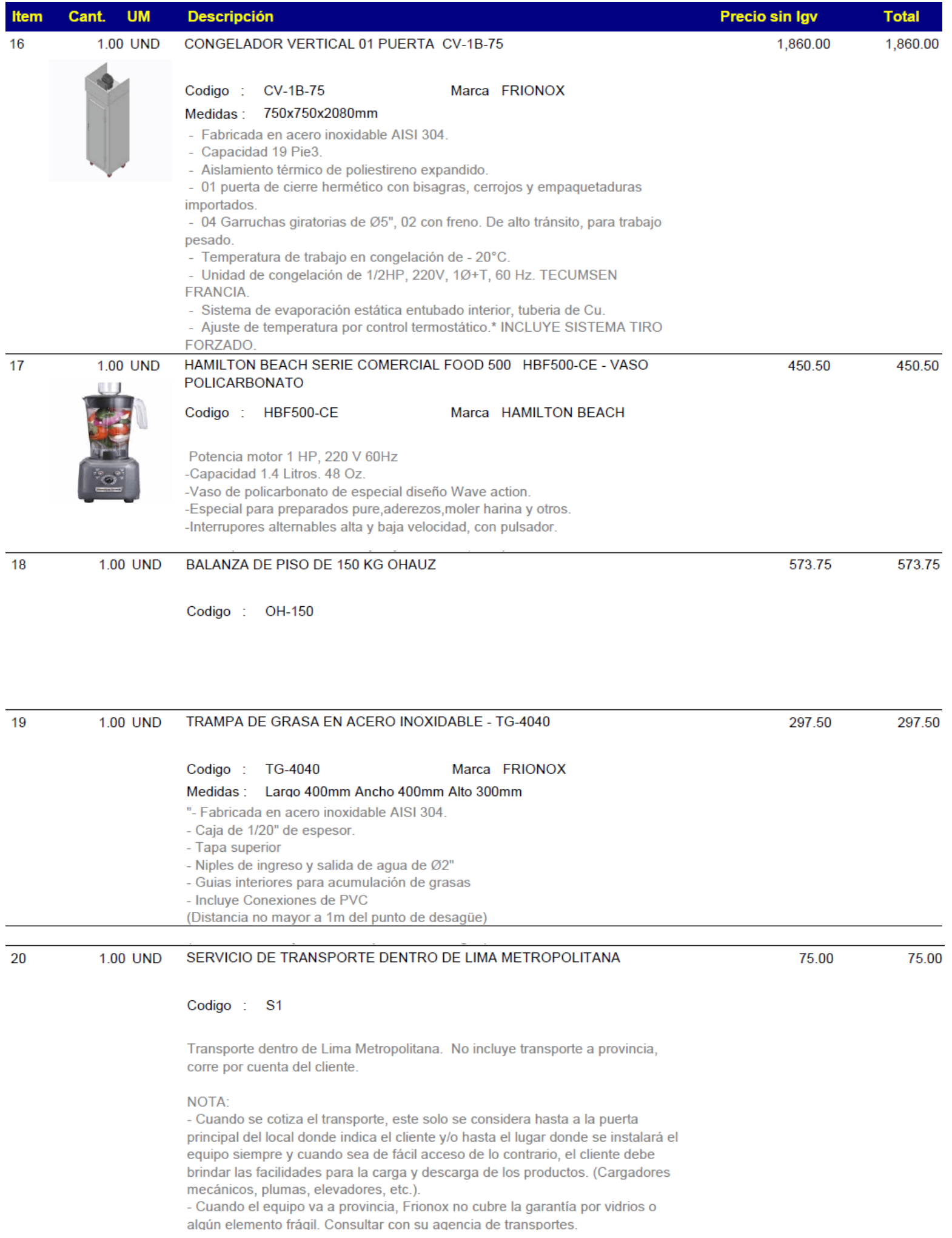


Codigo : $\mathrm{S} 3$

SERVICIO DE INSTALACIÓN DE LOS EQUIPOS COTIZADOS, PRUEBAS Y PUESTA EN MARCHA.

LOS PUNTOS ELÉCTRICOS, DE AGUA, DESAGÜE Y DE GAS, TIENEN QUE SER HABILITADOS POR EL CLIENTE.

LOS ENCHUFES Y TOMACORRIENTES PARA EQUIPOS CON POTENCIA

ELÉCTRICA MAYOR A 2000w DEBEN SER INDUSTRIALES Y HABILITADOS

POR EL CLIENTE.

LOS ENCHUFES Y TOMACORRIENTES PARA EQUIPOS CON PANEL

ELÉCTRONICO DEBEN SER INDUSTRIALES Y HABILITADOS POR EL

CLIENTE.

NO INCLUYE TRABAJOS DE OBRA CIVIL, CABLEADO ELÉCTRICO,

RECORRIDO DE TUBERIAS, ETC

PARA TRABAJOS EN ALTURA.

EL CLIENTE DEBE HABILITAR ANDAMIOS O CUALQUIER OTRO

ELEMENTOS DE IZAJE CORRESPONDIENTE PARA LA INSTALACIÓN.

\section{Condiciones de venta :}

Precios expresados en Dólares Americanos

Forma de Pago
Sub total : US\$

Impuestos : US\$

Total: US\$
$36,486.25$

$6,567.53$

$43,053.78$

Tiempo de entrega

60 DIAS

Validez de la oferta

7 dias

Vendedor

Israel Echegaray

Telefonos: 5221181

99424122

Usuario :

iech

Aprobada nuestra cotización, puede realizar el depósito en nuestra cuenta corriente:

Cuenta 1: $\quad$ BCP\$ 191-1413731-1-20 S/.191-1419820-0-15

Cuenta 2: $\quad$ BBVA $\$ 110176010004799153$ S/.110176010004798350

Realizado el pago, enviar constancia a

facturacion@frionox.com

Observaciones

Garantía : 1 año. La garantía cubre, reparación, modificación y/o cambio del equipo según revisión de un técnico autorizado por la empresa por cualquier defecto de fabricación. Cabe señalar que esta garantía queda anulada por daños y averías causados por terceros, falta de mantenimiento, uso inadecuado, desgaste natural por el uso del equipo, desastres o accidentes, etc. En el caso de servicios de mantenimiento, el periodo de garant ía es de 03 meses por los repuestos y accesorios cambiados.

IMPORTANTE :La garantía no cubre elementos frágiles, tales como vidrios, luminarias, etc 


\section{Tor.i.a.m.

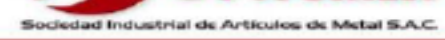

$\begin{array}{ll}\text { Cliente } & \text { ABEPER GROUP } \\ \text { Dirección } & \text { Ca. Monte Grande 185-Santiago de Surco } \\ \text { Atención } & \text { Alejandro Villa-García Vargas } \\ \text { Teléfono } & 965760825 \\ \text { Email } & \text { avillagarcia@abeper.com }\end{array}$

\begin{tabular}{|c|c|c|c|c|c|c|c|c|c|c|}
\hline \multirow{2}{*}{ Item } & \multirow{2}{*}{ Cant. } & \multirow{2}{*}{ Descripción } & \multicolumn{3}{|c|}{ Dim. $\mathbf{m m}$} & \multirow{2}{*}{\multicolumn{2}{|c|}{ Valor Unit. \$. }} & \multirow{2}{*}{ Dscto \% } & \multirow{2}{*}{\multicolumn{2}{|c|}{ Valor Total. \$. }} \\
\hline & & & $\mathbf{L}$ & $\mathbf{P}$ & A & & & & & \\
\hline \multirow[t]{10}{*}{1.0} & 1 & PLANCHA LISA A GAS & 900 & 650 & 900 & $\$$ & 889.50 & $10 \%$ & $\$$ & 800.55 \\
\hline & & Marca: SIAM ( Perú ). Modelo: PL90 & & & & & & & & \\
\hline & & Fabricación integra en acero inoxidable. & & & & & & & & \\
\hline & & 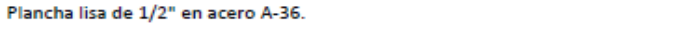 & & & & & & & & \\
\hline & & Quemador tipo Ancla de $45,000 \mathrm{Btu} / \mathrm{Hr}$. & & & & & & & & \\
\hline & & Presión de trabajo: 0.5 Psi ( Baja presión ). & & & & & & & & \\
\hline & & Perilla de la válvula en acero cromado. & & & & & & & & \\
\hline & & Bandeja para los desperdicios. & & & & & & & & \\
\hline & & Repisa inferior tipo rejilla. & & & & & & & & \\
\hline & & Patas de tubo cuadrado de acero inoxidable de $11 / 2 " \times 1.5 \mathrm{~mm}$ de espesor. & & & & & & & & \\
\hline \multirow[t]{3}{*}{1.1} & 1 & MANGUERA DE CONEXIÓN DE GAS 3/4" BAJA PRESIÓN & 1200 & & & s & 69.00 & $10 \%$ & 5 & 62.10 \\
\hline & & Marca: SIAM ( Perú ). Modelo: MRG-120 × 3/4" BP & & & & & & & & \\
\hline & & $\begin{array}{l}\text { Manguera reforzada para gas 3/4" x } 500 \text { PSI con terminales roscados. } \\
\text { CÓDIGO SIAM: CCVA920004 }\end{array}$ & & & & & & & & \\
\hline \multirow[t]{9}{*}{2.0} & 1 & COCINA ISLA DE 2 QUEMADORES A GAS & 950 & 650 & 900 & $\$$ & 565.10 & $10 \%$ & $\$$ & 508.59 \\
\hline & & Marca: SIAM ( Perú ). Modelo: CI2Q & & & & & & & & \\
\hline & & Fabricación integra en acero inoxidable. & & & & & & & & \\
\hline & & Tablero superior de $1 / 16^{\prime \prime}$ de espesor. & & & & & & & & \\
\hline & & Quemadores a gas de fierro fundido de 5 " de diámetro ( $31,500 \mathrm{Btu} / \mathrm{Hr} \mathrm{c} / \mathrm{u}$ ). & & & & & & & & \\
\hline & & Presión de trabajo 15 Psi ( Alta presión ). & & & & & & & & \\
\hline & & Parrillas de $380 \times 380 \mathrm{~mm}$. & & & & & & & & \\
\hline & & Bandejas de desperdicios. & & & & & & & & \\
\hline & & Patas de tubo cuadrado de acero inoxidable de $11 / 2^{\prime \prime} \times 1.5 \mathrm{~mm}$ de espesor, & & & & & & & & \\
\hline \multirow[t]{3}{*}{2.1} & 1 & MANGUERA DE CONEXIÓN DE GAS $1 / 2^{\prime \prime}$ ALTA PRESIÓN & 1200 & & & s & 69.00 & $10 \%$ & $\$$ & 62.10 \\
\hline & & Marca: SIAM ( Perú ). Modelo: MRG-120 x 1/2" AP & & & & & & & & \\
\hline & & $\begin{array}{l}\text { Manguera reforzada para gas 1/2" x } 500 \text { PSI con terminales roscados. } \\
\text { CÓDIGO SIAM: CCVA920005 }\end{array}$ & & & & & & & & \\
\hline
\end{tabular}

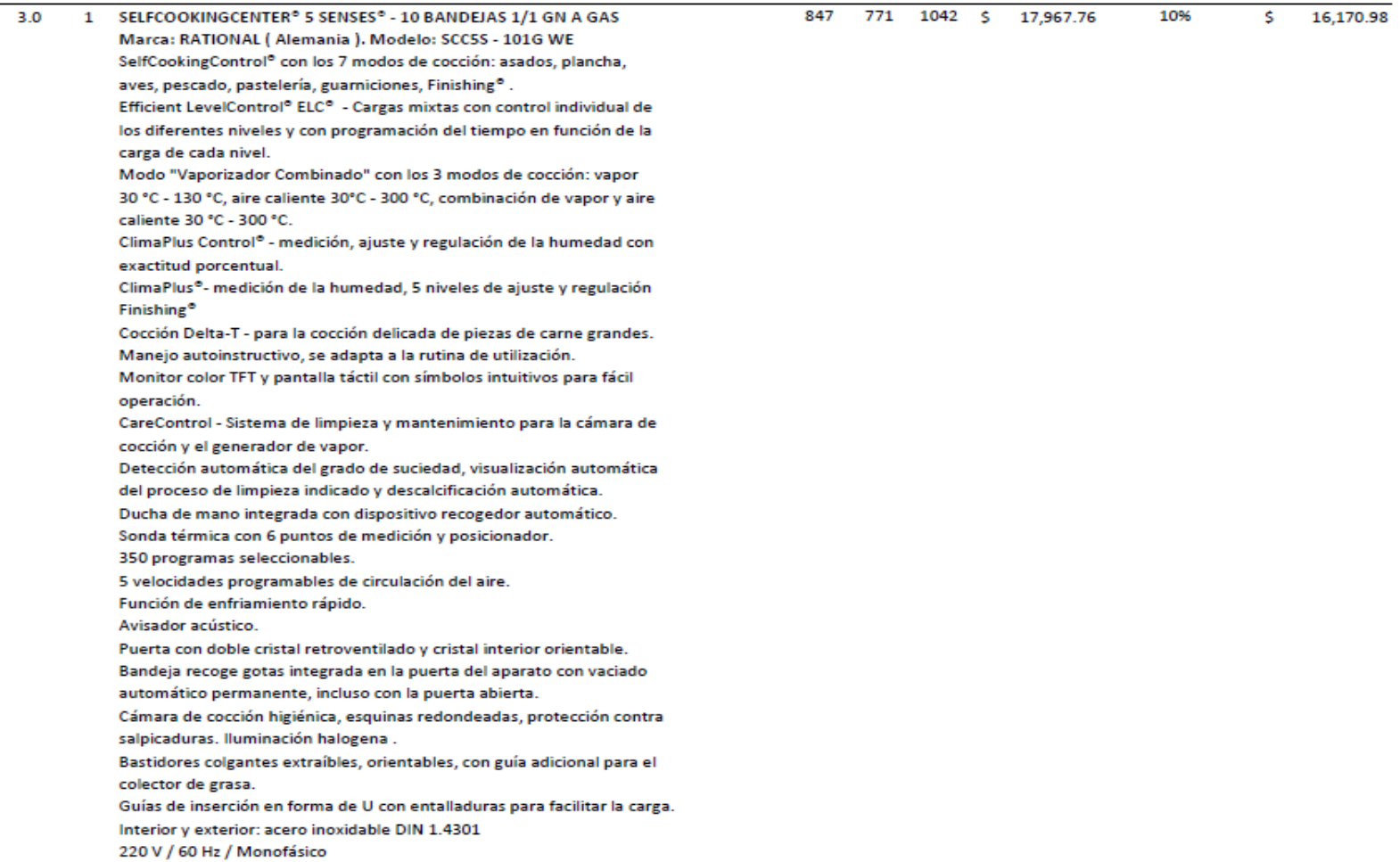




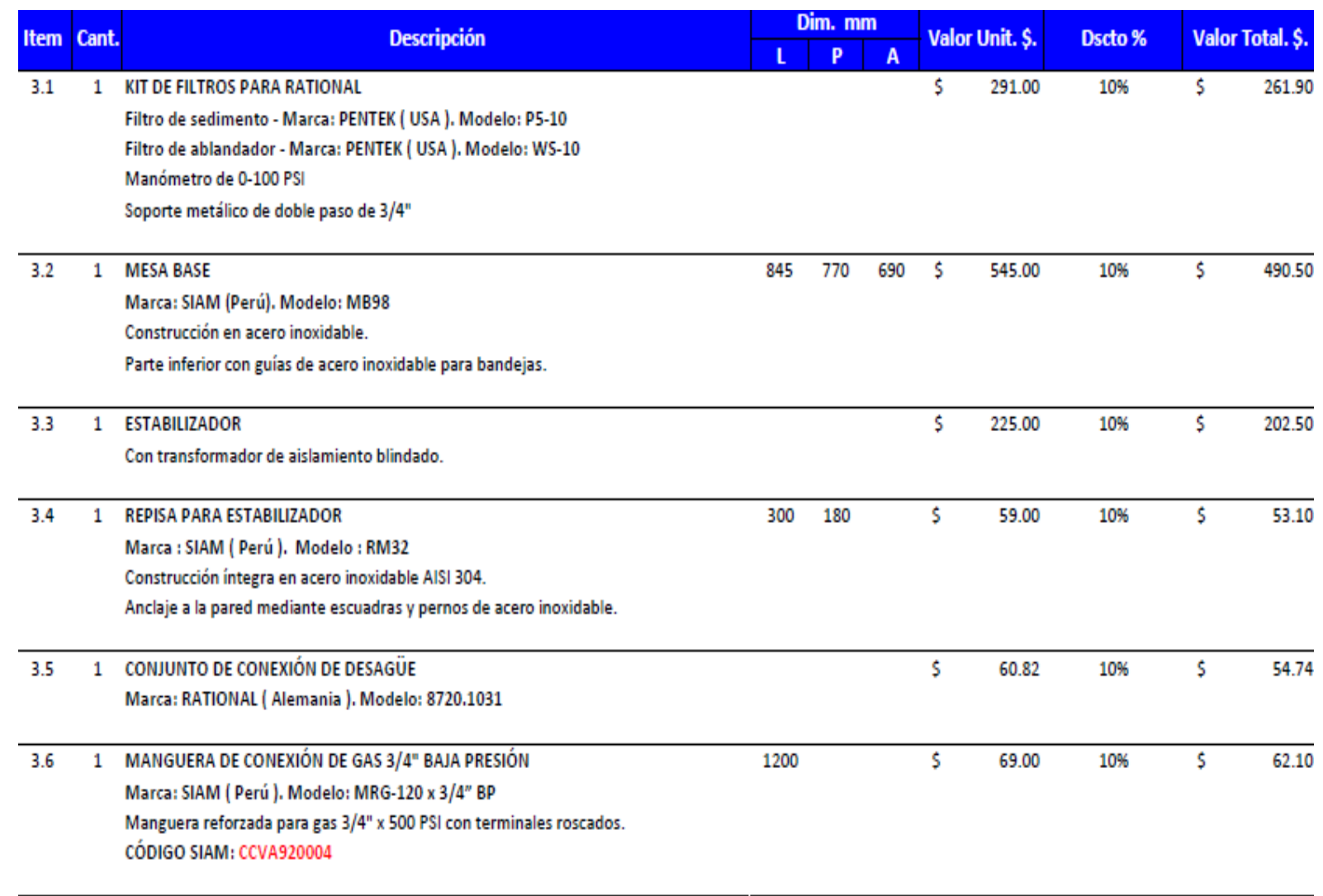

4.0 1 ABATIDOR DE TEMPERATURA MULTIFRESH - EF LINE

$\begin{array}{lllllllll}790 & 771 & 870 & \$ & 10,709.31 & 10 \% & \$ & 9,638.38\end{array}$

Marca: IRINOX ( Italia ). Modelo: EF 20.1

Fabricación en acero inoxidable.

Entre 30\% y $40 \%$ mayor eficiencia.

Tiempos de enfriamiento mucho más rápidos.

Ciclo delicado $+3^{\circ} \mathrm{C}$ : enfriamiento de prod. de espesor reducido.

Ciclo fuerte $+3^{\circ} \mathrm{C}$ : efriamiento de prod. de alto contenido graso.

Ciclo delicado $-18^{\circ} \mathrm{C}$ : congelación de prod. de consistencia delicada.

Ciclo fuerte $-18^{\circ} \mathrm{C}$ : congelación prod. crudos y cocidos de gran espesor.

Descongelamiento automático ( $30 \mathrm{~min}$. como máx) .

MultiRack: guías desmontables y regulables en altura para las bandejas.

Se pueden utilizar bandejas "GN" o bandejas de $600 \times 400 \mathrm{~mm}$.

Capacidad: 4 band. de $600 \times 400 \mathrm{~mm}$ ó $\mathrm{GN} 1 / 1$ de $65 \mathrm{~mm}$ de profundidad.

Capacidad: 5 band. de $600 \times 400 \mathrm{~mm}$ ó $\mathrm{GN} 1 / 1$ de $40 \mathrm{~mm}$ de profundidad.

Capacidad: 8 band. de $600 \times 400 \mathrm{~mm}$ ó GN 1/1 de $20 \mathrm{~mm}$ de profundidad.

Rendimiento por ciclo: $20 \mathrm{~kg}$.

Gas refrigerante ecológico R404.

Sonda Multi Sensor automática.

Panel de manejo sencillo con teclas parpadeantes.

Manija empotrada a la puerta.

Limpieza sencilla de ventiladores y evaporadores.

Bandeja para recolección del agua de la condensación.

Opcional - Conector USB: Control de los ciclos de trabajo mediante

ordenador.

Opcional - Sistema de higienización Sanigen": Libera iones activos

para reducir la carga microbiana presente en el aire tratado y las

superficies.

INCLUYE Kit de Voltaje: $230 \mathrm{~V} / 60 \mathrm{~Hz} / 1$ ( Monofásico ). Mod: 8E005100090 


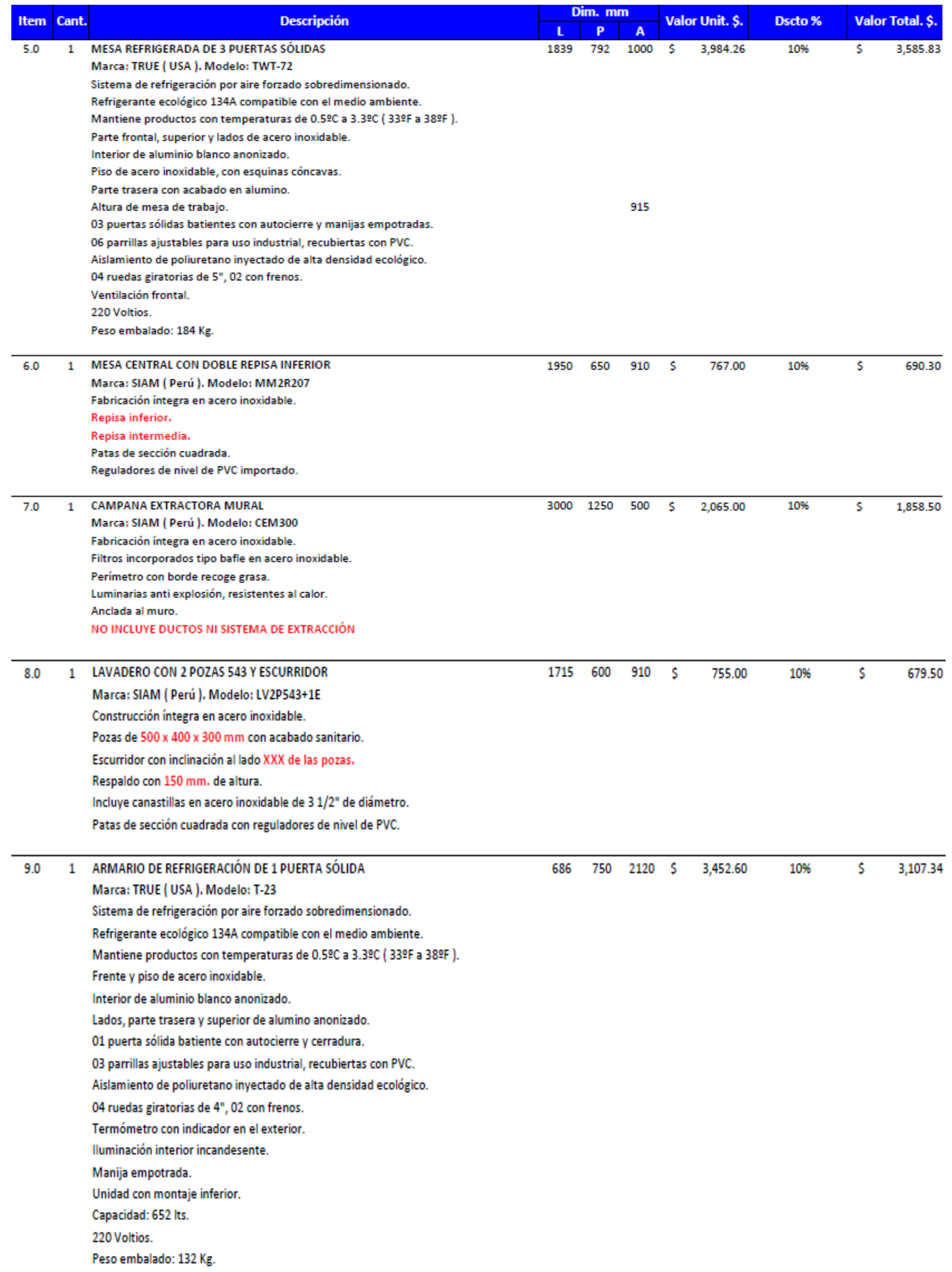




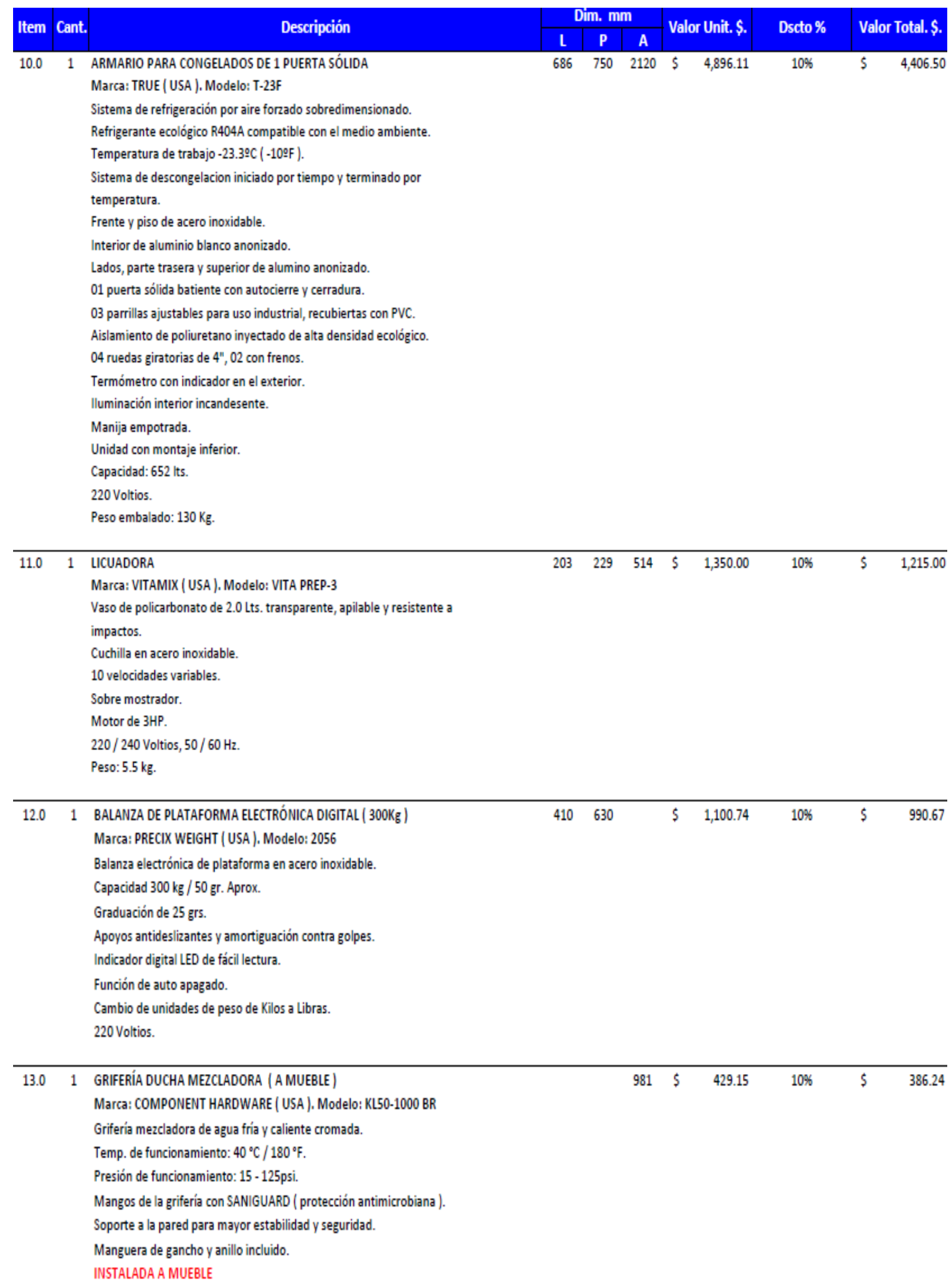




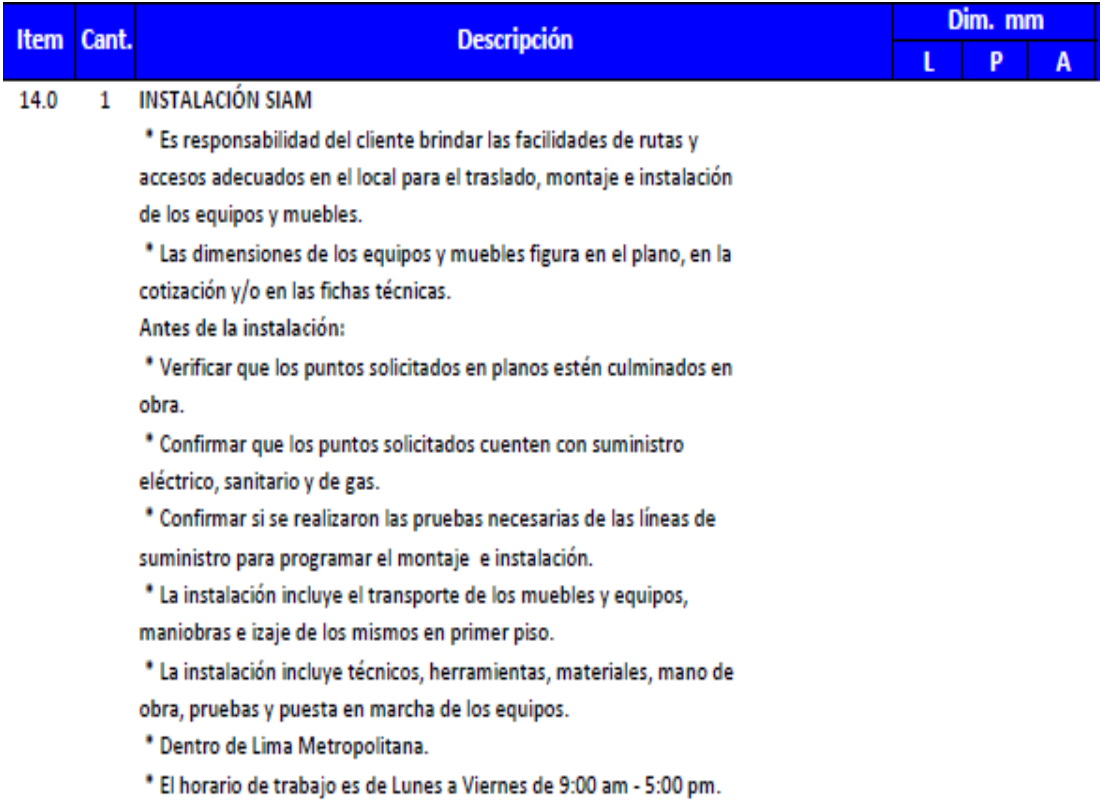

A

14.011 INSTALACIÓN SIAM

' Es responsabilidad del cliente brindar las facilidades de rutas y

accesos adecuados en el local para el traslado, montaje e instalación

de los equipos y muebles.

- Las dimensiones de los equipos y muebles figura en el plano, en la cotización y/o en las fichas técnicas.

Antes de la instalación:

- Verificar que los puntos solicitados en planos estén culminados en

obra.

- Confirmar que los puntos solicitados cuenten con suministro

eléctrico, sanitario y de gas.

- Confirmar si se realizaron las pruebas necesarias de las líneas de

suministro para programar el montaje e instalación.

- La instalación incluye el transporte de los muebles y equipos,

maniobras e izaje de los mismos en primer piso.

- La instalación incluye técnicos, herramientas, materiales, mano de

obra, pruebas y puesta en marcha de los equipos.

- Dentro de Lima Metropolitana.

- El horario de trabajo es de Lunes a Viernes de 9:00 am - 5:00 pm.

\begin{tabular}{rrr} 
TOTAL VALOR DE VENTA & $\$$ & $45,287.42$ \\
IGV $18 \%$ & $\$$ & $8,151.73$ \\
\cline { 2 - 3 } PRECIO DE VENTA & $\$$ & $53,439.15$ \\
\hline
\end{tabular}

* Precios

En dólares estadounidenses (USS)

${ }^{*}$ Forma de pago

$50 \%$ de anticipo

Saldo contra entrega

* Plazo de entrega

4 semanas aprox. para fabricación nacional una vez cancelado el anticipo

De 10 a 12 semanas aprox. para productos de importación una vez cancelado el anticipo

* Números de cuenta

BCP: Moneda nacional (nuevos soles) 191-0823680-0-99

BCP: Moneda extranjera (dólares) 191-0661057-1-52

Continental: Moneda nacional (nuevos soles) 0130-23-0100006976

Continental: Moneda extranjera (dólares) 0130-26-01000017412

Scotiabank: Moneda nacional (nuevos soles) 01-000-87955525

Scotiabank: Moneda extranjera (dólares) 07-000-383132

* Importante

Es necesario enviar comprobante del depósito vía mail a icoste@siam.com.pe y/o a gviccina@siam.com.pe y/o a ventas@siam.com.pe

o vía fax al 421-8148 para proceder con el despacho ( en caso de que el pago sea abonado en una de nuestras cuentas )

De acuerdo a disposición de SUNAT y según reglamento de comprobantes de pago, no se emitirán facturas si no se ha recibido

previamente el depósito correspondiente. En caso de facturas adelantadas y/o anticipos sólo se enviarán escaneadas hasta

que se confirme el depósito en nuestra cuenta.

* No incluve

Transporte fuera de Lima Metropolitana

Cualquier suministro no especificado en la presente oferta

* Validez de la oferta

15 días calendario 


\section{FoodService}

Para:

Alejando Villa
Proyecto:

Equipos sangucheria

\section{Cotización}

De:

FoodService

Pamela Carhuayal

Calle Los Asteroides 115-117

La Campiña Chorrillos

Lima 00009

618-0500 (Teléfono)

Número de Referencia: HPC07081A

\begin{tabular}{|c|c|c|c|c|}
\hline Artículo & Cnt. & Descripción & Presupuesto & $\begin{array}{r}\text { Presupuesto } \\
\text { Total }\end{array}$ \\
\hline 1 & $1 \mathrm{ea}$ & $\begin{array}{l}\text { BAR BLENDER } \\
\text { Waring Modelo No. MX1050XTXE6 } \\
\text { Xtreme High-Power Blender, heavy duty, } 48 \text { oz. capacity, electronic } \\
\text { membrane keypad, one piece removable jar pad, unbreakable } \\
\text { polycarbonate container, } 220 \mathrm{v} / 60 \mathrm{~Hz} / 1 \mathrm{~F}, 3.5 \mathrm{HP}, \mathrm{NSF}, \mathrm{CUL} \& \text { UL listed } \\
\quad \text { Peso: } 15 \text { lbs total }\end{array}$ & $\$ 875.00$ & $\$ 875.00$ \\
\hline $\begin{array}{l}2 \\
= \\
{[}\end{array}$ & $1 \mathrm{ea}$ & $\begin{array}{l}\text { REACH-IN REFRIGERATOR } \\
\text { True Food Service Equipment Modelo No. T- } 23 \\
\text { refrigerador, vertical, una sección, puerta de acero inoxidable, de } \\
\text { acero inoxidable parte de adelante, laterales de aluminio, interior de } \\
\text { aluminio blanco con de acero inoxidable piso, (3) ajustable(s) } \\
\text { recubiertas de PVC repisas de alambre, iluminación interior, } 10.16 \mathrm{~cm} \\
\text { ruedas, } 1 / 3 \mathrm{HP}, 220 \mathrm{~V} / 60 / 1,7.6 \text { Amperios, } 2.7432 \mathrm{~m} \text { cordón, NEMA } \\
\text { 5-15P, cUL, UL-Energía, NSF, CE, Energy } \mathrm{Star}^{\odot} \text {, hecho en USA } \\
\text { *** EQUIPO EN STOCK*** } \\
\text { Dimensiones } 78.38(\mathrm{~h}) \times 27.00(\mathrm{w}) \times 29.50(\mathrm{~d}) \\
\text { Peso: } 290 \mathrm{lbs} \text { total }\end{array}$ & $\$ 3,095.00$ & $\$ 3,095.00$ \\
\hline $\begin{array}{l}3 \\
= \\
{[}\end{array}$ & $1 \mathrm{ea}$ & $\begin{array}{l}\text { REACH-IN FREEZER } \\
\text { True Food Service Equipment Modelo No. T-23F } \\
\text { congelador, vertical, }-10^{\circ} \mathrm{F} \text {, una sección, puerta de acero inoxidable, } \\
\text { de acero inoxidable parte de adelante, laterales de aluminio, interior } \\
\text { de aluminio blanco con de acero inoxidable piso, (3) ajustable(s) } \\
\text { recubiertas de PVC repisas de alambre, iluminación interior, } 10.16 \mathrm{~cm} \\
\text { ruedas, } 1 / 3 \mathrm{HP}, 220 \mathrm{~V} / 60 / 1,7.2 \text { Amperios, NEMA 5-15P, } 2.7432 \mathrm{~m} \\
\text { cordón, Energy Star }^{\odot} \text {, hecho en USA }{ }^{* * *} \text { EQUIPO EN STOCK*** } \\
\text { Dimensiones } 78.38(\mathrm{~h}) \times 27.00(\mathrm{w}) \times 29.50 \text { (d) }\end{array}$ & $\$ 4,138.35$ & $\$ 4,138.35$ \\
\hline
\end{tabular}


Rational Modelo No. SCC WE $101 \mathrm{G}$

RATIONAL SelfCooking centro ${ }^{\odot}$ WhiteEfficiency ${ }^{\odot} 101$, de tamaño medio, gas, SelfCooking control con 7 funciones, HiDensityControl ${ }^{\odot}$, de buen rendimiento LevelControl ${ }^{\circ}$, CareControl, Horno/Horno a Vapor con 3 funciones, (10) $33.02 \mathrm{~cm} \times 45.72 \mathrm{~cm}$ o (10) $30.48 \mathrm{~cm} \times 50.8 \mathrm{~cm}$ capacidad de bandejas, sonda de penetración para tomar la temperatura del centro con 6 Punto medida, ducha de mano con automático(a) retracting sistema, Interfaz, 82,000 BTU. *** EQUIPO EN STOCK*** Dimensiones 40.00(h) x 33.25(w) x 30.38(d)

1 ea 60.70 .464 kit de instalación de agua y desagüe RATIONAL

1 ea Custom FILTROS DE AGUA Kit de filtros que incluye: 02 carcasas, 01 filtro de carbón activada 01 filtro de sedimentos. 02 sujetadores de filtro y un manometro

1 ea Dormont Manufacturing 1575 NPFS-36" Manguera conectora a gas de $3 / 4$ " de diametro, sistema fijo, cuerpo de metal flexible con recubrimientos sintéticos, 36 " de largo.

1 ea Custom BPH-001 Base o mesa de acero inoxidable para equipo Rational de 10 bandejas.

EasyFresh Enfriador rápido/Abatidor de temperatura, vertical, (4) $30.48 \mathrm{~cm} \times 50.8 \mathrm{~cm} \times 6.35 \mathrm{~cm}$ o (8) $45.72 \mathrm{~cm} \times 33.02 \mathrm{~cm}$ tamaño medio bandejas para hornear (de) capacidad $20 \mathrm{KG}$ enfria $194^{\circ} \mathrm{Fahrenheit}$ hasta $37^{\circ} \mathrm{F} / 90$ minutos o menos y/e 55 libras. congela a $0^{\circ} \mathrm{F} / 4$ horas o menos, puerta abisagrada en la izquierda, controles digitales. Medidas: $790 \times 771 \times 870 \mathrm{~mm}$ Dimensiones 35.25(h) x 31.00(w) x 30.50(d)

1 ea Custom ESTABILIZADOR Estabilizador de energia

Peso: $330 \mathrm{lbs}$ total

TOTAL POR ARTICULO:

ISA Modelo No. ZERO T5 SP

Abatidor-congelador de temperatura, $5 \times 1 / 1 \mathrm{GN}$, carga $18 \mathrm{Kg}$ de $+90 \circ \mathrm{C}$ $\mathrm{a}+3{ }^{\circ} \mathrm{C}$ y carga de 12 kilos de $+90^{\circ} \mathrm{C}$ a $-18^{\circ} \mathrm{C}$, interior y exterior en Acero Inoxidable, sistema de enfriamiento auto contenido, gas refrigerante R404A, potencia 4500 Watts. Medidas: $800 \times 700 \times 920 \mathrm{~mm}$.

$220 \mathrm{~V} / 6 \mathrm{OHz} / 3 \mathrm{~F}$

Dimensiones 40.00(h) x 33.25(w) x 30.38(d) 
True Food Service Equipment Modelo No. TWT-72

Refrigerador con Superficie de Trabajo, tres secciones, (6) repisas, superficie de acero inoxidable con peto posterior \& lados, interior de aluminio blanco con de acero inoxidable piso, (3) puertas de acero inoxidable, $12.7 \mathrm{~cm}$ ruedas, montado en la parte de atrás, $1 / 3 \mathrm{HP}$, 220V/60/1, 8.5 Amperios, NEMA 5-15P, 2.1336m cordón, hecho en USA

Dimensiones 33.38(h) x 72.38(w) x 30.13(d) Peso: 405 lbs total

\begin{tabular}{|c|c|c|c|c|}
\hline \multirow[t]{6}{*}{7} & 1 ea & MESA DE TRABAJO MURAL & $\$ 944.44$ & $\$ 944.44$ \\
\hline & & CARPINTERIA METALICA Modelo No. MM-1965-2N & & \\
\hline & & Mesa de trabajo con 01 niveles inferiores, fabricado integramente en & & \\
\hline & & bordes redondeados. 02 nivel inferior de $1 / 20 "$ de espesor. Patas & & \\
\hline & & tubulares de $\emptyset 11 / 2 "$ con regatones regulables importados CH-USA. & & \\
\hline & & Respaldar sanitario de $100 \mathrm{~mm}$ de altura. Medidas:1950x650x900mm & & \\
\hline \multirow[t]{5}{*}{8} & 1 ea & BALANZA DE PLATAFORMA & $\$ 611.00$ & $\$ 611.00$ \\
\hline & & Custom Modelo No. 2056 & & \\
\hline & & Balanza de plataforma con capacidad de carga de $150 \mathrm{~kg}$. Indicador & & \\
\hline & & 8513 en acero inoxidable Plataforma de $60 \mathrm{~cm} \times 45 \mathrm{~cm}$ en acero & & \\
\hline & & inoxidable (A304) & & \\
\hline \multirow[t]{9}{*}{9} & 3 ea & CAMPANA MURAL CON FILTROS & $\$ 772.22$ & $\$ 2,316.66$ \\
\hline & & CARPINTERIA METALICA Modelo No. CEM-100 & & \\
\hline & & CAMPANA EXTRACTORA MURAL, Fabricada integramente en acero & & \\
\hline & & inoxidable AISI 304; con PL. de 1/27" de espesor, reforzados en los & & \\
\hline & & laterales con plancha de $1 / 20 "$; diseñada para alojar 02 filtros lavables & & \\
\hline & & de grasa tipo Bafle en acero galvanizado de $500 \times 500 \mathrm{~mm}$. & & \\
\hline & & MEDIDAS:1000x1200x600mm. & & \\
\hline & & Dimensiones $72.00(\mathrm{~h}) \times 42.00(\mathrm{w}) \times 18.00(\mathrm{~d})$ & & \\
\hline & & Peso: 167.43 lbs total Volumen: 17.76 & & \\
\hline \multirow[t]{5}{*}{9.1} & 3 ea & FANAL DE ILUMINACION & $\$ 61.11$ & $\$ 183.33$ \\
\hline & & CARPINTERIA METALICA Modelo No. FANAL & & \\
\hline & & FANALES DE ILUMINACION EMPAVONADOS & & \\
\hline & & Dimensiones $72.00(\mathrm{~h}) \times 42.00(\mathrm{w}) \times 18.00(\mathrm{~d})$ & & \\
\hline & & Peso: 167.43 lbs total Volumen: 17.76 & & \\
\hline \multirow[t]{3}{*}{10} & $1 \mathrm{ea}$ & COCINA LINEALDE 02 QUEMADORES & $\$ 888.89$ & $\$ 888.89$ \\
\hline & & CARPINTERIA METALICA Modelo No. CC-2 & & \\
\hline & & Cocina lineal de 02 quemadores, estructura integral en acero & & \\
\hline
\end{tabular}


inoxidable AISI 304. Tablero superior de $1 / 16 "$ de espesor.

Quemadores a gas de Fe. Fdo. de $\varnothing$ 5" (41 500 Btu/Hr c/u) Presión de

trabajo 15 Psi (Alta Presión). Parrillas de fierro fundido de

$380 \times 380 \mathrm{~mm}$. Válvulas con perillas de acero cromado. Bandeja de

desperdicios. Respaldar sanitario de $100 \mathrm{~mm}$ de altura. $01 \mathrm{Nivel}$

inferior con rejilla tipo parrilla. Patas de tubo cuadrado de 1

1/2"x1.5mm de espesor. Medidas: $950 \times 650 \times 900 \mathrm{~mm}$

Dimensiones 78.38(h) x 54.13(w) x 29.50(d)

1 ea Custom Manguera conectora a gas de $1 / 2$ " de diametro.

$\$ 72.22$

Peso: 425 lbs total

TOTAL POR ARTICULO:

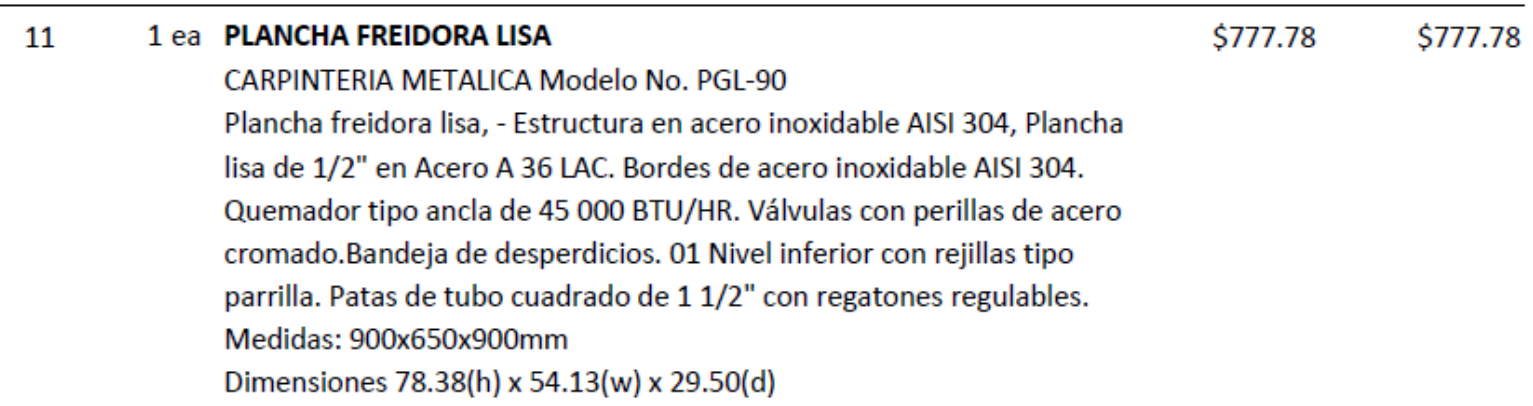

1 ea Custom Manguera conectora a gas de 1/2" de diametro.

Peso: $425 \mathrm{lbs}$ total

TOTAL POR ARTICULO:

\begin{tabular}{|c|c|c|c|c|}
\hline \multirow[t]{7}{*}{12} & 1 ea & LAVADERO DE 02 POZAS CON DESCONCHE & $\$ 772.22$ & $\$ 772.22$ \\
\hline & & CARPINTERIA METALICA Modelo No. L-2A-175 & & \\
\hline & & LAVADERO DE 02 POZAS con escurridero, fabricada integramente en & & \\
\hline & & acero inoxidable AISI 304 , tope de $1 / 16 "$ de espesor, amarres & & \\
\hline & & tubulares, 02 poza: $300 \times 450 \times 300 \mathrm{~mm}$. Patas tubulares de $1.5 \mathrm{~mm}$ de & & \\
\hline & & espesor con regatones regulables importados. Respaldar sanitario de & & \\
\hline & & $20 \mathrm{~cm}$. Medidas: $1750 \times 650 \times 900 \mathrm{~mm}$ & & \\
\hline \multirow[t]{5}{*}{12.1} & 1 ea & PRE-RINSE & $\$ 438.89$ & $\$ 438.89$ \\
\hline & & Fisher Modelo No. 34169 & & \\
\hline & & Pre-Rinse Unit, single deck dual control, with spring action flexible & & \\
\hline & & gooseneck, wall bracket, Add-On-Faucet with 6" spout & & \\
\hline & & Peso: $15 \mathrm{lbs}$ total & & \\
\hline \multirow[t]{3}{*}{12.2} & 2 ea & CESTA PARA DESAGÜE & $\$ 50.00$ & $\$ 100.00$ \\
\hline & & Component Hardware Modelo No. SD-4 & & \\
\hline & & Canastilla de drenaje, latón & & \\
\hline
\end{tabular}


Peso: 2 lbs total

\begin{tabular}{|c|c|c|c|c|c|}
\hline \multirow[t]{3}{*}{13} & 1 ea & \multicolumn{2}{|l|}{ TRAMPA DE GRASA } & $\$ 390.00$ & $\$ 390.00$ \\
\hline & & \multicolumn{4}{|l|}{ CARPINTERIA METALICA Modelo No. TG } \\
\hline & & \multicolumn{4}{|c|}{$\begin{array}{l}\text { Trampa de grasa, Fabricado en acero inoxidable AISI 304, Uniones fijas } \\
\text { por soldadura TIG, con fino acabado, Medidas } 500 \times 400 \times 300 \mathrm{~mm}\end{array}$} \\
\hline \multirow[t]{6}{*}{$* * * *$} & 1 ea & INSTALACION & & $\$ 2,950.00$ & $\$ 2,950.00$ \\
\hline & & Custom Modelo No. INSTALACION & & & \\
\hline & & $\begin{array}{l}\text { La instalacion incluye conexión, calibración, puesta en marcha, } \\
\text { capacitación de uso y materiales de instalación }\end{array}$ & & & \\
\hline & & \multicolumn{3}{|c|}{ Mercadería } & $\$ 48,483.94$ \\
\hline & & \multicolumn{3}{|c|}{$\begin{array}{l}\text { Impuestos } \\
(18 \%)\end{array}$} & $\$ 8,727.11$ \\
\hline & & \multicolumn{3}{|c|}{ TOTAL } & $\$ 57,211.05$ \\
\hline
\end{tabular}

Condiciones de Venta:

* Precios no incluyen I.G.V.

* Precios expresados en dólares americanos

* Entrega de equipos en Lima Metropolitana

* Precios unitarios no incluye instalacion de equipos, esto es cotizado en un item

a parte

* Entrega de equipos:

Carpinteria metalica: 04 a 06 semanas

Equipos importados: 08 a 12 semanas

* Forma de Pago: 50\% adelanto, 50\% contraentrega.

* Validez de la oferta: 15 días

Pamela Carhuayal

Asesora Comercial 


\section{Utensilios}

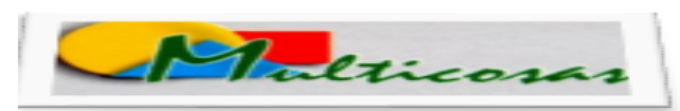

MULTICOSAS TIENDAS DEL PERU SAC AV.PASEO DE LA REPUBLICA 5453 - SURQUILLO

\begin{tabular}{|c|c|}
\hline SEÑORES & Restaura \\
\hline $\begin{array}{l}\text { CONTACTO } \\
\text { EMAIL }\end{array}$ & Dsala@akiparestaurant.com \\
\hline
\end{tabular}

\begin{tabular}{|c|c|c|c|c|c|}
\hline CANTIDAD & UN/MED & DESCRIPCION & MARCA & PRECIO/U & TOTAL \\
\hline 3 & UND. & Cuchillo chef & $\begin{array}{c}\text { 24011/OO8 CUCHILLO CENTURY } \\
\text { CHEFF TRAMONTINA }\end{array}$ & 80.41 & 241.23 \\
\hline 3 & UND. & Cuchillo chef & $\begin{array}{c}\text { 24011/O10 CUCHILLO CENTURY } \\
\text { CHEFF TRAMONTINA }\end{array}$ & 94.90 & 284.70 \\
\hline 3 & UND. & Cuchillo Ofiice & $\begin{array}{c}\text { 24010/OO4 CUCHILLO CENTURY } \\
\text { OFICIO TRAMONTINA }\end{array}$ & 35.52 & 106.56 \\
\hline 4 & UND. & Tabla picar & TABLAS $60 \times 40$ COLOR & 72.75 & 291.00 \\
\hline 8 & UND. & Bowl s.s. 16.5 & $\begin{array}{c}\text { BOLO ACE INOX \#16 CM PROFES } \\
\text { VINOD }\end{array}$ & 5.88 & 47.04 \\
\hline 8 & UND. & Bowl s.s. 20.5 & $\begin{array}{c}\text { BOLO ACE INOX \#2O CM PROFES } \\
\text { VINOD }\end{array}$ & 9.20 & 73.60 \\
\hline 8 & UND. & Bowl s.s. 25 & $\begin{array}{c}\text { BOLO ACE INOX } \# 24 \text { CM PROFES } \\
\text { KB-4OOVINOD }\end{array}$ & 11.07 & 88.56 \\
\hline 8 & UND. & Bowl s.5. 25 & $\begin{array}{c}\text { BOLO ACE INOX \#26 CM PROFES } \\
\text { KB-5OOVINOD }\end{array}$ & 15.08 & 120.64 \\
\hline
\end{tabular}

\begin{tabular}{|c|c|c|c|c|c|}
\hline 8 & UND. & Bowl s.s. 29.5 & $\begin{array}{c}\text { BOLO ACE INOX \#28 CM PROFES } \\
\text { KB-6OOVINOD }\end{array}$ & 13.97 & 111.76 \\
\hline 8 & UND. & Bowl s.s. 29.5 & $\begin{array}{c}\text { BOLO ACE INOX \#3O CM PROFES } \\
\text { KB-8OOVINOD }\end{array}$ & 19.17 & 153.36 \\
\hline 3 & UND. & Pinza c/seguro $9 " \mathrm{c} /$ cabeza nylon & & & - \\
\hline 3 & UND. & Olla $20 \mathrm{~cm} 5$ Star s.s. & $\begin{array}{c}\text { OLLA A/INOX MILENIUM F/DIF \# } \\
22 \text { T/ACERO O830220123 } \\
\text { RECORD }\end{array}$ & 158.00 & 474.00 \\
\hline 20 & UND. & Tappers para almacenamiento basa & $\begin{array}{l}\text { CAJA CONSERVADORA NO } 4 \\
\text { BASA }\end{array}$ & 6.20 & 124.00 \\
\hline 20 & UND. & Tappers para almacenamiento basa & $\begin{array}{l}\text { CAJA CONSERVADORA NO } 5 \\
\text { BASA }\end{array}$ & 10.70 & 214.00 \\
\hline 1 & UND. & Cuchillo tipo machete con el mango acrilico & $\begin{array}{c}\text { MANGO BLANCO TRAMONTINA } \\
10^{\prime \prime}\end{array}$ & 35.00 & 35.00 \\
\hline 2 & UND. & Guantes protectores de calor & $\begin{array}{l}\text { GUANTES PARA HORNEAR } \\
\text { RESISTENTE } 400^{\prime F} \text {. N }{ }^{*} 15\end{array}$ & 14.00 & 28.00 \\
\hline 2 & UND. & Guantes protectores de calor & \begin{tabular}{|c|} 
GUANTES PARA HORNEAR DE \\
FELPA RESISTENTE $600^{\circ} \mathrm{F} . \mathrm{N}^{\circ} 17$ \\
\end{tabular} & 19.32 & 38.64 \\
\hline 10 & UND. & Secadores & & 4.90 & 49.00 \\
\hline 10 & UND. & Secadores & & 3.50 & 35.00 \\
\hline 10 & UND. & Secadores & & 2.50 & 25.00 \\
\hline 3 & UND. & Cucharon de acero inoxidable & $\begin{array}{l}\text { LDI-12 CUCHARON DE } 1 \text { PZ - } \\
12 \mathrm{OZ} \text { (375 ML) WINCO }\end{array}$ & 15.40 & 46.20 \\
\hline 3 & UND. & Cucharon de acero inoxidable & $\begin{array}{|ll|}\text { LDT-32 } & \text { CUCHARON } 40.6 \mathrm{CM}- \\
32 \mathrm{OZ} \text { WINCO }\end{array}$ & 23.70 & 71.10 \\
\hline
\end{tabular}

\begin{tabular}{|c|c|c|c|c|c|}
\hline 10 & UND. & Envases de plástico con tapa & $\begin{array}{l}\text { WINWARE BOTELLA C/ } \\
\text { REGULACION DE } 24 \text { OZ } \\
\text { TRANSPARENTE } 6 \text { PACK }\end{array}$ & 5.60 & 56.00 \\
\hline 10 & UND. & Envases de plástico con tapa & $\begin{array}{l}\text { WINWARE BOTELLA C/ } \\
\text { REGULACION DE } 32 \mathrm{OZ} \\
\text { TRANSPARENTE } 6 \text { PACK }\end{array}$ & 6.44 & 64.40 \\
\hline 2 & UND. & Baldes con capacidad para $20 \mathrm{Lt}$ & $\begin{array}{c}\text { BALDE COMERCIAL } 20 \text { LT C/TAPA } \\
\text { Y ASA METAL REY }\end{array}$ & 19.42 & 38.84 \\
\hline 4 & UND. & Tacho de basura de plástico con tapa vaivén & $\begin{array}{c}\text { PAPELERA COSMOS \# } 80 \mathrm{C} / \text { TAPA } \\
\text { REY }\end{array}$ & 41.31 & 165.24 \\
\hline 4 & UND. & Baldes de plástico transparente de 20 Lt con tapa & $\begin{array}{c}\text { BALDE } 20 \text { LT TRANSPARENTE } \\
\text { C/TAPA DURAPLAST }\end{array}$ & 24.9 & 99.60 \\
\hline 4 & UND. & $\begin{array}{l}\text { Jarras medidoras con unidades de medida de } \\
\text { Onzas, Litros, y Tazas }\end{array}$ & $\begin{array}{l}\text { PIMCP-2OU JARRAS MEDIDORAS } \\
\text { POLICARBONATO } 1.890 \mathrm{ml}\end{array}$ & 42.30 & 169.20 \\
\hline 10 & UND. & mascarilla & MASCARILLAS X 50 UND. & 9.00 & 90.00 \\
\hline 10 & UND. & Guantes plásticos & \begin{tabular}{|c|} 
QUIRURGICOS DESCARTABLES X \\
100
\end{tabular} & 18.00 & 180.00 \\
\hline 10 & UND. & malla portectora para el cabello & GORROS DESCARTABLES X 100 & 14.50 & 145.00 \\
\hline 20 & UND. & Trapos, esponjas o paños & PAÑOS SCOTCH BRITE X 4 & 9.40 & 188.00 \\
\hline
\end{tabular}

PRECIOS INCLUIDO IGV

SUB TOTAL

IGV

TOTAL S/,
$3,266.67$ 


\section{Unión Ẏchicaua 5.A.}

JR.JUNIN \# 758-774 LIMA

Central TIf. $4260955 \quad 103-104$

Fax: 428-3994

Por medio de la presente, le hacemos llegar la siguiente cotización

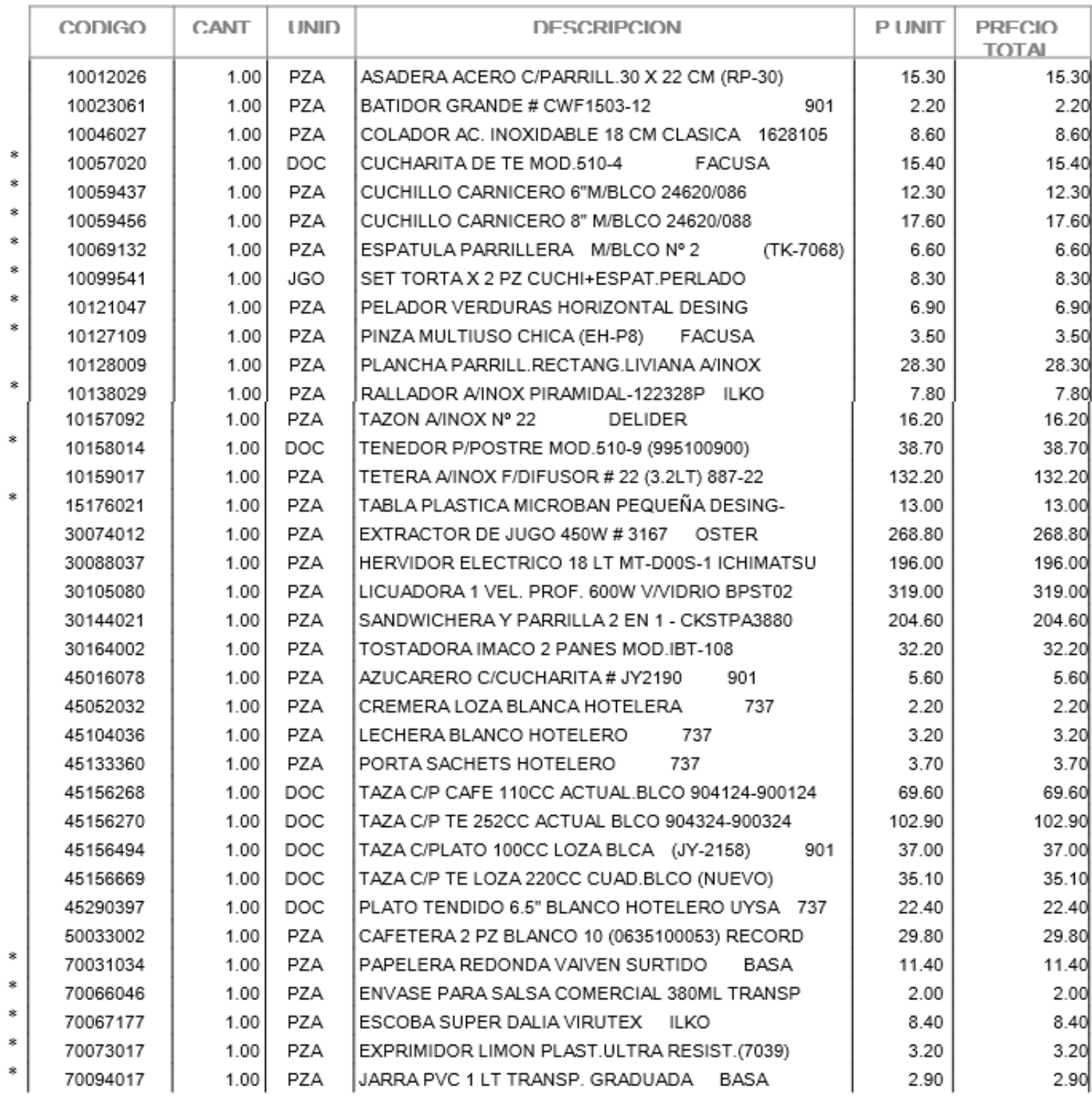




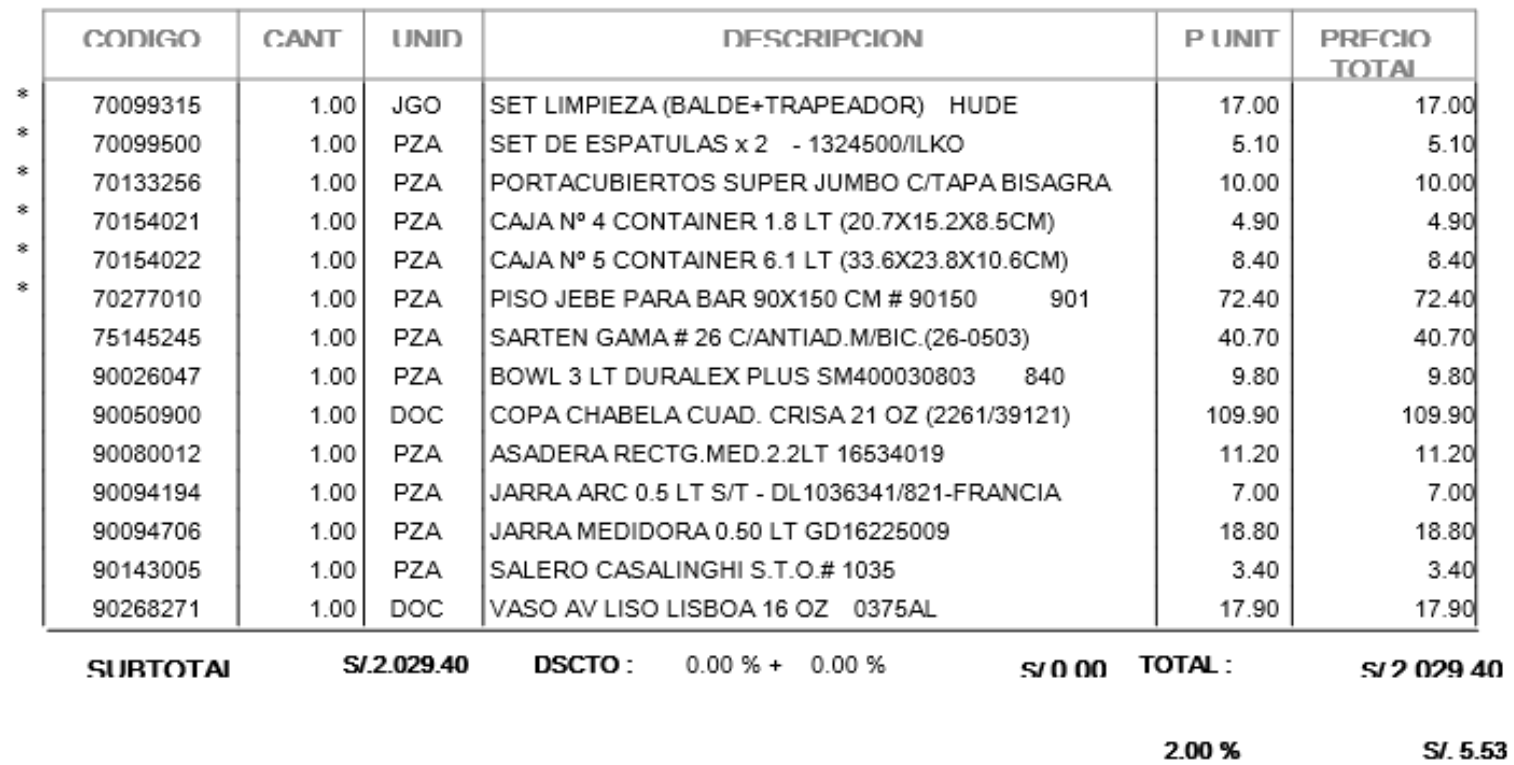

\begin{tabular}{|r|r|r|rc|r|r|}
\hline COIIGO & CANT & IUNII & \multicolumn{2}{|c|}{ DFSCRIPCION } & P IJNIT & \multicolumn{1}{c|}{$\begin{array}{c}\text { PRFCIO } \\
\text { TOTAN }\end{array}$} \\
\hline 90050210 & 1.00 & DOC & COPA AV LISA LEX.HELADO 0507AL & CRISTAR & 22.50 & 22.50 \\
90050299 & 1.00 & DOC & COPA AV LISA MALTEADA 0268AL & CRISTAR & 34.00 & 34.00 \\
90167158 & 1.00 & DOC & VASO AV LISO LEX.BEBIDA 0044AL & CRISTAR & 14.70 & 14.70 \\
\hline
\end{tabular}

SI JRTOTAI

\$I.71.20

DSCTO : $\quad 0.00 \%+0.00 \%$

SIOON TOTAL:

s/71 20

|

$2.00 \%$

SI. 0.00

\section{CONDICIONFS DF VFNTA \\ Los precios incluyen I.G.V}

Precios en Soles

TiDo de Venta: CONTADO

Cotización valida oor 7 días

Brindamos el servicio esoecial de reoarto en nuestras unidades de transporte. de acuerdo al rol v rutas de despachosemanales.

ROCIO TFNORIO

F.IFCIITIVO DF VFNTA

vtienda@uvsa.com.pe
Nextel: $118^{*} 8934$

Cel. : 4271982 - 
Anexo 9. Costeo de Recetas

Recetas

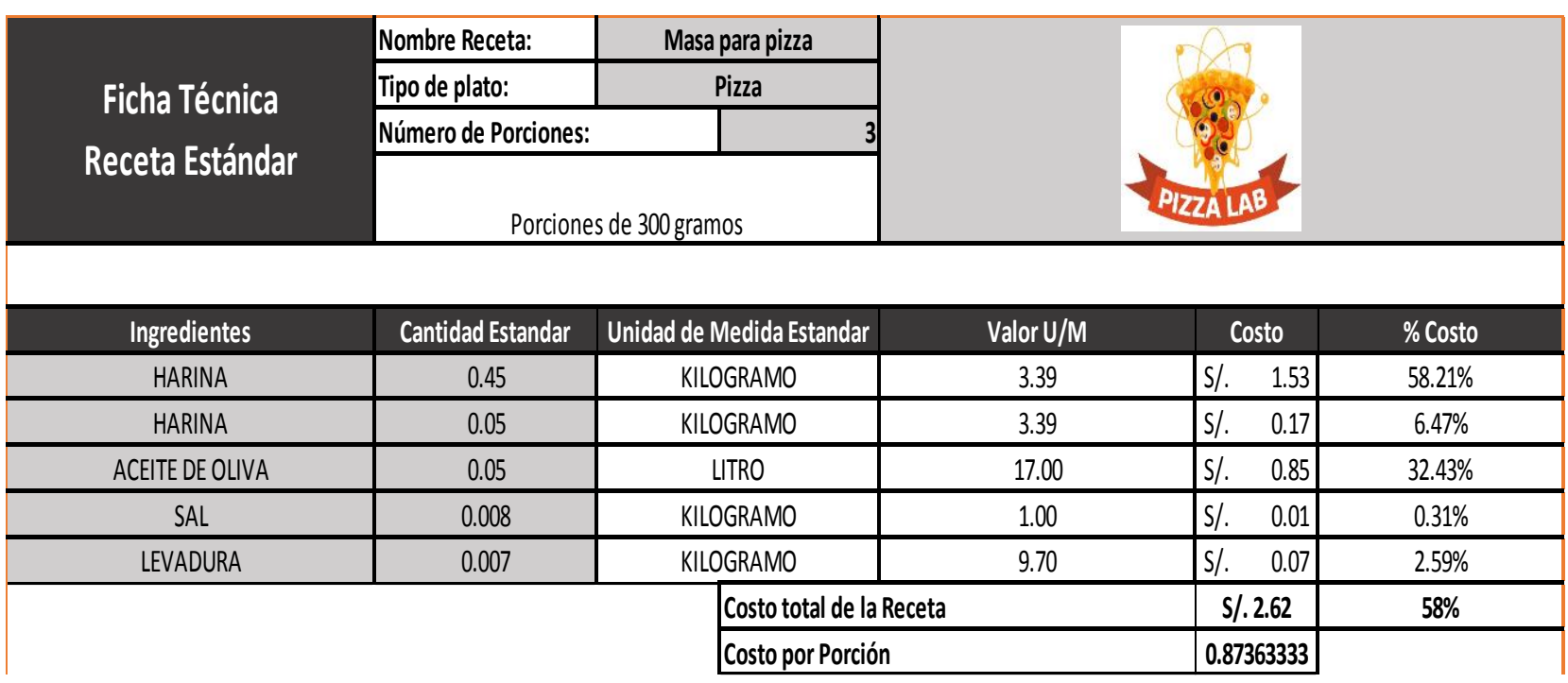

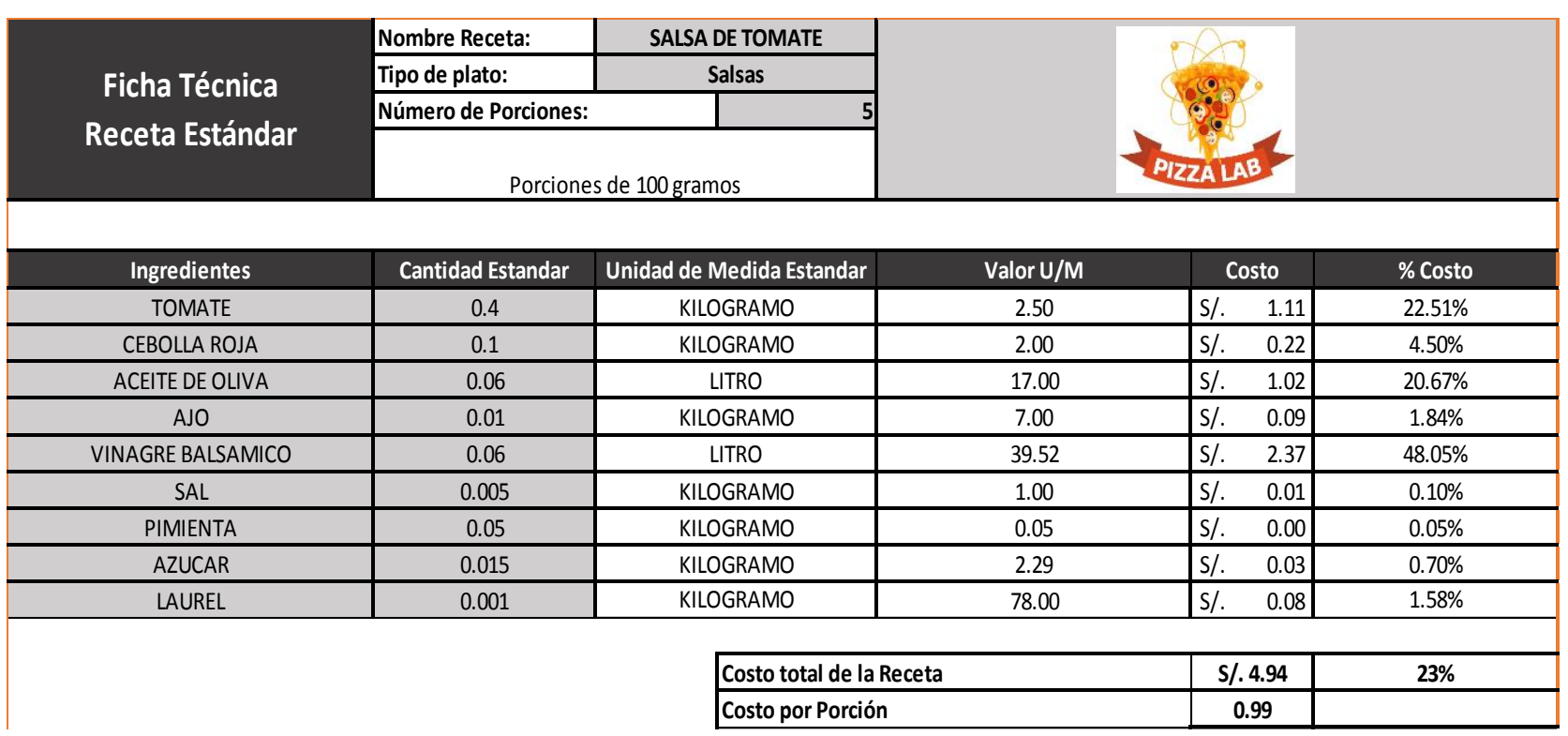




\begin{tabular}{|c|c|c|c|c|c|}
\hline \multirow{4}{*}{$\begin{array}{c}\text { Ficha Técnica } \\
\text { Receta Estándar }\end{array}$} & Nombre Receta: & SALSA MARINARA & & \multirow{4}{*}{ ZZA LAB } & \\
\hline & Tipo de plato: & Salsas & & & \\
\hline & \multicolumn{2}{|l|}{ Número de Porciones: } & & & \\
\hline & \multicolumn{2}{|c|}{ Porciones de 100 gramos } & & & \\
\hline Ingredientes & Cantidad Estandar & Unidad de Medida Estandar & Valor U/M & Costo & $\%$ Costo \\
\hline ACEITE DE OLIVA & 0.06 & LITRO & 17.00 & S/. 1.02 & $36.05 \%$ \\
\hline AJO & 0.01 & KILOGRAMO & 7.00 & S/. $\quad 0.09$ & $3.21 \%$ \\
\hline TOMATE & 0.41 & KILOGRAMO & 2.50 & $\begin{array}{|ll|}\text { S/. } & 1.14 \\
\end{array}$ & $40.25 \%$ \\
\hline SAL & 0.005 & KILOGRAMO & 1.00 & S/. $\quad 0.01$ & $0.18 \%$ \\
\hline AZUCAR & 0.005 & KILOGRAMO & 2.29 & \begin{tabular}{|ll} 
S/. & 0.01 \\
\end{tabular} & $0.40 \%$ \\
\hline OREGANO & 0.02 & KILOGRAMO & 20.39 & S/. $\quad 0.41$ & $14.41 \%$ \\
\hline \multirow[t]{3}{*}{ ALBAHACA } & 0.02 & ATADO & 3.50 & \begin{tabular}{ll|} 
S/. & 0.16 \\
\end{tabular} & $5.50 \%$ \\
\hline & & \multicolumn{2}{|c|}{ Costo total de la Receta } & $S / .2 .83$ & $36 \%$ \\
\hline & & \multicolumn{2}{|c|}{ Costo por Porción } & 0.57 & \\
\hline
\end{tabular}

\begin{tabular}{|c|c|c|c|c|c|}
\hline \multirow{4}{*}{$\begin{array}{c}\text { Ficha Técnica } \\
\text { Receta Estándar }\end{array}$} & Nombre Receta: & \multirow{3}{*}{$\begin{array}{c}\text { SALSA BLANCA } \\
\text { Salsas }\end{array}$} & & \multirow{3}{*}{$9^{\circ}$} & \\
\hline & Tipo de plato: & & & & \\
\hline & Número de Porciones: & & & & \\
\hline & \multicolumn{2}{|c|}{ Porciones de 30 gramos } & & & \\
\hline Ingredientes & Cantidad Estandar & Unidad de Medida Estandar & Valor U/M & Costo & $\%$ Costo \\
\hline MANTEQUILLA & 0.1 & KILOGRAMO & 24.30 & S/. 2.43 & $49.62 \%$ \\
\hline HARINA & 0.1 & KILOGRAMO & 3.39 & $\begin{array}{|ll|}\text { S/. } & 0.34 \\
\end{array}$ & $6.92 \%$ \\
\hline LECHE FRESCA & 0.75 & LITRO & 2.76 & S/. 2.07 & $42.27 \%$ \\
\hline SAL & 0.005 & KILOGRAMO & 1.00 & S/. $\quad 0.01$ & $0.10 \%$ \\
\hline PIMIENTA & 0.005 & KILOGRAMO & 0.05 & S/. $\quad 0.00$ & $0.01 \%$ \\
\hline NUEZ MOSCADA & 0.002 & KILOGRAMO & 26.67 & S/. $\quad 0.05$ & $1.09 \%$ \\
\hline & & Costo total de la & & $S / .4 .90$ & $50 \%$ \\
\hline & & Costo por Porciór & & 0.98 & \\
\hline
\end{tabular}

Resumen de Costos por tipos de producto

\begin{tabular}{|c|c|c|c|c|c|}
\hline \multicolumn{6}{|c|}{ Costos de Alimentos } \\
\hline \multicolumn{2}{|c|}{ MASA DE PIZZA } & \multicolumn{2}{|c|}{ SALSA BASE } & \multicolumn{2}{|c|}{ QUESO } \\
\hline $\begin{array}{l}\text { MASA } \\
\text { TRADICIONAL }\end{array}$ & S/. 0.87 & $\begin{array}{l}\text { SALSA DE } \\
\text { TOMATE }\end{array}$ & S/. 0.99 & $\begin{array}{l}\text { QUESO } \\
\text { MOZZARELLA }\end{array}$ & S/. 2.90 \\
\hline $\begin{array}{l}\text { MASA } \\
\text { DELGADA }\end{array}$ & S/. $\quad 0.44$ & $\begin{array}{l}\text { SALSA } \\
\text { MARINARA }\end{array}$ & S/. 0.57 & QUESO ANDINO & S/. $\quad 3.10$ \\
\hline & & $\begin{array}{l}\text { SALSA } \\
\text { BLANCA }\end{array}$ & S/. 0.98 & & \\
\hline
\end{tabular}


Lista de Toppings y su costo

\begin{tabular}{|c|c|c|c|c|c|}
\hline \multicolumn{6}{|c|}{ TOPPINGS } \\
\hline INGREDIENTE & $\mathrm{U} / \mathrm{M}$ & $\begin{array}{c}\text { PRECIO POR } \\
\text { U/M }\end{array}$ & $\begin{array}{c}\text { PESO POR } \\
\text { RECETA U/Mn }\end{array}$ & \multicolumn{2}{|c|}{$\begin{array}{r}\text { CANTIDAD } \\
\text { POR PORCIĆn }\end{array}$} \\
\hline ACEITUNA NEGRA & KILO & \begin{tabular}{|ll}
$\mathrm{S} /$. & 12.54
\end{tabular} & 0.03 & $\mathrm{~S} / \mathrm{.}$ & 0.38 \\
\hline ACEITUNA VERDE & KILO & S/. $\quad 10.20$ & 0.03 & $\mathrm{~S} / \mathrm{.}$ & 0.31 \\
\hline ALBAHACA & KILO & S/. $\quad 15.00$ & 0.005 & S/. & 0.08 \\
\hline ALCACHOFA & KILO & S/. 22.00 & 0.03 & $\mathrm{~S} / \mathrm{.}$ & 0.66 \\
\hline ALCAPARRAS & KILO & $\begin{array}{ll}\text { S/. } & 63.00\end{array}$ & 0.005 & $\mathrm{~S} / \mathrm{.}$ & 0.32 \\
\hline ARÚGULA & KILO & S/. 28.45 & 0.005 & $\mathrm{~S} / \mathrm{.}$ & 0.14 \\
\hline CEBOLLA BLANCA & KILO & 2.50 & 0.03 & $\mathrm{~S} / \mathrm{.}$ & 0.08 \\
\hline CEBOLLA ROJA & KILO & 2.00 & 0.03 & $\mathrm{~S} / \mathrm{.}$ & 0.06 \\
\hline CHAMPIÑONES & KILO & S/. 20.00 & 0.03 & $\mathrm{~S} /$. & 0.60 \\
\hline CHOCLO DESGRANADO & KILO & S/. $\quad 10.80$ & 0.03 & $\mathrm{~S} / \mathrm{.}$ & 0.32 \\
\hline DURAZNO & KILO & S/. $\quad 12.00$ & 0.03 & $\mathrm{~S} / \mathrm{.}$ & 0.36 \\
\hline ESPARRAGOS & KILO & S/. 14.00 & 0.034 & $\mathrm{~S} / \mathrm{.}$ & 0.48 \\
\hline ESPINACA & KILO & 5.00 & 0.005 & $\mathrm{~S} /$. & 0.03 \\
\hline HONGOS PORTOBELLOS & KILO & S/. 22.00 & 0.03 & $\mathrm{~S} / \mathrm{s}$ & 0.66 \\
\hline PAPA & KILO & 1.50 & 0.04 & $\mathrm{~S} / \mathrm{.}$ & 0.06 \\
\hline PIMIENTO & KILO & 1.80 & 0.04 & $\mathrm{~S} /$. & 0.07 \\
\hline PIÑA & KILO & 3.20 & 0.04 & $\mathrm{~S} / \mathrm{.}$ & 0.13 \\
\hline QUINUA & KILO & S/. 18.00 & 0.02 & $\mathrm{~S} /$. & 0.36 \\
\hline TOMATE & KILO & 2.50 & 0.04 & $\mathrm{~S} / \mathrm{.}$ & 0.10 \\
\hline VAINITA & KILO & 1.70 & 0.04 & $\mathrm{~S} / \mathrm{.}$ & 0.07 \\
\hline ZANAHORIA & KILO & 2.00 & 0.04 & $\mathrm{~S} / \mathrm{.}$ & 0.08 \\
\hline \multicolumn{4}{|c|}{ Precio Promedio } & $\mathrm{S} /$. & 0.25 \\
\hline
\end{tabular}

\section{Costeos de Receta de productos finales}

\begin{tabular}{|c|c|c|c|c|}
\hline \multicolumn{5}{|c|}{ OPCIÓN 1. PEPPERONI } \\
\hline Pepperoni & $\mathrm{S} /$. & 1.36 & & \\
\hline Masa de Pizza & $\mathrm{S} /$. & 0.87 & & \\
\hline Salsa Base & $\mathrm{S} /$. & 0.99 & & \\
\hline Queso & $\mathrm{S} /$. & 3.10 & & \\
\hline Toppings & $\mathrm{S} /$. & 1.52 & & \\
\hline Envase & $\mathrm{S} /$. & 0.38 & & \\
\hline Cubiertos & $\mathrm{S} /$. & 0.12 & & \\
\hline Costo Directo & $\mathrm{S} /$. & 8.34 & Costo Directo & 8.34 \\
\hline Food Cost $40 \%$ & $\mathrm{~S} /$. & 20.853 & Food Cost & 21.186 \\
\hline Precio de Vent & $\mathrm{S} / \mathrm{.}$ & 24.61 & Precio de venta real & 25 \\
\hline Costo Estandar & & $40.00 \%$ & Nuevo Costo \% & $39.37 \%$ \\
\hline
\end{tabular}




\begin{tabular}{|c|c|c|c|c|}
\hline \multicolumn{5}{|c|}{ OPCIÓN 2. CARNE } \\
\hline Carne & $\mathrm{S} /$. & 1.84 & & \\
\hline Arroz & $\mathrm{S} /$. & 0.87 & & \\
\hline Salsa Base & $\mathrm{S} /$. & 0.99 & & \\
\hline Queso & $\mathrm{S} /$. & 3.10 & & \\
\hline Toppings & $\mathrm{S} /$. & 1.52 & & \\
\hline Envase & $\mathrm{S} /$. & 0.38 & & \\
\hline Cubiertos & $\mathrm{S} /$. & 0.12 & & \\
\hline Costo Directo & $\mathrm{S} /$. & 8.82 & Costo Directo & 8.82 \\
\hline Food Cost $40 \%$ & $\mathrm{~S} /$. & 22.05 & Food Cost & 22.881 \\
\hline Precio de Venta & $\mathrm{S} /$. & 26.02 & Precio de venta real & 27 \\
\hline Costo Estandar & & $40.00 \%$ & Nuevo Costo \% & $38.55 \%$ \\
\hline
\end{tabular}

\begin{tabular}{|c|c|c|c|c|}
\hline \multicolumn{5}{|c|}{ OPCIÓN 3. JAMÓN } \\
\hline Jamón & $\mathrm{S} /$. & 1.28 & & \\
\hline Masa de Pizza & $\mathrm{S} /$. & 0.87 & & \\
\hline Salsa Base & $\mathrm{S} /$. & 0.99 & & \\
\hline Queso & $\mathrm{S} /$. & 3.10 & & \\
\hline Toppings & $\mathrm{S} /$. & 1.52 & & \\
\hline Envase & $\mathrm{S} /$. & 0.38 & & \\
\hline Cubiertos & $\mathrm{S} /$. & 0.12 & & \\
\hline Costo Directo & $\mathrm{S} /$. & 8.26 & Costo Directo & 8.26 \\
\hline Food Cost $40 \%$ & $\mathrm{~S} /$. & 20.65 & Food Cost & 21.186 \\
\hline Precio de Vent & $\mathrm{S} /$. & 24.37 & Precio de venta real & 25 \\
\hline Costo Estandar & & $40.00 \%$ & Nuevo Costo \% & $38.99 \%$ \\
\hline
\end{tabular}

\begin{tabular}{|c|c|c|c|c|}
\hline \multicolumn{5}{|c|}{ OPCIÓN 4. SALCHICHA } \\
\hline Salchicha & $\mathrm{S} /$. & 1.44 & & \\
\hline Masa de Pizza & $\mathrm{S} /$. & 0.87 & & \\
\hline Salsa Base & $\mathrm{S} /$. & 0.99 & & \\
\hline Queso & $\mathrm{S} /$. & 3.10 & & \\
\hline Toppings & $\mathrm{S} /$. & 1.52 & & \\
\hline Envase & $\mathrm{S} /$. & 0.38 & & \\
\hline Cubiertos & $\mathrm{S} /$. & 0.12 & & \\
\hline Costo Directo & $\mathrm{S} /$. & 8.42 & Costo Directo & 8.42 \\
\hline Food Cost $40 \%$ & $\mathrm{~S} /$. & 21.05 & Food Cost & 21.186 \\
\hline Precio de Venta & $\mathrm{S} / \mathrm{.}$ & 24.84 & Precio de venta real & 25 \\
\hline Costo Estandar & & $40.00 \%$ & Nuevo Costo \% & $39.75 \%$ \\
\hline
\end{tabular}




\begin{tabular}{|c|c|c|c|c|}
\hline \multicolumn{5}{|c|}{ OPCIÓN 5. TOCINO } \\
\hline Tocino & S/. & 2.24 & & \\
\hline Masa de Pizza & $\mathrm{S} /$. & 0.87 & & \\
\hline Salsa Base & $\mathrm{S} /$. & 0.99 & & \\
\hline Queso & S/. & 3.10 & & \\
\hline Toppings & $\mathrm{S} /$. & 1.52 & & \\
\hline Envase & $\mathrm{S} /$. & 0.38 & & \\
\hline Cubiertos & $\mathrm{S} /$. & 0.12 & & \\
\hline Costo Directo & $\mathrm{S} / \mathrm{.}$ & 9.22 & Costo Directo & 9.22 \\
\hline Food Cost $40 \%$ & $\mathrm{~S} /$. & 23.05 & Food Cost & 22.881 \\
\hline Precio de Vent & S/. & 27.20 & Precio de venta real & 27 \\
\hline Costo Estandar & & $40.00 \%$ & Nuevo Costo \% & $40.30 \%$ \\
\hline
\end{tabular}

\begin{tabular}{|c|c|c|c|c|}
\hline \multicolumn{5}{|c|}{ OPCIÓN 6. POLLO } \\
\hline Pechuga de pollo & $\mathrm{S} /$. & 1.36 & & \\
\hline Masa de Pizza & $\mathrm{S} /$. & 0.87 & & \\
\hline Salsa Base & $\mathrm{S} /$. & 0.99 & & \\
\hline Queso & $\mathrm{S} /$. & 3.10 & & \\
\hline Toppings & $\mathrm{S} /$. & 1.52 & & \\
\hline Envase & $\mathrm{S} /$. & 0.38 & & \\
\hline Cubiertos & $\mathrm{S} /$. & 0.12 & & \\
\hline Costo Directo & $\mathrm{S} /$. & 8.34 & Costo Directo & 8.34 \\
\hline Costo Directo & $\mathrm{S} /$. & 20.85 & Food Cost & 21.186 \\
\hline Precio de Venta & $\mathrm{S} /$. & 24.61 & Precio de venta real & 25 \\
\hline Costo Estandar & & $40.00 \%$ & Nuevo Costo \% & $39.37 \%$ \\
\hline
\end{tabular}

\begin{tabular}{|c|c|c|c|c|}
\hline \multicolumn{5}{|c|}{ OPCIÓN 7. CHORIZO } \\
\hline Chorizo & S/. & 1.76 & & \\
\hline Masa de Pizza & S/. & 0.87 & & \\
\hline Salsa Base & S/. & 0.99 & & \\
\hline Queso & S/. & 3.10 & & \\
\hline \begin{tabular}{|l|} 
Toppings \\
\end{tabular} & $\mathrm{S} / \mathrm{.}$ & 1.52 & & \\
\hline Envase & $\mathrm{S} / \mathrm{.}$ & 0.38 & & \\
\hline Cubiertos & S/. & 0.12 & & \\
\hline Costo Directo & S/. & 8.74 & Costo Directo & 8.74 \\
\hline Food Cost $40 \%$ & S/. & 21.85 & Food Cost & 22.881 \\
\hline Precio de Vent & $\mathrm{S} / \mathrm{s}$ & 25.79 & Precio de venta real & 27 \\
\hline Costo Estandar & & $40.00 \%$ & Nuevo Costo $\%$ & $38.20 \%$ \\
\hline
\end{tabular}




\begin{tabular}{|c|c|c|c|c|c|}
\hline \multicolumn{6}{|c|}{ OPCIÓN 8. LOMITO AHUMADO } \\
\hline Lomito Ahumad & S/. & 1.20 & & & \\
\hline Masa de Pizza & $\mathrm{S} /$. & 0.87 & & & \\
\hline Salsa Base & $\mathrm{S} /$. & 0.99 & & & \\
\hline Queso & $\mathrm{S} /$. & 3.10 & & & \\
\hline Toppings & $\mathrm{S} /$. & 1.52 & & & \\
\hline Envase & $\mathrm{S} /$. & 0.38 & & & \\
\hline Cubiertos & $\mathrm{S} /$. & 0.12 & & & \\
\hline Costo Directo & $\mathrm{S} /$. & 8.18 & Costo Directo & $\mathrm{S} /$. & 8.18 \\
\hline Food Cost $40 \%$ & $\mathrm{~S} /$. & 29.22 & Food Cost & & 21.186 \\
\hline Precio de Vent & $\mathrm{S} /$. & 34.48 & Precio de venta real & & 25 \\
\hline Costo Estandar & & $28.00 \%$ & Nuevo Costo \% & & $38.62 \%$ \\
\hline
\end{tabular}

\begin{tabular}{|c|c|c|c|c|}
\hline \multicolumn{5}{|c|}{ OPCIÓN 9. SALAME } \\
\hline Salami & $\mathrm{S} /$. & 2.72 & & \\
\hline Masa de Pizza & $\mathrm{S} /$. & 0.87 & & \\
\hline Salsa Base & $\mathrm{S} / \mathrm{.}$ & 0.99 & & \\
\hline Queso & $\mathrm{S} /$. & 3.10 & & \\
\hline Toppings & $\mathrm{S} /$. & 1.52 & & \\
\hline Envase & $\mathrm{S} /$. & 0.38 & & \\
\hline Cubiertos & S/. & 0.12 & & \\
\hline Costo Directo & $\mathrm{S} / \mathrm{.}$ & 9.70 & Costo Directo & 9.70 \\
\hline Food Cost $40 \%$ & $\mathrm{~S} /$. & 24.25 & Food Cost & 22.881 \\
\hline Precio de Vent & $\mathrm{S} / \mathrm{.}$ & 28.62 & Precio de venta real & 27 \\
\hline Costo Estandar & & $40.00 \%$ & Nuevo Costo \% & $42.40 \%$ \\
\hline
\end{tabular}

\begin{tabular}{|c|c|c|c|c|c|}
\hline \multicolumn{6}{|c|}{ OPCIÓN 10. VEGGIE } \\
\hline Masa de Pizza & $\mathrm{S} / \mathrm{.}$ & 0.87 & & & \\
\hline Salsa Base & $\mathrm{S} /$. & 0.99 & & & \\
\hline Queso & $\mathrm{S} /$. & 3.10 & & & \\
\hline Toppings & $\mathrm{S} /$. & 2.03 & & & \\
\hline Envase & $\mathrm{S} /$. & 0.38 & & & \\
\hline Cubiertos & $\mathrm{S} /$. & 0.12 & & & \\
\hline Costo Directo & $\mathrm{S} /$. & 7.49 & Costo Directo & $\mathrm{S} /$. & 7.49 \\
\hline Food Cost $40 \%$ & $\mathrm{~S} /$. & 18.72 & Food Cost & & 18.644 \\
\hline Precio de Venta & $\mathrm{S} /$. & 22.09 & Precio de venta real & & 22 \\
\hline Costo Estandar & & $40.00 \%$ & Nuevo Costo \% & & $40.16 \%$ \\
\hline
\end{tabular}


Anexo 10: Perfiles

Fecha: $\quad 02 / 11 / 2017$

PERFIL DE PUESTO

1. IDENTIFICACION DEL PUESTO

Nombre del Puesto

Unidad

Restaurante

Reporta

Manager

Supervisa a

$\mathrm{N} / \mathrm{a}$

2. OBJETO GENERAL DEL CARGO

Realizar y asegurar el cumplimiento de las recetas para la preparación de las pizzas y acompañamientos 3. FUNCIONES PRINCIPALES

Verificar el stock de insumos para la preparación de pizzas según proyección del restaurante.

Organizar los materiales, utensilios y equipos para la preparación de alimentos.

Realizar la producción diaria garantizando los estándares de calidad requeridos.

Verificar el buen funcionamiento y asegurarse de que los insumos se encuentren en buen estado.

\begin{tabular}{lccc}
\hline \multirow{2}{*}{ 4. COMPETENCIAS } & & Nivel & \\
\cline { 2 - 4 } & Alto & Medio & Bajo \\
\hline 4.1. GENERALES & & & \\
\hline 1. Comunicación efectiva & & $\mathrm{x}$ & \\
2. Orientación al cliente & $\mathrm{x}$ & & $\mathrm{x}$ \\
3. Excelencia & $\mathrm{x}$ & & \\
4. Innovación y Creatividad & $\mathrm{x}$ & & \\
5. Trabajo de Equipo & $\mathrm{x}$ & & \\
6. Puntualidad & $\mathrm{x}$ & & \\
7. Responsabilidad & $\mathrm{x}$ & & \\
8. Organización & & $\mathrm{x}$ & \\
9. Proactividad & $\mathrm{x}$ & & \\
10. Honestidad & &
\end{tabular}

10. Honestidad

Masculino Edad Entre:19 a Residencia: Lima

23 años

4.2 CONOCIMIENTOS

Formación

Indispensable

Deseable

Especializaciones N/A

Idiomas N/A

Computación (Manejo de

Software y app)

Experiencia

1-2 años

5. CONDICIONES

Horario de Trabajo. (Régimen de

horario realizado)

Horario fijo Rotativo

Sueldo Bruto

S/. $1,200.00$ 
Fecha: $\quad 02 / 11 / 2017$

PERFIL DE PUESTO

\begin{tabular}{lcc}
\hline \multicolumn{2}{l}{ 1. IDENTIFICACION DEL PUESTO } & \\
\hline Nombre del Puesto & Cocinero de Reposición \\
Unidad & Restaurante & \\
Reporta & Manager & \\
Supervisa a & N/a & \\
\hline
\end{tabular}

Garantizar el cumplimiento de insumos necesarios en tiempos óptimos.

3. FUNCIONES PRINCIPALES

Verificar el stock de insumos para la preparación de pizzas según la proyección del restaurante.

Realizar la reposición de insumos según las salidas de los platos.

Organizar los materiales y equipos para la preparación de alimentos.

Asegurar el buen estado de alimentos y que éstos sean almacenados correctamente.

\begin{tabular}{|c|c|c|c|c|}
\hline \multirow{2}{*}{ 4. COMPETENCIAS } & & \multicolumn{3}{|c|}{ Nivel } \\
\hline & & Alto & Medio & Bajo \\
\hline \multicolumn{5}{|l|}{ 4.1. GENERALES } \\
\hline 1. Comunicación efectiva & & & $\mathrm{x}$ & \\
\hline 2. Orientación al cliente & & & $\mathrm{x}$ & \\
\hline 3. Excelencia & & $\mathrm{x}$ & & \\
\hline 4. Innovación y Creatividad & & & $\mathrm{x}$ & \\
\hline 5. Trabajo de Equipo & & & $\mathrm{x}$ & \\
\hline 6. Puntualidad & & $\mathrm{x}$ & & \\
\hline 7. Responsabilidad & & $\mathrm{x}$ & & \\
\hline 8. Organización & & $\mathrm{x}$ & & \\
\hline 9. Proactividad & & & $\mathrm{x}$ & \\
\hline 10. Honestidad & & $\mathrm{x}$ & & \\
\hline Sexo & Masculino Edad & $\begin{array}{l}\text { Entre: } 19 \text { a } \\
23 \text { años }\end{array}$ & Residencia: & Lima \\
\hline
\end{tabular}

\subsection{CONOCIMIENTOS}

Formación

Cheff - Técnico

Especializaciones $\quad \mathrm{N} / \mathrm{A}$

Idiomas N/A

Computación (Manejo de

Software y app)

Experiencia

1-2 años

\section{CONDICIONES}

Horario de Trabajo. (Régimen de

horario realizado)

Sueldo Bruto S/. 1,200.00

Horario fijo Rotativo

Deseable 
Fecha: $\quad 02 / 11 / 2017$

\begin{tabular}{|c|c|c|}
\hline \multicolumn{3}{|c|}{ PERFIL DE PUESTO } \\
\hline \multicolumn{3}{|c|}{ 1. IDENTIFICACION DEL PUESTO } \\
\hline Nombre del Puesto & & Manager \\
\hline Unidad & Restaurante & \\
\hline Reporta & Accionistas & \\
\hline Supervisa a & Todos & \\
\hline
\end{tabular}

Administrar y controlar las tareas administrativas del personal y asegurar el cumplimiento de los procesos de las Empresas.

3. FUNCIONES PRINCIPALES

Coordinar y supervisar las tareas del personal.

Gestionar la documentación interna del Restaurante.

Realizar indicadores de los diferentes procesos.

Realizar las evaluaciones financieras de la Empresa.

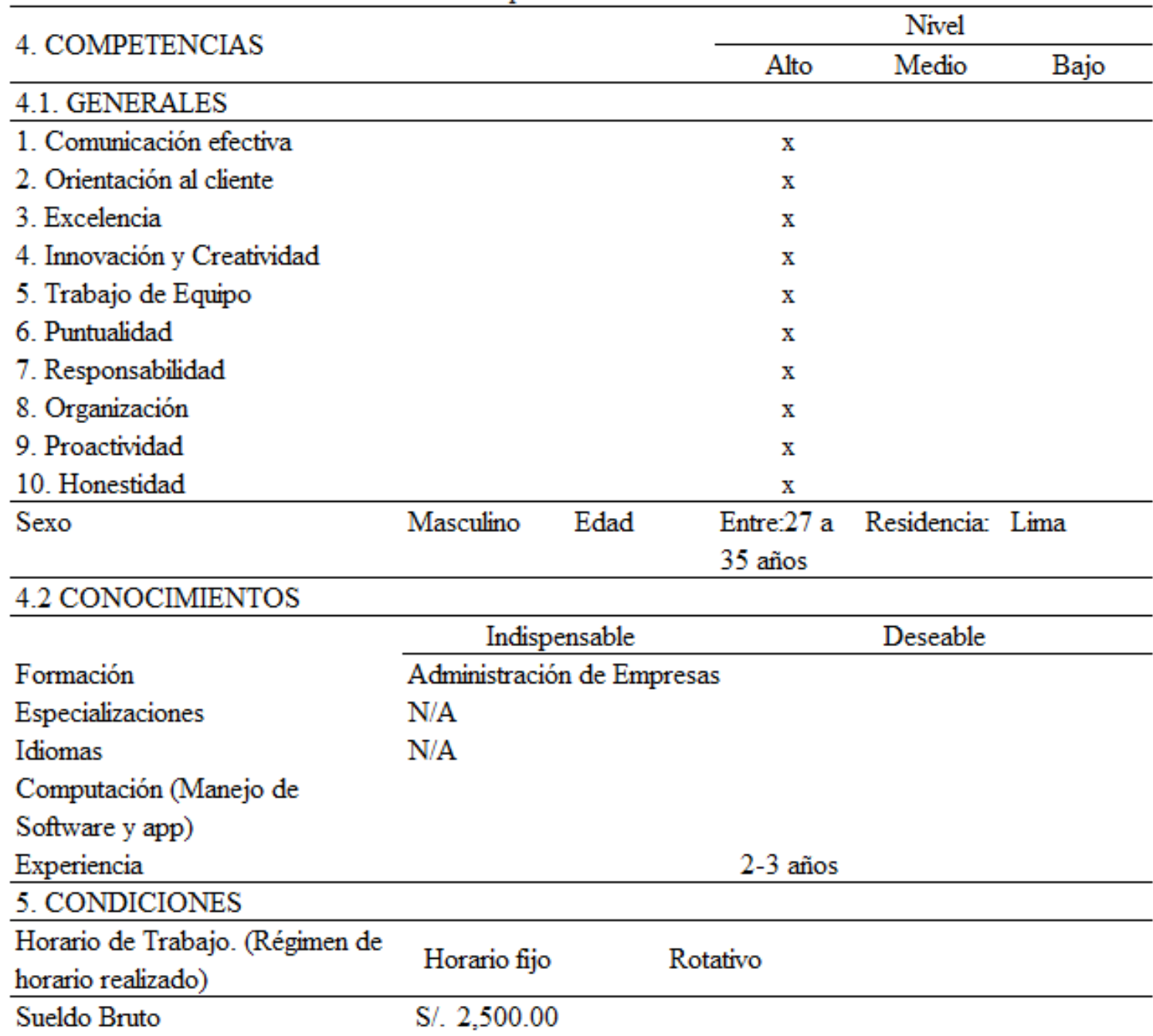


Fecha

$02 / 11 / 2017$

PERFIL DE PUESTO

1. IDENTIFICACION DEL PUESTO

Nombre del Puesto

Unidad

Restaurante

Reporta

Manager

Supervisa a

Nadie

2. OBJETO GENERAL DEL CARGO

Supervisar el cumplimiento de los procedimientos establecidos por la Empresa.

3. FUNCIONES PRINCIPALES

Responsable del control de los procesos de la Empresa.

Verificar que los trabajadores cumplan con sus funciones, horarios/turnos y descansos.

Asistir al cliente ante cualquier necesidad.

Asistir en cualquier solicitud del administrador u otra área.

\begin{tabular}{|c|c|c|c|}
\hline \multirow{2}{*}{ 4. COMPETENCIAS } & \multicolumn{3}{|c|}{ Nivel } \\
\hline & Alto & Medio & Bajo \\
\hline \multicolumn{4}{|l|}{ 4.1. GENERALES } \\
\hline 1. Comunicación efectiva & $\mathrm{x}$ & & \\
\hline 2. Orientación al cliente & $\mathrm{x}$ & & \\
\hline 3. Excelencia & $\mathrm{x}$ & & \\
\hline 4. Innovación y Creatividad & & $\mathrm{x}$ & \\
\hline 5. Trabajo de Equipo & $\mathrm{x}$ & & \\
\hline 6. Puntualidad & $\mathrm{x}$ & & \\
\hline 7. Responsabilidad & $\mathrm{x}$ & & \\
\hline 8. Organización & $\mathrm{x}$ & & \\
\hline 9. Proactividad & $\mathrm{x}$ & & \\
\hline 10. Honestidad & $\mathrm{x}$ & & \\
\hline
\end{tabular}

\begin{tabular}{|c|c|c|}
\hline Sexo & Masculino & $\begin{array}{l}\text { Entre:25 a Residencia: Lima } \\
30 \text { años }\end{array}$ \\
\hline \multicolumn{3}{|l|}{4.2 CONOCIMIENTOS } \\
\hline & Indispensable & Deseable \\
\hline Formación & \multicolumn{2}{|l|}{ Administración de Empresas } \\
\hline Especializaciones & \multicolumn{2}{|l|}{ N/A } \\
\hline Idiomas & \multicolumn{2}{|l|}{ N/A } \\
\hline \multicolumn{3}{|l|}{ Computación (Manejo de } \\
\hline \multicolumn{3}{|l|}{ Software y app) } \\
\hline Experiencia & \multicolumn{2}{|r|}{ 1-3años } \\
\hline \multicolumn{3}{|l|}{ 5. CONDICIONES } \\
\hline $\begin{array}{l}\text { Horario de Trabajo. (Régimen de } \\
\text { horario realizado) }\end{array}$ & Horario fijo & ativo \\
\hline
\end{tabular}

Sueldo Bruto S/. $1,500.00$ 
Fecha: $\quad 02 / 11 / 2017$

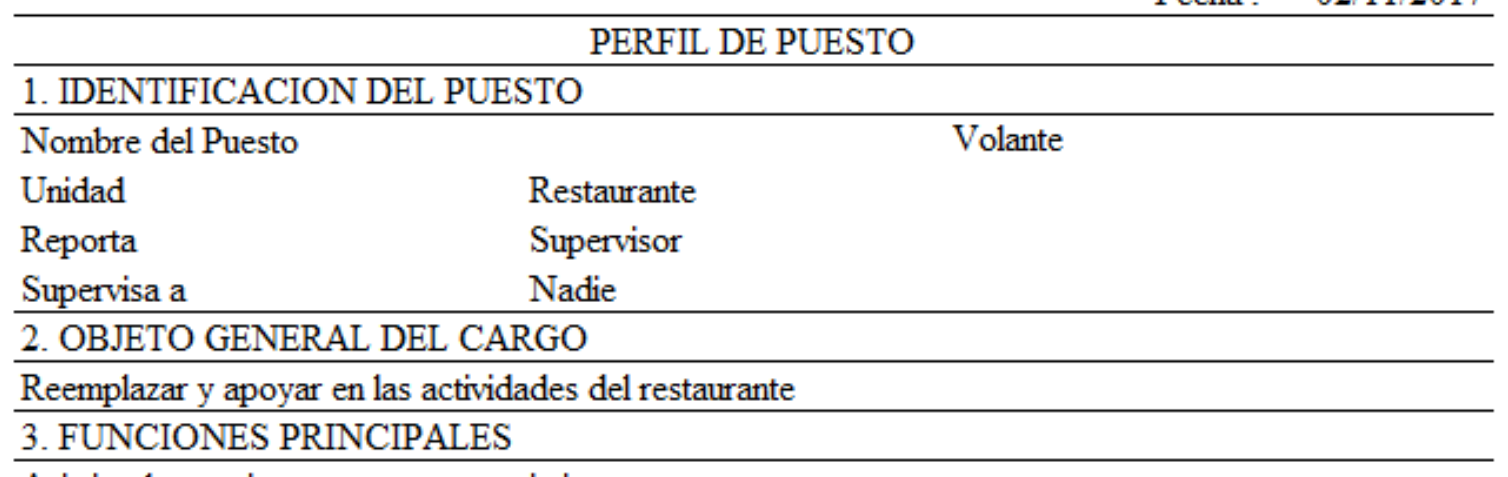

Asistir a los cocineros en sus requerimientos.

Asistir a los clientes ante cualquier requerimiento.

Apoyar en la limpieza y seguridad del local.

Reemplazar al personal en sus descansos semanales.

\begin{tabular}{|c|c|c|c|c|}
\hline \multirow{2}{*}{ 4. COMPETENCIAS } & & \multicolumn{3}{|c|}{ Nivel } \\
\hline & & Alto & Medio & Bajo \\
\hline \multicolumn{5}{|l|}{ 4.1. GENERALES } \\
\hline 1. Comunicación efectiva & & & $\mathrm{x}$ & \\
\hline 2. Orientación al cliente & & & $\mathrm{x}$ & \\
\hline 3. Excelencia & & & $\mathrm{x}$ & \\
\hline \multicolumn{5}{|l|}{ 4. Innovación y Creatividad } \\
\hline 5. Trabajo de Equipo & & & $\mathrm{x}$ & \\
\hline 6. Puntualidad & & & $\mathrm{x}$ & \\
\hline 7. Responsabilidad & & & $\mathrm{x}$ & \\
\hline 8. Organización & & & $\mathrm{x}$ & \\
\hline 9. Proactividad & & & $\mathrm{x}$ & \\
\hline 10. Honestidad & & & $\mathrm{x}$ & \\
\hline Sexo & Masculino Edad & $\begin{array}{l}\text { Entre: } 18 \text { a } \\
23 \text { años }\end{array}$ & Residencia: & Lima \\
\hline \multicolumn{5}{|l|}{4.2 CONOCIMIENTOS } \\
\hline & Indispensable & & Deseable & \\
\hline Formación & Secundaria completa & & & \\
\hline Especializaciones & $\mathrm{N} / \mathrm{A}$ & & & \\
\hline Idiomas & N/A & & & \\
\hline \multirow{2}{*}{\multicolumn{5}{|c|}{$\begin{array}{l}\text { Computación (Manejo de } \\
\text { Software y app) }\end{array}$}} \\
\hline & & & & \\
\hline Experiencia & & 1-2años & & \\
\hline \multicolumn{5}{|l|}{ 5. CONDICIONES } \\
\hline $\begin{array}{l}\text { Horario de Trabajo. (Régimen de } \\
\text { horario realizado) }\end{array}$ & Horario fijo & Rotativo & & \\
\hline
\end{tabular}


Fecha:

$02 / 11 / 2017$

PERFIL DEL PUESTO

\begin{tabular}{ll}
\hline 1. IDENTIFICACION DEL PUESTO & \\
\hline Nombre del Puesto & Gerente de Tienda \\
Unidad & Restaurante \\
Reporta & Accionistas \\
Supervisa a & Todos \\
\hline OBJETO GENERAL DEL CARGO &
\end{tabular}

2. OBJETO GENERAL DEL CARGO

Planificar, supervisar y controlar el funcionamiento de los locales de Pizza Lab.

3. FUNCIONES PRINCIPALES

Dirigir, supervisar y evaluar el buen funcionamiento de los locales.

Elaborar, supervisar y controlar los presupuestos anuales de los locales.

Establecer políticas y estrategias para la mejora continua.

Elaborar programas y objetivos a corto, mediano y a largo plazo.

Proponer medidas y ajustes a sus actividades y elaborar informes para sus superiores.

Auditar la documentación financiera.

Representar a la Empresa en cualquier actividad pública y privada.

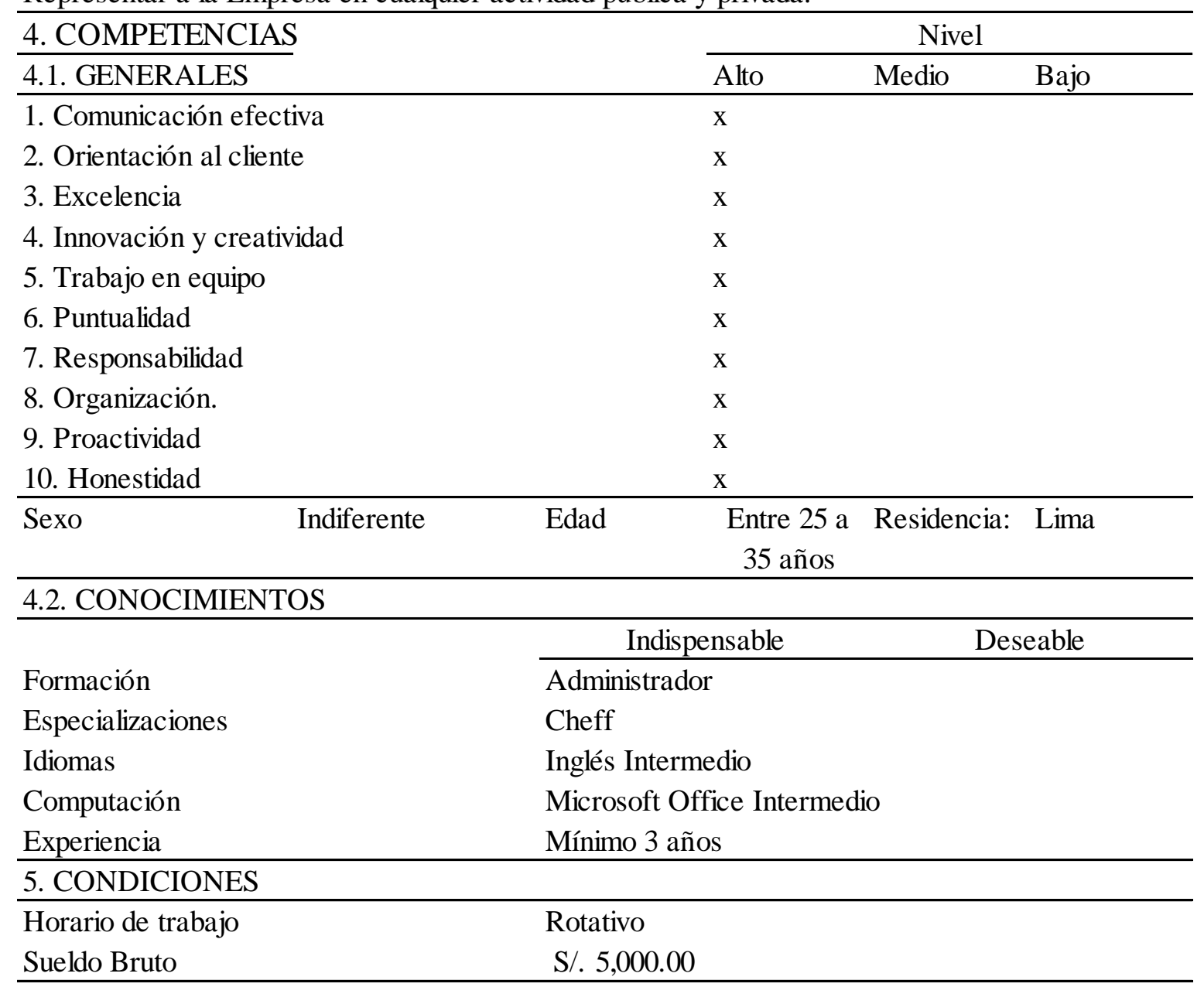


Anexo 11: cálculo de muestra

Bases de Datos:

\begin{tabular}{lllllll}
\hline Genero & Lima & Lima & Lima & Lima & Lima & Lima Sur \\
& Metropolitana & Norte & Este & Centro & Moderna & \\
& & & & & & \\
\hline Masculino & $4^{\prime} 688,115$ & $1^{\prime} 189,544$ & $1^{\prime} 166,097$ & 372,848 & 577,580 & 899,452 \\
& & & & & & \\
\hline Femenino & $4^{\prime} 900,870$ & $1^{\prime} 231,263$ & $1^{\prime} 174,092$ & 393,333 & 681,759 & 920,217 \\
\hline Total & $9^{\prime} 588,985$ & $2^{\prime} 420,807$ & $2^{\prime} 340,189$ & 766,181 & $1^{\prime} 259,339$ & $1^{\prime} 819,669$
\end{tabular}

\section{Número de Personas según Edad y Zonas de Lima}

\begin{tabular}{crrrrr}
\hline Edad & \multicolumn{2}{l}{$\begin{array}{l}\text { Lima } \\
\text { Metropolitana }\end{array}$} & \multicolumn{4}{c}{ Zonas de Lima } \\
\cline { 3 - 6 } & Norte & Centro & Moderna & \multicolumn{1}{l}{ Sur } \\
\hline Menos de 7 & 1182405 & 307899 & 80706 & 109001 & 241805 \\
\hline De 7 a 12 & 1028562 & 271787 & 71163 & 98276 & 211787 \\
\hline De 13 a 20 & 1529333 & 395693 & 113030 & 162519 & 302351 \\
\hline De 21 a 35 & 2780063 & 699335 & 211356 & 332715 & 538872 \\
\hline De 36 a 59 & 2652834 & 665281 & 225684 & 410430 & 480977 \\
\hline
\end{tabular}

\begin{tabular}{ccc}
\hline Nivel & Lima & Zonas de Lima \\
Socioeconómico & Metropolitana &
\end{tabular}

\begin{tabular}{cccccc}
\hline & & Norte & Centro & Moderna & Sur \\
\hline NSE A & $3.62 \%$ & $0.23 \%$ & $0.23 \%$ & $92.33 \%$ & $5.44 \%$ \\
\hline NSE A1 & $0.62 \%$ & $0.00 \%$ & $0.00 \%$ & $95.50 \%$ & $4.50 \%$ \\
\hline NSE A2 & $3.01 \%$ & $0.28 \%$ & $0.28 \%$ & $91.68 \%$ & $5.63 \%$ \\
\hline NSE B & $12.11 \%$ & $10.05 \%$ & $11.78 \%$ & $46.09 \%$ & $11.36 \%$ \\
\hline NSE B1 & $5.48 \%$ & $9.03 \%$ & $5.52 \%$ & $55.97 \%$ & $9.80 \%$ \\
\hline NSE B2 & $6.64 \%$ & $10.89 \%$ & $16.96 \%$ & $37.93 \%$ & $12.66 \%$ \\
\hline NSE C & $33.91 \%$ & $29.35 \%$ & $9.23 \%$ & $4.25 \%$ & $20.09 \%$ \\
\hline NSE C1 & $13.33 \%$ & $31.90 \%$ & $9.99 \%$ & $6.92 \%$ & $18.39 \%$ \\
\hline NSE C2 & $20.58 \%$ & $27.69 \%$ & $8.73 \%$ & $2.52 \%$ & $21.19 \%$ \\
\hline
\end{tabular}




\begin{tabular}{|c|c|c|c|c|c|c|c|c|c|}
\hline & $15-19$ & $20-24$ & $25-29$ & $30-34$ & $35-39$ & $40-44$ & $45-49$ & $50-54$ & $55-59$ \\
\hline LIMA & 21,666 & 23,595 & 21,171 & 20,754 & 20,559 & 18,516 & 18,112 & 16,705 & 13,875 \\
\hline ANCON & 4,169 & 3,838 & 3,380 & 3,252 & 3,475 & 2,975 & 2,526 & 2,178 & 1,572 \\
\hline ATE & 60,988 & 69,026 & 57,518 & 52,557 & 48,196 & 39,098 & 34,234 & 29,221 & 22,630 \\
\hline BARRANCO & 2,034 & 2,258 & 2,074 & 2,183 & 2,214 & 1,883 & 2,156 & 2,217 & 1,839 \\
\hline BREÑA & 5,811 & 6,232 & 5,752 & 5,528 & 5,410 & 5,143 & 5,298 & 5,015 & 4,213 \\
\hline CARABAYLLO & 28,116 & 28,506 & 25,095 & 24,914 & 24,375 & 19,436 & 16,671 & 13,798 & 11,175 \\
\hline CHACLACAYO & 3,647 & 3,811 & 3,369 & 3,522 & 3,403 & 2,768 & 2,622 & 2,372 & 2,112 \\
\hline CHORRILLOS & 28,871 & 31,055 & 27,428 & 26,751 & 26,226 & 22,162 & 19,789 & 17,416 & 13,873 \\
\hline CIENEGUILLA & 4,787 & 4,807 & 3,803 & 3,785 & 3,354 & 2,858 & 2,493 & 2,386 & 2,000 \\
\hline COMAS & 45,499 & 47,490 & 43,993 & 44,502 & 42,520 & 33,582 & 29,208 & 26,743 & 23,136 \\
\hline EL AGUSTINO & 18,078 & 19,780 & 16,456 & 15,040 & 14,393 & 12,431 & 11,301 & 9,745 & 7,183 \\
\hline INDEPENDENCIA & 18,874 & 19,806 & 17,774 & 17,810 & 18,304 & 15,468 & 12,606 & 10,113 & 7,796 \\
\hline JESUS MARIA & 4,901 & 5,694 & 5,368 & 5,378 & 5,269 & 4,672 & 4,839 & 5,161 & 4,431 \\
\hline LA MOLINA & 13,898 & 15,074 & 13,032 & 13,001 & 13,415 & 11,953 & 11,969 & 12,102 & 10,274 \\
\hline LA VICTORIA & 14,585 & 17,152 & 14,240 & 13,153 & 12,364 & 10,945 & 10,501 & 9,912 & 8,176 \\
\hline LINCE & 3,501 & 3,929 & 3,885 & 3,847 & 3,735 & 3,362 & 3,488 & 3,608 & 3,048 \\
\hline LOS OLIVOS & 33,945 & 38,689 & 33,218 & 30,525 & 27,931 & 24,056 & 23,005 & 21,029 & 16,562 \\
\hline LURIGANCHO & 20,926 & 22,024 & 18,366 & 17,693 & 16,882 & 13,585 & 11,871 & 10,212 & 7,972 \\
\hline LURIN & 8,355 & 8,547 & 7,151 & 7,018 & 6,744 & 5,461 & 4,553 & 3,591 & 2,830 \\
\hline MAGDALENA DEL & 3,927 & 4,156 & 3,999 & 4,303 & 4,043 & 3,622 & 3,899 & 3,871 & 3,274 \\
\hline MAGDALENA VIE, & 5,487 & 5,893 & 5,433 & 5,556 & 5,372 & 5,067 & 5,499 & 5,388 & 4,539 \\
\hline MIRAFLORES & 4,633 & 5,699 & 6,154 & 6,662 & 6,330 & 5,398 & 5,988 & 6,192 & 5,554 \\
\hline PACHACAMAC & 12,210 & 13,228 & 11,497 & 11,633 & 11,047 & 8,232 & 6,141 & 4,905 & 3,644 \\
\hline PUCUSANA & 1,511 & 1,563 & 1,414 & 1,368 & 1,249 & 973 & 973 & 794 & 636 \\
\hline PUENTE PIEDRA & 36,079 & 37,896 & 30,272 & 28,455 & 27,505 & 22,563 & 19,502 & 15,675 & 10,809 \\
\hline PUNTA HERMOS & 686 & 687 & 596 & 590 & 667 & 520 & 504 & 466 & 331 \\
\hline PUNTA NEGRA & 649 & 724 & 620 & 647 & 659 & 540 & 447 & 465 & 348 \\
\hline RIMAC & 13,810 & 14,487 & 12,875 & 12,337 & 12,174 & 10,971 & 10,524 & 10,156 & 7,975 \\
\hline SAN BARTOLO & 912 & 824 & 583 & 596 & 566 & 542 & 461 & 387 & 234 \\
\hline SAN BORJA & 7,731 & 8,894 & 8,375 & 8,646 & 8,787 & 7,644 & 7,675 & 7,702 & 6,639 \\
\hline SAN ISIDRO & 3,087 & 3,562 & 3,615 & 3,708 & 4,067 & 3,918 & 4,010 & 4,164 & 3,537 \\
\hline SAN JUAN DE LU & 104,536 & 120,364 & 101,734 & 91,365 & 81,536 & 67,823 & 62,407 & 55,256 & 41,350 \\
\hline SAN JUAN DE MI & 37,078 & 40,649 & 34,794 & 32,618 & 30,720 & 26,978 & 25,071 & 21,899 & 16,213 \\
\hline SAN LUIS & 4,714 & 5,529 & 4,945 & 5,042 & 4,768 & 3,921 & 3,421 & 2,935 & 2,393 \\
\hline SAN MARTIN DE & 61,443 & 65,591 & 57,738 & 55,886 & 55,056 & 49,742 & 46,272 & 39,938 & 29,935 \\
\hline SAN MIGUEL & 10,059 & 10,998 & 10,472 & 10,629 & 10,499 & 9,295 & 9,487 & 8,934 & 7,514 \\
\hline SANTA ANITA & 20,618 & 26,805 & 23,076 & 20,957 & 17,372 & 13,076 & 11,448 & 10,500 & 9,305 \\
\hline SANTA MARIA DE & 136 & 155 & 151 & 122 & 143 & 117 & 106 & 70 & 73 \\
\hline SANTA ROSA & 1,673 & 1,597 & 1,400 & 1,528 & 1,381 & 1,247 & 1,251 & 1,126 & 866 \\
\hline SANTIAGO DE SY & 26,299 & 27,340 & 25,292 & 26,728 & 27,985 & 24,535 & 24,784 & 23,279 & 19,124 \\
\hline SURQUILLO & 6,700 & 7,583 & 7,315 & 7,575 & 7,013 & 6,029 & 5,886 & 5,884 & 5,186 \\
\hline VILLA EL SALVAD & 43,613 & 46,768 & 40,194 & 40,295 & 38,199 & 28,156 & 24,031 & 21,000 & 18,078 \\
\hline VILLA MARIA DEL & 40,188 & 42,283 & 38,750 & 39,660 & 37,397 & 28,771 & 23,687 & 20,986 & 16,832 \\
\hline
\end{tabular}


- Calculo de cuotas en base a estratos seleccionados, según criterio del investigador

\begin{tabular}{lllll}
\hline $\begin{array}{l}\text { Grupos de } \\
\text { personas }\end{array}$ & & & $13-20$ & \\
\hline $\begin{array}{l}\text { Cantidad de } \\
\text { personas }\end{array}$ & Norte & Centro & Moderna & Sur \\
\hline $13-20$ & $395,693.00$ & $113,030.00$ & $162,519.00$ & $302,351.00$ \\
\hline MASCULINO & $1,189,544.00$ & $372,848.00$ & $577,580.00$ & $899,452.00$ \\
\hline & & & & \\
& $n i=n \cdot \frac{N i}{N}$ & $N=N_{1}+N_{2}+\ldots+N_{k}$ &
\end{tabular}

N=Número de elementos de la población

$\mathrm{n}=$ Numero de la muestra

$\mathrm{Ni}=$ número del estrato $\mathrm{i}$

\begin{tabular}{lllll}
\hline Norte & centro & Moderna & Sur & TOTAL \\
\hline 10 & 11 & 11 & 12 & 44 \\
\hline $\mathrm{n} 1$ & $\mathrm{n} 2$ & $\mathrm{n} 3$ & $\mathrm{n} 4$ & $\mathrm{Ni}$ \\
\hline
\end{tabular}

\begin{tabular}{lllll}
\hline Grupos de edad & \multicolumn{5}{l}{$21-35$} \\
\hline $\begin{array}{l}\text { Cantidad de } \\
\text { personas }\end{array}$ & Norte & Centro & Moderna & Sur \\
\hline $21-35$ & $699,335.00$ & $211,356.00$ & $332,715.00$ & $538,872.00$ \\
\hline MASCULINO & & & & \\
& $1,189,544.00$ & $372,848.00$ & $577,580.00$ & $899,452.00$ \\
\hline
\end{tabular}

$$
n i=n \cdot \frac{N i}{N} \quad N=N_{1}+N_{2}+\ldots+N_{k}
$$


N=Número de elementos de la población

$\mathrm{n}=$ Numero de la muestra

$\mathrm{Ni}=$ número del estrato $\mathrm{i}$

\begin{tabular}{ccccc}
\hline Norte & centro & Moderna & Sur & TOTAL \\
\hline 11 & 9 & 9 & 9 & 37 \\
\hline $\mathrm{n} 1$ & $\mathrm{n} 2$ & $\mathrm{n} 3$ & $\mathrm{n} 4$ & $\mathrm{Ni}$ \\
\hline
\end{tabular}

\begin{tabular}{lllll}
\hline $\begin{array}{l}\text { Grupos de } \\
\text { edad }\end{array}$ & & & $36-59$ & \\
\hline $\begin{array}{l}\text { Cantidad de } \\
\text { personas }\end{array}$ & Norte & Centro & Moderna & Sur
\end{tabular}

\begin{tabular}{lcccc}
\hline $36-59$ & $665,281.00$ & $225,684.00$ & $410,430.00$ & $480,977.00$ \\
\hline FEMENINO & $1,189,544.00$ & $372,848.00$ & $577,580.00$ & $899,452.00$ \\
\hline
\end{tabular}

$$
n i=n \cdot \frac{N i}{N} \quad N=N_{1}+N_{2}+\ldots+N_{k}
$$

N=Número de elementos de la población

$\mathrm{n}=$ Numero de la muestra

$\mathrm{Ni}=$ número del estrato $\mathrm{i}$

\begin{tabular}{ccccrr}
\hline Norte & centro & $\begin{array}{c}\text { Mode } \\
\text { rna }\end{array}$ & r & OTAL \\
\hline 4 & 4 & 4 & & 4 & 16 \\
\hline $\mathrm{n} 1$ & $\mathrm{n} 2$ & $\mathrm{n} 3$ & & \\
& & & $\mathrm{n} 4$ & $\mathrm{Ni}$ \\
\hline
\end{tabular}




\begin{tabular}{lccccc}
\hline GRUPOS DE EDAD & \multicolumn{5}{c}{$13-20$} \\
$\begin{array}{l}\text { CANTIDAD DE } \\
\text { PERSONAS }\end{array}$ & Norte & Centro & Moderna & Sur & Total \\
\hline $13-20$ & $395,693.00$ & $113,030.00$ & $162,519.00$ & $302,351.00$ & $973,593.00$ \\
\hline FEMENINO & $1,231,263.00$ & $393,333.00$ & $681,759.00$ & $920,217.00$ & $3,226,572.00$ \\
\hline NSE A & $23.00 \%$ & $23.00 \%$ & $32.00 \%$ & $5.44 \%$ & 0.83 \\
\hline Formula & 13 & 11 & 10 & 13 & 47 \\
\hline & $\mathrm{n} 1$ & $\mathrm{n} 2$ & $\mathrm{n} 3$ & $\mathrm{n} 4$ & $\mathrm{Ni}$ \\
\hline
\end{tabular}

\begin{tabular}{|c|c|c|c|c|c|c|}
\hline $\begin{array}{l}\text { GRUPOS } \\
\text { EDAD }\end{array}$ & $\mathrm{DE}$ & & & $21-35$ & & \\
\hline $\begin{array}{l}\text { CANTIDAD } \\
\text { PERSONAS }\end{array}$ & $\mathrm{DE}$ & Norte & Centro & Moderna & Sur & Total \\
\hline $21-35$ & & $699,335.00$ & $211,356.00$ & $332,715.00$ & $538,872.00$ & $1,782,278.00$ \\
\hline FEMENINO & & $1,189,544.00$ & $372,848.00$ & $577,580.00$ & $899,452.00$ & $3,039,424.00$ \\
\hline \multirow[t]{3}{*}{ NSE A } & & $0.23 \%$ & $0.23 \%$ & $92.33 \%$ & $5.44 \%$ & 0.98 \\
\hline & & 6 & 11 & 12 & 11 & 41 \\
\hline & & $\mathrm{n} 1$ & $\mathrm{n} 2$ & n3 & $\mathrm{n} 4$ & $\mathrm{Ni}$ \\
\hline
\end{tabular}

\begin{tabular}{lccccc}
\hline GRUPOS DE EDAD & \multicolumn{5}{c}{$36-59$} \\
$\begin{array}{l}\text { CANTIDAD DE } \\
\text { PERSONAS }\end{array}$ & Norte & Centro & Moderna & Sur & Total \\
\hline $36-59$ & $665,281.00$ & $225,684.00$ & $410,430.00$ & $480,977.00$ & \\
\hline FEMENINO & $1,189,544.00$ & $372,848.00$ & $577,580.00$ & $899,452.00$ & $3,039,424.00$ \\
\hline NSE A & $0.23 \%$ & $0.23 \%$ & $92.33 \%$ & $5.44 \%$ & 0.98 \\
\hline & 3 & 3 & 4 & 5 & 14 \\
\hline & $\mathrm{n} 1$ & $\mathrm{n} 2$ & $\mathrm{n} 3$ & $\mathrm{n} 4$ & $\mathrm{Ni}$ \\
\hline
\end{tabular}


GRUPOS

DE EDAD

\begin{tabular}{llllll}
\hline $\begin{array}{l}\text { CANTIDAD } \\
\text { DE } \\
\text { PERSONAS }\end{array}$ & Norte & Centro & Moderna & Sur & Total \\
\hline $21-35$ & $699,335.00$ & $211,356.00$ & $332,715.00$ & $538,872.00$ & $1,782,278.00$ \\
\hline FEMENINO & $1,189,544.00$ & $372,848.00$ & $577,580.00$ & $899,452.00$ & $3,039,424.00$ \\
\hline NSE B & $10.05 \%$ & $11.78 \%$ & $46.09 \%$ & $11.36 \%$ & $79 \%$ \\
\hline CUOTA & 8 & 5 & 4 & 6 & 23 \\
\hline & $\mathrm{n} 1$ & $\mathrm{n} 2$ & $\mathrm{n} 3$ & $\mathrm{n} 4$ & $\mathrm{Ni}$ \\
\hline
\end{tabular}

GRUPOS

DE EDAD

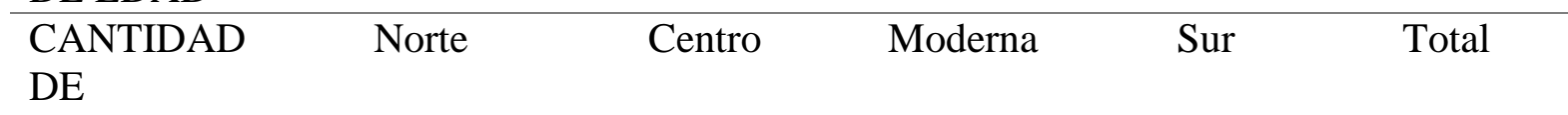

PERSONAS

\begin{tabular}{lccccc}
\hline $36-59$ & $665,281.00$ & $225,684.00$ & $410,430.00$ & $480,977.00$ & $1,782,372.00$ \\
\hline FEMENINO & $1,189,544.00$ & $372,848.00$ & $577,580.00$ & $899,452.00$ & $3,039,424.00$ \\
\hline NSE B & $10.05 \%$ & $11.78 \%$ & $46.09 \%$ & $11.36 \%$ & $79 \%$ \\
\hline CUOTA & 6 & 8 & 9 & 7 & 30 \\
\hline & $\mathrm{n} 1$ & $\mathrm{n} 2$ & $\mathrm{n} 3$ & $\mathrm{n} 4$ & $\mathrm{Ni}$ \\
\hline
\end{tabular}

GRUPOS DE

EDAD

\begin{tabular}{lcccc}
\hline $\begin{array}{l}\text { CANTIDAD } \\
\text { DE } \\
\text { PERSONAS }\end{array}$ & Norte & Centro & Moderna & Sur \\
\hline $21-35$ & & & & \\
\hline MASCULINO & $1,189,544.00$ & $372,848.00$ & $577,580.00$ & $899,452.00$ \\
\hline NSE B & $10.05 \%$ & $11.78 \%$ & $46.09 \%$ & $11.36 \%$ \\
\hline CUOTA & 8 & 8 & 9 & 11 \\
\hline & $\mathrm{n} 1$ & $\mathrm{n} 2$ & $\mathrm{n} 3$ & $\mathrm{n} 4$ \\
\hline
\end{tabular}

GRUPOS

36-59

DE EDAD

\begin{tabular}{lcccc}
\hline $\begin{array}{l}\text { CANTIDAD } \\
\text { DE } \\
\text { PERSONAS }\end{array}$ & Norte & Centro & Moderna & Sur \\
\hline $36-59$ & $665,281.00$ & $225,684.00$ & $410,430.00$ & $480,977.00$ \\
\hline FEMENINO & $1,189,544.00$ & $372,848.00$ & $577,580.00$ & $899,452.00$ \\
\hline NSE B & $10.05 \%$ & $11.78 \%$ & $46.09 \%$ & $11.36 \%$ \\
\hline CUOTA & 6 & 6 & 7 & 8 \\
\hline & $\mathrm{n} 1$ & $\mathrm{n} 2$ & $\mathrm{n} 3$ & $\mathrm{n} 4$
\end{tabular}

